\title{
Using GIS and landowner survey to determine if the Forest Stewardship Program is effective at generating involvement in forest health issues in West Virginia
}

\author{
David Page McCann \\ West Virginia University
}

Follow this and additional works at: https://researchrepository.wvu.edu/etd

\footnotetext{
Recommended Citation

McCann, David Page, "Using GIS and landowner survey to determine if the Forest Stewardship Program is effective at generating involvement in forest health issues in West Virginia" (2005). Graduate Theses, Dissertations, and Problem Reports. 4173.

https://researchrepository.wvu.edu/etd/4173
}

This Thesis is protected by copyright and/or related rights. It has been brought to you by the The Research Repository @WVU with permission from the rights-holder(s). You are free to use this Thesis in any way that is permitted by the copyright and related rights legislation that applies to your use. For other uses you must obtain permission from the rights-holder(s) directly, unless additional rights are indicated by a Creative Commons license in the record and/ or on the work itself. This Thesis has been accepted for inclusion in WVU Graduate Theses, Dissertations, and Problem Reports collection by an authorized administrator of The Research Repository @ WVU. For more information, please contact researchrepository@mail.wvu.edu. 


\title{
Using GIS and landowner survey to determine if the Forest Stewardship Program is effective at generating involvement in forest health issues in West Virginia
}

\author{
David Page McCann
}

Thesis submitted to the Davis College of Agriculture, Forestry, and Consumer Sciences at West Virginia University in partial fulfillment of the requirements for the degree of

\author{
Master of Science in Forest Management \\ David W. McGill, Ph.D., Chair \\ Linda Butler, Ph.D. \\ William L. MacDonald, Ph.D. \\ Andrew Liebhold, Ph.D. \\ Division of Forestry \\ Morgantown, West Virginia \\ 2005
}

Keywords: Forest Stewardship Program, Mail Survey, Forest Pest/Disease Management, Adelges tsugae Annand, Lymantria dispar L., Beech Bark Disease, ArcMap 


\begin{abstract}
Using GIS and landowner survey to determine if the Forest Stewardship Program is effective at generating involvement in forest health issues in West Virginia
\end{abstract}

\title{
David Page McCann
}

A risk rating map created from 22 shapefiles of pest and disease activity data was used to produce maps of individual properties distributed to half of survey subjects along with a postcard questionnaire. In total, 933 landowners were surveyed; $21 \%$ responded. The affects of three factors - the Forest Stewardship Program (FSP), region, and a map — on landowner interest were investigated using ANOVA and logistic regression. The affects of covariables risk rating and acreage were evaluated using ANCOVA. Logistic regression identified preferred delivery methods and pests and diseases relevant to landowners. FSP participation significantly affected interest level, the selection of gypsy moth, and requests for information. Region significantly affected risk rating and the selection of Beech Bark Disease. Map reception did not significantly affect any dependent variable. Acreage and risk rating were insignificant covariables. Sudden Oak Death and information sheets were the most often chosen pests and delivery methods. 


\section{Acknowledgements}

This research would not have been possible without funding from the United States Department of Agriculture Forest Service, through the Appalachian Hardwood Center (AHC) at the West Virginia University, Division of Forestry, and the assistance of many individuals. The entire staff and faculty of the Division of Forestry at West Virginia University provided invaluable assistance and expertise throughout this process, naming them all is simply not possible.

In particular, thanks go out to Dr. David McGill and Shawn Grushecky; they developed the project for which funding was provided and from which the bulk of data were acquired. I thank David specifically for his mentoring and for affording me the opportunity to come back home to the Appalachian region and continue an education that began far too late and resulted in, by far, the greatest accomplishment of my life to date. Dr. Linda Butler deserves many thanks not only for her guidance on entomological issues but as a source of support throughout my time here at West Virginia. Dr. William MacDonald also served as a valuable mentor, guide, and source of inspiration during my time here.

Dr Mike Strager receives many thanks for his assistance in learning and understanding ArcMap and GIS technology, as well as for his direct help with manipulating the GIS data acquired for this project. Steve Harouff of the AHC also provided essential guidance and assistance through the maze of GIS technology. Dr. Sandy Liebhold guided me to Ann Steketee and Gino Luzader at the United States Department of Agriculture Forest Service Station in Star City, WV, who thankfully provided the data necessary for developing the GIS components of this project. Kevin Hart and the folks at WVU printing services get special thanks for their prompt service in printing postcards and the superb copies of maps that were sent to survey subjects. Lastly, but not least, I thank Dr.George Seidel for his statistical assistance, Dr. Kathryn Arano for providing the names of landowners not involved in the Forest Stewardship Program (FSP), and the staffs of all the assessors' offices visited to gather data on no-FSP owners. 


\section{Table of Contents}

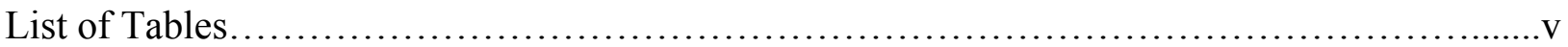

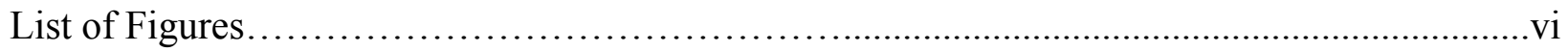

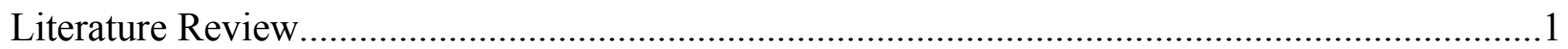

Outreach................................................................................... 1

Forest Stewardship Program...........................................................4

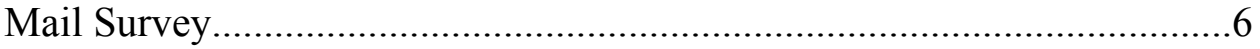

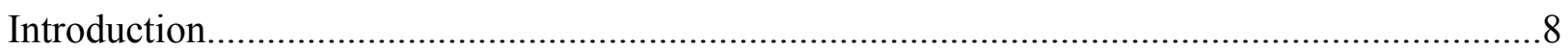

Purpose and Objectives........................................................... 11

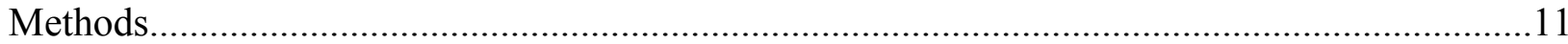

Forest Landowner Survey............................................................. 11

Landowners............................................................................. 11

Pest and Disease Risk Rating Maps...........................................12

Pest and Disease Shapefiles.........................................12

Risk Rating System................................................... 14

Study Site Selection............................................................16

Sampling Survey Subjects.......................................................21

Maps for Survey Subjects....................................................23

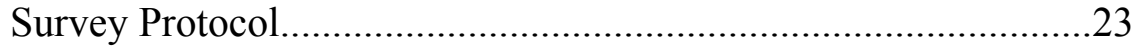

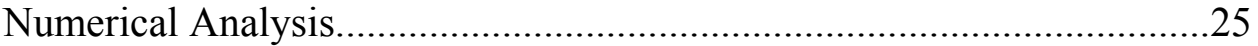

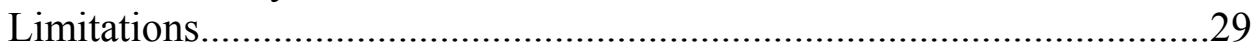

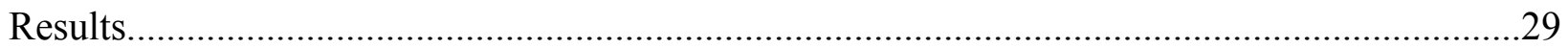

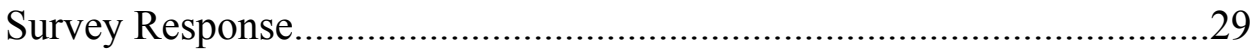

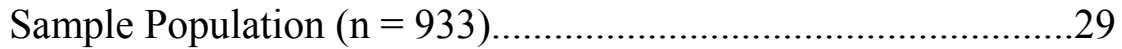

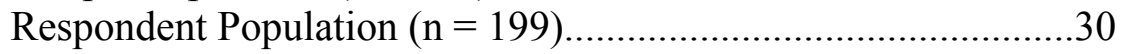

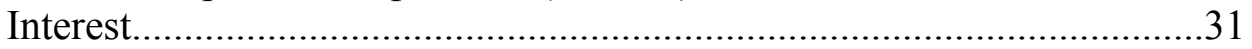

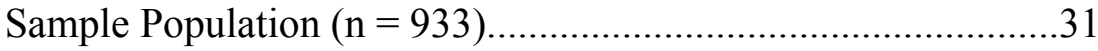

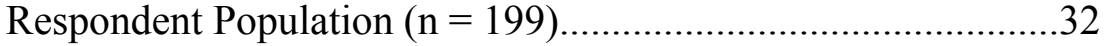

Postcard Statements, Chosen Pests and Diseases, Chosen Delivery

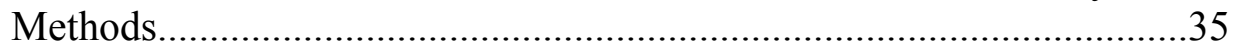

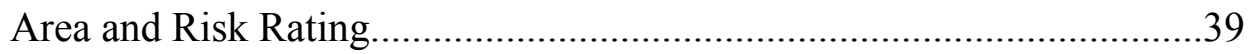

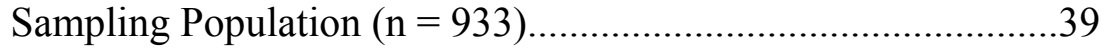

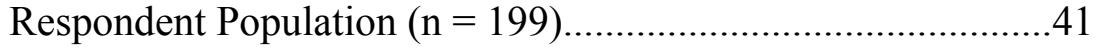

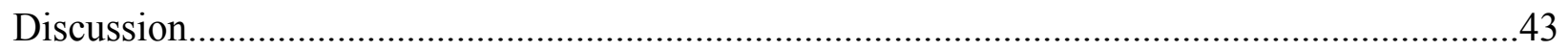

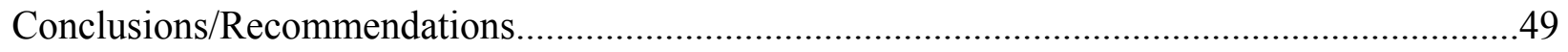

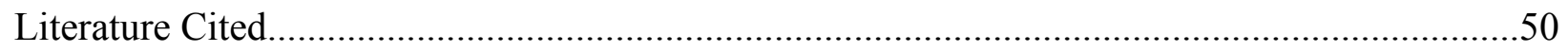

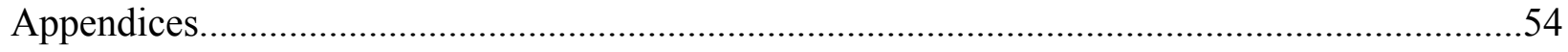


Appendix 1: Shapefiles for Risk Rating Map and Survey Subject Map.......................................54

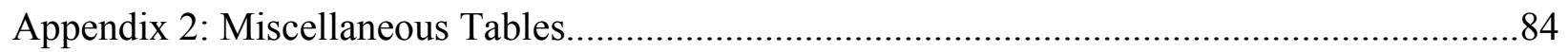

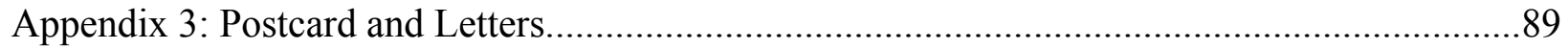

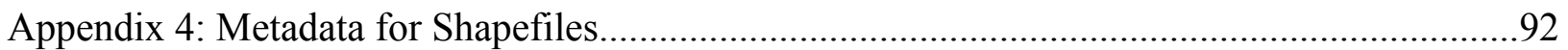

\section{List of Tables}

Table 1: Counties selected as study sites for outreach survey.........................................21

Table 2: Categorization of interest levels as derived from postcard (Appendix 3) responses

Table 3: Table 3: Partitioning of source of error variance for three-factor ANOVA and

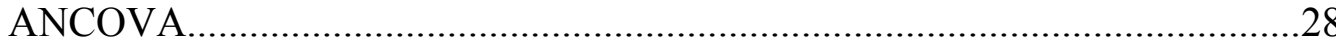

Table 4: Sample population response rates of treatment categories and overall. 30

Table 5: Sample population response rates of ANOVA treatment combinations..............30

Table 6: Respondent population response rates of treatment categories $(n=199) \ldots \ldots \ldots . . .30$

Table 7: Respondent population response rates of ANOVA treatment combinations $(\mathrm{n}=199)$.

Table 8: Contingency table results for interest of the sample population as represented by the return of a postcard.

Table 9: Respondent population mean interest levels of treatment categories $(\mathrm{n}=199) . .32$

Table 10: ANOVA results with interest as the dependent variable for the respondent population. Interest is a function of the index created for this study

Table 11: ANCOVA results with interest as the dependent variable for the respondent population. Interest is a function of the index created for this study.

Table 12: Respondent population mean interest levels of ANOVA treatment combinations $(\mathrm{n}=199)$.

Table 13: Respondent population interest level distributions. 
Table 14: Respondent population responses to beech bark disease and "I am not interested in forest pests and diseases".

Table 15: Respondent population responses to gypsy moth and "I would prefer information on pests and diseases".

Table 16: Sample population mean acreages and risk ratings of treatment categories.....38

Table 17: ANOVA results with area as the dependent variable for the sample population.

Table 18: Sample population mean acreages of ANOVA treatment combinations

Table 19: ANOVA results with risk rating as the dependent variable for the sample population.

Table 20: Sample population mean risk ratings of ANOVA treatment combinations........

Table 21: Respondent population mean acreages and risk ratings of treatment categories.

Table 22: ANOVA results with area as the dependent variable for the respondent population.

Table 23: Respondent population mean acreages of ANOVA treatment combinations...41

Table 24: ANOVA results with risk rating as the dependent variable for the respondent population.

Table 25: Respondent population mean risk ratings of ANOVA treatment combinations.

\section{List of Figures}

Figure 1: West Virginia pest and disease risk rating map. Red areas of high risk indicate more intense pest and disease activity relative to areas of orange or yellow where activity is moderate or green areas where activity is absent and risk is low. Risk rating is a function of historical and predicted pest and disease defoliations and distributions.

Figure 2: Ecoregions of West Virginia based on Bailey classification system. Source: United States Forest Service, reprojected by West Virginia University GIS Technical Center. 
Figure3: Counties chosen for study sites are highlighted in white. Red areas of high risk indicate more intense pest and disease activity relative to areas of orange or yellow where activity is moderate or green areas where activity is absent and risk is low. Risk rating is a function of historical and predicted pest and disease defoliations and distributions........................................................... 18

Figure 4: The western study site. Risk ratings range from zero, green areas of no pest or disease activity, to four, orange areas of moderate disease activity. Risk rating is a function of historical and predicted pest and disease defoliations and distributions.

Figure 5: The eastern study site. Risk ratings range from zero, green areas of no pest or disease activity, to eleven, red areas of relatively intense disease activity. Risk rating is a function of historical and predicted pest and disease defoliations and distributions

Figure 6: Interest levels vs. area for respondent population. Interest does not follow a pattern that correlates with property size $(n=199)$.

Figure 7: Percents of respondent population requesting information on pests and diseases. .36

Figure 8: Percents of respondent population requesting selected delivery methods.........37

Figure 9: Percents of respondent population checking postcard statements. .37 


\section{Literature Review}

\section{Outreach}

West Virginia has 260, 000 non-industrial private forest (NIPF) landowners (Birch 1996). The problem with NIPF owners has historically been orchestrating forest and pest or disease management on a regional scale. Probing small landowners to identify what makes them aware of these issues would help facilitate the education and empowerment of the landowner and perhaps improve forest pest and disease management by placing knowledgeable eyes and ears in areas that management professionals may never see.

Various outreach methods are available to forest management professionals, but resources often are limited and the methods landowners prefer need to be identified. Unidirectional methods include pest alerts, media advertisements, or any mechanism for the one way flow of information. Interactive methods include visits by professionals, workshops, or any method where an exchange of information or a dialogue takes place (Esseks and Moulton 2000). Educational information in general increases knowledge of and support for forest management activities including prescribed fire (Loomis et al. 2001) timber harvesting (Harmon and Jones 1997) and mechanized thinning (Shindler and Toman 2003), and the same concept could apply to pest and disease management.

The aim of outreach is to affect public and private opinions concerning different forest management practices and foster a stakeholder attitude in landowners (Jacobsen 1999). Adult learning applies in outreach situations, and outreach efforts are most effective when topics and informational materials are relevant to ones experience (Toman et al. 2004). In an online survey in March 2005, concerning sudden oak death (Phytophtora ramorum) in Northern California, 
Alexander et al. (2005) found $90 \%$ of responses were from infected areas indicating exposure to the disease prompts interest. Furthermore, efficacy is increased when topics and materials are meaningful in context and performed interactively as a personal exchange of information (Toman et al. 2004). In their study, exploring outreach methods used for disseminating information on prescribed fire, they found interactive methods more effective for education, trustworthy if not internet based, and more likely to change behavior. The type of interaction is key. Public meetings were perceived to be an untrustworthy, unidirectional flow of information, whereas a personal visit to one's property with a dialogue by a professional was deemed most trusted (Toman et al. 2004). The Toman et al. (2004) survey achieved a $47 \%$ overall response rate from 1561 total subjects using a survey of moderate length containing categorical and linkert-type items.

Numerous studies have been conducted to identify perceptions and attitudes of forest professionals and forest landowners regarding various forestry issues as well as to identify factors that encourage landowner involvement in forest management on private lands (Pokorny 1998; Esseks and Moulton 2000; Egan et al. 2001; Shindler and Toman 2003; Jennings et al. 2004; Magill et al. 2004a; Toman et al. 2004; Alexander et al. 2005; Chandran and Steele 2005). A survey of Midwestern urban foresters with 468 mailings consisting of a ten question survey yielded 206 responses (Pokorny 1998). Results indicated urban foresters prefer fact sheets to disseminate information, but fact sheets may not be preferred or trusted by forest landowners and may not generate as much real interest as personal communications with professionals. Conversely, workshops were highly rated by Midwestern urban foresters. Most importantly the survey by Pokorny (1998) led to the inclusion of health management into plans previously lacking these considerations. 
In 2000, Shindler and Toman (2003) conducted a follow-up survey as part of a longitudinal analysis of eastern Washington and Oregon landowners affected by prescribed fire and mechanized thinning. The study was used to identify changes in attitudes following an original 1996 survey conducted by Shindler and Reed. Information source preferences and influences on public response to fuel reduction were the main foci of the 2000 study. In the 2000 mailings, questions were updated and explanations of prescribed fire and mechanized thinning were provided; also, a brief 15 question True/False quiz was included to estimate public knowledge of prescribed fire. Support for prescribed fire and mechanized thinning was still high in 2000 according to more than $95 \%$ of the 533 respondents ( $76 \%$ response rate), but trust in management agencies to implement the activities was low and decreased since 1996.

Friends, relatives, and newspapers remained the highest ranked information sources while environmental groups and the internet were unpopular in 2000 (Shindler and Toman 2003). Knowledge about treatments was generally high and in 2000 there was a strong relationship between knowledge and acceptance of management activities. Educational efforts concerning prescribed fire and mechanized thinning have the potential to increase awareness of other issues: $75 \%$ of respondents to Shindler and Toman (2003) know prescribed fire is sometimes capable of mitigating pests and diseases. Outreach activities concerning pests and diseases may likewise increase public knowledge on other issues.

Chandran and Steele (2005) gathered data concerning invasive plants in West Virginia (WV) using a woodland owner survey. Landowners on three study sites in two of the ecological provinces of WV (USDA Forest Service 1995, Map 1) were surveyed by mail after newspaper advertisements were distributed prior to survey mailings. In total, 1492 woodland owners were 
surveyed. Mailing content was developed with input from forest management professionals and included a cover letter, fact sheet, and questionnaire. Chandran and Steele (2005) had a 43.9\% response rate: $88 \%$ of respondents who were aware of invasive plants on their land managed for them. Friends, relatives, and personal communications were the source of information on invasives for $70 \%$; however, $72 \%$ would seek out extension specialists and $70 \%$ would seek out West Virginia Department of Agriculture professionals to inquire about management activities. Building awareness of invasive plants is clearly important to outreach efforts aimed at managing invasive plants (Chandran and Steele 2005; Steele et al. forthcoming).

\section{Forest Stewardship Program}

The West Virginia Forest Stewardship Program (WVFSP) is part of a federal program administered by state agencies. The Forest Stewardship Program (FSP) has been in place since 1990 and is part of the Farm Bill passed by congress that year. The goal of the program is to

protect water, recreation, aesthetic, wildlife, soil, and timber values into the future while helping landowners reach objectives pertaining to their land (Jennings 2003). Through involvement in FSP private landowners can develop management plans for their property, these plans may be written by private or state foresters but state foresters review all plans (Jennings and McGill 2003).

West Virginia is $78 \%$ forested (Gillespie 2002), of which $80 \%$ is privately owned (Smith et al. 2004), and $76 \%$ of private forestland is non-industrial private forest (Birch 1996). About 600,000 of the over 12 million total forest acres in West Virginia are in the FSP (Magill et al. 2004b). As of 2005 , the FSP has developed nearly 4000 plans totaling $\sim 6 \%$ of the private forestland in West Virginia. The most frequently recommended activities in plans to date are 
grapevine removal, wildlife habitat improvement, timber stand improvement, and timber harvesting (Jennings 2003). Enrollment in FSP continually increased until 1997 when the Stewardship Incentive Program (SIP) — a cost sharing program — was discontinued (Jennings et al. 2003).

A relatively extensive survey of WVFSP participants by Jennings (2003) yielded a 63\% response rate from mailings to 1672 up-to-date addresses. Implementation of management activities was found to be improved when assistance was provided and specific recommendations were made. Jennings et al. (2004) received a 67\% response rate from a mail survey of 3092 WVFSP participants when open-ended questions and opportunities for free expression were offered to identify successes and shortcomings of the WVFSP. The written plan, associated maps, and professional visits to properties were the favorite attributes of the FSP in WV. A seven page questionnaire was used by Magill et al. (2004b) to survey 3500 WVFSP participants in early 2003 and achieved a 63\% response rate when asking questions about demographics and plan content or implementation.

West Virginia woodland owners were surveyed by Magill et al. (2004a) to identify topics and assistance methods desired by landowners. They sent a questionnaire with queries on demographic status, owner objectives, management information, and preferred delivery methods to 1080 landowners in the winter of 1999-2000. Of the 1080 addresses, 974 were up-to-date from which a $43 \%$ response rate was achieved. Damage prevention-including pest and disease damage — was the most popular assistance topic; $68 \%$ of respondents wanted one-on-one technical aid from a professional, while 53\% preferred group learning in workshops. Interestingly, the third most desired area for assistance was rights and liabilities (Magill et al. 
2004a). Many property owners manage for recreational values (Chandran and Steele 2005), and these owners may be especially interested in pests and diseases since these organisms create hazards on their property.

Protecting the values targeted by FSP includes protecting against pests and diseases in forests. Stand improvement activities have occurred on $45 \%$ of the properties involved in the WVFSP (Jennings 2003). Surveys in four other regions including Pacific states, mountain/plain states, southern sates, and northern states reveal forest health improvement practices occur on $65-77 \%$ of FSP properties (Esseks and Moulton 2000). These activities may well include pest and disease management. A survey of FSP owners in WV can estimate how many are currently and specifically managing for pests or diseases, and a survey of private forest landowners not enrolled in FSP could be used to compare the knowledge level and attitudes of FSP participants and other private forest landowners regarding forest pests and diseases. These characteristics can be used to gauge how much importance landowners place on forest health issues and their responsiveness to new information.

\section{Mail Survey}

Response rates are typically low with mail surveys (20-30\%). Using the Total Design Method (TDM) mail survey response rates can be raised to $50-70 \%$ for general populations and $60-80 \%$ for educated populations (Dillman 1978, 1983). The TDM is based on the social exchange theory and its assertion that response is more likely if potential respondents view the subject as more beneficial than costly (Dillman 1978).

Mail surveys are desirable because they are inexpensive, easy to implement, and they may reduce measurement error as socially desired or coerced answers are uncommon (Dillman 1978). 
In addition to measurement error there are three other sources of error common to mail surveys; they include sampling error, non-coverage error, and non-response error (Cui 2003). Any of these can render survey results inaccurate (Dillman 1991). Measurement error results from mistakes made by subjects in filling out questionnaires; sampling error results from the exclusion of potential subjects through the selection process; non-coverage error comes from the exclusion of subjects from the selection process; and non-response error results from differences in responses between respondents and non-respondents that can not be measured (Cui 2003).

Large sample populations reduce sample homogeneity and sampling error. Non-coverage error can be reduced by complete, up-to-date lists of populations (Cui 2003). Non-response error may be reduced by inspiring a personal stake, using short, easy questionnaires (Dillman 1978; Herberlein and Baumgartner 1978; Dillman 1983), conferring official (i.e. University) sponsorship (Dillman 1978; Herberlein and Baumgartner 1978; Dillman 1983; Fox et al.1988), providing return postage as opposed to business reply (Armstrong and Luske, 1987; Fox et al.1988), and using a green questionnaire (Fox et al. 1988). Furthermore, the use of an official letterhead on a signed letter highlighting the importance of the study and assurances of confidentiality may improve response rates (Dillman 1978, 1983). The use of graphics, such as a map, may potentially increase response rates (Dillman 1978, 1991). Ribe (1999) found positive changes in response rates when providing photos to highlight Forest Service objectives and educate the public on harvest practices.

Surveys of demographic characteristics of FSP and private landowners have been done (Esseks and Moulton 2000; Egan et al. 2001; Jennings 2003; Magill et al. 2004a; Magill et al. 2004b; Chandran and Steele 2005). Therefore, a long survey including this information is not currently 
necessary when exploring issues related to pests and diseases. Literature cited above suggests a mail survey with a West Virginia University affiliated cover letter, a map disseminating information to the respondent, and a green postcard-style questionnaire with return postage could effectively sample a population of private forest landowners.

\section{Introduction}

The efficacy of available outreach methods varies. Further, expectations of landowners do not always coincide with management professional attitudes. Landowners seem to prefer personal communications (Magill et al. 2004a; Toman et al. 2004), whereas professionals may prefer to communicate through fact sheets (Pokorny 1998).

Outreach to forestland owners is an adult learning situation and most effective when material is meaningful to the target and delivered in a trustworthy, interactive method (Toman et al. 2004; Alexander 2005). Educating landowners can increase knowledge on selected issues (Loomis et al. 2001) and benefit forest management efforts. Activities possibly involving pest and disease damage control have been identified by West Virginia (WV) landowners as popular assistance topics (Esseks and Moulton 2000; Jennings 2003; Magill et al. 2004a).

Mail surveys are relatively inexpensive and easy to implement, but traditional response rates of 20-30\% (Dillman 1978) are not very high. However, the Total Design Method, based on the social exchange theory, suggests brief questionnaires on topics meaningful to subjects, among other survey features, can raise response rates to as high as 70-80\% (Dillman 1978). Recent surveys of forestland owners in WV and other regions have achieved response rates from 4347\% (Magill et al 2004a; Toman et al. 2004; Chandran and Steele 2005; Steele et al. 
forthcoming); and recent surveys of FSP participants have gathered response rates as high as 6367\% (Jennings 2003; Jennings et al. 2004; Magill et al. 2004b).

Morin et al. (2005) describe three exotic pests and diseases currently spreading through WV and able to cause significant mortality in hosts. They include gypsy moth (GM: Lymantria dispar L.); beech bark disease (BBD, causal agents: the beech scale Cryptococcus fagisuga Lind.; and the fungus Nectria coccinea var. faginata Lohman, Watson, Ayers-NCF); and hemlock woolly adelgid (HWA: Adelges tsugae Annand). The GM is a Lepidopteran whose larvae feed on various hardwoods, significantly favoring oak foliage. Since its introduction to the Boston, MA area in 1869 by an amateur entomologist, the GM has spread West and South (Liebhold et al. 1992; Sharov et al. 2002), and has spread through WV since entering the Eastern Panhandle in 1978 (Davidson et al. 2001).

Beech bark disease has a causal complex that begins with a scale insect infestation paving the way for a deadly fungal infection. (Houston 2005). When the exotic beech scale came to Nova Scotia from Europe in the mid 1800's, the exotic, highly infectious NCF came with it. Other Nectria fungi are also included in the BBD complex, most notably Nectria galligena-NG, a native to North America (Houston and O'Brien 2004). BBD spread is characterized by an advancing front; a killing front; and an aftermath zone (Houston 2005). Currently advancing and killing fronts exist in WV.

The HWA came to North America from Asia in the 1920's. Populations exist in the Pacific Northwest and in the East from Massachusetts to North Carolina. The eastern population is currently spreading through WV. HWA is an insect with a complicated life cycle utilizing 
primary and secondary hosts. Hemlock is the primary host and loses vigor and dies as immature adelgids cause discoloration and defoliation by sapfeeding at needle bases (McClure et al. 2001).

The Forest Stewardship Program (FSP) was designed to assist forest landowners in writing management plans for reaching their own goals while protecting values important to forest health. The USDA Forest Service Northeastern Area has implemented a Spatial Analysis Project (SAP) in which FSP properties in WV are being digitized to create a GIS database to assist land management decisions. We used the database from the SAP and WV tax records to obtain lists of FSP participants and no-FSP participants, respectively. The two lists combined served as a population to select subjects for a mail survey. A risk rating map developed from data on the three organisms noted above was distributed to some survey subjects to add relevance and evaluate the effect of the map on response.

This study used returned postcard correspondence to evaluate the levels of interest of FSP participants and other landowners in forest health issues. Postcard responses also identified preferred topics and delivery methods for educational information. If FSP owners are more knowledgeable and receptive, then FSP participation can be an effective vehicle for the promotion of pest and disease control. Conversely, interest in pest and diseases may encourage participation in FSP. In either case, the empowerment and education of the private individual may lessen burdens of management professionals and improve pest and disease management efforts. 


\section{Purpose and Objectives}

The purpose of this study was to assess the level of interest in and awareness of forest health issues and the effectiveness of various forest health outreach methods. Several objectives were identified to fulfill this purpose:

1. Determine what affect, if any, FSP participation, region in West Virginia, or receipt of educational information (a map) has on response rate or level of interest.

2. Evaluate the affect of risk rating on response rate or interest level.

3. Identify pests and pathogens specifically relevant to landowners.

4. Identify preferred forest health educational outreach methods.

\section{Methods}

\section{Forest Landowner Survey}

\section{Landowners}

A mailed questionnaire was used in this study to assess potential factors influencing participation of forest landowners in forest health issues. Factors of interest include: 1) participation in FSP; 2) geographic location; and, 3) receipt of relevant forest health information —a risk rating map.

A total of 1000 private forest landowners were selected from various contact lists for this mailing. From the FSP contact list, maintained by the West Virginia University Division of Forestry 500 landowners were randomly sampled from selected counties. Also, 500 landowners were selected from the WV Tax Database for comparison with FSP participants. A list of FSP landowners could be sampled and matched with other private landowners not involved in FSP. To improve chances of including forest landowners we sampled counties with $60 \%$ or more 
forestland. Sampling counties with 40 or more properties enrolled in FSP facilitated selection of 500 FSP participants. Furthermore, counties with greater insect and disease activity had to be identified.

\section{Pest and Disease Risk Rating Map}

\section{Pest and Disease Shapefiles}

We wanted to evaluate whether or not a piece of educational information would affect response rates, so we developed a map to distribute to survey subjects. Color isopleth maps are used extensively to display information, such as in weather maps, and therefore are familiar to and easily understood by the general public. Siniscalchi et al. (2006) displayed multiple variables related to sociodemographic change in a color isopleth map, or "social weather map". Their map was designed to reduce volumes of tables and visual displays into one composite map of social change to assist management decisions. We created a similar map to represent multiple layers of pest and disease data in a single map to be used as educational information in our mail survey.

Digital layers of pest and disease distributions were obtained from the USDA Forest Service Forestry Sciences Laboratory at Morgantown, West Virginia. These layers included: shapefiles of annual GM defoliations from 1986-1998, 2002-2004, and predicted and current spreads of BBD and HWA. A Layer of GM defoliation combined with scarlet oak sawfly (SOS: Caliroa quercuscoccineae Dyar) defoliation and various unidentified diebacks, declines, and wilts in 2000 and another layer of GM defoliation in 2001 were obtained from the SAP. Three shapefiles were created from the layer of combined organisms from the year 2000 to display the separate organisms individually: one of GM defoliation in 2000; one of SOS defoliation in 2000; and one of diebacks, declines, and wilts in 2000 (Figures 23-25, Appendix 1). 
These layers are seen in the maps in Figures 1-22 of Appendix 1; there were 22 layers in all, and some manipulation of the data using ArcMap was necessary. Some data in the shapefiles extended beyond WV borders, but these data were cut out during transformations as the extent of data was defined by WV state boundaries. Shapefiles of predicted spreads of BBD and HWA had to be reclassified so data already included by current spread was not duplicated. All layers excepting BBD and HWA layers were vector based (Table 1, Appendix 2).

Vector based data layers of pest and disease defoliations, diebacks, and wilts had to be converted to raster to enable the combination all data layers into a single representation of pest and disease activity. After conversion to raster, each shapefile was reclassified so areas with no pest or pathogen activity in ArcMap had values of zero (0) and all the areas with pest or pathogen activity were given a value of one (1). All 22 layers of Table 1 in Appendix 2 were thus coded and the ultimate outcome of combining these layers was a risk rating range of, potentially, 1-22 where each layer had equal weight and represented a single event, past, present, or predicted.

Additionally, BBD and HWA distribution data was not detailed: distribution boundaries coincided with county boundaries, providing little information applicable to this study. However, when combined with host distributions defined by a raster based layer of land cover [Land Cover (WV GAP)] (Figure 26, Appendix 1) available at the West Virginia University GIS Technical Center (WVGISTC) website (www.wvgis.wvu.edu/), a more applicable representation of the spread of BBD and HWA was created. The land cover types used as representative of American beech (Fagus grandifolia Ehrhart) habitat (Figure 27, Appendix 1) and eastern hemlock (Tsuga canadensis L.) habitat (Figure 28, Appendix 1) used in combination with predicted and current spreads of BBD and HWA are listed in Table 2 of Appendix 2. Since 
vector based polygons specifically identified areas of GM defoliation, host distributions were not needed to provide detail.

Projections of each raster-based layer were checked to ensure inclusion in the same spatial reference and extent chosen for display in ArcMap-West Virginia. Projections were adjusted to account for problems arising from layers being defined in various projections. When layers are combined, they must all be set to compatible projections in ArcMap display, regardless of their defined projection. All layers were projected in North American Datum 1983, Zone 17 (NAD 83, Zone 17), excepting HWA files, which were projected in North American Datum 1980, Zone 17 (NAD 80, Zone 17). Defined projections for each layer are shown in Table 3 of Appendix 2.

\section{Risk Rating System}

With each layer ready in raster form and projected accordingly, the raster calculator in ArcMap was used to add together the 22 layers of pest and disease related events into one layer. A color ramp was chosen over unique categories for a legend because it more clearly displayed various levels of risk and identified hot spots. The resulting map seen in Figure 1 was given a color ramp ranging from green — least affected by pests and diseases, to red — most affected by pests and diseases. The risk rating created represents the number of events occurring in any given area, whether that event was a defoliation or a predicted spread. For example, a risk rating of five (5) at a given point means that point has been or could be affected by five different events. Therefore, a rating of zero (0), or darkest green, indicates very low risk; whereas a rating of eleven (11), or darkest red on the map, would indicate an area of highest risk. Although 22 layers were combined they never all appeared at a given point at once. The highest risk rating 
identified on the resulting map is 11 , so no more than 11 events combine to affect any one area in West Virginia. Each property, FSP participating or not, has an associated risk rating whether the landowner was informed of this rating or not.

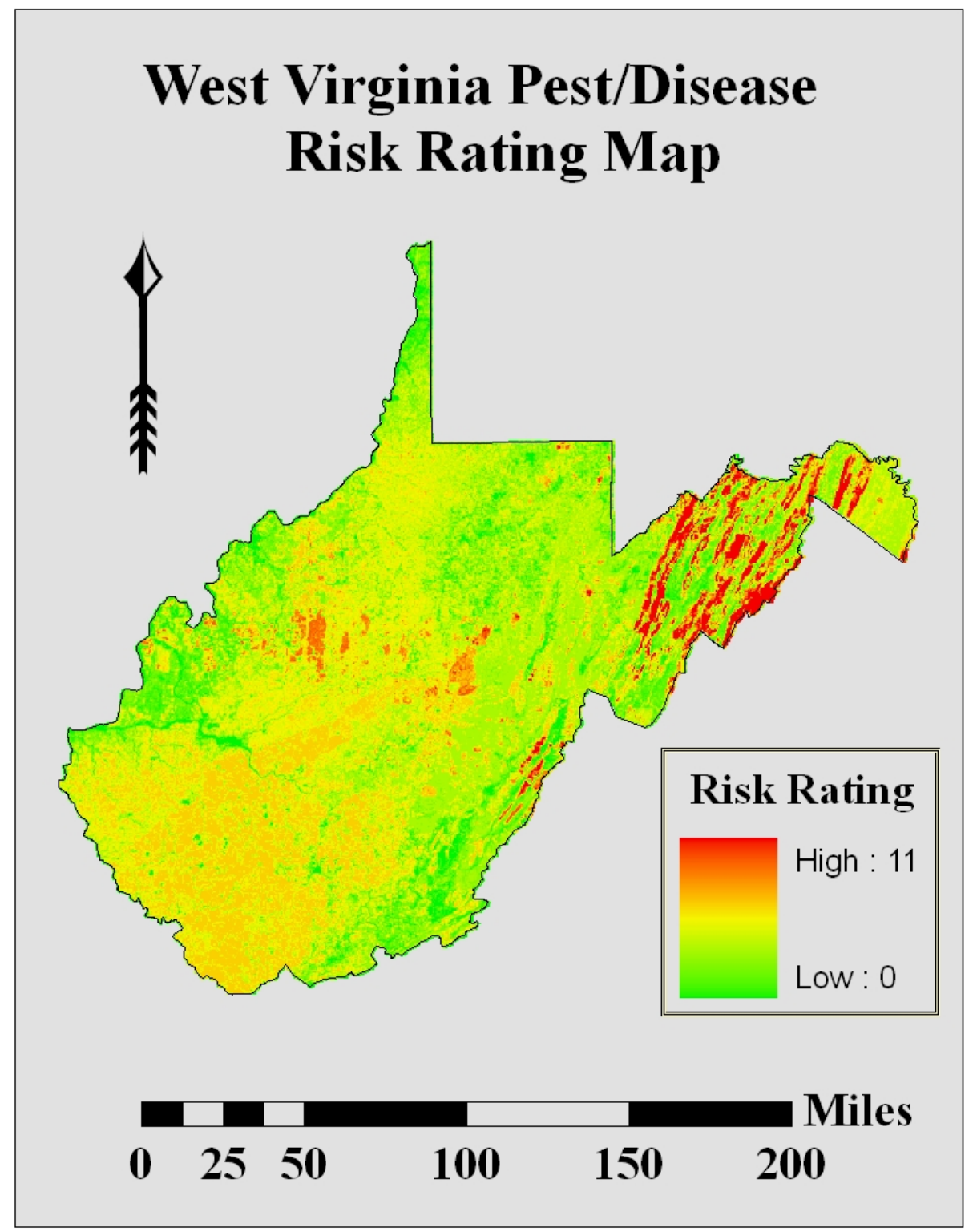

Figure 1: West Virginia pest and disease risk rating map. Red areas of high risk indicate more intense pest and disease activity relative to areas of orange or yellow where activity is moderate or green areas where activity is absent and risk is low. Risk rating is a function of historical and predicted pest and disease defoliations and distributions. 


\section{Study Site Selection}

Evaluating the affects of region on survey response was a goal of this study. Two regions of West Virginia stand out as parts of distinct ecoregions where landowners in different environments could be sampled (Figure 2). The western half of the state is characterized by rolling hills and the eastern panhandle by sharp ridges and valleys. Once a risk rating map based on defoliations and distributions of selected organisms was developed, hot spots were identified in 11 counties where spreading organisms and their damage were most varied and prominent (Figure 3). We selected six counties in the west central portion of the state (Figure 4), (Southern Unglaciated Appalachian Plateau Section of the Eastern Broadleaf Forest Ecological Province; USDA Forest Service 1995, Map1); and five in the eastern panhandle (Figure 5), (Northern Ridge and Valley and Allegheny Mountains Sections of the Central Appalachian Broadleaf Forest—Coniferous Forest—Meadow Ecological Province; USDA Forest Service 1995, Map1). 


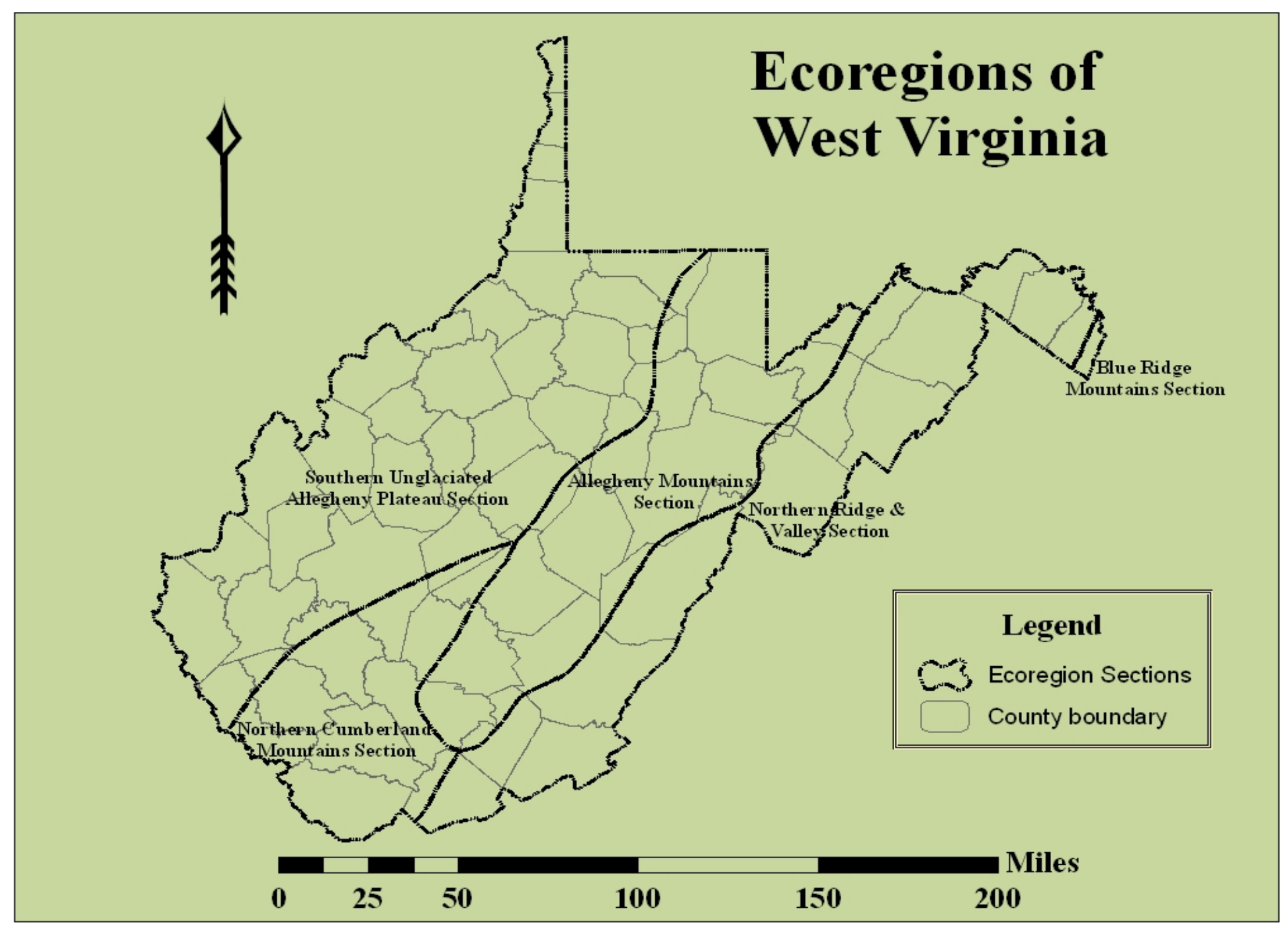

Figure 2: Ecoregions of West Virginia based on Bailey classification system. Source: United States Forest Service, reprojected by West Virginia University GIS Technical Center. 


\section{Counties Chosen for Study Sites}

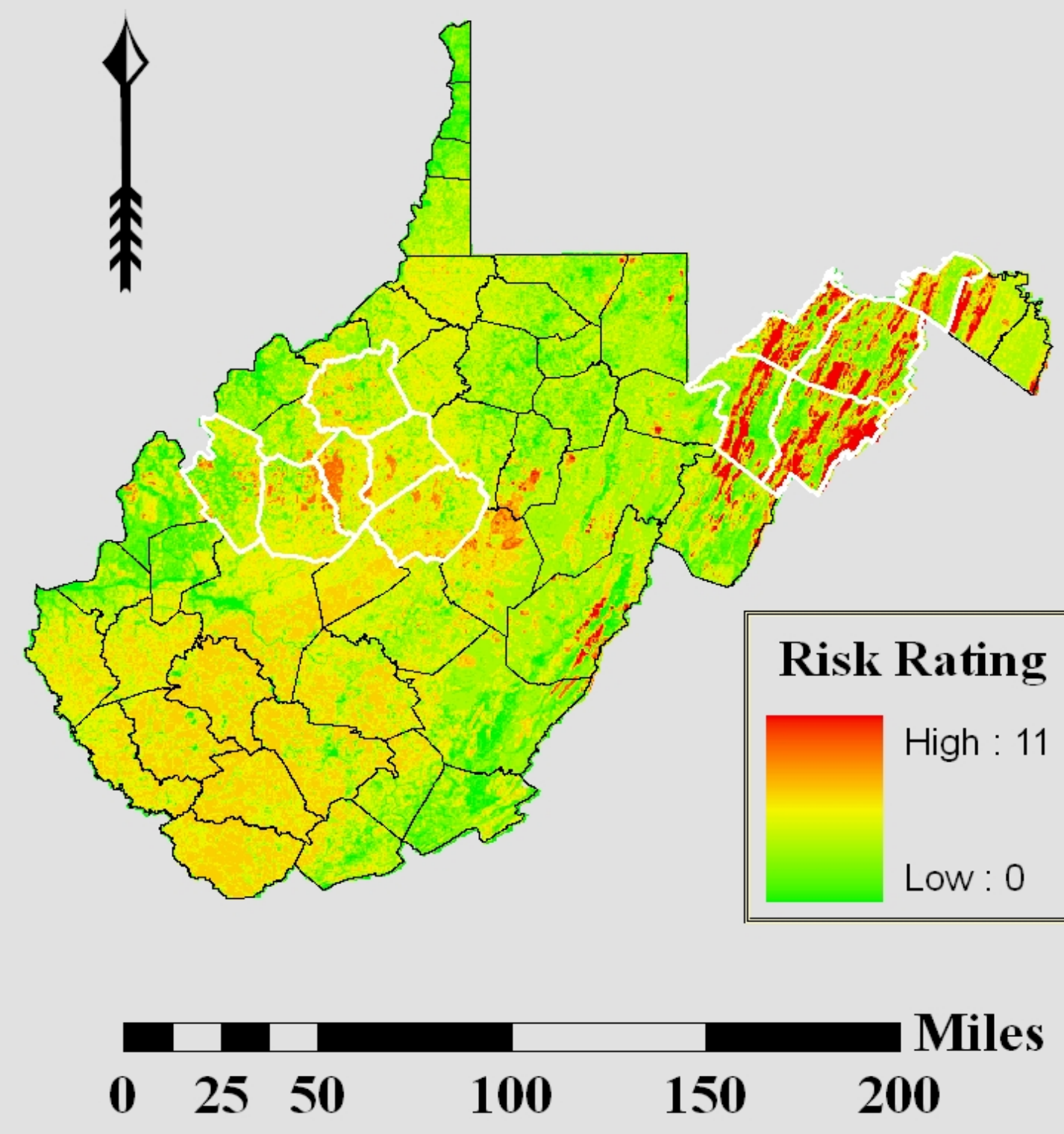

Figure 3: Counties chosen for study sites are highlighted in white. Red areas of high risk indicate more intense pest and disease activity relative to areas of orange or yellow where activity is moderate or green areas where activity is absent and risk is low. Risk rating is a function of historical and predicted pest and disease defoliations and distributions. 


\section{Western Study Site}

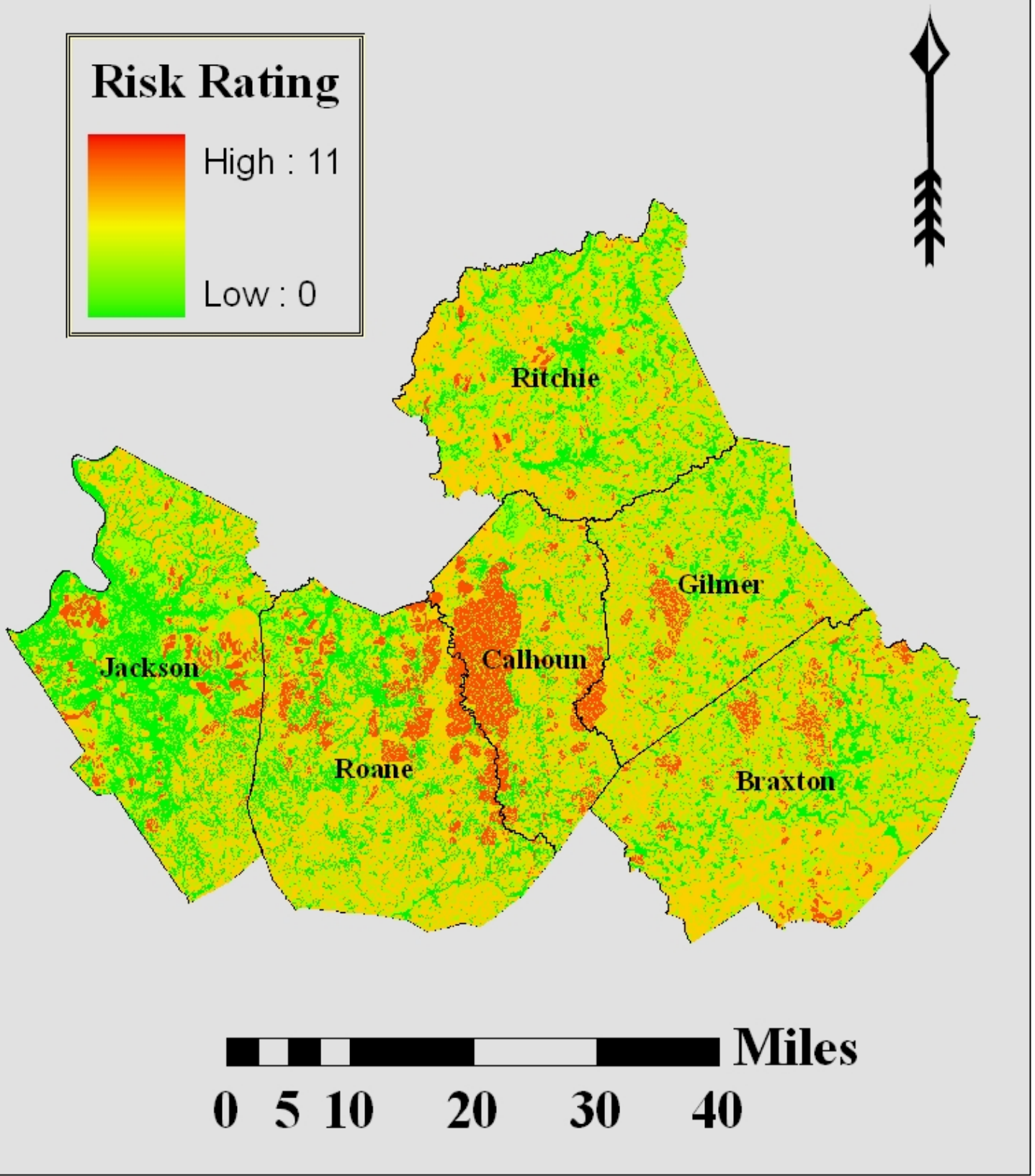

Figure 4: The western study site. Risk ratings range from zero, green areas of no pest or disease activity, to four, orange areas of moderate disease activity. Risk rating is a function of historical and predicted pest and disease defoliations and distributions. 


\section{Eastern Study Site}

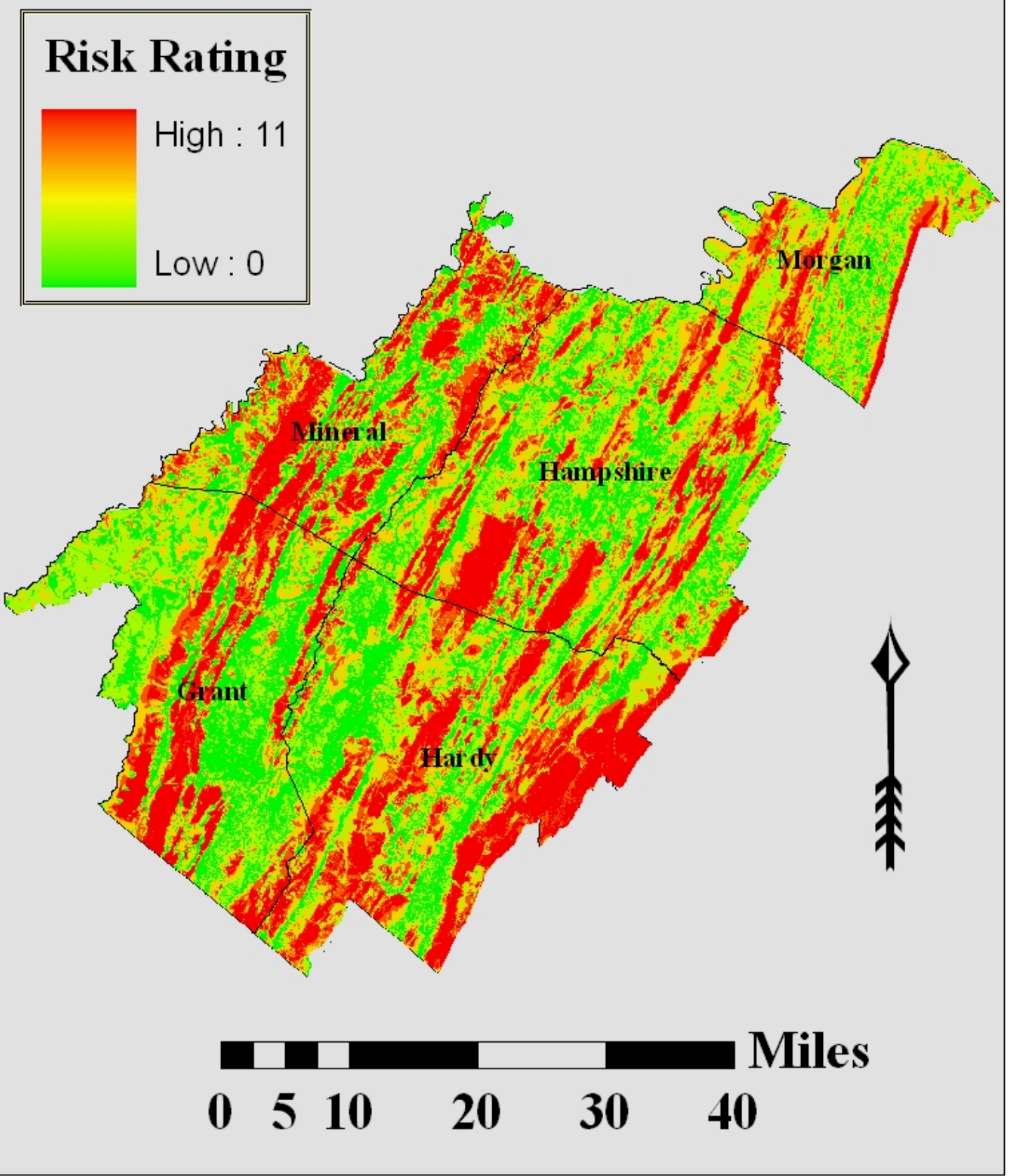

Figure 5: The eastern study site. Risk ratings range from zero, green areas of no pest or disease activity, to eleven, red areas of relatively intense disease activity. Risk rating is a function of historical and predicted pest and disease defoliations and distributions. 


\section{Sampling Survey Subjects}

The complete study area of 11 counties on two sites has 1118 FSP owners with plans on file with the WVDOF. Percentages of private forestland range from $61-85 \%$ (Table 1). A random sample of survey subjects was taken from each set of counties, grouped by region. FSP participants were chosen from the list of 1118 FSP owners compiled as part of the SAP. No-FSP participants were selected from lists of private forest landowners in WV provided by the USDA Forest Service and complied by faculty of the WVU Division of Forestry who referenced tax records in 2004.

Table 1: Counties selected as study sites for outreach survey.

\begin{tabular}{cccc}
\hline County & Physiographic Section & $\begin{array}{c}\text { Private Forestland } \\
(\mathbf{\%})\end{array}$ & $\begin{array}{c}\text { Stewardship } \\
\text { Plans }\end{array}$ \\
\hline Braxton & Allegheny Plateau & 74 & 101 \\
Calhoun & Allegheny Plateau & 85 & 57 \\
Gilmer & Allegheny Plateau & 80 & 57 \\
Jackson & Allegheny Plateau & 64 & 63 \\
Ritchie & Allegheny Plateau & 81 & 69 \\
Roane & Allegheny Plateau & 72 & 90 \\
Grant & Valley and Ridge/Allegheny Mountains & 69 & 60 \\
Hampshire & Valley and Ridge & 67 & 362 \\
Hardy & Valley and Ridge & 61 & 83 \\
Mineral & Valley and Ridge/Allegheny Mountains & 73 & 98 \\
Morgan & Valley and Ridge & 71 & 78 \\
\hline
\end{tabular}

Names of FSP landowners in counties of study sites were randomly sorted in Excel and the first 250 names from each study site were selected, giving a total of $500 \mathrm{FSP}$ participants. The first 125 names on each study site were chosen for maps, thus 250 FSP participants were surveyed with a map.

Partial lists of no-FSP landowners in counties within study areas were randomly sorted, grouped by county, and the number of subjects chosen from each county equaled the number of FSP participants chosen in that county. This helped survey no-FSP participants in a comparable 
spatial reference: for each FSP participant surveyed, a no-FSP landowner in the same county was surveyed in the same manner. In all, mailings were sent to 1000 private forestland owners--500 involved in FSP and 500 not involved in FSP.

Lists of survey subjects were compiled by study site into map and no-map lists sorted by FSP participation and county. Attention \#'s (Attn \#) were assigned to keep track of survey subjects while protecting their privacy. Western site $=$ Attn $\# 1-500$; eastern site $=$ Attn $\# 500-1000$. The first 250 subjects on each site received maps, of which the first 125 were FSP participants and the next 125 were not FSP participants.

Names of no-FSP landowners had to be checked against a list of all known FSP participants in WV to ensure a lack of FSP participation. The complete list of 1000 subjects was checked for duplications and cross referenced with lists of incorrect addresses identified by recent, unrelated surveys. If at any time during the filtering of the dataset a name needed to be replaced, the appropriate original randomized list was consulted and a name chosen from the bottom of the list up.

FSP participants chosen for map reception already had points digitized for the SAP and available to create maps. However, points on properties of no-FSP survey subjects did not exist and had to be digitized from topographic maps and tax records. County courthouses were visited on September 1, 2, 6, and 7 with lists of no-FSP subjects. Tax maps were referenced in county assessor offices. The cost of courthouse produced copies of tax maps and restrictions against copying or tracing tax maps dictated individual maps be hand drawn by referencing tax maps and noting scales and measurements. A sample of a hand drawn map is seen in Figure 29 of Appendix 1. Hampshire County data was available on-line at http//157.182.136.80/hampshire/. The site did not operate on September 21, 2005, so the courthouse was visited on September 22 
and 23, 2005 and parcel numbers gathered for use with a digital map of Hampshire County parcels created by the West Virginia University GIS Technical Center (WVGISTC).

\section{Maps for Survey Subjects}

Once points were gathered for no-FSP subjects they were digitized in Arc-Map using a gazetteer, digital topo-maps, road shapefiles, and stream shapefiles from the WVGISTC. Individual, $8 \mathrm{X}$ 11 inch maps for survey subjects were made using digitized points and the risk rating layer produced for this project. Experimentation determined a scale of $\approx 1: 44,725$ to be both most visually appealing and able to clearly convey the necessary information. A scale bar, legend, and North arrow were added to each map, and a point on the survey subjects' property was highlighted in navy blue and accompanied by text identifying the risk rating representing current and predicted pest and disease activity at that point.

County boundaries, major roads, minor roads, and streams (from WVGISTC shapefiles) were included in maps to help survey subjects orient themselves on the map. The shapefile of minor roads included major roads, but a separate shapefile of major roads only was used to differentiate the two road types and offer quick reference. Whenever possible the point on a property was placed in the center of the map, but occasionally state borders or surrounding risk rating distribution encouraged a non-central placement of a point to sufficiently display the spatial orientation of a property within the risk rating layer. A sample of maps distributed to survey subjects is seen in Figure 30 of Appendix 1.

\section{Survey Protocol}

Cover letters for map and no-map recipients, and the map informing landowners of the position of their property relative to a risk rating were distributed to survey subjects. Half of each group of landowners was surveyed without an enclosed map to investigate the effect of including a 
map. Cover letters were developed using WVU Institutional Review Board guidelines, which ensure the privacy and protection of human participants in research of all kinds. A postcard was included for return correspondence along with a cover letter and map. There was no return service to the landowner. Cover letters and postcard can be seen in Appendix 3.

Mailings were sent out on September 28, 2005. The cost of stamps prevented their use and dictated using business reply return postage. Within a week mailings were returned for various reasons: no such number, address not known, unable to forward, forwarding order ended, deceased, or no longer at that address; some mailings that were not forwarded came back with new addresses available. During the time spent waiting for responses, courthouses were revisited on October 5, 6, 7, 11, and 12, 2005 to locate properties of no-FSP survey subjects not receiving maps. The level of pest and disease activity on the landscape should be apparent even to those subjects not receiving a map, so risk ratings had to be identified for all survey subjects to evaluate the effects of risk rating on response rate with a full model statistically.

Some FSP members not receiving maps did not yet have points digitized for SAP, so locations for those properties were also sought out. Some address corrections were made using courthouse records, and any chosen survey subjects that did not appear in tax records were replaced with existing landowners in tax records. These replacements were selected from the place in alphabetical order where erroneous names should have been, for example, the last name Hubbell did not appear in tax records but was a chosen survey subject, so it was replaced by the last name Hubbard. Points were digitized for corrected addresses and other replacements as described above. On October 15, 2005 a second set of mailings consisting of corrected addresses and replacements for erroneous names was sent out. Since postcards with appropriate Attn \#s were not necessarily available for new subjects because only 1000 were printed, returned postcards 
within undeliverable envelopes were re-used, and when Attn \#s were not correct for the subject, the correct Attn \# was inserted following a hyphen placed at the end of the cards original Attn \#.

As postcards were returned the responses of subjects were entered into the Excel spreadsheet created to record and track the survey subjects. The circumstances for return of the postcard were noted and responses to each statement on the postcard were recorded as either existent (1) or non-existent (0). Further, each subject's overall response and thus potential interest level in pests and diseases was categorized as described below under Numerical Analysis.

\section{Numerical analysis}

A three-factor analysis of variance (ANOVA) was used to evaluate the effects of various experimental factors on forest health interest levels among private forestland owners in West Virginia. As stated previously, experimental factors included: 1) FSP-involvement in the FSP program; 2) region-eastern panhandle or western WV; and, 3) MAP-map provided in survey mailing.

A primary dependent variable of interest is "response rate", or the proportion of forestland owners returning the survey postcard. We developed an "interest" variable as an indicator of a respondent's engagement with forest health issues.

Inferences were made to develop an interest index from the numerous possible combinations of postcard responses. Chosen pests or diseases are dependent on the host species a landowner has on their land and may not necessarily reflect their interest level. A request for a professional visit or a workshop may show more interest than just a request for fact sheets because the subject would be willing to take time to meet with others and have a dialogue (Toman et al. 2004). 
Only returned, completed postcards were used to record interest. To begin with, a six category index was developed: 1) checking box 3-“I am not interested in pests/diseases"-(Post card, Appendix 3) indicates indifferent interest - it was at least returned; 2) checking box 1 ("I am currently knowledgeable about....”) indicates minimal interest—at least there is some awareness; 3) checking box 2 ("I am currently engaged in.....") or both boxes 1 and 2 indicates mild interest - awareness is coupled with action, but no information is requested; 4) checking box 4 ("I would prefer information on....") indicates high interest—information is being requested; 5) checking boxes 1 and 4 indicates very high interest—subject is knowledgeable but wants to learn more; 6) and checking boxes 1, 2, and 4 indicates highest interest — knowledge and action are combined with a desire to learn more.

Additionally, the high category was split into low and moderate; the very high category was split into moderately high and high, and the highest category was split into very high and highest to account for chosen delivery method. Note that these categories define interest levels within the context of the survey. Ultimately, interest levels were recorded on spreadsheets ranging from one (1) —indifferent, to nine (9) — highest (Table 2). 
Table 2: Categorization of interest levels as derived from postcard (Appendix 3) responses.

\begin{tabular}{clll}
\hline $\begin{array}{c}\text { Interest Level } \\
\text { (numeric) }\end{array}$ & \multicolumn{1}{c}{$\begin{array}{c}\text { Interest } \\
\text { Level }\end{array}$} & $\begin{array}{c}\text { Post Card Statements } \\
\text { Checked }\end{array}$ & \multicolumn{1}{c}{$\begin{array}{c}\text { Preferred Delivery } \\
\text { Method }\end{array}$} \\
\hline 1 & Indifferent & 3 & -- \\
2 & Minimal & 1 & -- \\
3 & Mild & 2 or $1 \& 2$ & -- \\
4 & Low & 4 & Information Sheets \\
5 & Moderate & 4 & Professional Visit or Workshop \\
6 & Moderately high & $1 \& 4$ & Information Sheets \\
7 & High & $1 \& 4$ & Professional Visit or Workshop \\
8 & Very high & $1,2, \& 4$ & Information Sheets \\
9 & Highest & $1,2, \& 4$ & Professional Visit or Workshop \\
\hline
\end{tabular}

The affects of the independent variables of FSP participation, region, and use of a map on the dependent interest level were tested using an $\mathrm{A} \times \mathrm{B} \times \mathrm{C}$ factorial ANOVA analysis where the levels of interest displayed by survey subjects or other dependent variables were used as the observations in each cell of the three-factor design and $a=2, b=2, c=2$, and $n=125$ :

$$
\begin{aligned}
& \text { Model: } \quad \text { Interest }=\mu+\mathrm{FSP}_{\mathrm{i}}+\text { Region }_{\mathrm{j}}+\mathrm{Map}_{\mathrm{k}}+\mathrm{FSP}^{*} \text { Region }_{\mathrm{ij}}+\mathrm{FSP}^{*} \mathrm{Map}_{\mathrm{ik}}+ \\
& \text { Region*Map } \mathrm{jk}_{\mathrm{j}}+\mathrm{FSP} * \text { Region*Map } \mathrm{Mjk}+\varepsilon_{\mathrm{ijk} 1} \\
& \mathrm{i}=1,2 \\
& \mathrm{j}=1,2 \\
& \mathrm{k}=1,2 \\
& 1=1, \ldots, 125 \\
& \varepsilon_{\mathrm{ijkl}}=\text { the random effect due to sampling }
\end{aligned}
$$

Analysis of covariance (ANCOVA) was used to test risk and acreage as covariates that might account for differences in the response variables. The ANCOVA model is identical to the regular ANOVA, but includes an additional term - the covariate:

$$
\begin{aligned}
& \text { Interest }=\mu+\text { FSP }_{\mathrm{i}}+\text { Region }_{\mathrm{j}}+\text { Map }_{\mathrm{k}}+\mathrm{FSP}^{*} \text { Region }_{\mathrm{ij}}+\mathrm{FSP}^{*} \mathrm{Map}_{\mathrm{ik}}+ \\
& \text { Region}^{*} \mathrm{Map}_{\mathrm{jk}}+\mathrm{FSP} * \text { Region*Map } \mathrm{Mjk}+\beta\left(\mathrm{x}_{\mathrm{ijkl}}-\text { mean of } \mathrm{x} \ldots .\right)+\varepsilon_{\mathrm{ijkl}}
\end{aligned}
$$


The standard three-factor ANOVA table can be adjusted to include the ANCOVA (Table 3).

Only returned postcards with responses to statements were used in analysis of variance and covariance.

Table 3: Partitioning of source of error variance for three-factor ANOVA and ANCOVA.

\begin{tabular}{lrr}
\hline Source & \multicolumn{1}{c}{ df } & df, Adjusted for Regression \\
\hline FSP & $(\mathrm{a}-1)=1$ & $(\mathrm{a}-1)=1$ \\
Region & $(\mathrm{b}-1)=1$ & $(\mathrm{~b}-1)=1$ \\
Map & $(\mathrm{c}-1)=1$ & $(\mathrm{c}-1)=1$ \\
FSP x Region & $(\mathrm{a}-1)(\mathrm{b}-1)=1$ & $(\mathrm{a}-1)(\mathrm{b}-1)=1$ \\
FSP x Map & $(\mathrm{a}-1)(\mathrm{c}-1)=1$ & $(\mathrm{a}-1)(\mathrm{c}-1)=1$ \\
Region x Map & $(\mathrm{b}-1)(\mathrm{c}-1)=1$ & $(\mathrm{~b}-1)(\mathrm{c}-1)=1$ \\
FSP x Region x Map & $(\mathrm{a}-1)(\mathrm{b}-1)(\mathrm{c}-1)=1$ & $(\mathrm{a}-1)(\mathrm{b}-1)(\mathrm{c}-1)=1$ \\
Error & $\mathrm{abc}(\mathrm{n}-1)=992^{*}$ & $\mathrm{abc}(\mathrm{n}-1)-1=991^{*}$ \\
\hline Total & $\mathrm{abcn}-1=999^{*}$ & $\mathrm{abcn}-2=998^{*}$ \\
\hline
\end{tabular}

* Numbers used for example only: actual df will change as n changes for each ANOVA or ANCOVA cell due to survey response, problems contacting survey subjects, and missing acre and risk values.

Logistic regression (PROC Logistic) was used to test for factors influencing interest level as a binary dependent variable represented by the simple return of a postcard, regardless of the reason for the return. A returned postcard was a positive response and no return a negative response. Incorrect addresses were excluded from the dataset and thrown out of the statistical analysis, as where postcards returned labeled as deceased or no longer landowner. These returns could not be counted as a response to this survey because the mailing never reached and procured a response from its intended target, a forest landowner. Logistic regression was used to test for factors that might influence a landowner's interest in a particular organism and their preferred method of information delivery.

Descriptive statistics were used to evaluate the overall response for each treatment combination, to identify the most commonly inquired about organisms and preferred delivery methods for 
educational information, and to find average values for risk rating and acres. A hand calculator, Excel, and SAS were used to obtain descriptive statistics.

\section{Limitations}

The findings of this study may be interpreted to represent only West Virginia landowners at the sites sampled. The study relied on honest, complete participation by survey subjects. Interest levels were developed by the author for survey respondents only and cannot be immediately extrapolated to other survey subjects or surveys; and non-responses were assumed to represent a negative response or lack of interest for statistical analyses of the entire sample population when this may not actually be the case. We intended to sample a willingness to respond with a onetime mailing designed to be as un-intrusive as possible for a population of subjects inundated with surveys in recent years. This limited the collection of more detailed demographic information and the possibility of achieving a higher response rate thorough follow-up mail or phone surveys utilized by surveys experiencing relatively high response rates.

\section{Results}

\section{Survey Response}

\section{Sample Population $(N=933)$}

Of the 1000 mailings sent to landowners 64 came back due to incorrect addresses; also, two postcards were returned labeled no longer landowner, and one came back labeled deceased. Incorrect addresses were left out of analyses because the survey never reached a forest landowner. The two recent sellers and one deceased landowner were thrown out because they

did not reach a current forest landowner. Responses were not recorded after November 15, 2005. The final total sample population was 933. Postcards were completed and returned by 199 subjects, resulting in a $21 \%$ response rate. 
Overall in the 933 sample population FSP participants provided the highest response (26\%), and no-FSP subjects the lowest (17\%). Map recipients were less likely to respond than subjects not receiving a map (Table 4). Among the eight possible ANOVA treatment combinations for the sample population, the highest response rate (29\%) occurred among FSP participants from the eastern site who did not receive a map, and the lowest response rate (11\%) was garnered from no-FSP owners in the western site receiving a map (Table 5).

Table 4: Sample population response rates of treatment categories and overall.

\begin{tabular}{|c|c|c|c|c|c|c|}
\hline & FSP & No-FSP & $\begin{array}{c}\text { Western } \\
\text { Site }\end{array}$ & $\begin{array}{c}\text { Eastern } \\
\text { Site }\end{array}$ & Map & No-Map \\
\hline $\begin{array}{c}\text { Treatment } \\
\text { Only } \\
\text { Overall }(n=933)\end{array}$ & $\begin{array}{c}26 \% \\
\mathrm{n}=468 \\
13 \%\end{array}$ & $\begin{array}{c}17 \% \\
\mathrm{n}=459 \\
8 \%\end{array}$ & $\begin{array}{c}20 \% \\
\mathrm{n}=463 \\
10 \%\end{array}$ & $\begin{array}{c}23 \% \\
\mathrm{n}=464 \\
12 \%\end{array}$ & $\begin{array}{c}20 \% \\
\mathrm{n}=467 \\
10 \%\end{array}$ & $\begin{array}{c}23 \% \\
\mathrm{n}=460 \\
11 \%\end{array}$ \\
\hline
\end{tabular}

Table 5: Sample population response rates of ANOVA treatment combinations.

\begin{tabular}{cccc}
\hline Site & Map & FSP & No-FSP \\
\hline Western & Yes & $26 \% ; \mathrm{n}=121$ & $11 \% ; \mathrm{n}=114$ \\
& No & $25 \% ; \mathrm{n}=118$ & $15 \% ; \mathrm{n}=110$ \\
Eastern & Yes & $23 \% ; \mathrm{n}=114$ & $21 \% ; \mathrm{n}=118$ \\
& No & $29 \% ; \mathrm{n}=115$ & $21 \% ; \mathrm{n}=117$ \\
\hline
\end{tabular}

\section{Respondent Population $(N=199)$}

In the population of 199 respondents, FSP participants had the highest response rate (61\%), whereas no-FSP subjects had the lowest (39\%); and again, map recipients responded less than those not receiving a map (Table 6). Among treatment combinations response rates are consistently higher for FSP participants; response rates range from 6-17\% (Table 7).

Table 6: Respondent population response rates of treatment categories $(n=199)$.

\begin{tabular}{cccccc}
\hline FSP & No-FSP & Western Site & Eastern Site & Map & No-Map \\
\hline $61 \%$ & $39 \%$ & $45 \%$ & $54 \%$ & $48 \%$ & $52 \%$ \\
\hline
\end{tabular}


Table 7: Respondent population response rates of ANOVA treatment combinations $(\mathbf{n}=199)$.

\begin{tabular}{cccc}
\hline Site & Map & FSP & No-FSP \\
\hline Western & Yes & $16 \%$ & $6 \%$ \\
& No & $15 \%$ & $8 \%$ \\
Eastern & Yes & $13 \%$ & $13 \%$ \\
& No & $17 \%$ & $13 \%$ \\
\hline
\end{tabular}

\section{Interest}

Sample Population $(N=933)$

Logistic regression was performed on the entire sample population using returned postcards as a binary dependent variable representing interest. If a postcard was returned by a forest landowner it was a positive response, a postcard not returned but assumed to reach the subject was a negative response. Incorrect addresses and cards not returned and labeled deceased or no longer landowner where thrown out of the analysis. The only significant factor found was FSP $\left(\chi^{2}=\right.$ 10.4274; $\mathrm{p}=0.0012$ ). A contingency table of FSP vs returned shows when postcards were returned they were returned more often by FSP participants (Table 8). ANCOVAs with area and risk as covariables individually and together found no significance for either factor.

Table 8: Contingency table results for interest of the sample population as represented by the return of a postcard.

\begin{tabular}{llccc}
\hline & & Returned & Not Returned & Total \\
\hline \multirow{3}{*}{ FSP } & Frequency & 121 & 352 & 473 \\
& Percent & 12.97 & 37.73 & 50.70 \\
& Row \% & 25.58 & 74.42 & -- \\
& Column \% & 60.80 & 47.96 & -- \\
\hline No- & Frequency & 78 & 382 & 460 \\
FSP & Percent & 8.36 & 40.94 & 49.30 \\
& Row \% & 16.96 & 83.04 & -- \\
& Column \% & 39.20 & 52.40 & -- \\
\hline Total & Frequency & 199 & 734 & 933 \\
& Percent & 21.33 & 78.67 & 100.00 \\
\hline
\end{tabular}




\section{Respondent Population $(N=199)$}

Average respondent interest, as defined by the nine-category index created for this study, was 4.60 and ranged from 4.28-4.81 for treatment categories (Table 9). ANOVA shows FSP was statistically related to interest (Table 10). On average, FSP participant response (\%) to the survey was higher than no-FSP response (\%). Acreage and risk did not significantly affect interest when added to the model as independent covariables individually (acre: $F=0.03 ; p=$ 0.8534 ; risk: $\mathrm{F}=2.81 ; \mathrm{p}=0.0951)$ or together (Table 11$)$. As we will see below, acreage is significantly larger for FSP properties, but interest levels do not show a pattern of being affected by area (Figure 6). Whenever FSP is part of a treatment combination, interest is higher (Table 12). The mode and median for interest were both four (4). Table 13 shows the distribution of interest levels: lower interest level observations are relatively evenly distributed, but as interest levels increase, FSP gradually accounts for a higher percentage of observations - as interest level increases, so does the role of FSP participation.

Table 9: Respondent population mean interest levels of treatment categories $(n=199)$.

\begin{tabular}{cccccc}
\hline FSP & No-FSP & Western Site & Eastern Site & Map & No-Map \\
\hline 4.81 & 4.28 & 4.60 & 4.60 & 4.52 & 4.68 \\
\hline
\end{tabular}

Table 10: ANOVA results with interest as the dependent variable for the respondent population. Interest is a function of the index created for this study.

\begin{tabular}{lccc}
\hline \multicolumn{1}{c}{ Source } & df & F-stat & p-value \\
\hline FSP & 1 & 3.88 & 0.050 \\
Region & 1 & 0.13 & 0.7200 \\
Map & 1 & 0.35 & 0.5533 \\
FSP x Region & 1 & 0.46 & 0.4995 \\
FSP x Map & 1 & 0.08 & 0.7766 \\
Region x Map & 1 & 0.30 & 0.5823 \\
FSP x Region x Map & 1 & 0.13 & 0.7159 \\
Error & 191 & -- & -- \\
\hline Total & 198 & -- & -- \\
\hline
\end{tabular}


Table 11: ANCOVA results with interest as the dependent variable for the respondent population. Interest is a function of the index created for this study.

\begin{tabular}{lccc}
\hline \multicolumn{1}{c}{ Source } & df & F-stat & p-value \\
\hline Area $\left(\mathrm{x}_{1}\right)$ & 1 & 0.04 & 0.8366 \\
Risk $\left(\mathrm{x}_{2}\right)$ & 1 & 2.81 & 0.0956 \\
FSP & 1 & 3.10 & 0.0799 \\
Region & 1 & 0.04 & 0.8387 \\
Map & 1 & 0.53 & 0.4671 \\
FSP x Region & 1 & 0.62 & 0.4330 \\
FSP x Map & 1 & 0.04 & 0.8472 \\
Region x Map & 1 & 0.67 & 0.4126 \\
FSP x Region x Map & 1 & 0.09 & 0.7603 \\
Error & 188 & -- & -- \\
\hline Total & 197 & -- & -- \\
\hline
\end{tabular}

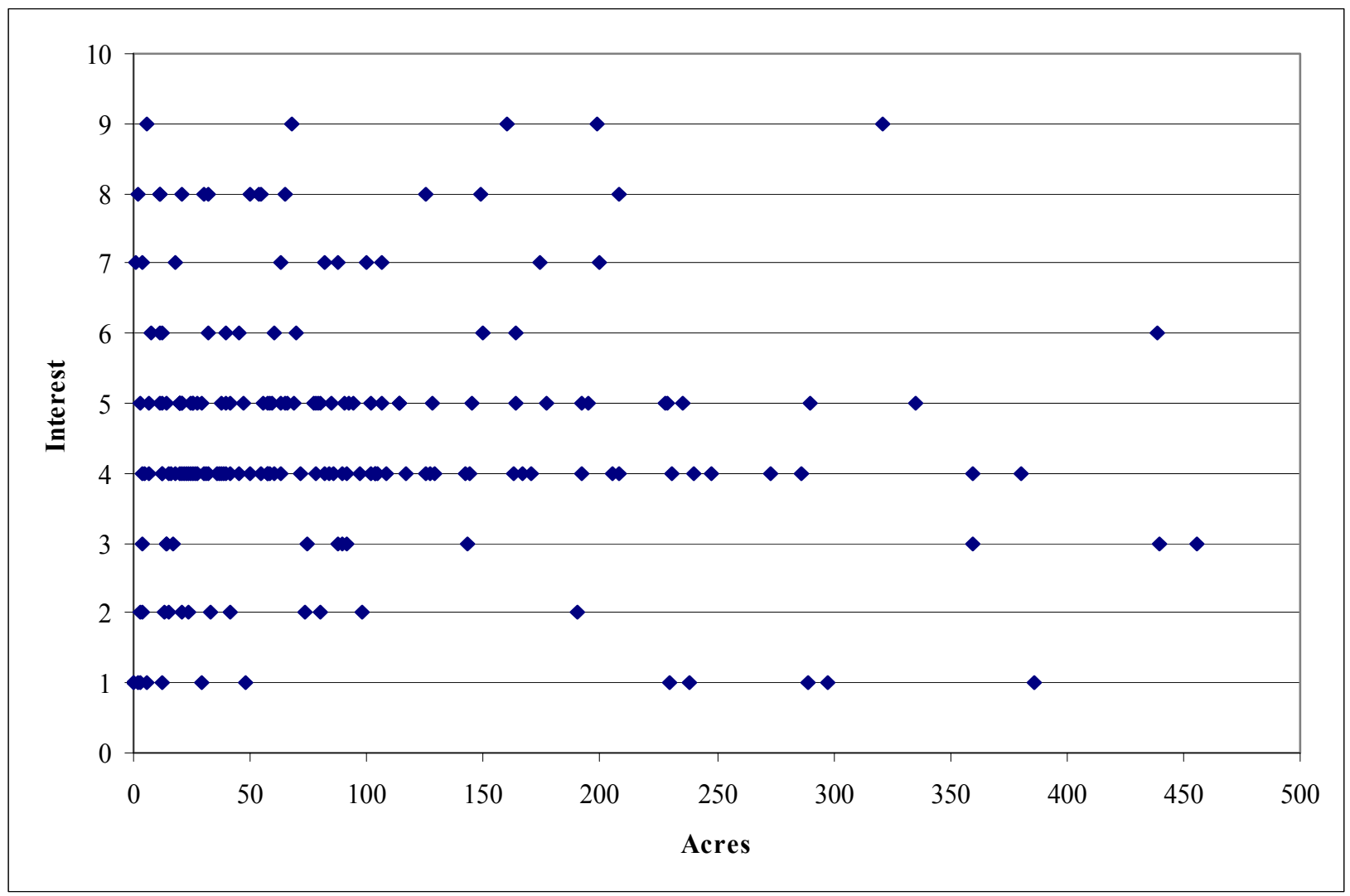

Figure 6: Interest levels vs. area for respondent population. Interest does not follow a pattern that correlates with property size. Seven outliers over 500 acres were eliminated $(n=192)$. Table 3 in Appendix 2 shows outliers and their interest levels. 
Table 12: Respondent population mean interest levels of ANOVA treatment combinations (n= 199).

\begin{tabular}{cccc}
\hline Site & Map & FSP & No-FSP \\
\hline Western & Yes & 4.84 & 4.08 \\
& No & 4.83 & 4.12 \\
Eastern & Yes & 4.50 & 4.32 \\
& No & 5.00 & 4.46 \\
\hline
\end{tabular}

Table 13: Respondent population interest level distributions.

\begin{tabular}{|c|c|c|c|c|c|c|c|c|c|c|c|}
\hline & \multicolumn{10}{|c|}{ Interest Level } & \multirow[t]{2}{*}{ Total } \\
\hline & & 1 & 2 & 3 & 4 & 5 & 6 & 7 & 8 & 9 & \\
\hline \multirow{4}{*}{ FSP } & Frequency & 6 & 6 & 7 & 40 & 32 & 8 & 7 & 9 & 6 & 121 \\
\hline & Percent & 3.02 & 3.02 & 3.52 & 20.10 & 16.08 & 4.02 & 3.52 & 4.52 & 3.02 & 60.80 \\
\hline & Row \% & 4.96 & 4.96 & 5.79 & 33.06 & 26.45 & 6.61 & 5.79 & 7.44 & 4.96 & -- \\
\hline & Column \% & 50.00 & 46.15 & 58.33 & 57.97 & 62.75 & 72.73 & 70.00 & 64.29 & 85.71 & -- \\
\hline \multirow{4}{*}{$\begin{array}{l}\text { No- } \\
\text { FSP }\end{array}$} & Frequency & 6 & 7 & 5 & 29 & 19 & 3 & 3 & 5 & 1 & 78 \\
\hline & Percent & 3.02 & 3.52 & 2.51 & 14.57 & 9.55 & 1.51 & 1.51 & 2.51 & 0.50 & 39.20 \\
\hline & Row \% & 7.69 & 8.97 & 6.41 & 37.18 & 24.36 & 3.85 & 3.85 & 6.41 & 1.28 & -- \\
\hline & Column \% & 50.00 & 53.85 & 41.67 & 42.03 & 37.25 & 27.27 & 30.00 & 35.71 & 14.29 & -- \\
\hline \multirow[t]{2}{*}{ Total } & Frequency & 12 & 13 & 12 & 69 & 51 & 11 & 10 & 14 & 7 & 199 \\
\hline & Percent & 6.03 & 6.53 & 6.03 & 34.67 & 25.63 & 5.53 & 5.03 & 7.04 & 3.52 & 100.00 \\
\hline
\end{tabular}

\section{Postcard Statements, Chosen Pests and Disease, Chosen Delivery Methods}

Logistic regression was performed on the binary dependent variables - postcard statements, pests and diseases chosen, and prefer delivery methods. Site was significant for $\operatorname{BBD}\left(\chi^{2}=4.6568 ; \mathrm{p}\right.$ $=0.0309)$ and statement three (3) on the post card $\left(\chi^{2}=4.4974 ; p=0.0339\right)$; and FSP was significant for GM $\left(\chi^{2}=5.5058 ; \mathrm{p}=0.0190\right)$ and statement four (4) on the postcard $\left(\chi^{2}=3.9431\right.$; $\mathrm{p}=0.0471)$. Western site subjects were statistically more likely to request information on BBD and significantly more likely to choose statement three (3) (Table 14). Similarly, participants in FSP had significantly more requests for information on gypsy moth and responded to statement four (4) statistically more often (Table 15). The FSP was not quite significant for sudden oak death (Phytophtora ramorum; SOD) $\left(\chi^{2}=3.6014 ; \mathrm{p}=0.0577\right)$. 
Table 14: Respondent population responses to beech bark disease and "I am not interested in forest pests and diseases".

\begin{tabular}{clccc|ccc}
\hline & BBD & BBD not & & Statement & Statement 3 \\
Chosen & Chosen & Total & 3 Chosen & $\begin{array}{c}\text { not Chosen } \\
\text { notal }\end{array}$ & Tot \\
\hline Western & Frequency & 32 & 59 & 91 & 10 & 81 & 91 \\
Site & Percent & 16.08 & 29.65 & 45.73 & 5.03 & 40.70 & 45.73 \\
& Row \% & 35.16 & 64.84 & -- & 10.99 & 89.01 & -- \\
& Column \% & 58.18 & 40.97 & -- & 71.43 & 43.78 & -- \\
\hline Eastern & Frequency & 23 & 85 & 108 & 4 & 104 & 108 \\
Site & Percent & 11.56 & 42.71 & 54.27 & 2.01 & 52.26 & 54.27 \\
& Row \% & 21.30 & 78.70 & -- & 3.70 & 96.30 & -- \\
& Column \% & 41.82 & 59.03 & -- & 28.57 & 56.22 & -- \\
\hline Total & Frequency & 55 & 144 & 199 & 14 & 185 & 199 \\
& Percent & 27.64 & 72.36 & 100.00 & 7.04 & 92.96 & 100.00 \\
\hline
\end{tabular}

Table 15: Respondent population responses to gypsy moth and "I would prefer information on pests and diseases".

\begin{tabular}{llccc|ccc}
\hline & $\begin{array}{c}\text { GM } \\
\text { Chosen }\end{array}$ & $\begin{array}{c}\text { GM not } \\
\text { Chosen }\end{array}$ & Total & $\begin{array}{c}\text { Statement } \\
\text { 4 Chosen }\end{array}$ & $\begin{array}{c}\text { Statement 4 } \\
\text { not Chosen }\end{array}$ & Total \\
\hline FSP & Frequency & 72 & 49 & 121 & 103 & 18 & 121 \\
& Percent & 36.18 & 24.62 & 60.80 & 51.76 & 9.05 & 60.80 \\
& Row \% & 59.50 & 40.50 & -- & 85.12 & 14.88 & -- \\
& Column \% & 68.57 & 52.13 & -- & 63.98 & 47.37 & -- \\
\hline No- & Frequency & 33 & 45 & 78 & 58 & 20 & 78 \\
FSP & Percent & 16.58 & 22.61 & 39.20 & 29.15 & 10.05 & 39.20 \\
& Row \% & 42.31 & 57.69 & -- & 74.36 & 25.64 & -- \\
& Column \% & 31.34 & 47.87 & -- & 36.02 & 52.36 & -- \\
\hline Total & Frequency & 105 & 94 & 199 & 161 & 38 & 199 \\
& Percent & 52.76 & 47.24 & 100.00 & 80.90 & 19.10 & 100.00 \\
\hline
\end{tabular}

The near significance of FSP for SOD $(F=3.601 ; p=0.0577)$ is worth mentioning because SOD was the most popular choice for information requests: $65 \%$ of responding subjects want SOD information, and although FSP was not significant, $66 \%$ of requests on SOD came from FSP participants (Figure 8). Gypsy moth ran second to SOD, with 53\% of response subjects wanting more information about GM (Figure 8). 


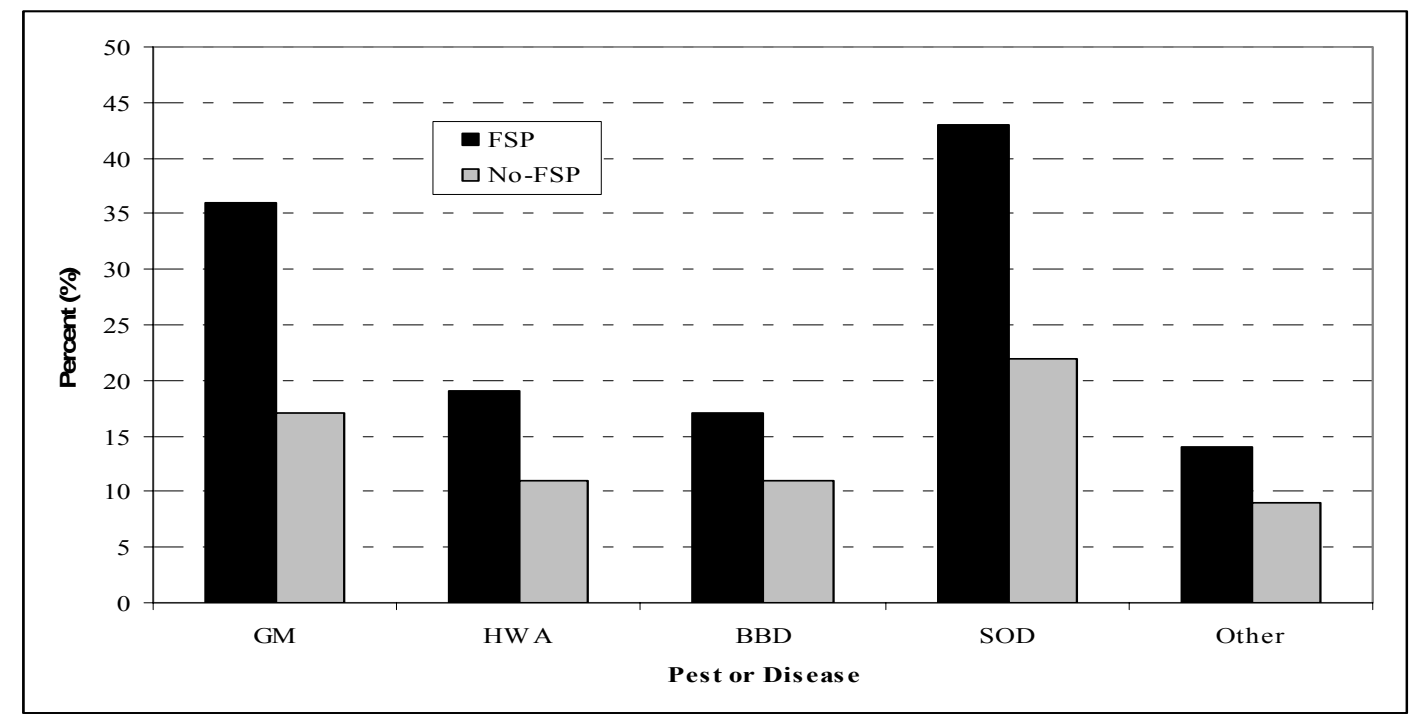

Figure 7: Percents of respondent population requesting information on pests and diseases.

The "other" category gave respondents the opportunity to identify organisms of concern that were not listed on the postcard. The species composition of a respondent's property would guide these choices. For example, five people requested information on anything relevant to their property, four requested information on pine pests and diseases, three people requested information on hickory pests and diseases; and one would like to know about ash and maple pests. Emerald ash borer (Agrilus planipennis Fairmaire) and red oak borer (Enaphalodes rufulus Haldeman) were the most often specifically identified organisms, receiving eight and four requests, respectively.

Information sheets were the most often preferred delivery method, being chosen by $60 \%$ of respondents (Figure 9). Personal visits were desired by $32 \%$ of subjects, a workshop was only requested $12 \%$ of the time, and four respondents $(2 \%)$ chose the other category for delivery method and wanted to be contacted by e-mail. The most often answered statement on postcards was statement four (4) — a request for information (81\%). Twenty seven percent of respondents think they are knowledgeable about pests and diseases while $13 \%$ currently manage for pests and diseases, and 7\% have no interest in pests and diseases at this time (Figure 10). 


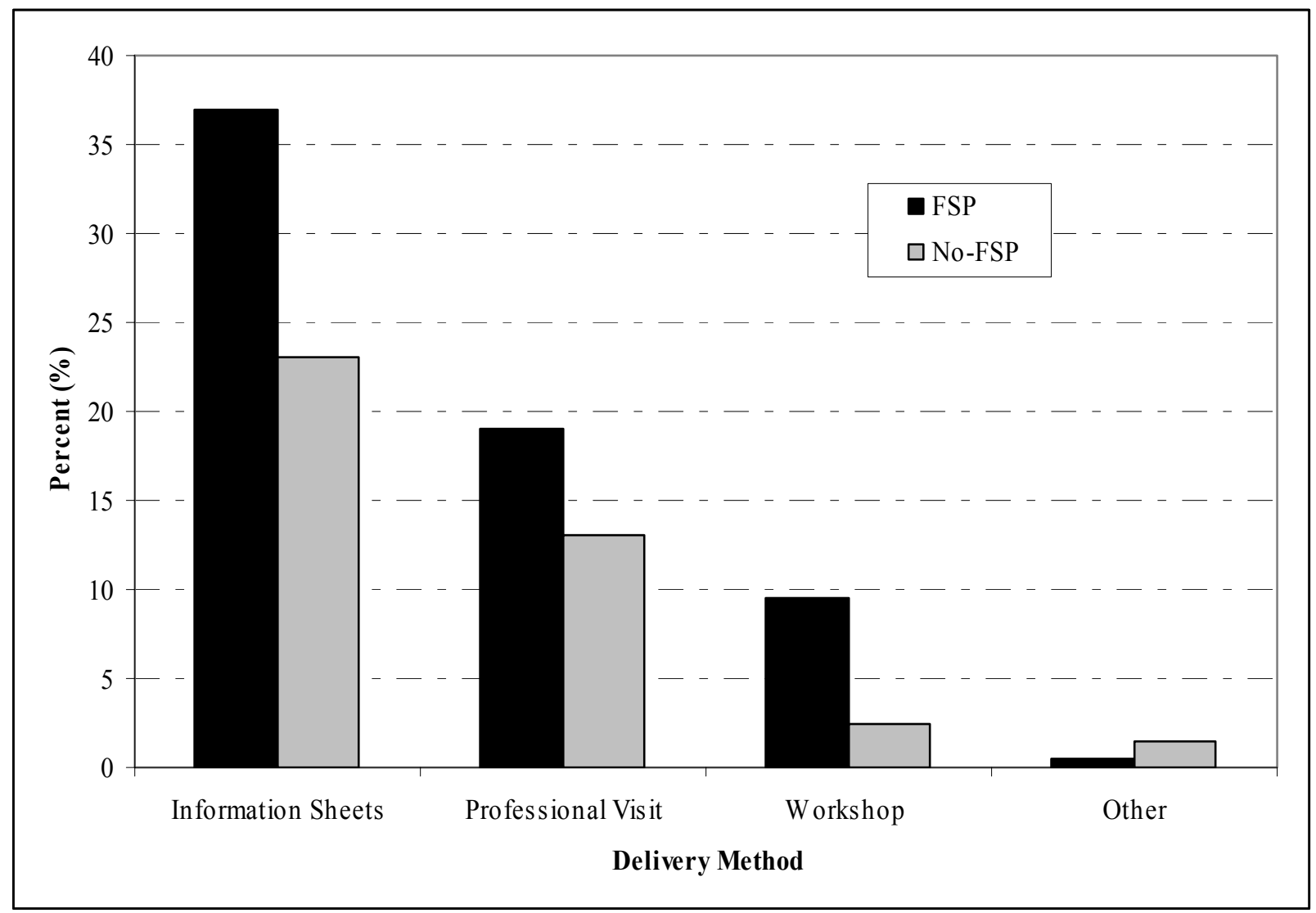

Figure 8: Percents of respondent population requesting selected delivery methods.

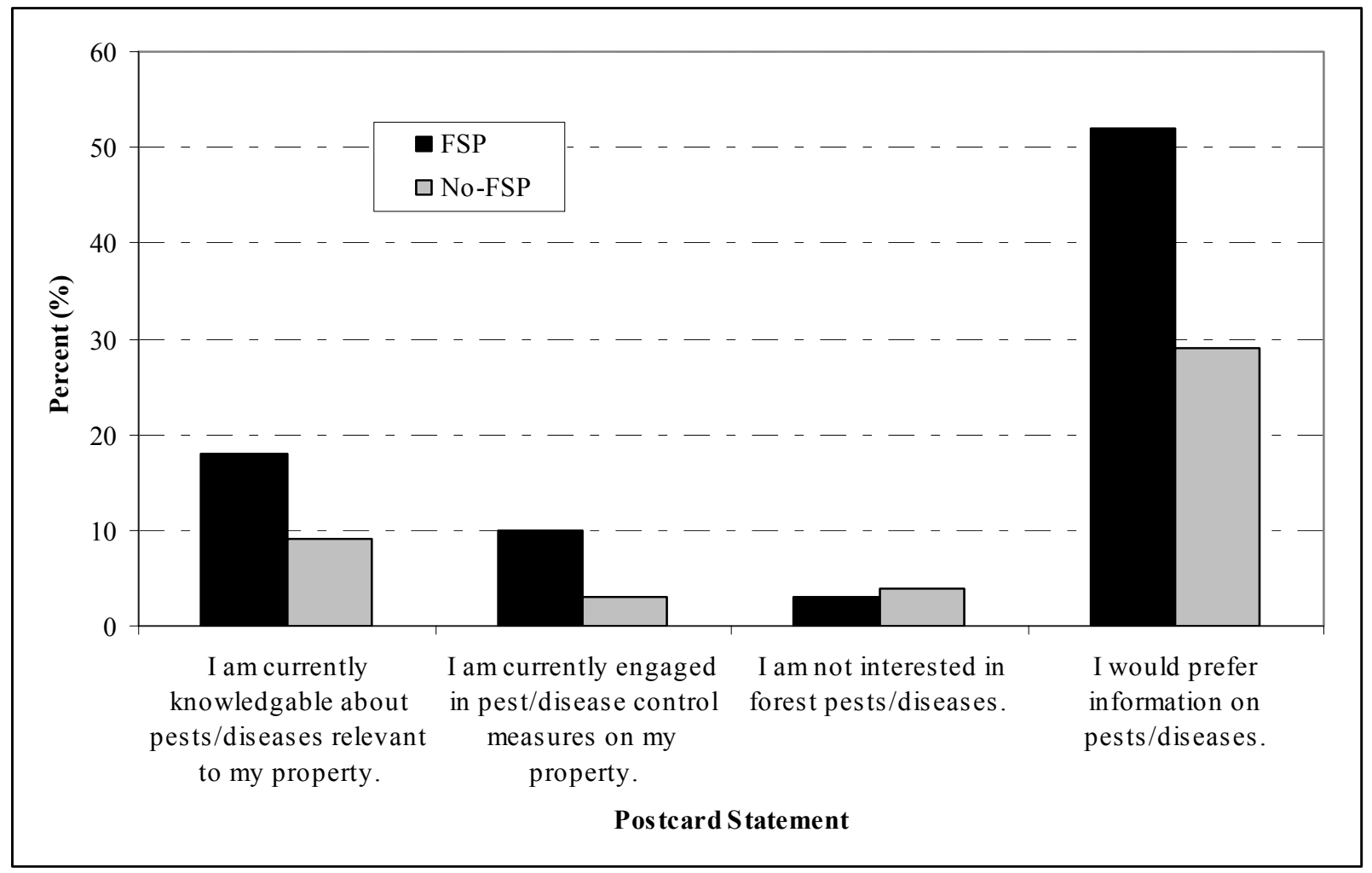

Figure 9: Percents of respondent population checking postcard statements. 


\section{Area and Risk Rating}

\section{Sample Population $(N=933)$}

Acreages and risk ratings were not available for all 933 survey subjects. The mean property area of subjects overall was 103.8 acres $(\mathrm{n}=928)$, and the mean risk rating was $1.6(\mathrm{n}=927)$ with a mode of 2. FSP properties averaged the largest in area (164.8 acres), and the eastern site had the highest overall risk rating among treatments-2.0 (Table 16). Property sizes ranged from 0.21657.0 acres, and risk ratings ranged from 0-10 with all values except nine (9) represented at least once.

Table 16: Sample population mean acreages and risk ratings of treatment categories.

\begin{tabular}{|c|c|c|c|c|c|c|}
\hline & FSP & No-FSP & $\begin{array}{c}\text { Western } \\
\text { Site } \\
\end{array}$ & $\begin{array}{c}\text { Eastern } \\
\text { Site }\end{array}$ & Map & No-Map \\
\hline Acres & $\begin{array}{l}* 164.8 \\
\mathrm{n}=472\end{array}$ & $\begin{array}{c}40.7 \\
n=456\end{array}$ & $\begin{array}{c}104.4 \\
\mathrm{n}=464\end{array}$ & $\begin{array}{c}59.0 \\
\mathrm{n}=464\end{array}$ & $\begin{array}{l}* 121.4 \\
\mathrm{n}=465\end{array}$ & $\begin{array}{c}86.1 ; \\
\mathrm{n}=463\end{array}$ \\
\hline $\begin{array}{c}\text { Risk } \\
\text { Rating }\end{array}$ & $\begin{array}{c}1.7 \\
\mathrm{n}=468\end{array}$ & $\begin{array}{c}1.6 ; \\
n=459\end{array}$ & $\begin{array}{c}1.3 ; \\
\mathrm{n}=463\end{array}$ & $\begin{array}{c}* 2.0 \\
\mathrm{n}=464\end{array}$ & $\begin{array}{c}1.7 \\
\mathrm{n}=467\end{array}$ & $\begin{array}{c}1.7 \\
\mathrm{n}=460\end{array}$ \\
\hline
\end{tabular}

*Significantly higher than other categories.

As can be seen in Table 16, FSP and map treatments seem to have larger areas than do other treatments. An ANOVA with acres as the dependent variable found statistical differences in acreages among FSP properties and map recipients; this phenomenon also results in a significant difference for the FSP*map treatment combination (Table 17). In any combination of treatments, whenever an FSP property or a map recipient is involved mean area is greater than when subjects are not FSP participants or did not receive maps (Table 18; Table 3 Appendix 2). 
Table 17: ANOVA results with area as the dependent variable for the sample population.

\begin{tabular}{lccc}
\hline \multicolumn{1}{c}{ Source } & df & F-stat & p-value \\
\hline FSP & 1 & 165.48 & $<0.0001$ \\
Region & 1 & 0.06 & 0.7991 \\
Map & 1 & 14.09 & 0.0002 \\
FSP x Region & 1 & 0.31 & 0.5807 \\
FSP x Map & 1 & 10.46 & 0.0013 \\
Region x Map & 1 & 0.04 & 0.8336 \\
FSP x Region x Map & 1 & 0.41 & 0.5207 \\
Error & 920 & -- & -- \\
\hline Total & 927 & -- & -- \\
\hline
\end{tabular}

Table 18: Sample population mean acreages of ANOVA treatment combinations.

\begin{tabular}{cccc}
\hline Site & Map & FSP & No-FSP \\
\hline Western & Yes & $196.2 ; \mathrm{n}=121$ & $41.2 ; \mathrm{n}=114$ \\
& No & $136.8 ; \mathrm{n}=121$ & $32.0 ; \mathrm{n}=108$ \\
Eastern & Yes & $201.6 ; \mathrm{n}=113$ & $44.9 ; \mathrm{n}=117$ \\
& No & $125.7 ; \mathrm{n}=117$ & $44.0 ; \mathrm{n}=117$ \\
\hline
\end{tabular}

When considering risk ratings for treatment combinations of the entire sample population, Table 19 and Figure 5 show risk to be greater in the eastern site. In an ANOVA where risk is the dependent variable, risk ratings are significantly different with site; also, ANOVA identifies risk as significantly different for the FSP*map treatment combination (Table 19). Whenever the eastern site is a part of a treatment combination the mean risk is greater than the risk of its counterpart where the western site is included (Table 20; Table 4, Appendix 3).

Table 19: ANOVA results with risk rating as the dependent variable for the sample population.

\begin{tabular}{lccc}
\hline \multicolumn{1}{c}{ Source } & df & F-stat & p-value \\
\hline FSP & 1 & 1.68 & 0.1947 \\
Region & 1 & 54.38 & $<0.0001$ \\
Map & 1 & 0.16 & 0.6873 \\
FSP x Region & 1 & 1.95 & 0.1626 \\
FSP x Map & 1 & 5.04 & 0.0250 \\
Region x Map & 1 & 0.69 & 0.4070 \\
FSP x Region x Map & 1 & 0.06 & 0.8047 \\
Error & 919 & -- & -- \\
\hline Total & 926 & -- & -- \\
\hline
\end{tabular}


Table 20: Sample population mean risk ratings of ANOVA treatment combinations.

\begin{tabular}{cccc}
\hline Site & Map & FSP & No-FSP \\
\hline Western & Yes & $1.2 ; \mathrm{n}=121$ & $1.4 ; \mathrm{n}=114$ \\
& No & $1.4 ; \mathrm{n}=118$ & $1.2 ; \mathrm{n}=110$ \\
Eastern & Yes & $2.0 ; \mathrm{n}=114$ & $2.0 ; \mathrm{n}=118$ \\
& No & $2.1 ; \mathrm{n}=115$ & $1.7 ; \mathrm{n}=117$ \\
\hline
\end{tabular}

\section{Respondent Population $(N=199)$}

When only the respondent population of 199 was analyzed, mean acreage was $114.7(\mathrm{n}=199)$ and the mean risk rating was $1.6(\mathrm{n}=198)$. FSP properties had the largest mean area $(163.1$ acres), and the eastern site had the highest mean risk rating-2.0 (Table 21). Areas ranged from 0.2-1070.0 acres and risk ranged from 0-8 with all values except seven (7) represented at least once.

Table 21: Respondent population mean acreages and risk ratings of treatment categories.

\begin{tabular}{|c|c|c|c|c|c|c|}
\hline & FSP & No-FSP & $\begin{array}{c}\text { Western } \\
\text { Site } \\
\end{array}$ & $\begin{array}{c}\text { Eastern } \\
\text { Site }\end{array}$ & Map & No-Map \\
\hline Acres & $\begin{array}{l}* 163.1 \\
\mathrm{n}=121\end{array}$ & $\begin{array}{c}39.7 \\
\mathrm{n}=78\end{array}$ & $\begin{array}{l}144.3 \\
\mathrm{n}=91\end{array}$ & $\begin{array}{c}89.9 \\
\mathrm{n}=108\end{array}$ & $\begin{array}{l}137.4 \\
\mathrm{n}=95\end{array}$ & $\begin{array}{c}94.0 \\
\mathrm{n}=104\end{array}$ \\
\hline Risk Rating & $\begin{array}{c}1.7 \\
\mathrm{n}=120\end{array}$ & $\begin{array}{c}1.6 \\
n=78\end{array}$ & $\begin{array}{c}1.1 \\
\mathrm{n}=90\end{array}$ & $\begin{array}{c}* 2.0 \\
\mathrm{n}=108\end{array}$ & $\begin{array}{c}1.8 \\
\mathrm{n}=95\end{array}$ & $\begin{array}{c}1.5 \\
\mathrm{n}=103\end{array}$ \\
\hline
\end{tabular}

*Significantly higher than other categories.

When considering only the respondent population and using acreage as the dependent variable in an ANOVA, area is significantly different with FSP (Table 22), and whenever FSP is part of the treatment combination, area is greater than when FSP is not part of the combination (Table 23; Table 5, Appendix 2). However, the statistical differences for map levels and FSP*map interactions found in the entire sample population dissolve (Table 22). 
Table 22: ANOVA results with area as the dependent variable for the respondent population.

\begin{tabular}{lccc}
\hline \multicolumn{1}{c}{ Source } & df & F-stat & p-value \\
\hline FSP & 1 & 35.41 & $<0.0001$ \\
Region & 1 & 2.20 & 0.1398 \\
Map & 1 & 2.68 & 0.1033 \\
FSP x Region & 1 & 1.22 & 0.2712 \\
FSP x Map & 1 & 2.43 & 0.1206 \\
Region x Map & 1 & 0.30 & 0.5856 \\
FSP x Region x Map & 1 & 0.18 & 0.6726 \\
Error & 191 & -- & -- \\
\hline Total & 198 & -- & -- \\
\hline
\end{tabular}

Table 23: Respondent population mean acreages of ANOVA treatment combinations.

\begin{tabular}{cccl}
\hline Site & Map & \multicolumn{1}{c}{ FSP } & \multicolumn{1}{c}{ No-FSP } \\
\hline Western & Yes & $232.3 ; \mathrm{n}=32$ & $46.8 ; \mathrm{n}=12$ \\
& No & $146.8 ; \mathrm{n}=30$ & $42.7 ; \mathrm{n}=108$ \\
Eastern & Yes & $159.3 ; \mathrm{n}=26$ & $36.5 ; \mathrm{n}=25$ \\
& No & $113.6 ; \mathrm{n}=33$ & $37.5 ; \mathrm{n}=24$ \\
\hline
\end{tabular}

When risk is considered a dependent variable, site is significant; and the site*map combination is significantly different (Table 24). Since the site*map combination was significantly different, and map was not a significant factor (Table 24), it is suspected that site was behind the site*map interaction. Whenever the eastern site is part of a treatment combination, the mean risk is higher than when the western site is part of the combination (Table 25; Table 6, Appendix 2). 
Table 24: ANOVA results with risk rating as the dependent variable for the respondent population.

\begin{tabular}{lccc}
\hline \multicolumn{1}{c}{ Source } & df & F-stat & p-value \\
\hline FSP & 1 & 1.15 & 0.2839 \\
Region & 1 & 21.06 & $<0.0001$ \\
Map & 1 & 2.08 & 0.1510 \\
FSP x Region & 1 & 0.73 & 0.3954 \\
FSP x Map & 1 & 0.25 & 0.6199 \\
Region x Map & 1 & 4.89 & 0.0282 \\
FSP x Region x Map & 1 & 0.33 & 0.5668 \\
Error & 190 & -- & -- \\
\hline Total & 197 & -- & -- \\
\hline
\end{tabular}

Table 25: Respondent population mean risk ratings of ANOVA treatment combinations.

\begin{tabular}{cccc}
\hline Site & Map & FSP & No-FSP \\
\hline Western & Yes & $1.1 ; \mathrm{n}=32$ & $1.0 ; \mathrm{n}=12$ \\
& No & $1.2 ; \mathrm{n}=29$ & $1.2 ; \mathrm{n}=17$ \\
Eastern & Yes & $2.5 ; \mathrm{n}=26$ & $2.4 ; \mathrm{n}=25$ \\
& No & $2.0 ; \mathrm{n}=33$ & $1.4 ; \mathrm{n}=24$ \\
\hline
\end{tabular}

\section{Discussion}

The response rate of $21 \%$ gathered by this study is relatively low compared to response rates of other recent mail surveys of forest landowners (FSP and no-FSP) around the country (Esseks and Moulton 2000: Shindler and Toman 2003; Toman et al. 2004) and of forest landowners in WV, including FSP participants (Jennings 2003; Jennings et al. 2004; Magill et al. 2004a; Magill et al. 2004b; Chandran and Steele 2005; Steele et al. forthcoming). Many studies that received higher response rates had the advantage of surveying over an extended period (Esseks and Moulton 2000; Shindler and Toman 2003), utilizing follow up surveys by mail or phone (Jennings 2003; Shindler and Toman 2003; Magill et al. 2004a; Toman et al. 2004; Steele et al. forthcoming), or employing pre-mailing advertisements (Chandran and Steele 2005). 
West Virginia landowners and FSP participants in particular have been inundated with surveys in recent years, as is evidenced by the work of Jennings and colleagues $(2003,2004)$ and Magill and others (2004a, 2004b). Furthermore, it is known to this author that WV landowners have been surveyed more than once over the last summer of 2005 for research concurrent, but not related, to this study. The sampling of a population potentially saturated with surveys led to the development of a brief postcard questionnaire. Furthermore, so we could evaluate a willingness to respond to a one-time survey, there were no follow up mailings except to replace returned, unopened mailings.

In this study FSP affects interest level. An ANOVA of the response population reveals FSP is not highly significant but does increase interest in pests and diseases. Logistic regression of the sample population with interest as a binary dependent variable and higher FSP response rates also indicate FSP participants have more interest as represented by the return of a postcard. Furthermore, interest increased as FSP participation increased and a request for information on pests and diseases more often came from FSP participants.

Egan et al. (2001) found FSP landowners to be more interested in forest health than income. Such interest in forest health would correlate with an increased interest in (but not necessarily an awareness of) pests and diseases exhibited by FSP participants in our survey. Results of this study also show FSP landowners are more likely to request information on GM than some other organisms. Management for GM is a component of many FSP plans; this fact, and the predominance of oak species on the WV landscape (favorite hosts of GM) indicates FSP owners are more interested in topics relevant to them as landowners, confirming the findings of Dillman (1979, 1983, 1991), Shindler and Toman (2003), Toman et al. (2004), Alexander (2005), and Downing and Finley (2005). 
Another problem for oaks, SOD, was the most popular pest or pathogen for FSP and no-FSP landowners requesting information. With the preponderance of oak species in West Virginia oak pests are clearly an important topic and it is encouraging to see landowners are interested in them. It is interesting to see FSP participants may well be more inclined to involve themselves with these issues.

Information sheets are most preferred by WV landowners in this study. This unidirectional delivery method (one way flow of information) was also found by other researchers to be preferred (Radhakrishna et al. 2003; Shindler and Toman 2003; Alexander 2005). However, other researchers have found unidirectional methods less preferred and less trustworthy than interactive methods (Toman et al. 2004; Downing and Finley 2005). Magill et al. (2004a) found in the absence of information sheets, technical assistance is most desired.

Internet outreach is preferred by $56 \%$ of foresters in the Midwest, but this delivery method ranks consistently low if not last in preference and trustworthiness by landowners (Shindler and Toman 2003; Toman et al. 2004; Radhakrishna et al. 2005). Internet is expectedly rated low by FSP participants in this and other studies: the average age of FSP owners is 62 according to Jennings (2003) and 57 according to Egan (2001) and Downing and Finley (2005). The mean age of woodland owners in WV in general is also 57 (Chandran and Steele 2005), so reaching out to forest land owners who are not likely active participants in the computer age through the internet would be ineffective. Clearly educational preferences vary and are affected by an individual's comfort level with different learning styles (Downing and Finley 2005).

Even though the inclusion of a map was identified by FSP participants as a favorite attribute of FSP management plans (Jennings et al. 2004), and some form of educational material seemed to improve response rates for other researchers, the inclusion of a map did not improve response 
rates for this study. Statistical analyses show map level did not significantly affect any results without the interaction of other factors.

Data on chosen postcard statements further confirms the findings of Alexander et al. (2005) that response to disease-related surveys is increased in areas where infections are more prevalent. When respondents checked box three (3) indicating no interest in pests and diseases, they were more often from the western site where pest and disease activity represented in the risk rating map produced for this study is less intense and varied. The western site also was the source of significantly more requests for BBD information. Requests for information on pests and diseases would expectedly be site specific and depend on species composition of a survey subject's property. For example, since only $28 \%$ of respondents requested BBD information, and the majority of $\mathrm{BBD}$ requests came from the western site, American beech may be a more significant stand constituent for landowners in the western site.

When considering the entire sample population of 933, FSP participants and map recipients have significantly larger properties; subsequently, the FSP*map treatment combination of the sample population has significantly larger areas also. When analyzing the respondent population of 199 only FSP participants had significantly larger properties, but map recipients and the FSP*map treatment combination no longer had significantly larger properties. Properties could be expected to be larger for FSP participants: private landowners in general could have properties ranging from less than 1 acre to several hundred acres; but landowners must have 10 acres to write a management plan for FSP (Jennings 2003). FSP properties may inherently be larger on average.

This study found a mean area of 164.8 acres for FSP participants in the entire sample population. Jennings (2004) and Egan (2001) found an average FSP enrollment area of 187 acres and 160 
acres respectively. Both are comparable to acreages found in this study. The average area of no-FSP lands in this study was 40.7 acres, whereas the average area for private lands overall in the West Virginia region was 102 acres in 1996 (National Private Landowners Survey).

In the entire sample population acreage is skewed by the $30 \%(n=456)$ of no-FSP lands in the sample population with areas less than 10 acres. Furthermore, only one no-FSP property in the sample population was larger than 500 acres (643.8 acres) and only $0.8 \%$ of no-FSP properties where larger than even 300 acres, while $3 \%(n=472)$ of FSP properties measured over 500 acres. Participation in FSP is the driving force behind the FSP*map interaction found in the acreages of the sample population.

Numbers are also skewed among the 199 subjects returning postcards where FSP areas average 163.1 acres, no-FSP areas 39.7 acres, and 9\% of no-FSP properties are less than 10 aces in size. The largest no-FSP property was only 127.4 acres, whereas $6 \%$ of FSP participants returning postcards had properties larger than 500 acres. When we removed all subjects from both the sample and respondent populations with properties less than 10 aces, descriptive statistics and results from ANOVA analyses with acreage as the dependent variable paralleled those found when not removing properties less than 10 acres. The randomly selected subjects for this study suggest FSP landowners have larger properties on average.

It was a concern that the property size might confound results, but the significance of the map factor and FSP*map interaction for property size dissolved in the response population relative to the sample population. Also, the lack of significance for area as a covariable in ANCOVAs and random distribution of interest levels across acreages indicate final results gathered from the respondent population were not adversely affected. 
Risk rating varied significantly between sites as evident in Figure 5. The three main organisms used to estimate risk in this survey entered WV in the east and spread West and South (Liebhold et al. 2002; Houston 2005; Morin et al. 2005). Risk ratings were significantly higher in the eastern site, which is composed of five counties in the eastern panhandle of WV. Response rate was slightly higher (23\%) for the eastern site than the overall $21 \%$ response rate and $20 \%$ rate of the western site. Alexander et al. (2005) also found their on-line survey response was higher in areas where SOD was known to be more evident, and Shindler and Toman (2003) found fireaffected communities have greater knowledge of fire than do those that are not affected. Risk did not affect results regarding interest as indicated by ANCOVAs using risk as a covariable.

The site*map interaction could have been problematic, but the significance comes from the eastern site as the results have shown. Risk ratings of landowners were not significantly different due to map level but rather due to the greater range of risk found in the eastern site $(0$ 11) relative to the western site (0-4). Although map reception did not significantly affect results in any analysis, the receipt of a map did not improve response rates since more subjects not receiving maps responded in both the sample and response populations. Adding a map was an attempt to confer meaning and local context through educational material and thus improve response rates, as suggested by Dillman (1978, 1983, 1991), Merriam and Caffarella (1999), and Downing and Finley (2005). Visual aids were employed by Shindler and Toman (2003) and found to be effective for improving response rates and understanding.

Larger areas of FSP lands may coincide with an increase in management activities, but just because a landowner has an activity in a management plan does not mean they actually know about everything involved with that management or its target. In fact, a self-perceived knowledge of pests and diseases may prompt a non-response to this study. If FSP owners are more aware, a statistical difference in responses to statements one (1) and two (2) on the postcard 
would be evident. Since there is no such difference, it could be assumed that FSP owners in this study are no more aware of, even though they may display more interest in, forest health issues than no-FSP owners.

\section{Conclusions/Recommendations}

FSP had a significant, positive affect on interest as determined by an index, return of a post card, and response rates. Map reception and region had no affect on response rate or interest level.

- ANOVA and ANCOVA show risk and acreage are not significant factors regarding interest.

Gypsy moth and SOD were most often cited by respondents as organisms for which they would like information.

Information sheets are most desired, followed by professional visits and then workshops. Outreach through the internet should be avoided

No-FSP landowners should not be left out of educational efforts regarding pests and diseases as their interest in pest and diseases, although not as great as FSP owners, does hint that they are stewardly minded.

- Pest and disease management may be a way to help management professionals engage no-FSP owners and in a way that could encourage enrollment in FSP.

Use available resources to identify host tree species compositions of FSP and no-FSP properties and use information sheets when distributing educational information. 
- Forest landowners willing to participate in interactive delivery methods such as a professional visit or workshop should be identified and contacted directly.

Education and empowerment of landowners in general should be the goal of outreach to forest landowners in WV. More educated eyes and ears in the field lessen the burden on management professionals and may improve forest health management.

Future surveys of FSP and no-FSP landowners need to account for the minimum ten acres of FSP properties and sample no-FSP landowners accordingly.

\section{Literature Cited}

Alexander, J.; Cunningham, I.; Rilla, E.; Frank, S. 2005. Effectiveness of the Sudden Oak Death outreach program: results of an on line Survey. California Oak Mortality Task Force [On-line] Available at: http://www.cnr.berkeley.edu/comtf/html/sod_outreach_survey_results.html

Armstrong, J.S., and Luske, E.J. 1987. Return postage in mail survey; a meta-analysis. Public Opinion Quarterly 51: 233-248.

Birch, T.W. 1996. Private forestland owners of the northern United States, 1994. Resource Bulletin NE-RB-136. Radnor, PA. USDA Forest Service, Northeastern Research Station. 293 p.

Chandran, R.S.; Steele, J. 2005. Identifying outreach strategies for engaging private forester landowners in invasive plant management. Report submitted to the USDA Forest Service, January.

Cui, W.W. 2003. Reducing error in mail surveys. Practical Assessment, Research and Evaluation 8(18): $8 \mathrm{p}$.

Davidson, C.B.; Gottschalk, K.W.; Johnson, J.E. 2001. European gypsy moth (Lymantria dispar L.) outbreaks: a review of the literature. Gen Tech. Rep. NE-278. Newton Square, PA: USDA Forest Service, Northeastern Research Station. 15 p.

Dillman, D.A. 1978. Mail and telephone surveys: The total design method. New York: Wiley and Sons.

Dillman, D.A. 1983. Mail and other self-administered questionnaires. In Rossi, P.H., Wright, J.D., and Anderson, A.B. (Eds.), Handbook of Survey Research. New York: Academic Press: 359-377. 
Dillman, D.A. 1991. The design and administration of a mail survey. Annual Review of Sociology 17: 225-249.

Downing, A.K.; Finley, J.C. 2005 Private forest landowners: what they want in an educational program. Journal of Extension 43(1): 8p.

Egan, A.; Gibson, D.; Whipkey, R. 2001. Evaluating the effectiveness of the Forest Stewardship Program in West Virginia. Journal of Forestry 99(3): 31-36.

Esseks, J.D.; Moulton, R.J. 2000. Evaluating the Forest Stewardship Program through a national survey of participating forest land owners. Center for Governmental Studies, Dekalb, Ill. 8 p.

Fox, R.J., Crask, M.R., and Kim, J. 1988. Mail survey response rate; a meta-analysis of selected techniques for inducing response. Public Opinion Quarterly 52: 467-491.

Gillespie, A.J.R. (2002). Forest industry and analysis [On-line] available at:

http://www.fia.fs.fed.us/

Harmon, A.H.; Jones, S.B. 1997. Forestry demonstrations: what good is a walk in the woods? Journal of Extension 35(1): 7 p.

Heberlein, T.A.; Baumgartner, R. 1978. Factors affecting response rates to mailed questionnaires: a quantitative analysis of the published literature. American Sociological Review 43: 447-462.

Houston, D.R. and O'Brien, J.T. 2004. Beech Bark Disease: Forest Insect \& Disease Leaflet 75. USDA Forest Service, Northeastern Area. [On-line] Available at: http://www.na.fs.fed.us/spfo/pubs/fidls/beechbark/fidl-beech.htm

Houston, D.R. 2005. Beech Bark Disease: 1934 to 2004: What's New Since Ehrlich? In: Evans, Celia A., Lucas, Jennifer A. and Twery, Mark J., eds. Beech Bark Disease: Proceedings of the Beech Bark Disease Symposium; 2004 June 16-18; Saranak Lake, NY. Gen. Tech. Rep. NE-331. Newtown Square, PA: USDA Forest Service, Northeastern Research Station: 2-13.

Jacobson, S.K. 1999. Communication skills for conservation professionals. Washington D.C.: Island Press.

Jennings, B.M. 2003. Implementation of recommended Forest Stewardship Program practices in West Virginia: ten-year assessment. Masters Thesis: West Virginia University, Morgantown, WV.

Jennings, B.M.; McGill, D.W. 2003. Evaluating the effectiveness of the Forest Stewardship Program in West Virginia: ten year assessment. Unpublished.

Jennings, B.M.; Magill, D.J.; McGill, D.W.; Warren, J. 2003. Patterns of forestland owner participation in the West Virginia Forest Stewardship Program. In: Van Sambeek, J.W.; Dawson, J.O.; Ponder Jr., F.; Loewenstein, E.F.; Fralish, J.S., eds. 2003. Proceedings, Thirteenth Central 
Hardwood Forest Conference. Gen. Tech. Rep. NC-234. St. Paul, MN: USDA Forest Service, North Central Research Station: 105-106.

Jennings, B.M.; McGill, D.W.; Grushecky, S.T.; Magill, D.J.; Lilly, D. 2004. Landowner perspectives on attributes of the West Virginia Forest Stewardship Program. In: Yaussy, D.A.; Hix, D.M.; Long, R.P.; Goebel, P.C., eds. Proceedings of the $14^{\text {th }}$ Central Hardwood Forest Conference. Gen. Tech. Rep. NE-316. Newton Square, PA: USDA Forest Service, Northeastern Research Station: 271-275.

Liebhold, A.M.; Halverson, J.A.; Elmes, G.A. 1992. Gypsy moth invasion in North America: a quantitative analysis. Journal of Biogeography 19: 513-520.

Loomis, J.B.; Bair, L.S.; Gonzalez-Caban, A. 2001. Prescribed fire and public support: knowledge gained, attitudes changed in Florida. Journal of Forestry 99(11): 18-22.

Magill, D.J.; McGill, D.W.; Fraser, R.F. 2004a. Refining outreach to woodland owners in West Virginia_-preferred topics and assistance methods. Journal of Extension 42(4): 9 p.

Magill, D.J.; McGill, D.W.; Grushecky, S.T.; Jennings, B.M. 2004b. Establishment, growth, and implementation of the forest stewardship program in West Virginia. In: Yaussy, D.A.; Hix, D.M.; Long, R.P.; Goebel, P.C., eds. Proceedings of the $14^{\text {th }}$ Central Hardwood Forest Conference. Gen. Tech. Rep. NE-316. Newton Square, PA: USDA Forest Service, Northeastern Research Station: 276-281.

McClure, M.S.; Salom, S.M.; Shields, K.S. 2001. Hemlock Woolly Adelgid. FHTET 2001-03. Morgantown, WV: USDA Forest Service, Forest Health Enterprise Team. 14 p.

Merriam, S.B.; Caffarella, R.S. (1999) Learning in adulthood $\left(2^{\text {nd }}\right.$ ed.). San Francicso, CA: Jossey-Bass.

Morin, R.S.; Liebhold, A.M.; Luzader, E.R.; Lister, A.J.; Gottschalk, K.W.; Twardus, D.B. 2005. Mapping host-species abundance of three major exotic forest pests. Res. Pap. NE-276. Newton Square, PA: USDA Forest Service, Northeastern Research Station. 11p.

National Private Landowners Survey. 1996. Environmental Resource Assessment Group, Athens, Ga. [On-line] available at: http://www.agecon.uga.edu/ erag/nplostab.htm

Pokorny, J.D. 1998. Urban forest health needs assessment survey: results and recommendations. NA-TP-01-98. St. Paul MN: USDA Forest Service, Northeastern Area State and Private Forestry. 22 p.

Ribe, R. 1999. Regeneration harvests versus clearcuts: public views of the acceptability and aesthetics of Northwest Forest Plan harvests. Northwest Science 73(special issue): 102-117.

Radhakrishna, R.B.; Nelson, L.; Franklin, R.; Kessler, G. Information sources and extension delivery methods used by private longleaf pine landowners. Journal of Extension 41(4): 9p. 
Sharov, A.A.; Leonard, D.; Liebhold, A.M.; Roberts, E.A.; Dickerson, W. 2002. "Slow the spread": a national program to contain the gypsy moth. Journal of Forestry 5(30): 30-35.

Shindler, B.; Toman, E. 2003. Fuel reduction strategies in forest communities: a longitudinal analysis. Journal of Forestry 101(6): 8-14.

Siniscalchi, J.M.; Pierskalla, C.D.; Selin, S.W. 2006. Mapping social change: a visualization method used in the Monongahela National Forest. Society and Natural Resources 19:71-78.

Smith, W.B.; Miles, P.D.; Visage, J.S.; Pugh, S.A. 2004. Forest Resources of the United States, 2002. Gen. Tech. Rep. NC-241. St. Paul, MN: USDA Forest Service, North Central Forest Experiment Station. [On-line] Available at:

http://www.treesearch.fs.fed.us/pubs/viewpub.jsp?index $=11987$

Steele, J.; Chandran, R.S.; Grafton, W.N.; Huebner, C.D.; McGill, D.W. Forthcoming. Awareness and management of invasive plants among West Virginia woodland owners. Journal of Forestry.

Toman, E.; Shindler, B.; Brunson, M. 2004. Fire and fuel management strategies: citizen evaluations of agency outreach programs. [On-line] Available at:

http://oregonstate.edu/ shindleb/jfsp/Fire and Fuel.pdf

USDA Forest Service. 1995. Description of the ecoregions of the United States. [On-line] Available at: http://www.fs.fed.us/land/ecosysmgmt/ecoreg1_home.html 


\section{Appendix 1: Shapefiles Used for Risk Rating Map and Survey Subject Map.}

\section{Gypsy Moth Defoliation Surveyed in 1986}
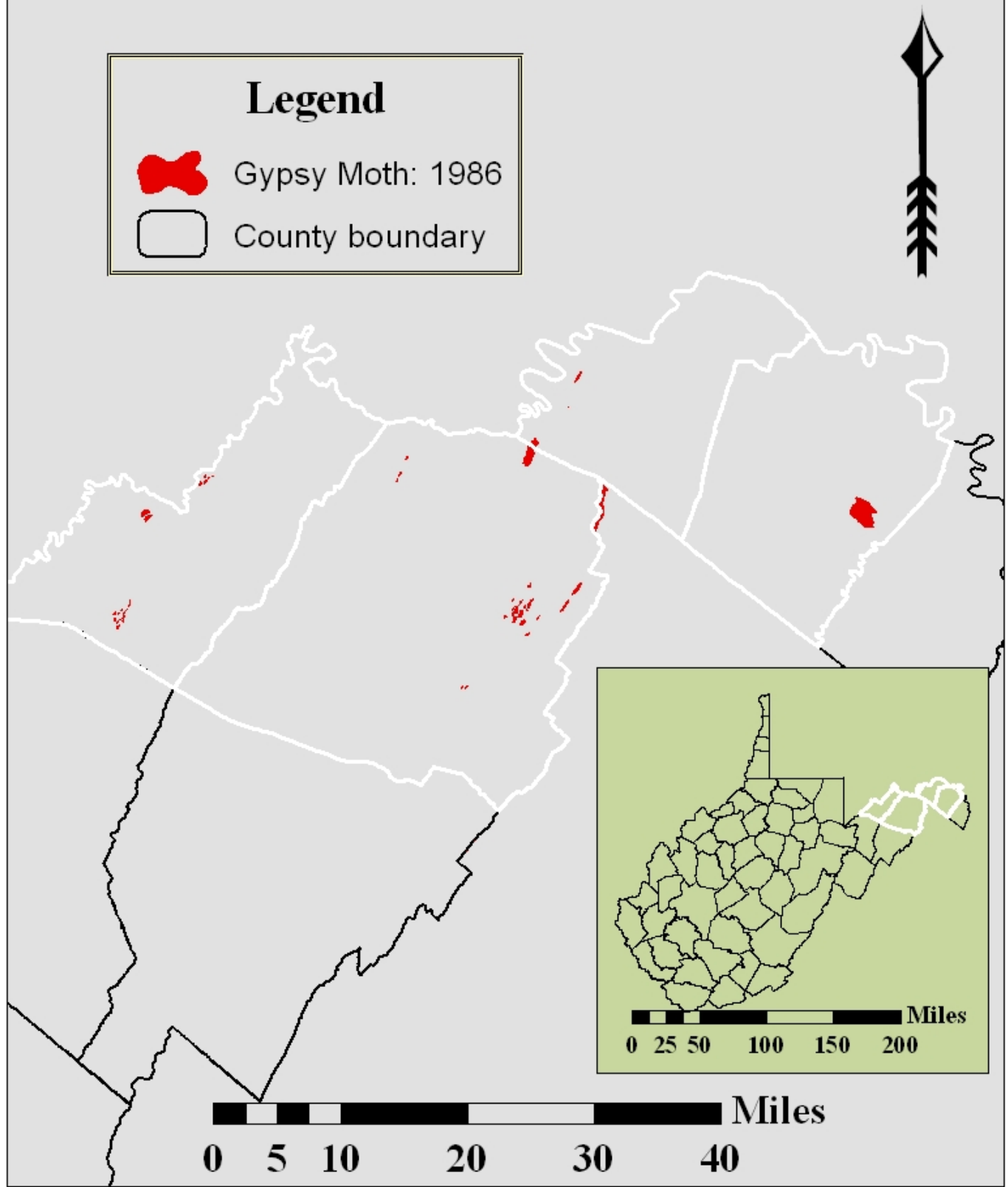

Figure 1: Gypsy moth defoliation aerially surveyed in 1986 in West Virginia. Counties highlighted in white are where defoliation occurred. 


\section{Gypsy Moth Defoliation Surveyed in 1987}

\section{Legend}

1 Gypsy Moth: 1987

$\square$ County boundary

Figure 2: Gypsy moth defoliation aerially surveyed in 1987 in West Virginia. Counties highlighted in white are where defoliation occurred. 


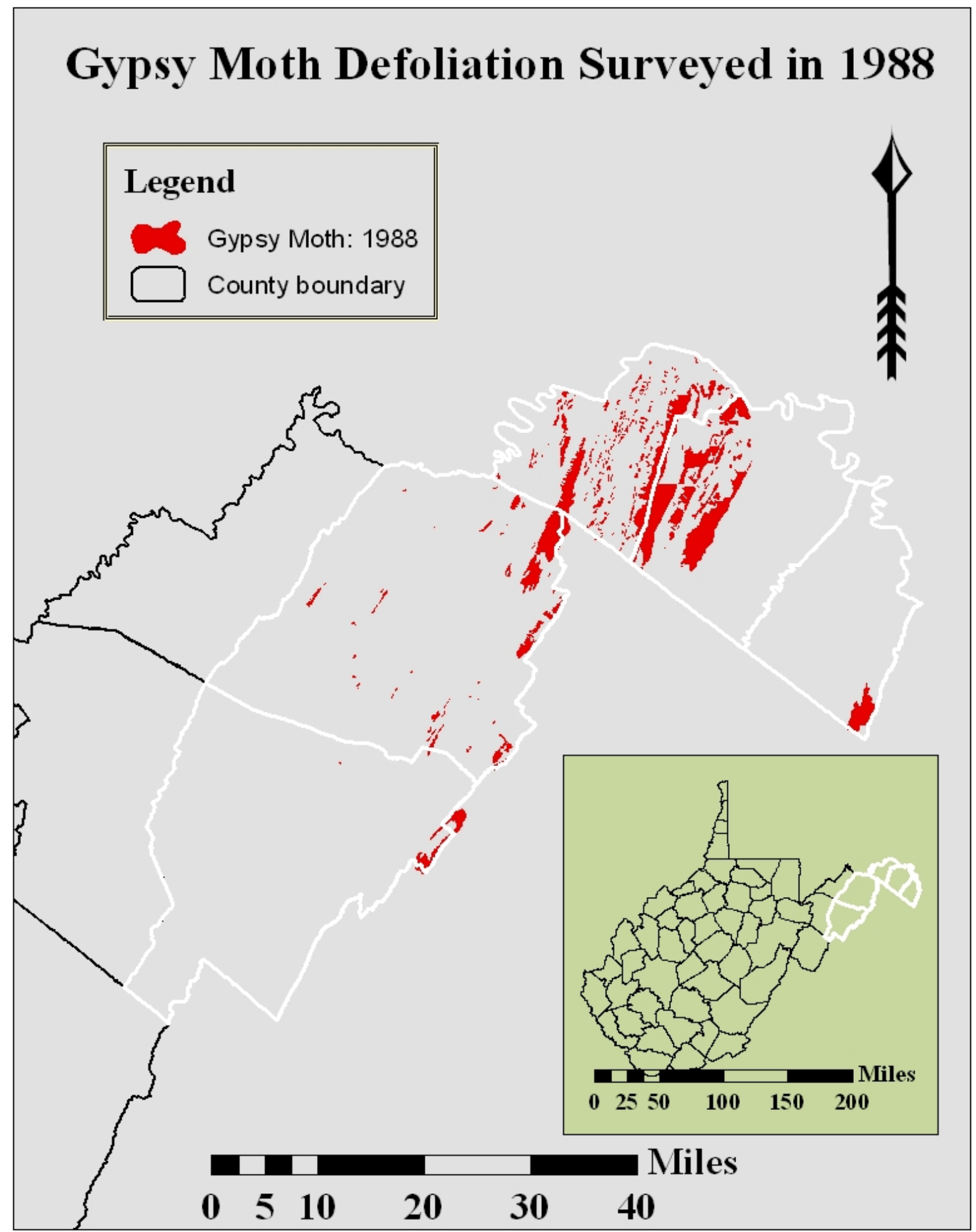

Figure 3: Gypsy moth defoliation aerially surveyed in 1988 in West Virginia. Counties highlighted in white are where defoliation occurred. 


\section{Gypsy Moth Defoliation Surveyed in 1989}

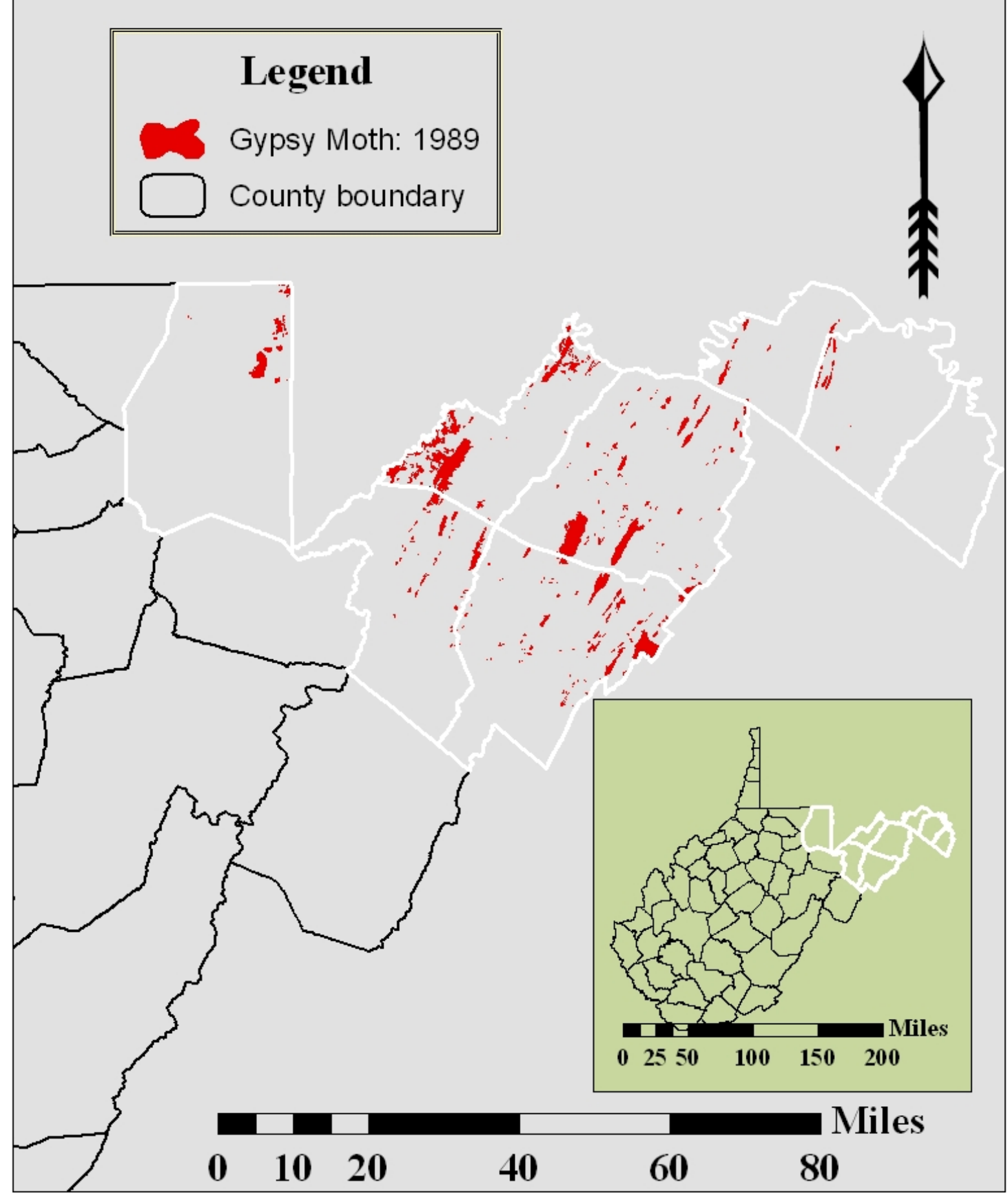

Figure 4: Gypsy moth defoliation aerially surveyed in 1989 in West Virginia. Counties highlighted in white are where defoliation occurred. 


\section{Gypsy Moth Defoliation Surveyed in 1990}

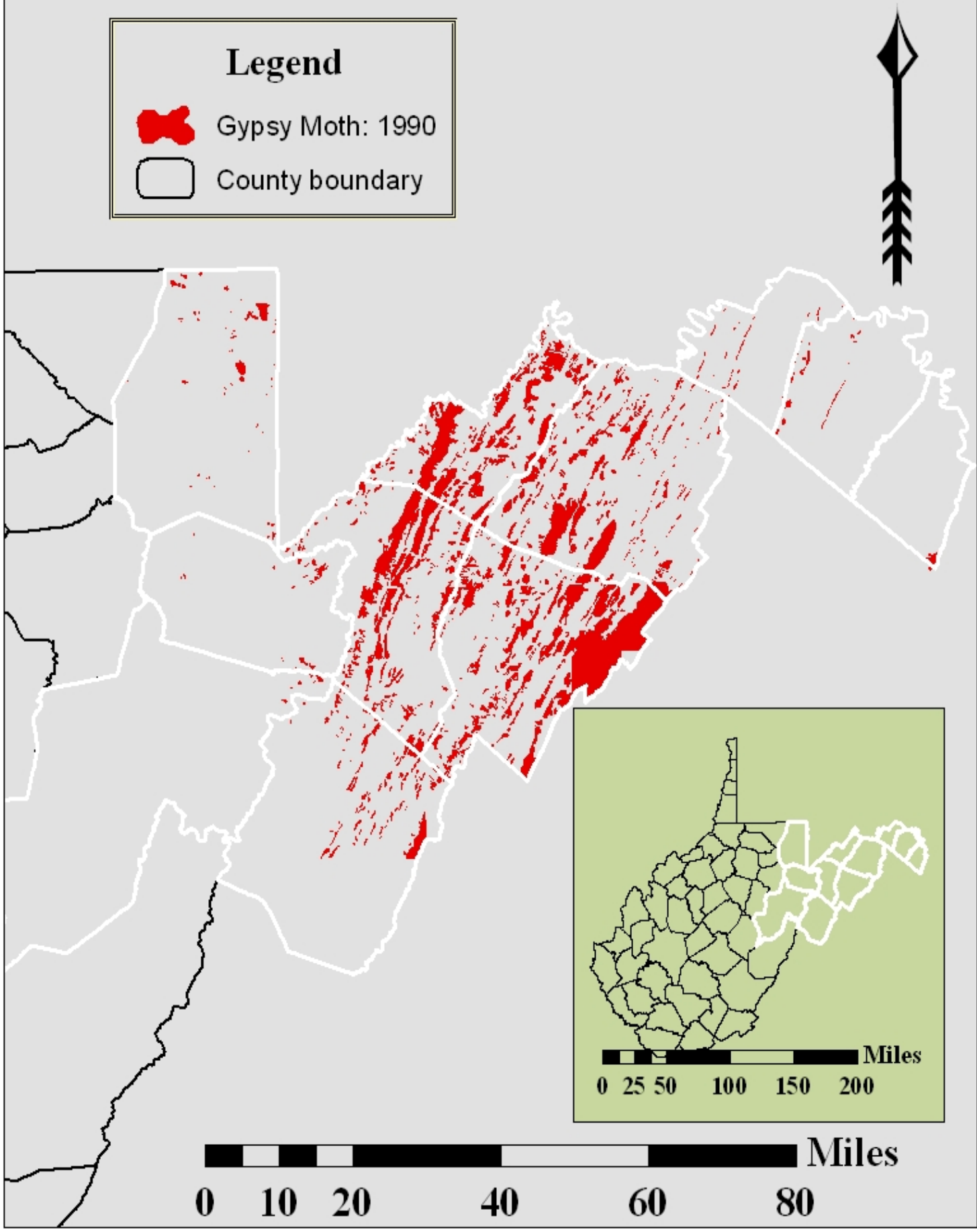

Figure 5: Gypsy moth defoliation aerially surveyed in 1990 in West Virginia. Counties highlighted in white are where defoliation occurred. 


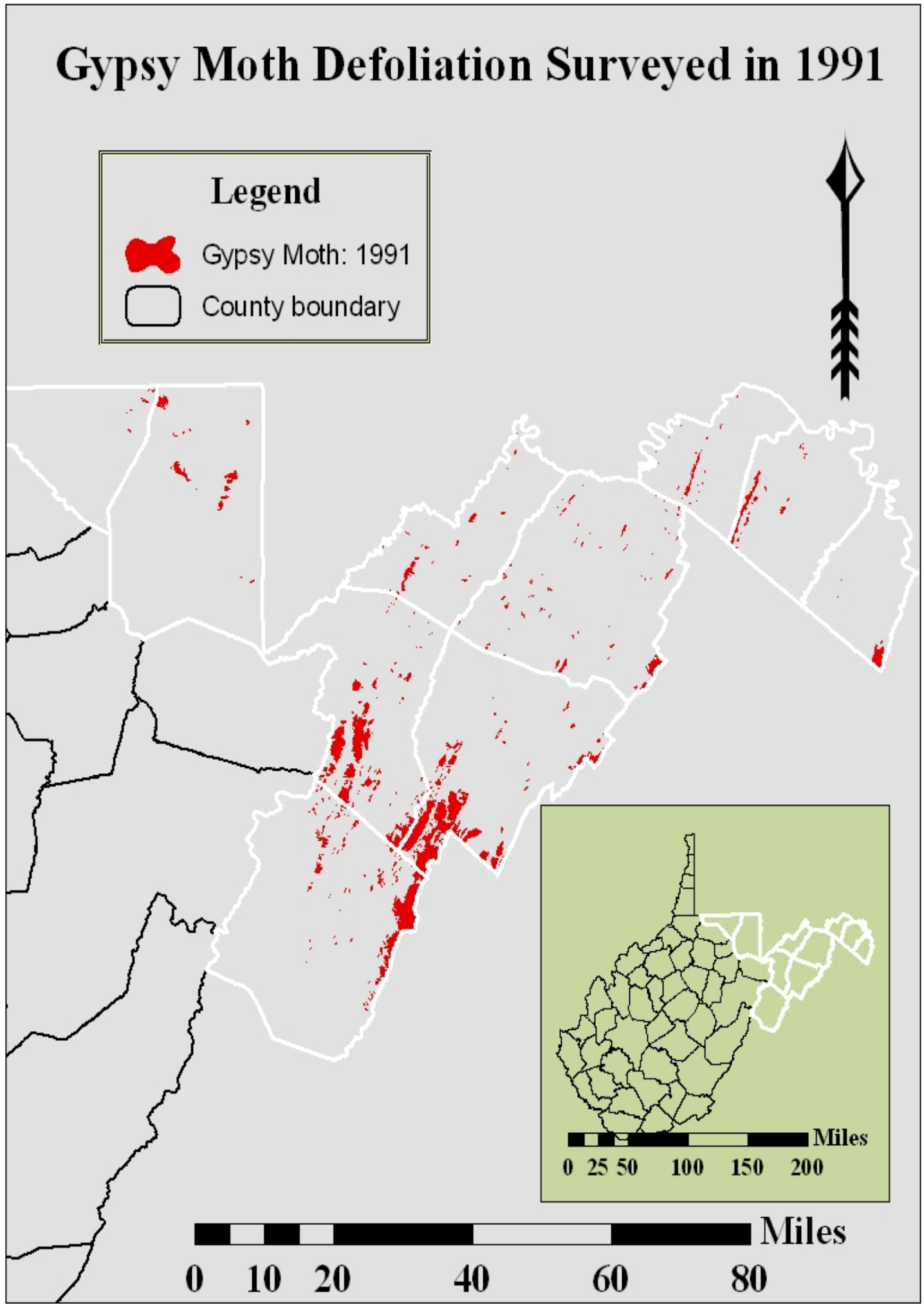

Figure 6: Gypsy moth defoliation aerially surveyed in 1991 in West Virginia . Counties highlighted in white are where defoliation occurred. 


\section{Gypsy Moth Defoliation Surveyed in 1992}

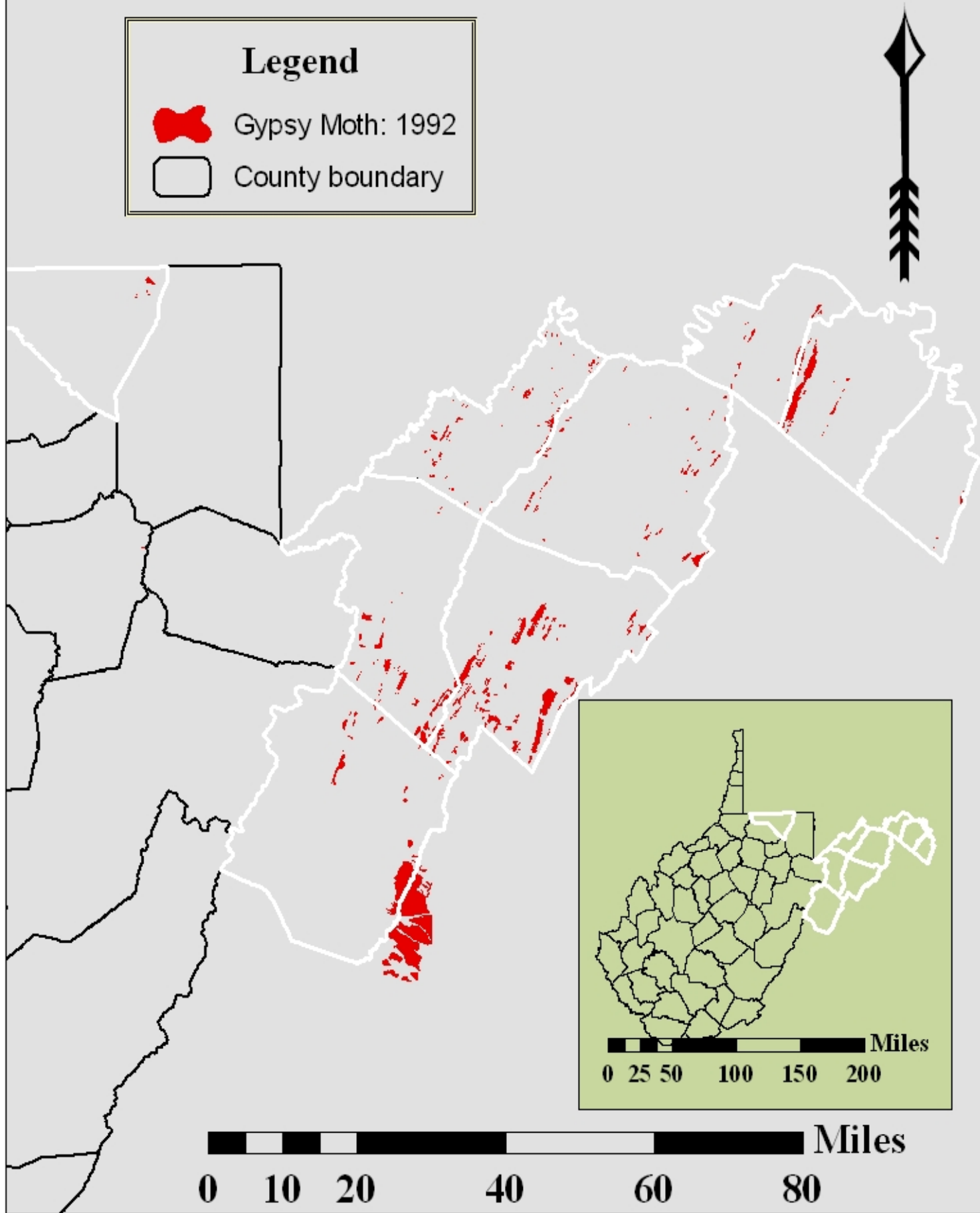

Figure 7: Gypsy moth defoliation aerially surveyed in 1992 in West Virginia. Counties highlighted in white are where defoliation occurred. 


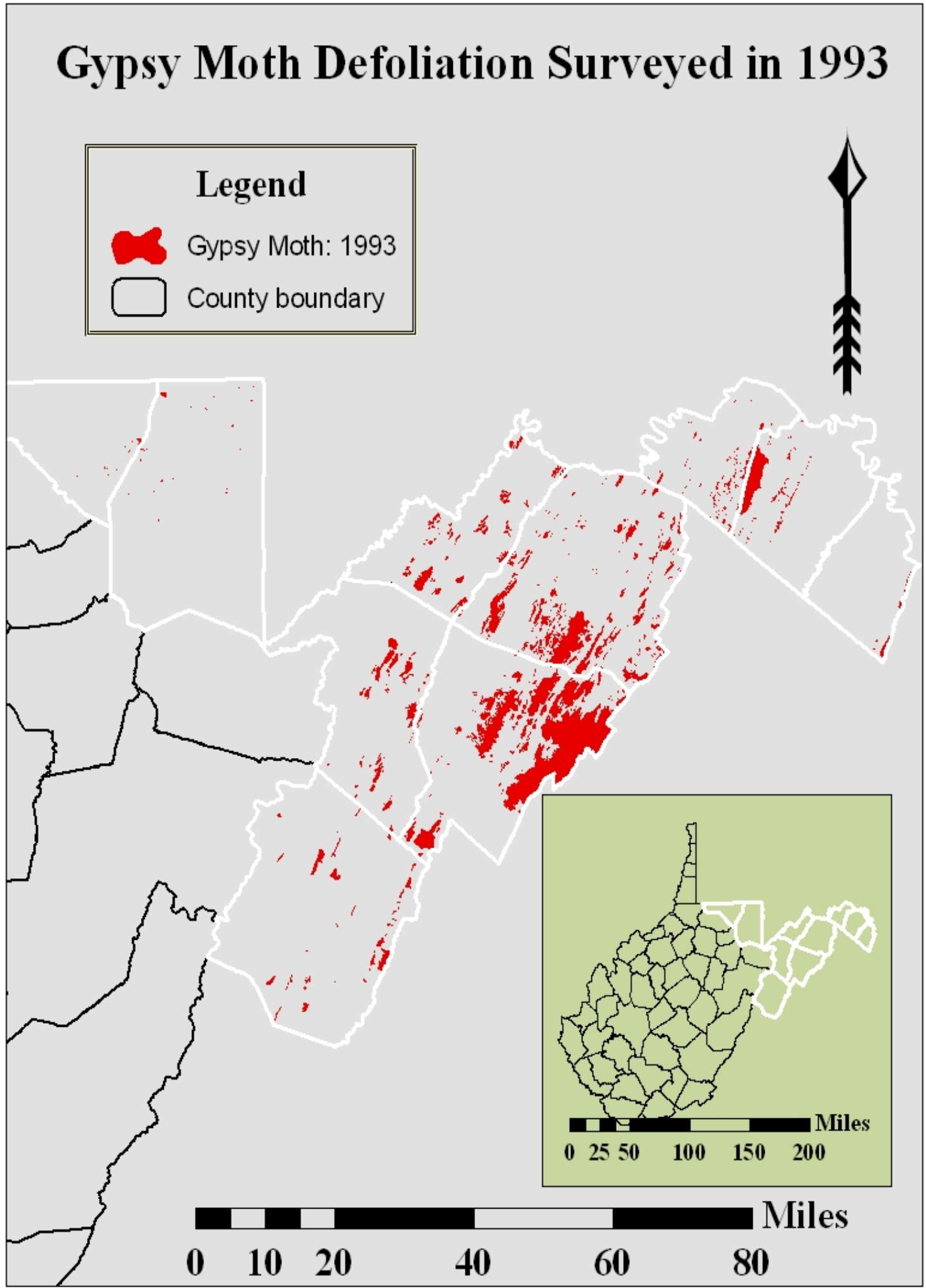

Figure 8: Gypsy moth defoliation aerially surveyed in 1993 in West Virginia. Counties highlighted in white are where defoliation occurred. 


\section{Gypsy Moth Defoliation Surveyed in 1994}

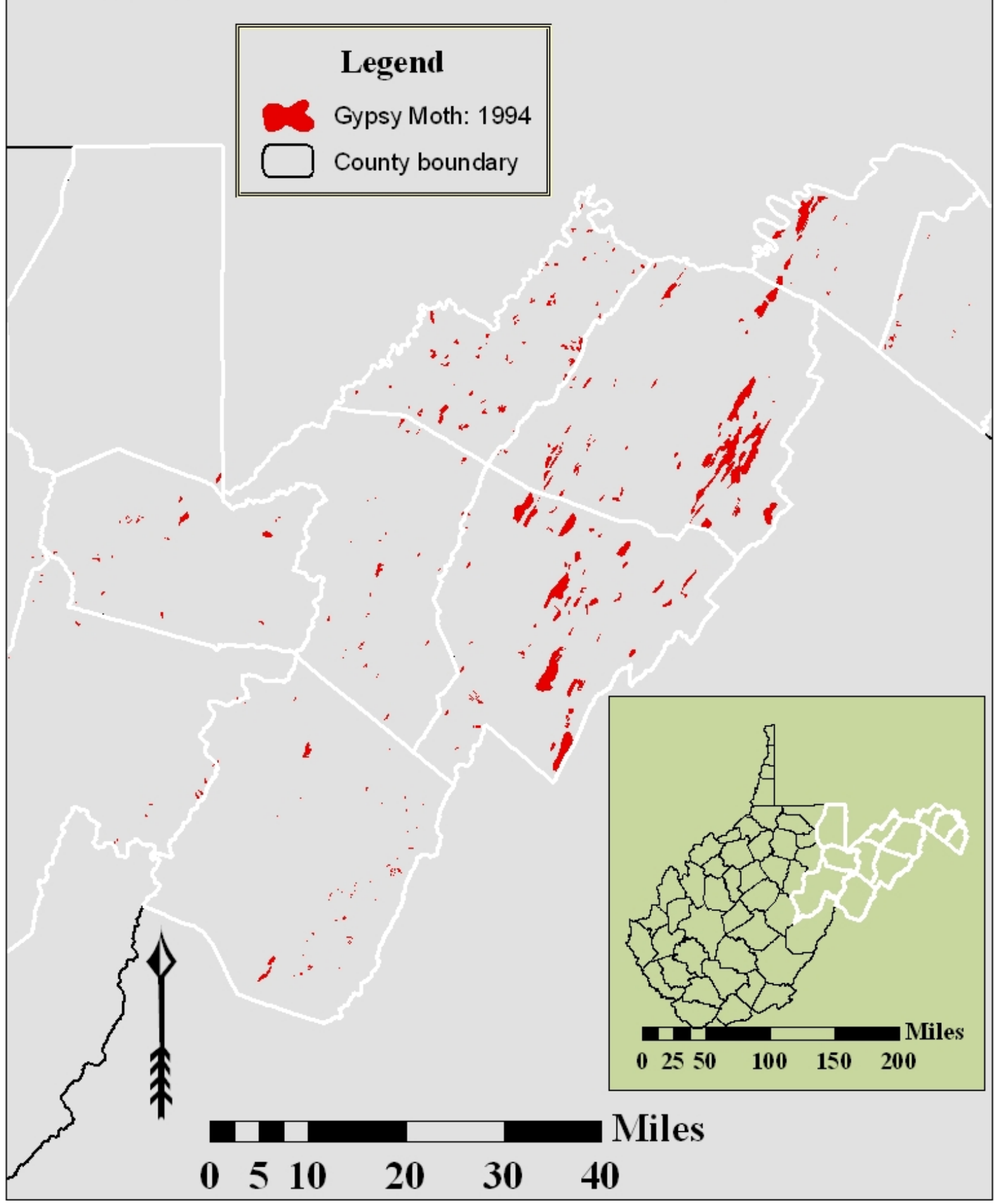

Figure 9: Gypsy moth defoliation aerially surveyed in 1994 in West Virginia . Counties highlighted in white are where defoliation occurred. 


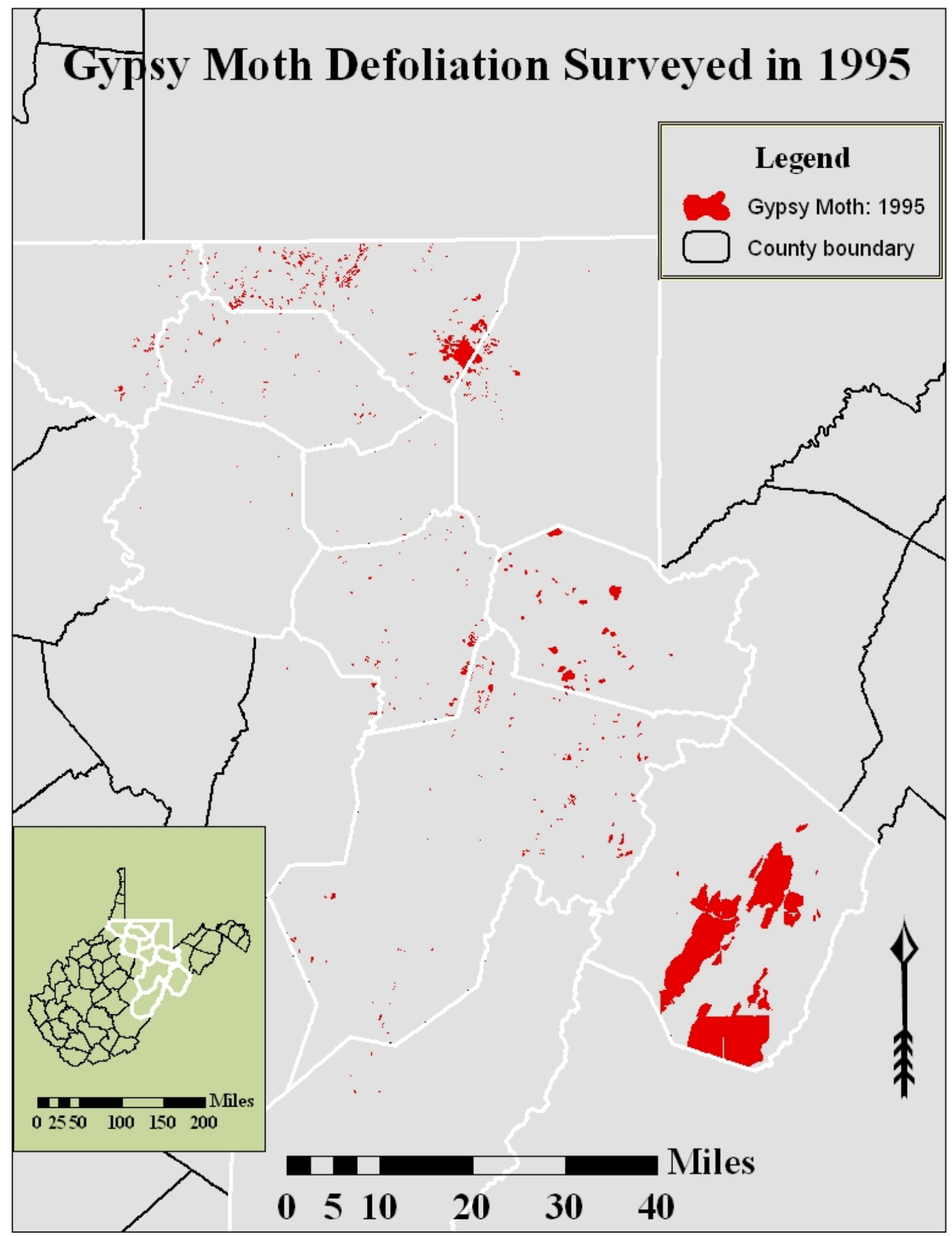

Figure 10: Gypsy moth defoliation aerially surveyed in 1995 in West Virginia. Counties highlighted in white are where defoliation occurred. 


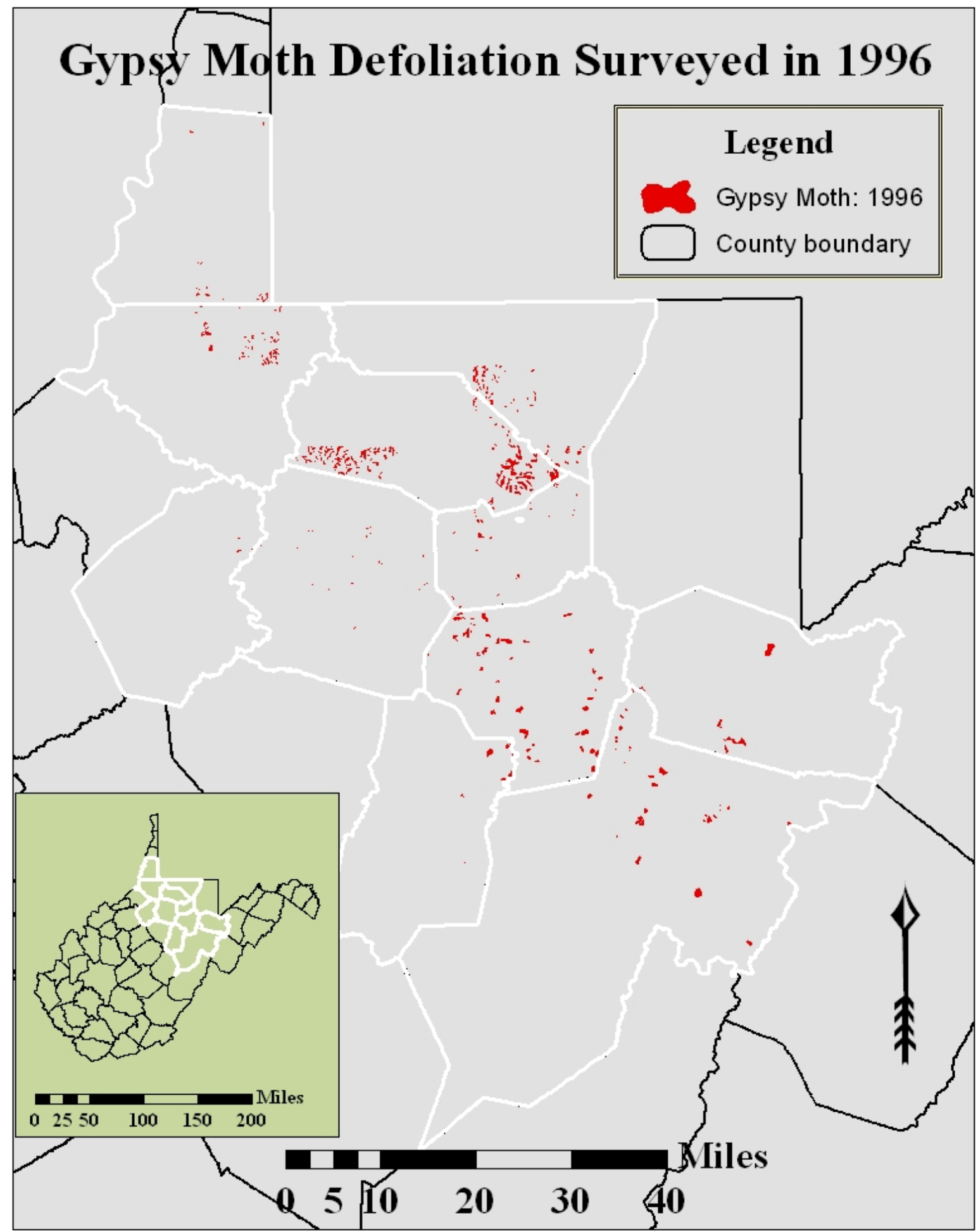

Figure 11: Gypsy moth defoliation aerially surveyed in 1996 in West Virginia. Counties highlighted in white are where defoliation occurred. 


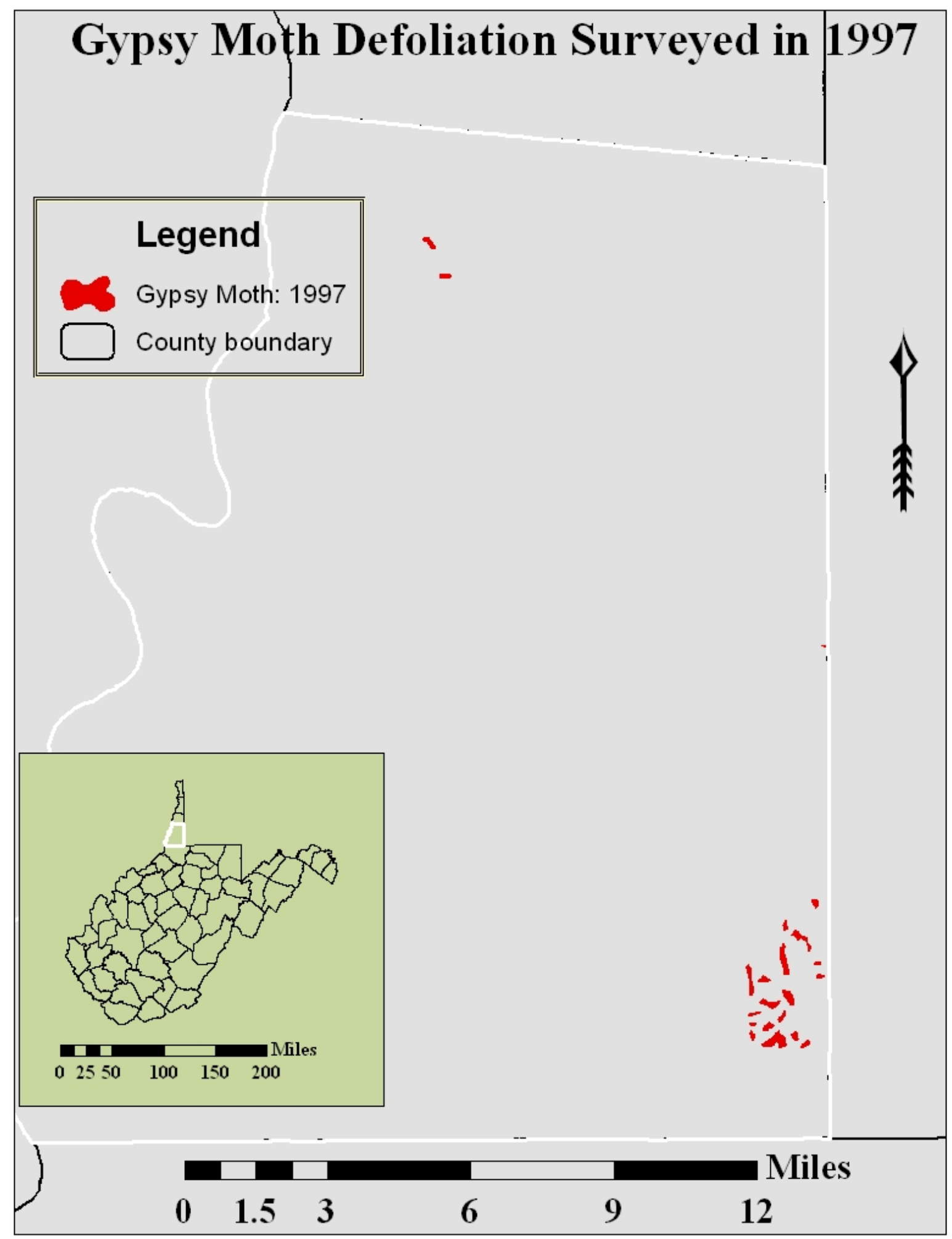

Figure 12: Gypsy moth defoliation aerially surveyed in 1997 in West Virginia. Counties highlighted in white are where defoliation occurred. 


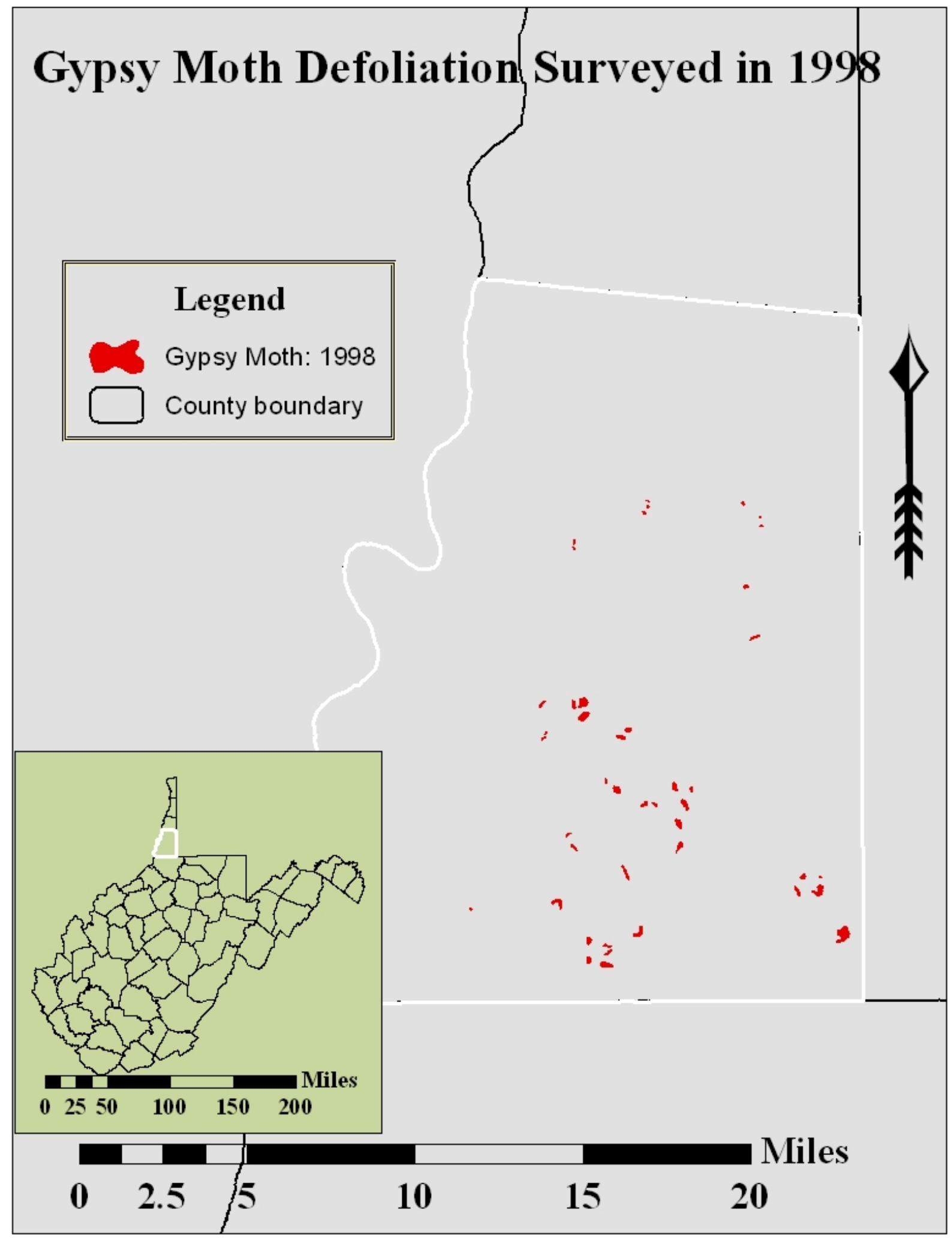

Figure 13: Gypsy moth defoliation aerially surveyed in 1998 in West Virginia. Counties highlighted in white are where defoliation occurred. 


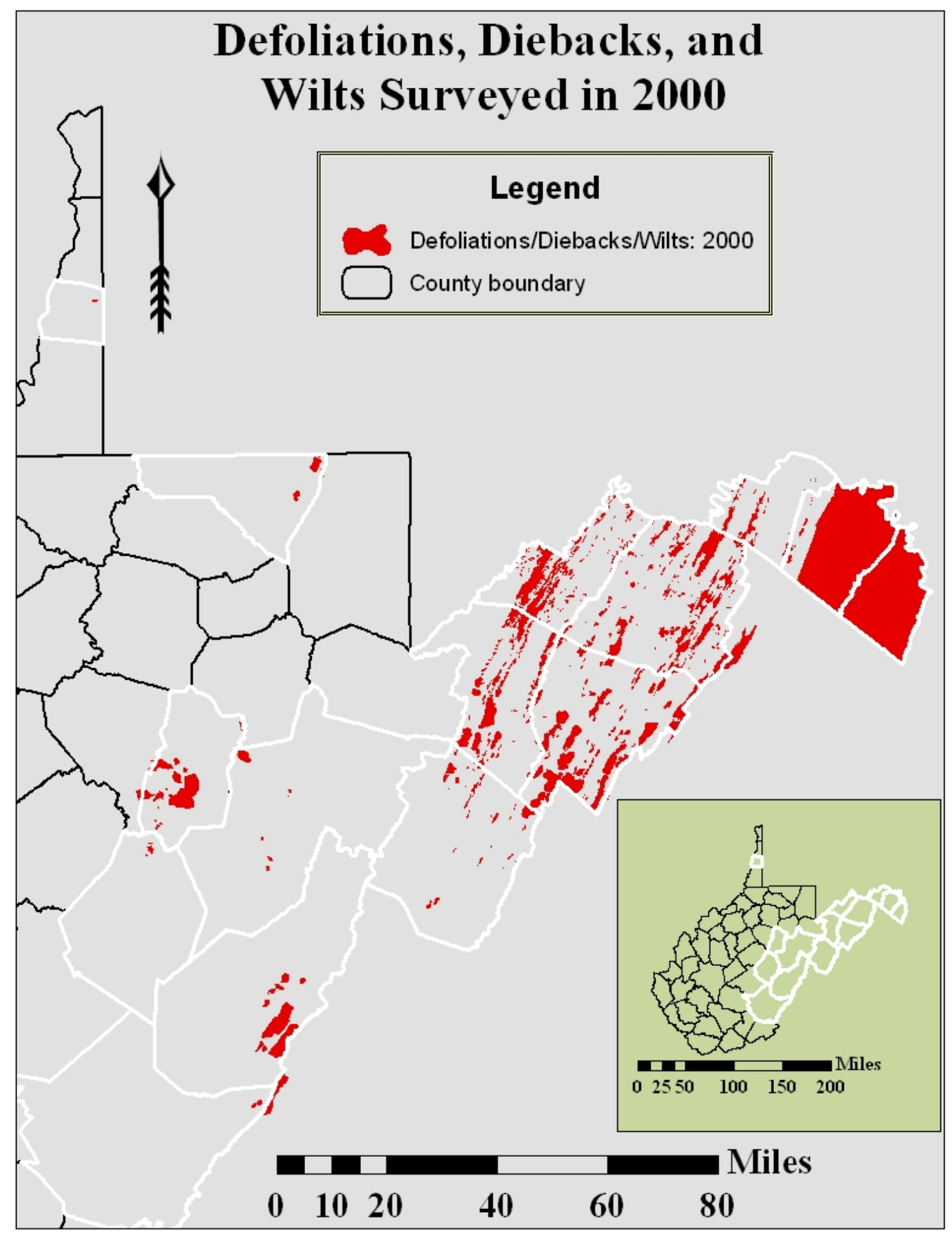

Figure 14: Defoliations, diebacks, and wilts aerially surveyed in 2000 in West Virginia. Counties highlighted in white are where pest and disease activity occurred. 


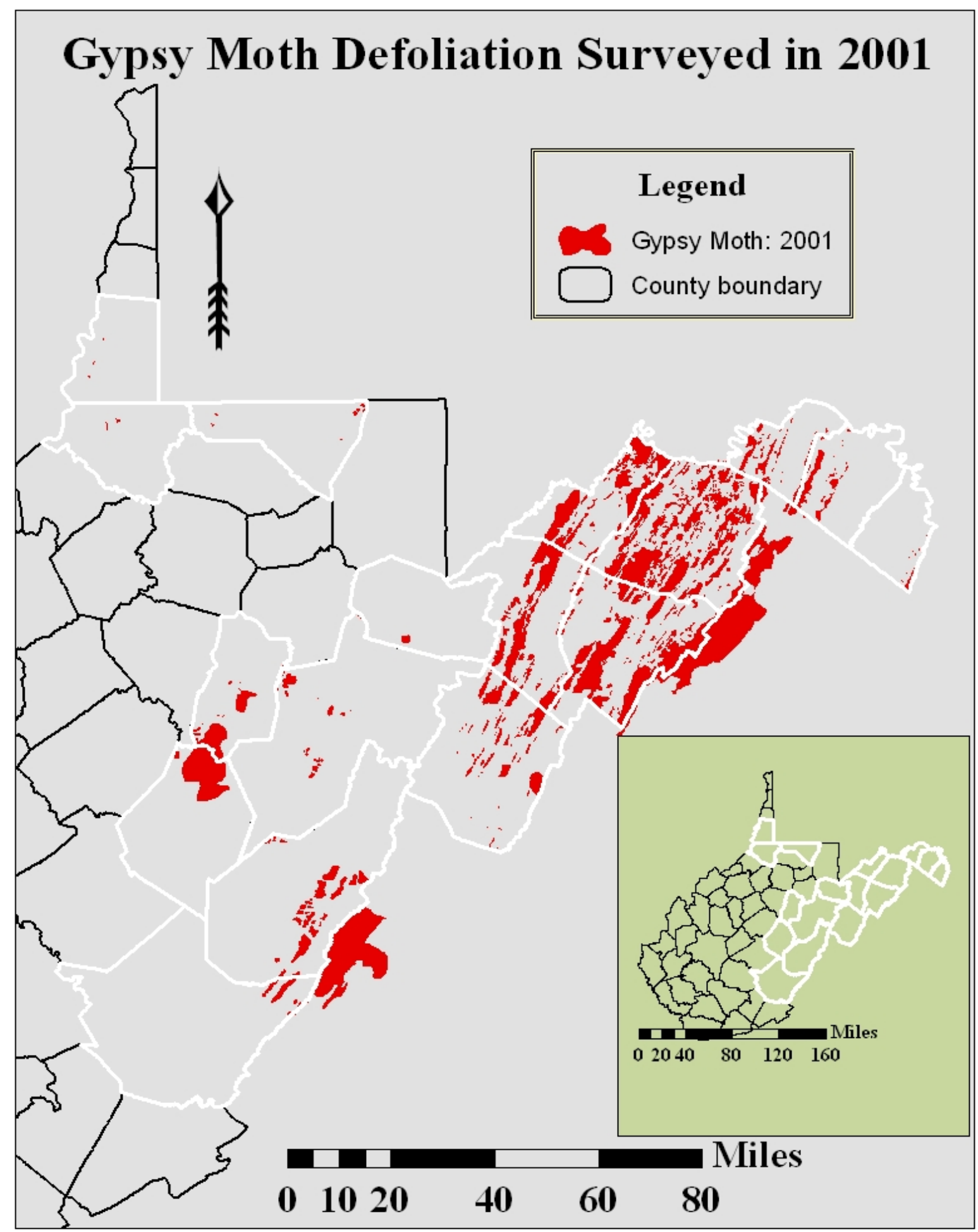

Figure 15: Gypsy moth defoliation aerially surveyed in 2001 in West Virginia. Counties highlighted in white are where defoliation occurred. 


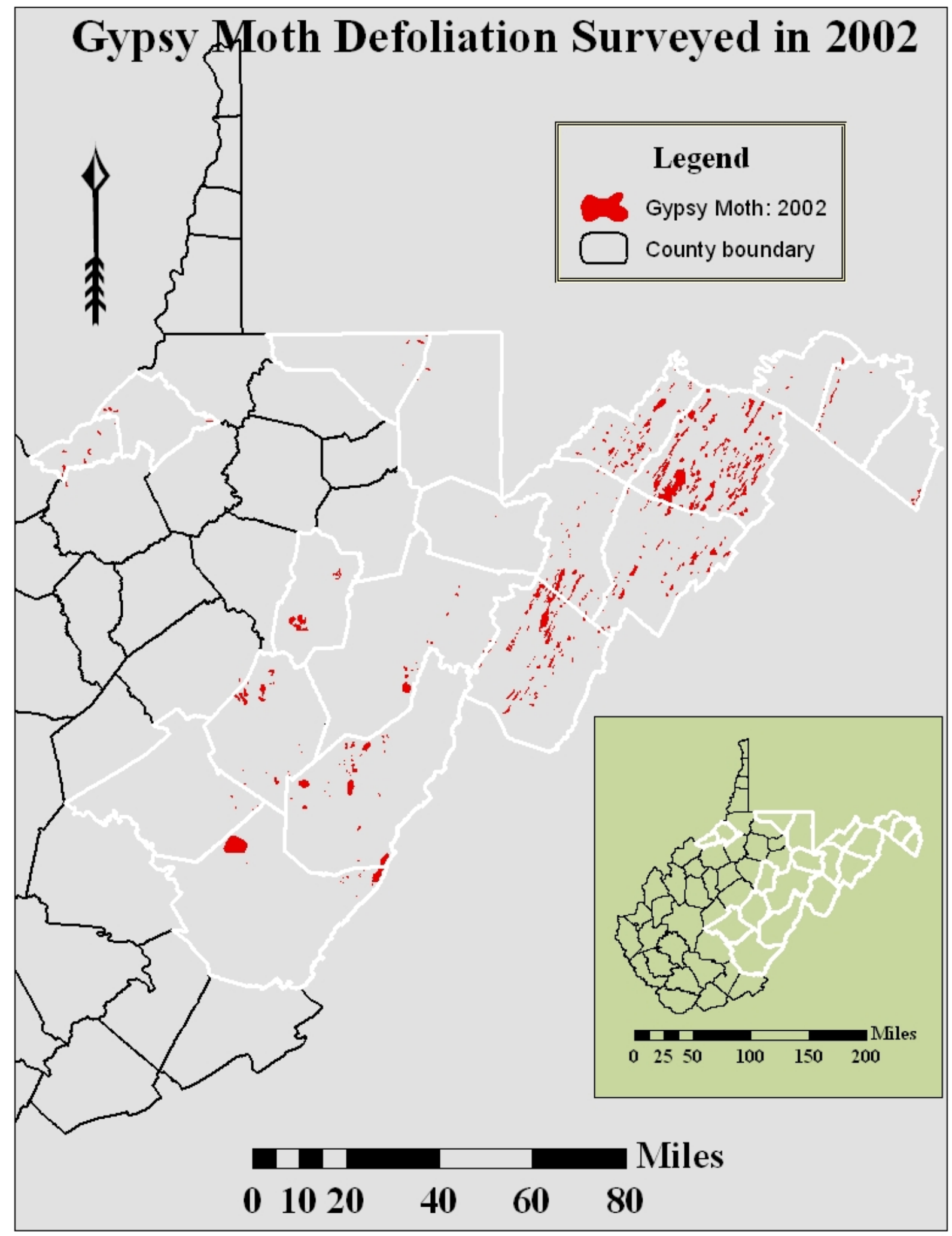

Figure 16: Gypsy moth defoliation aerially surveyed in 2002 in West Virginia. Counties highlighted in white are where defoliation occurred. 


\section{Gypsy Moth Defoliation Surveyed in 2003}

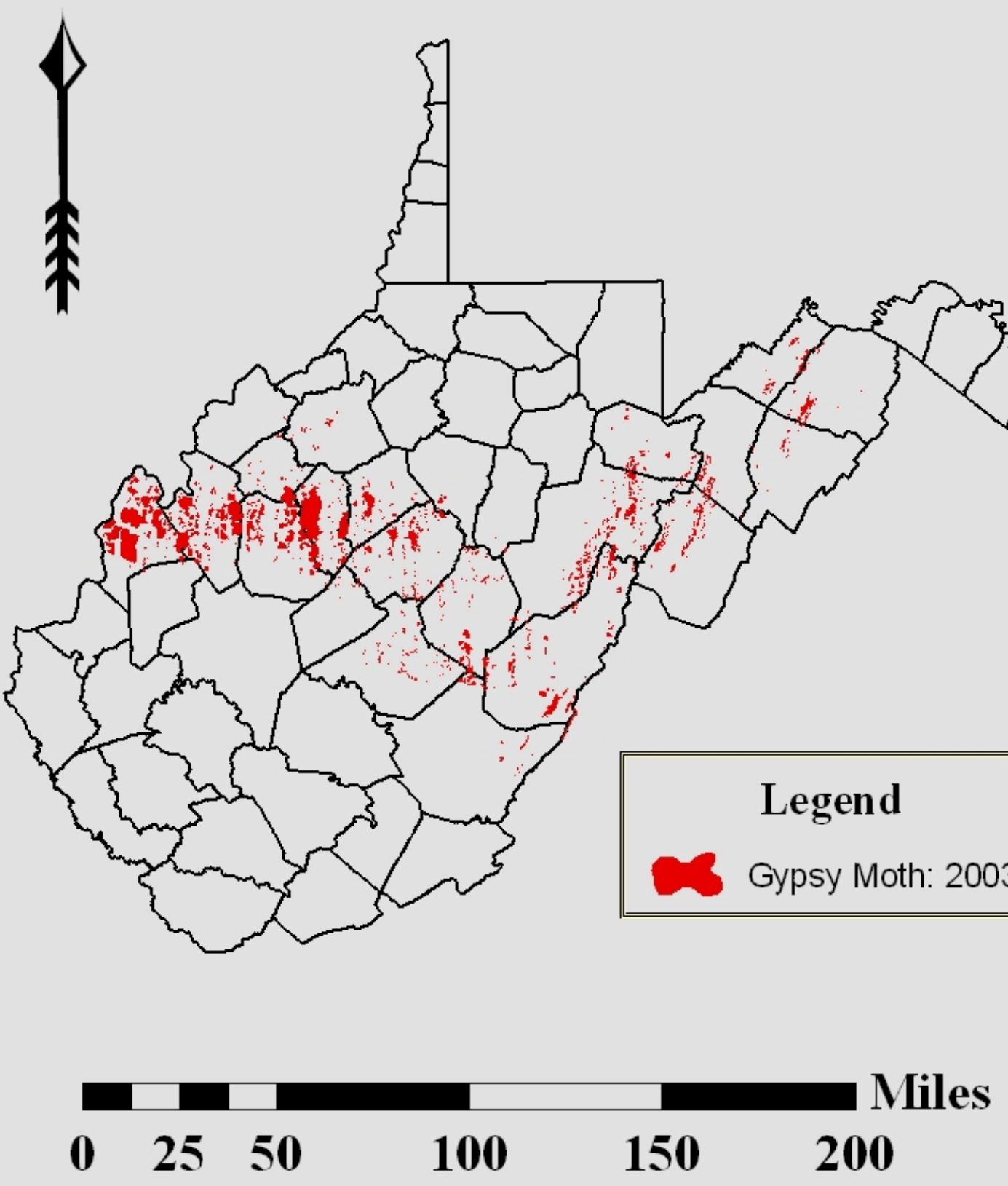

Figure 17: Gypsy moth defoliation aerially surveyed in 2003 in West Virginia. Counties highlighted in white are where defoliation occurred. 


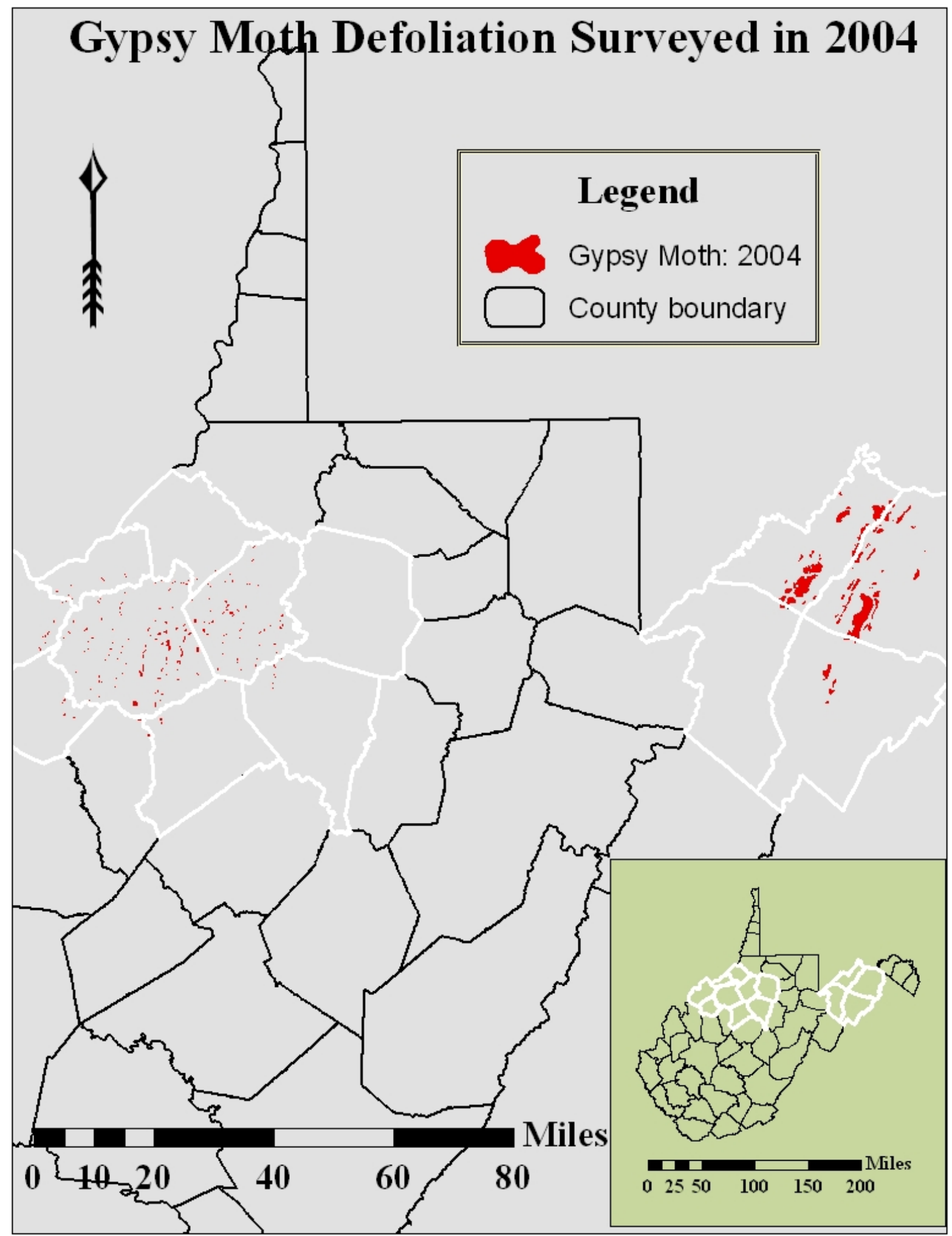

Figure 18: Gypsy moth defoliation aerially surveyed in 2004 in West Virginia. Counties highlighted in white are where defoliation occurred. 


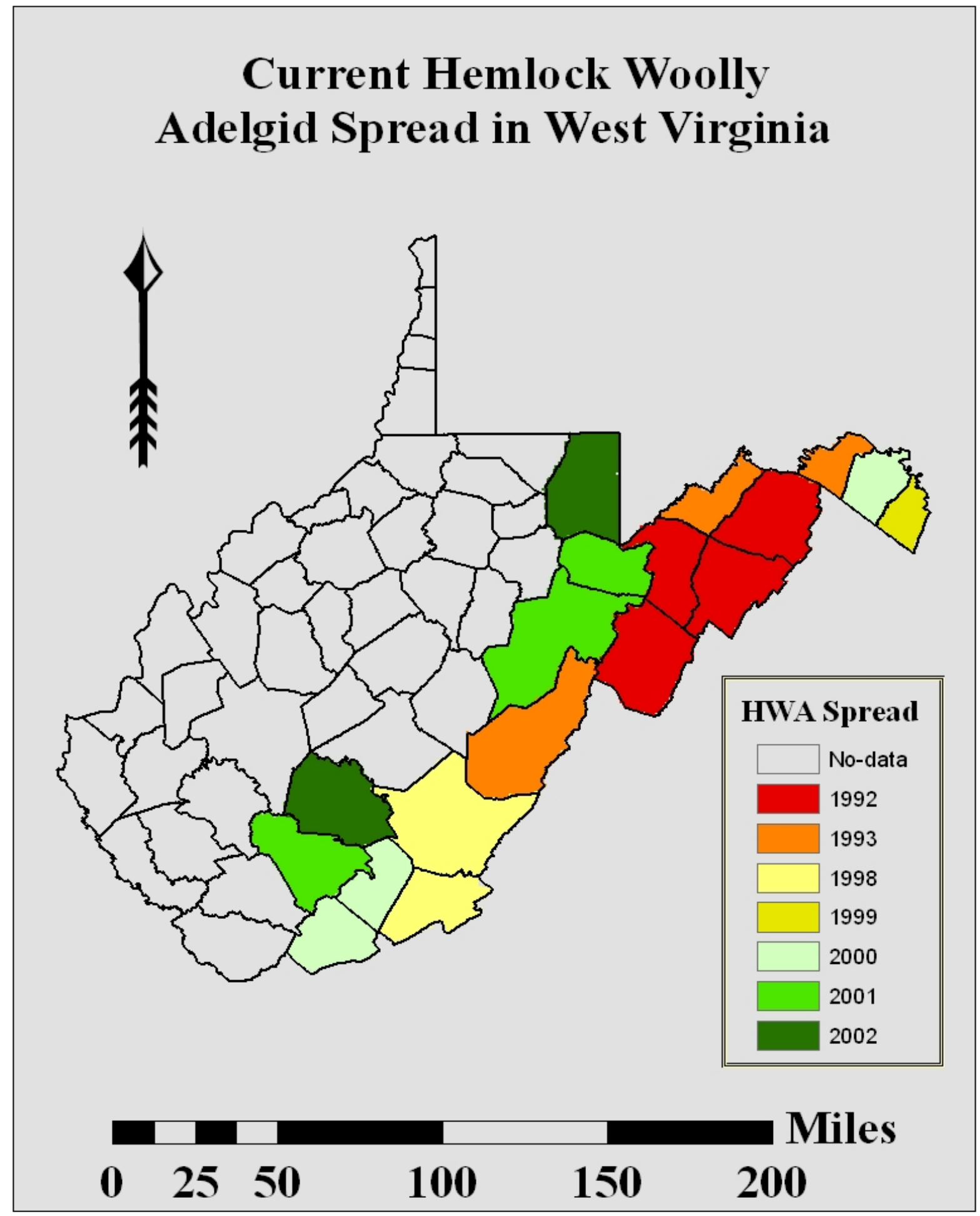

Figure 19: West Virginia counties where hemlock woolly adelgid has spread as of 2002. 


\section{Current \& Predicted Hemlock Woolly Adelgid Spread in West Virginia}

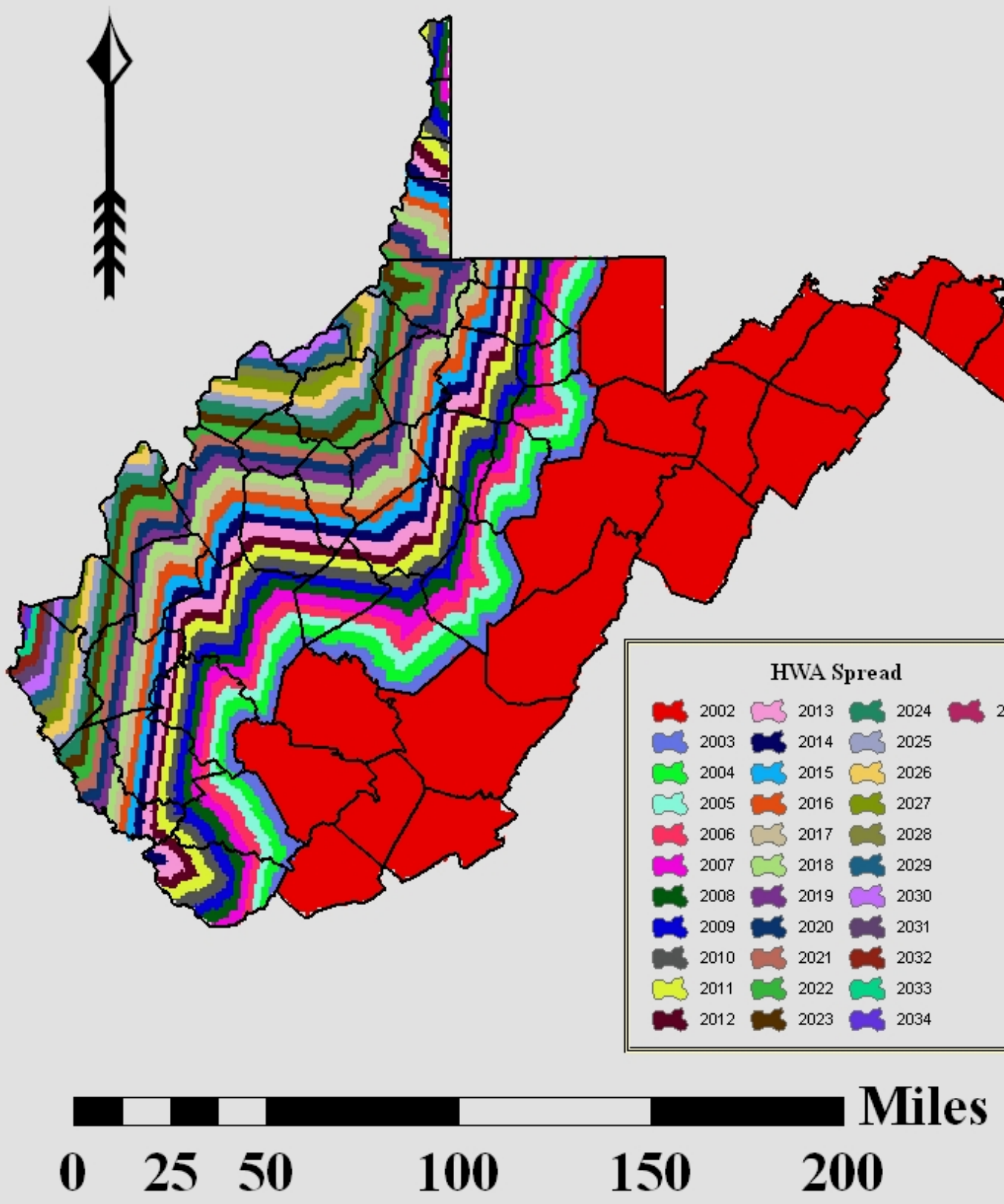

Figure 20: Current spread of hemlock woolly adelgid in West Virginia as of 2002 and predicted spread of hemlock woolly adelgid in West Virginia from 2003-2035. 


\section{Current Beech Bark Disease Spread in West Virginia}

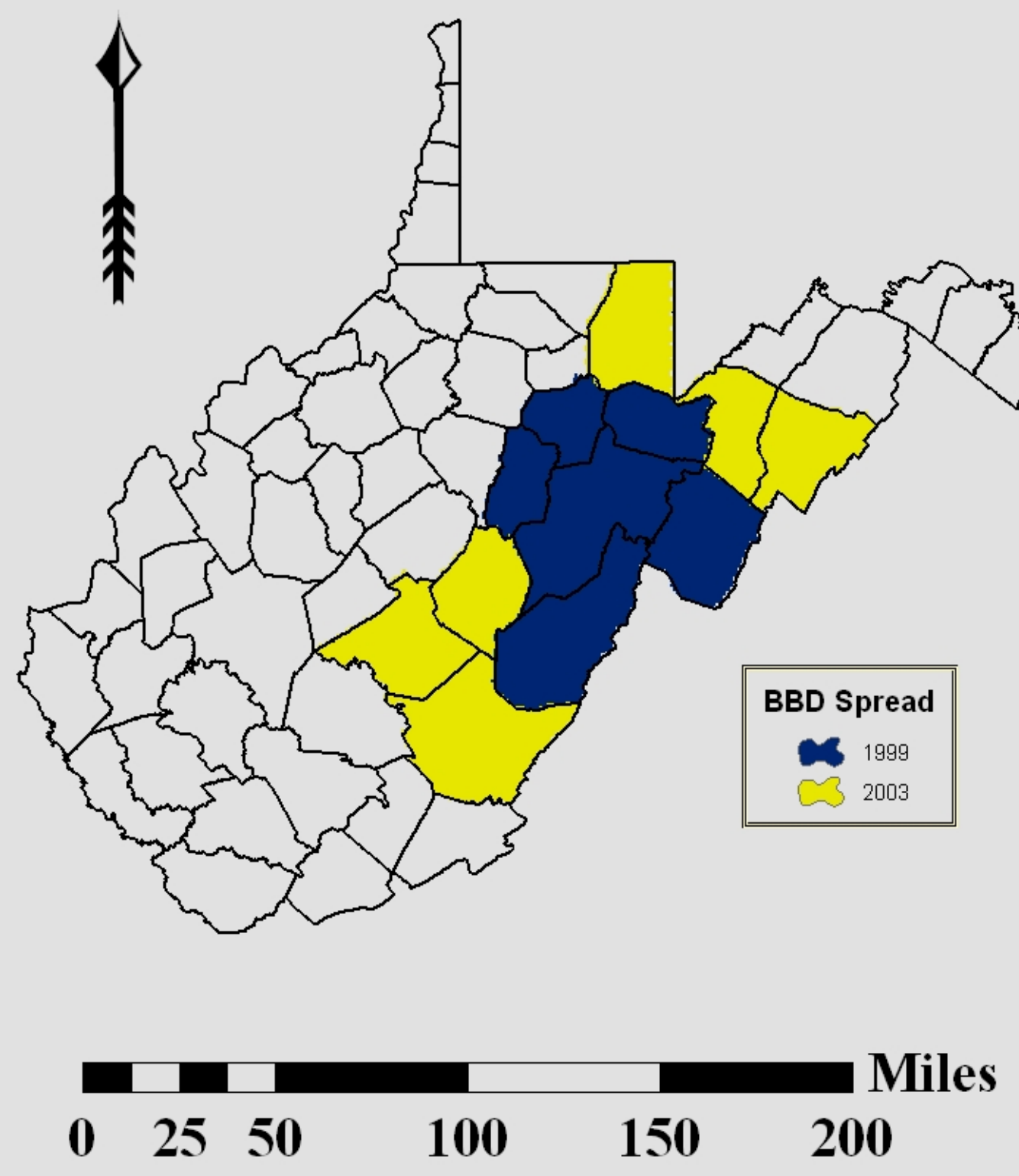

Figure 21: West Virginia counties where beech bark disease has spread as of 2003. 


\section{Current \& Predicted Beech Bark Disease Spread in West Virginia}

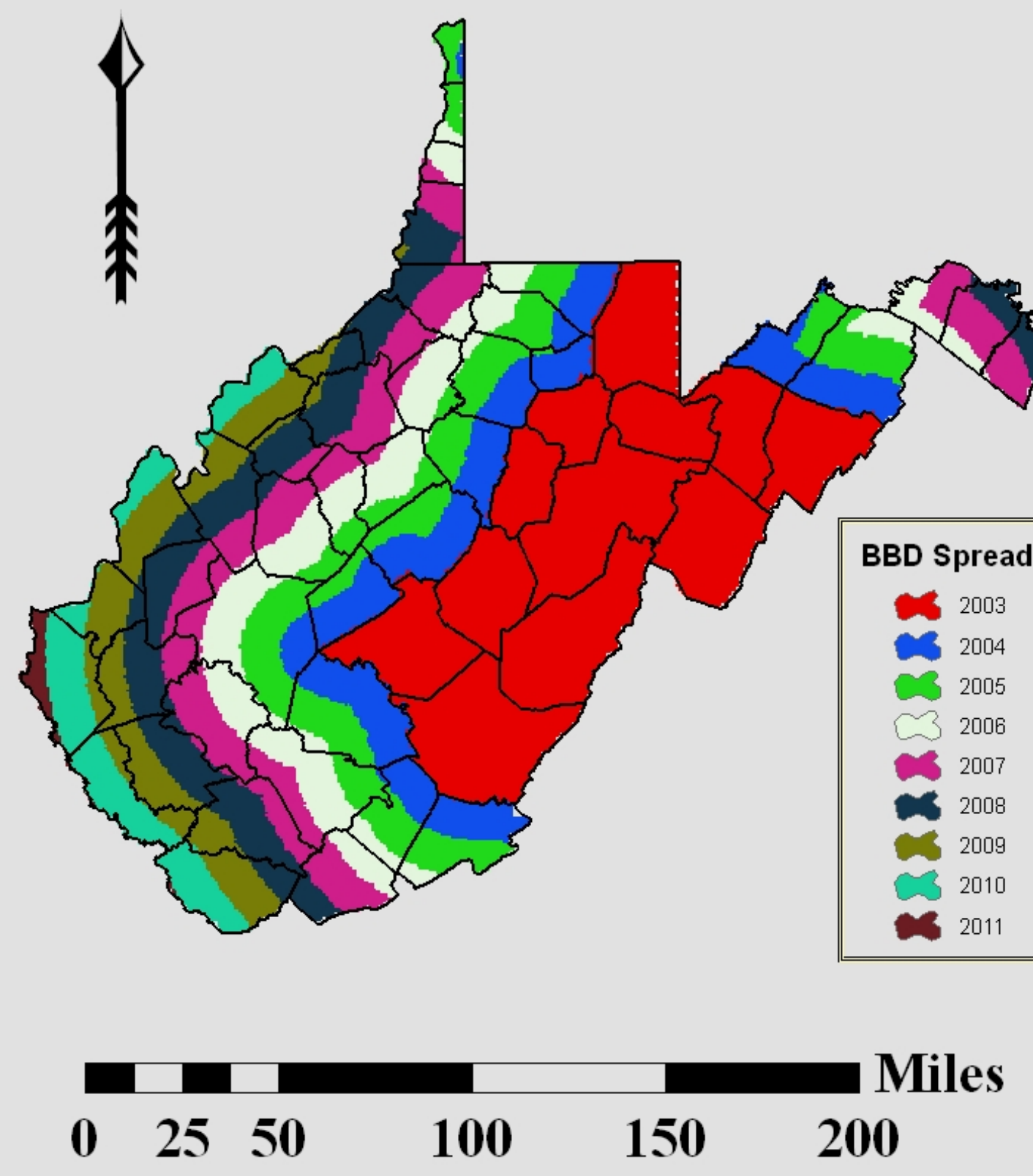

Figure 22: Current spread of beech bark disease in West Virginia as of 2003 and predicted spread of beech bark disease in West Virginia from 2004-2035. 


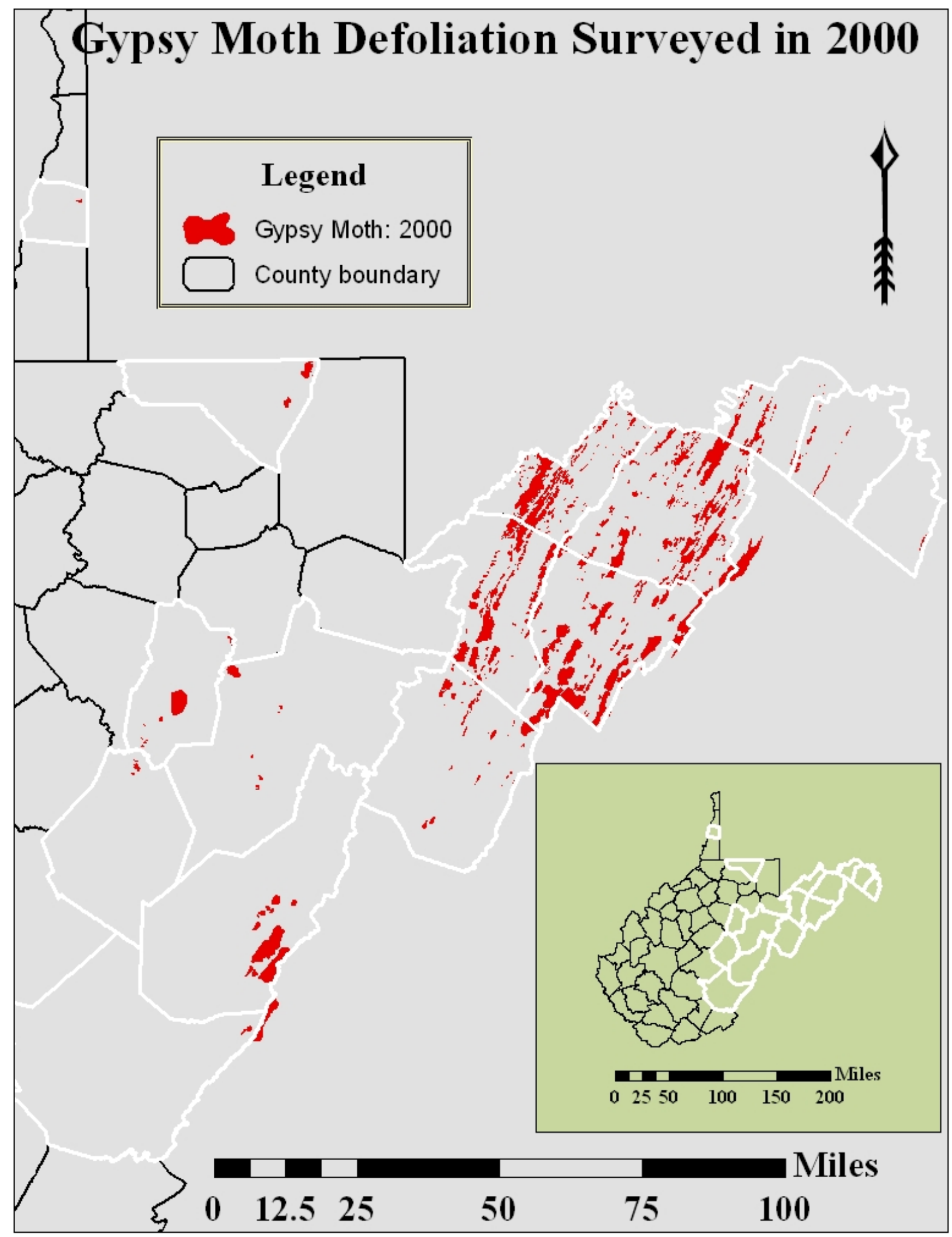

Figure 23: Gypsy moth defoliation aerially surveyed in 2000 in West Virginia. Counties highlighted in white are where defoliation occurred. 


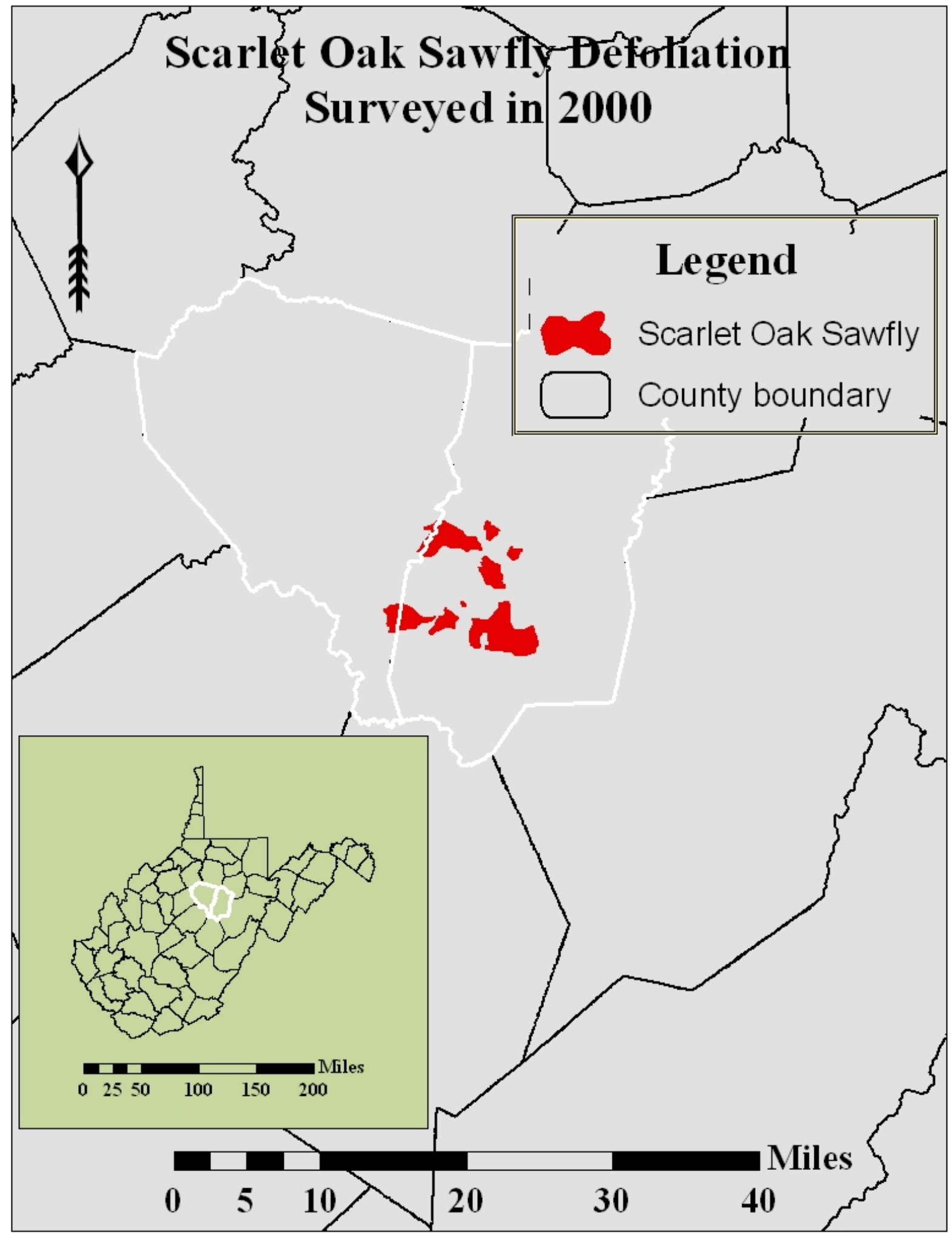

Figure 24: Scarlet oak sawfly defoliation aerially surveyed in 2002 in West Virginia. Counties highlighted in white are where defoliation occurred. 


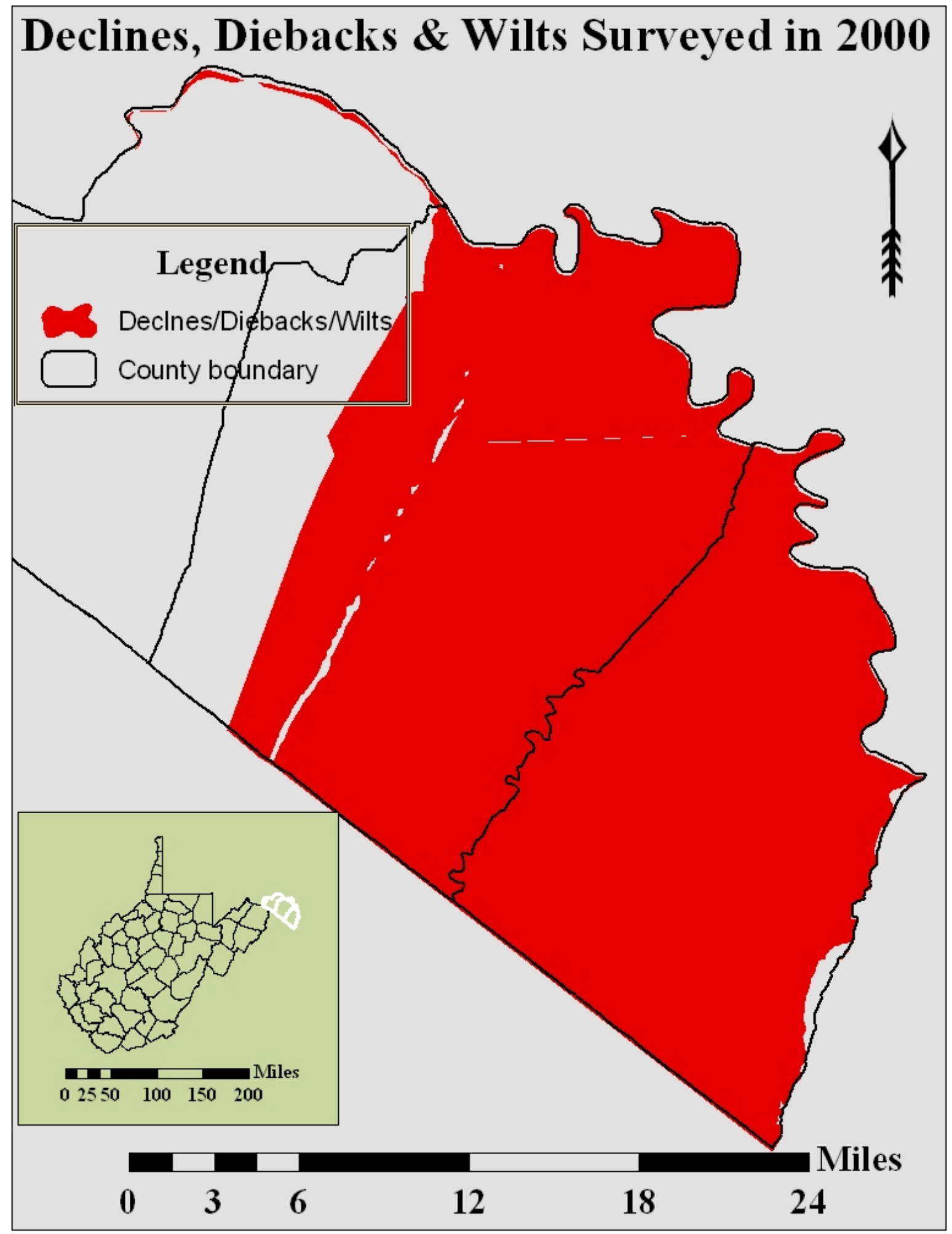

Figure 25: Declines, diebacks, and wilts aerially surveyed in 2002 in West Virginia. Counties highlighted in white are where defoliation occurred. 


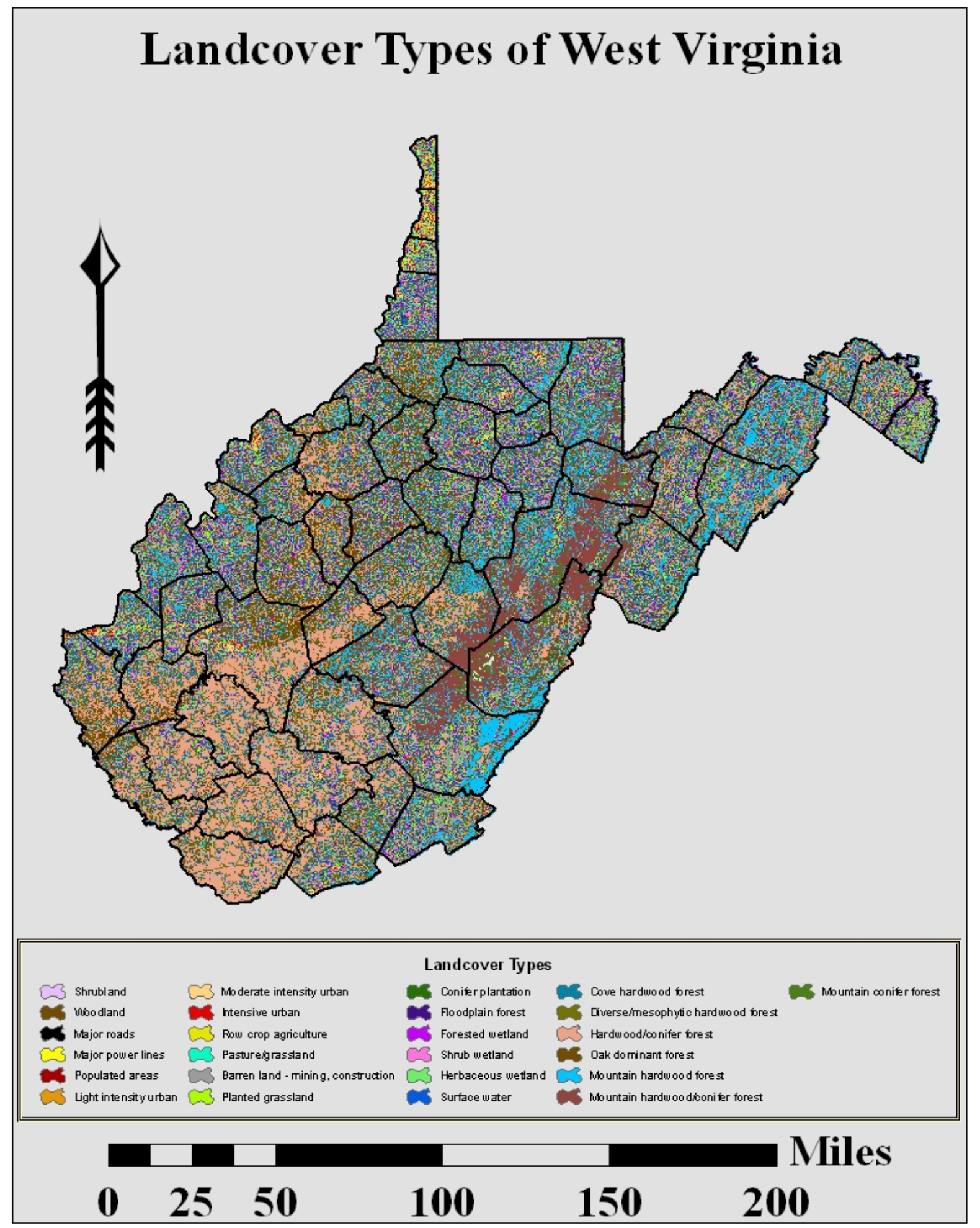

Figure 26: Land cover (WV GAP) map of West Virginia. Different land covers represent varying land uses and forest tree species compositions. Source: West Virginia University's Natural Resource Analysis Center. 


\section{Potential American Beech Habitat in West Virginia}

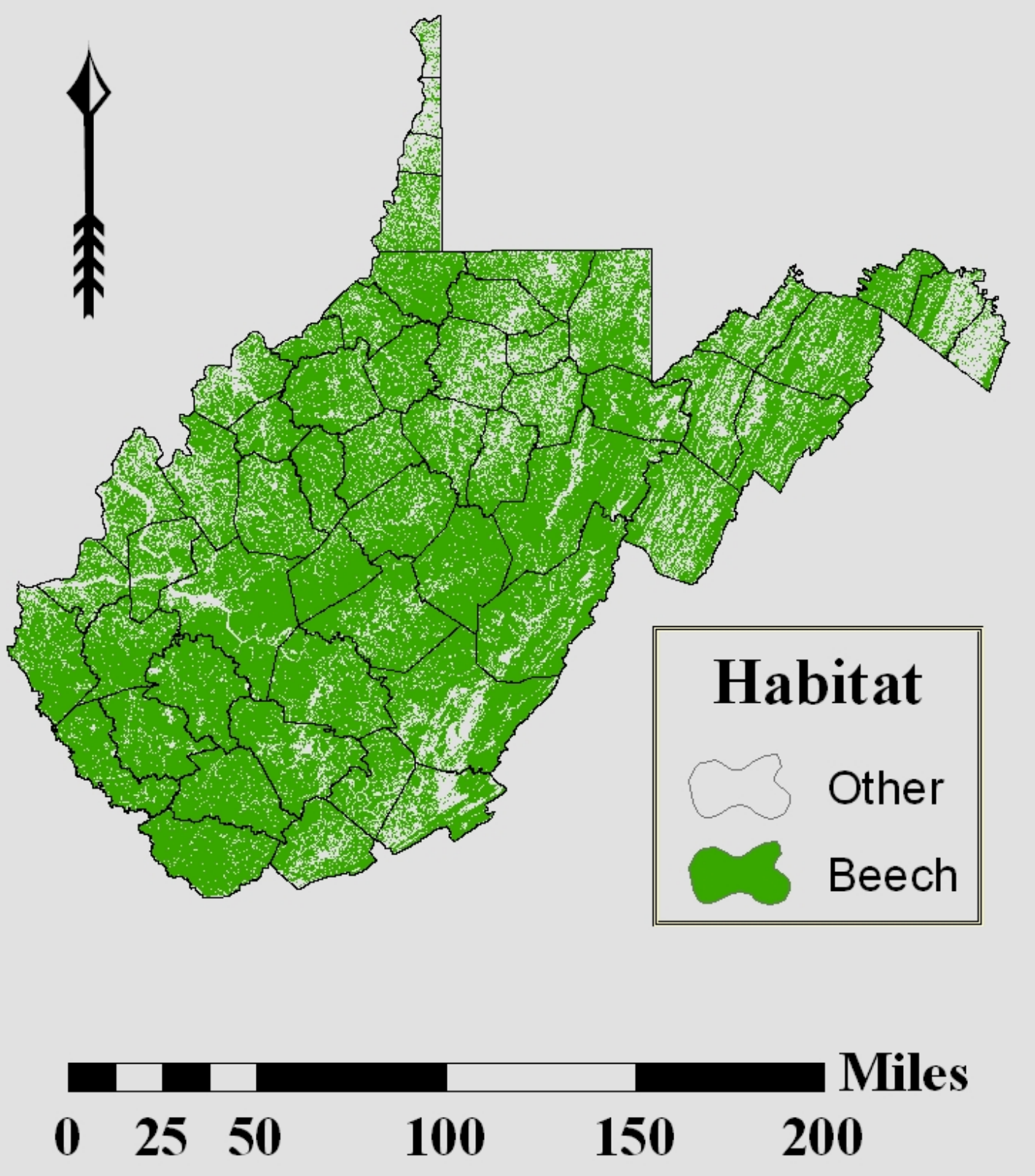

Figure 27: Potential American beech habitat as determined by land cover types of West Virginia. 


\section{Potential Eastern Hemlock Habitat in West Virginia}

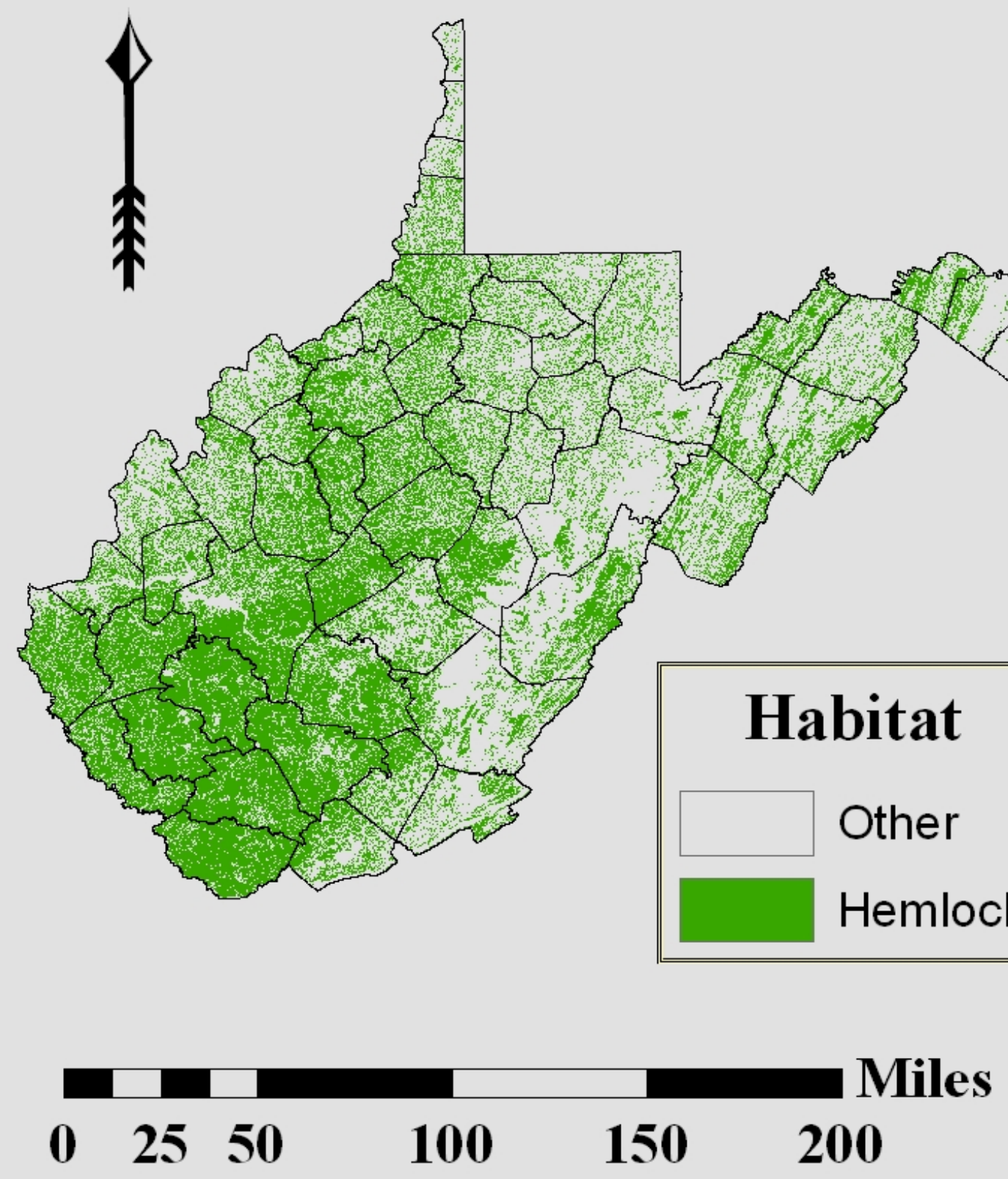

Figure 28: Potential eastern hemlock habitat as determined by land cover types of West Virginia. 


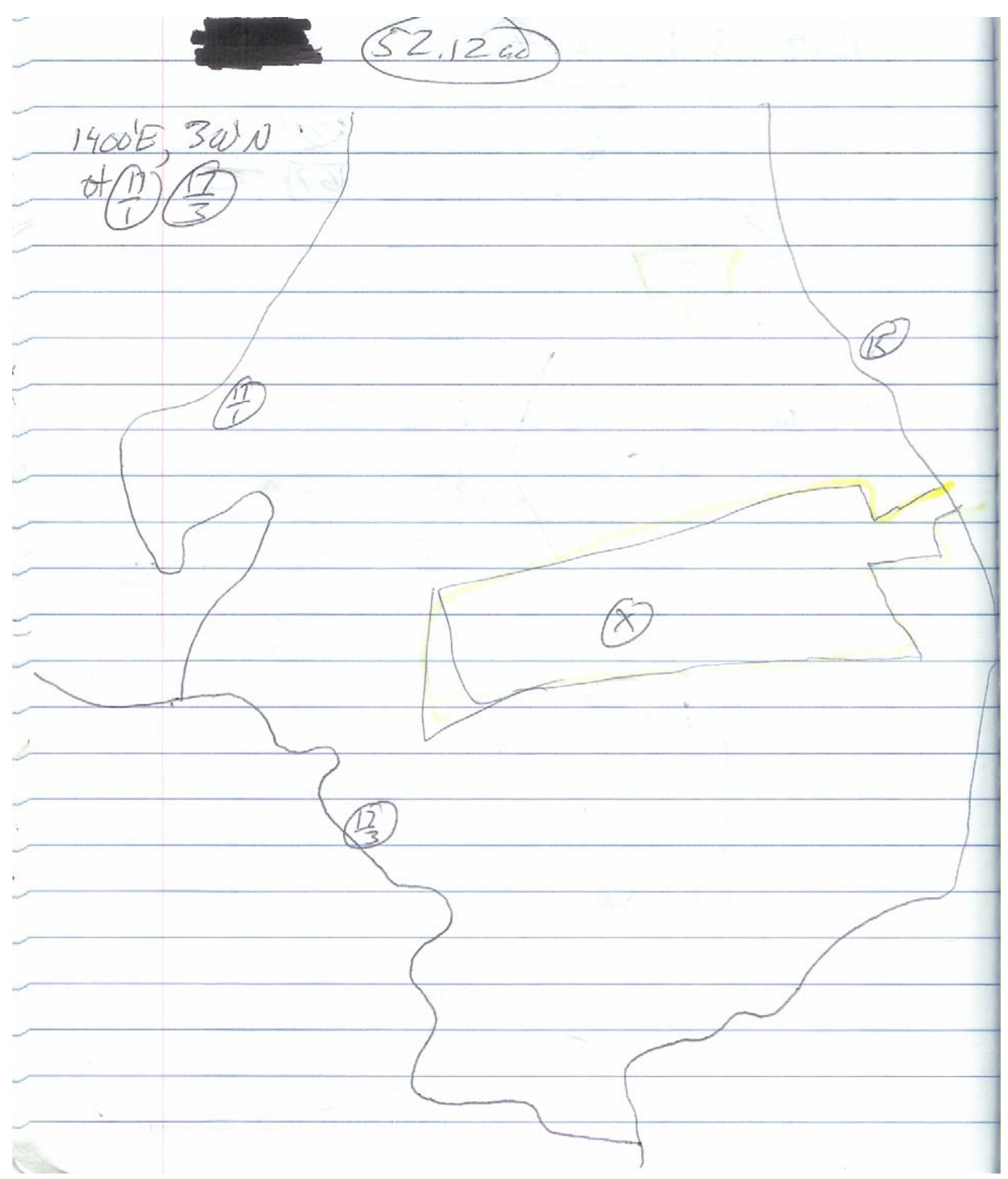

Figure 29: Sample of a hand drawn map representing a survey subject's property. Hand drawn maps were produced by referencing tax maps in county courthouses. 


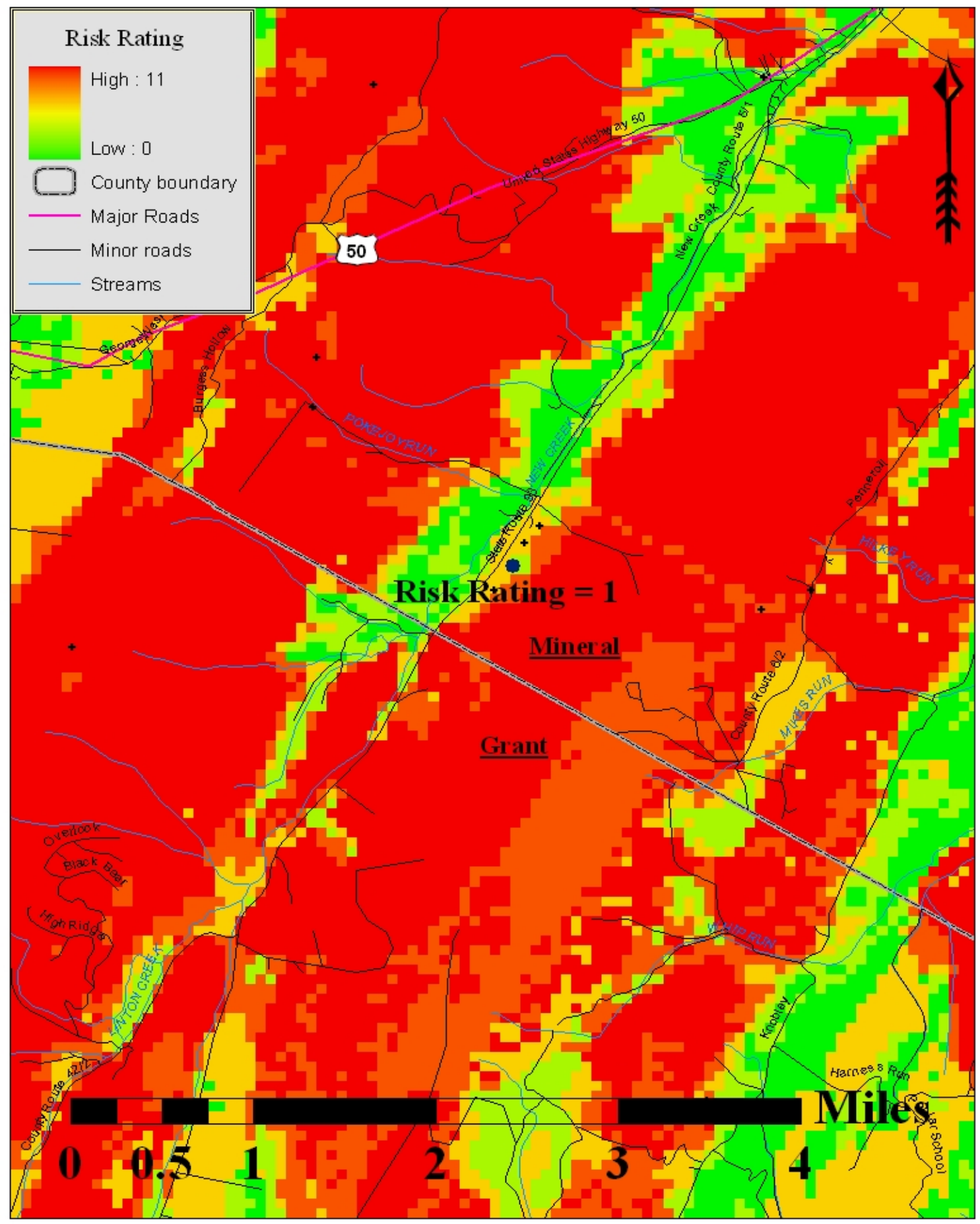

604

Figure 30: Sample of maps distributed to survey subjects. The dark blue dot is a point on a property. County boundaries, roads, and streams were included to help orientation. Red areas of high risk indicate more intense pest and disease activity relative to areas of orange or yellow where activity is moderate or green areas where activity is absent and risk is low. Risk rating is a function of historical and predicted pest and disease defoliations and distributions. 


\section{Appendix 2: Miscellaneous Tables}

Table 1: Defined projections and data formats of shapefiles used to create the pest and disease risk rating map.

\begin{tabular}{|c|c|c|}
\hline Shapefile & Defined Projection & Data Format \\
\hline Gypsy Moth: 1986 & NAD 1927-UTM-Zone 17 & Vector \\
\hline Gypsy Moth: 1987 & Unknown & Vector \\
\hline Gypsy Moth: 1988 & NAD 1927-UTM-Zone 17 & Vector \\
\hline Gypsy Moth: 1989 & NAD 1927-UTM-Zone 17 & Vector \\
\hline Gypsy Moth: 1990 & NAD 1927-UTM-Zone 17 & Vector \\
\hline Gypsy Moth: 1991 & NAD 1927-UTM-Zone 17 & Vector \\
\hline Gypsy Moth: 1992 & NAD 1927-UTM-Zone 17 & Vector \\
\hline Gypsy Moth: 1993 & NAD 1927-UTM-Zone 17 & Vector \\
\hline Gypsy Moth: 1994 & NAD 1927-UTM-Zone 17 & Vector \\
\hline Gypsy Moth: 1995 & NAD 1927-UTM-Zone 17 & Vector \\
\hline Gypsy Moth: 1996 & NAD 1927-UTM-Zone 17 & Vector \\
\hline Gypsy Moth: 1997 & NAD 1927-UTM-Zone 17 & Vector \\
\hline Gypsy Moth: 1998 & NAD 1927-UTM-Zone 17 & Vector \\
\hline Defoliations: 2000 & Clarke 1866-Albers Equal Area Conic & Vector \\
\hline Gypsy Moth: 2001 & Clarke 1866-Albers Equal Area Conic & Vector \\
\hline Gypsy Moth: 2002 & NAD 1927-UTM-Zone 17 & Vector \\
\hline Gypsy Moth: 2003 & NAD 1927-Albers Equal Area Conic & Vector \\
\hline Gypsy Moth: 2004 & NAD 1983-Albers Equal Area Conic & Vector \\
\hline Current BBD & NAD 1983-Albers Equal Area Conic & Raster \\
\hline Predicted BBD & Unknown & Raster \\
\hline Current HWA & Clarke 1866-Albers Equal Area Conic & Raster \\
\hline Predicted HWA & Clarke 1866-Albers Equal Area Conic & Raster \\
\hline
\end{tabular}

Table 2: Land cover types used for potential beech and hemlock habitats.

\begin{tabular}{ll}
\hline \multicolumn{1}{c}{ American Beech } & \multicolumn{1}{c}{ Eastern Hemlock } \\
\hline Floodplain Forest & Conifer Plantation \\
Forested Wetland & Floodplain Forest \\
Cove Hardwood Forest & Forested Wetland \\
Diverse/Mesophytic Hardwood Forest & Cove Hardwood Forest \\
Hardwood/Conifer Forest & Diverse/Mesophytic Hardwood Forest \\
Oak Dominant Forest & Hardwood/Conifer Forest \\
Mountain Hardwood Forest & Mountain Hardwood/Conifer Forest \\
Mountain Hardwood/Conifer Forest & Mountain Conifer Forest \\
\hline
\end{tabular}


Table 3: Respondent population outlying acreages and their interest levels.

\begin{tabular}{cc}
\hline Acreage & Interest \\
\hline 511 & 2 \\
536 & 9 \\
545 & 4 \\
591 & 8 \\
710 & 9 \\
944 & 4 \\
1070 & 4 \\
\hline
\end{tabular}

Table 4: SAS output of mean acres for treatment combinations of sample population.

\begin{tabular}{cccrc}
$\begin{array}{c}\text { Level of } \\
\text { FSP }\end{array}$ & \multicolumn{2}{c}{$\begin{array}{c}\text { Level of } \\
\text { Site }\end{array}$} & \multicolumn{3}{c}{ N } & Mean & Std Dev \\
& & & & \\
0 & 1 & 222 & 36.748694 & 44.426761 \\
0 & 2 & 234 & 44.438932 & 73.283272 \\
1 & 1 & 242 & 166.517769 & 185.294907 \\
1 & 2 & 230 & 162.972609 & 214.840614
\end{tabular}

\begin{tabular}{|c|c|c|c|c|c|}
\hline \multirow{2}{*}{$\begin{array}{l}\text { Level of } \\
\text { FSP }\end{array}$} & \multirow{2}{*}{\multicolumn{2}{|c|}{$\begin{array}{l}\text { Level of } \\
\text { Map }\end{array}$}} & \multirow[b]{2}{*}{$\mathrm{N}$} & \multicolumn{2}{|c|}{---------Acre---------- } \\
\hline & & & & Mean & Std Dev \\
\hline 0 & 0 & 225 & & 38.255156 & 56.831934 \\
\hline 0 & 1 & 231 & & 43.071472 & 64.878167 \\
\hline 1 & 0 & 238 & & 31.338655 & 145.392300 \\
\hline 1 & 1 & 234 & & 98.813675 & 238.906088 \\
\hline
\end{tabular}

\begin{tabular}{|c|c|c|c|c|}
\hline \multirow{2}{*}{$\begin{array}{l}\text { Level of } \\
\text { Site }\end{array}$} & \multirow{2}{*}{\multicolumn{2}{|c|}{$\begin{array}{l}\text { Level of } \\
\text { Map }\end{array}$}} & \multicolumn{2}{|c|}{-------------Acre------------- } \\
\hline & & & Mean & Std Dev \\
\hline 1 & 0 & 229 & 87.389563 & 119.822795 \\
\hline 1 & 1 & 235 & 121.035319 & 176.089358 \\
\hline 2 & 0 & 234 & 84.845299 & 121.882319 \\
\hline 2 & 1 & 230 & 121.863522 & 207.191877 \\
\hline
\end{tabular}

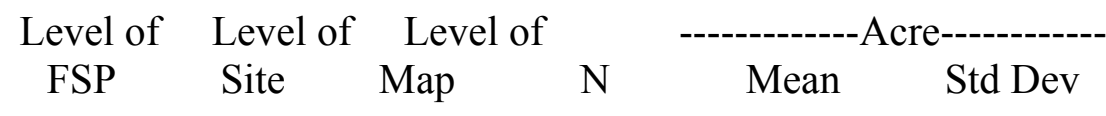

$\begin{array}{cccccc}0 & 1 & 0 & 108 & 32.014907 & 44.014116 \\ 0 & 1 & 1 & 114 & 41.233333 & 44.542716 \\ 0 & 2 & 0 & 117 & 44.015385 & 66.184041 \\ 0 & 2 & 1 & 117 & 44.862479 & 80.040512 \\ 1 & 1 & 0 & 121 & 136.814876 & 142.579604 \\ 1 & 1 & 1 & 121 & 196.220661 & 216.440181 \\ 1 & 2 & 0 & 117 & 125.675214 & 148.645310 \\ 1 & 2 & 1 & 113 & 201.590265 & 261.784547\end{array}$


Table 5: SAS output of mean risk for treatment combinations of sample population.

Level of Level of

FSP Site N Mean Std Dev

$\begin{array}{lllll}0 & 1 & 224 & 1.31696429 & 0.87438777 \\ 0 & 2 & 235 & 1.85106383 & 1.60099760 \\ 1 & 1 & 239 & 1.30543933 & 0.92741379 \\ 1 & 2 & 229 & 2.09170306 & 1.80043152\end{array}$

$\begin{array}{llll}\text { Level of } & \text { Level of } & & \text {-----------Risk----------- } \\ \text { Site } & \text { Map } & \text { N } & \text { Mean Std Dev }\end{array}$

$\begin{array}{lllll}1 & 0 & 228 & 1.33333333 & 0.90194764 \\ 1 & 1 & 235 & 1.28936170 & 0.90185802 \\ 2 & 0 & 232 & 1.91379310 & 1.69577507 \\ 2 & 1 & 232 & 2.02586207 & 1.71553234\end{array}$

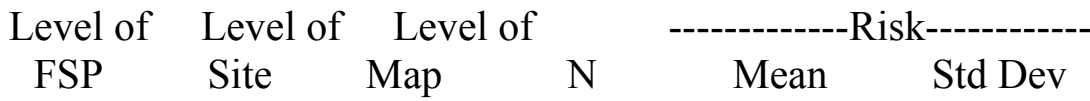

$\begin{array}{llllll}0 & 1 & 0 & 110 & 1.24545455 & 0.86931760 \\ 0 & 1 & 1 & 114 & 1.38596491 & 0.87753448 \\ 0 & 2 & 0 & 117 & 1.68376068 & 1.43628816 \\ 0 & 2 & 1 & 118 & 2.01694915 & 1.73935370 \\ 1 & 1 & 0 & 118 & 1.41525424 & 0.92751180 \\ 1 & 1 & 1 & 121 & 1.19834711 & 0.91851179 \\ 1 & 2 & 0 & 115 & 2.14782609 & 1.90218470 \\ 1 & 2 & 1 & 114 & 2.03508772 & 1.69815008\end{array}$


Table 6: SAS output of mean acres for treatment combinations of respondent population.

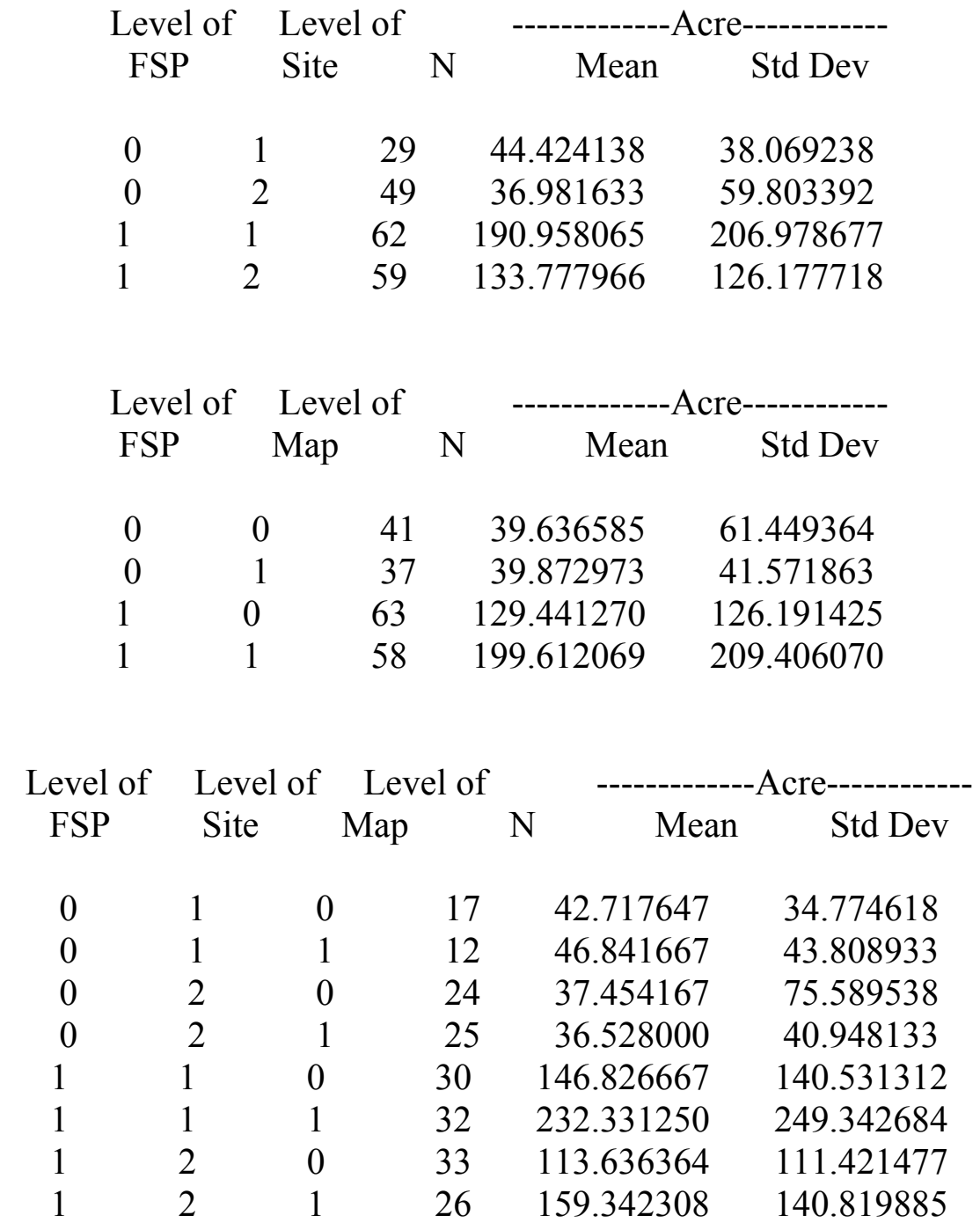


Table 7: SAS output of mean risk for treatment combinations of respondent population.

Level of Level of

FSP Site N Mean Std Dev

$\begin{array}{lllll}0 & 1 & 29 & 1.10344828 & 0.90019155 \\ 0 & 2 & 49 & 1.87755102 & 1.72762666 \\ 1 & 1 & 61 & 1.13114754 & 1.00789235 \\ 1 & 2 & 59 & 2.23728814 & 1.65403356\end{array}$

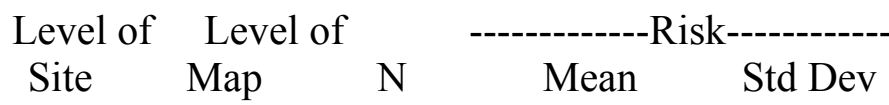

$\begin{array}{lllll}1 & 0 & 46 & 1.19565217 & 1.00265348 \\ 1 & 1 & 44 & 1.04545455 & 0.93893917 \\ 2 & 0 & 57 & 1.73684211 & 1.56440673 \\ 2 & 1 & 51 & 2.45098039 & 1.75856448\end{array}$

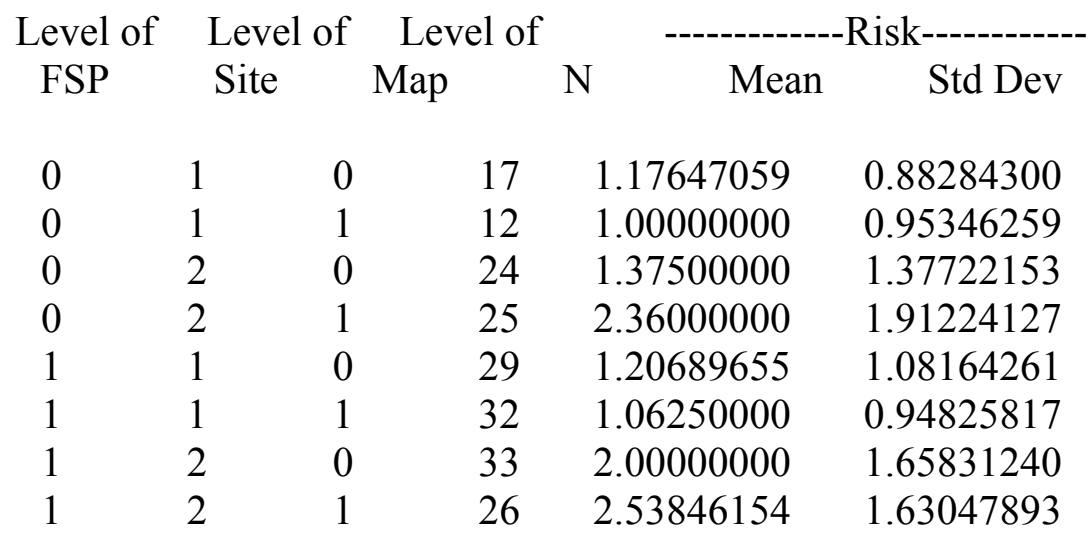




\section{Appendix 3: Postcard and Letters}

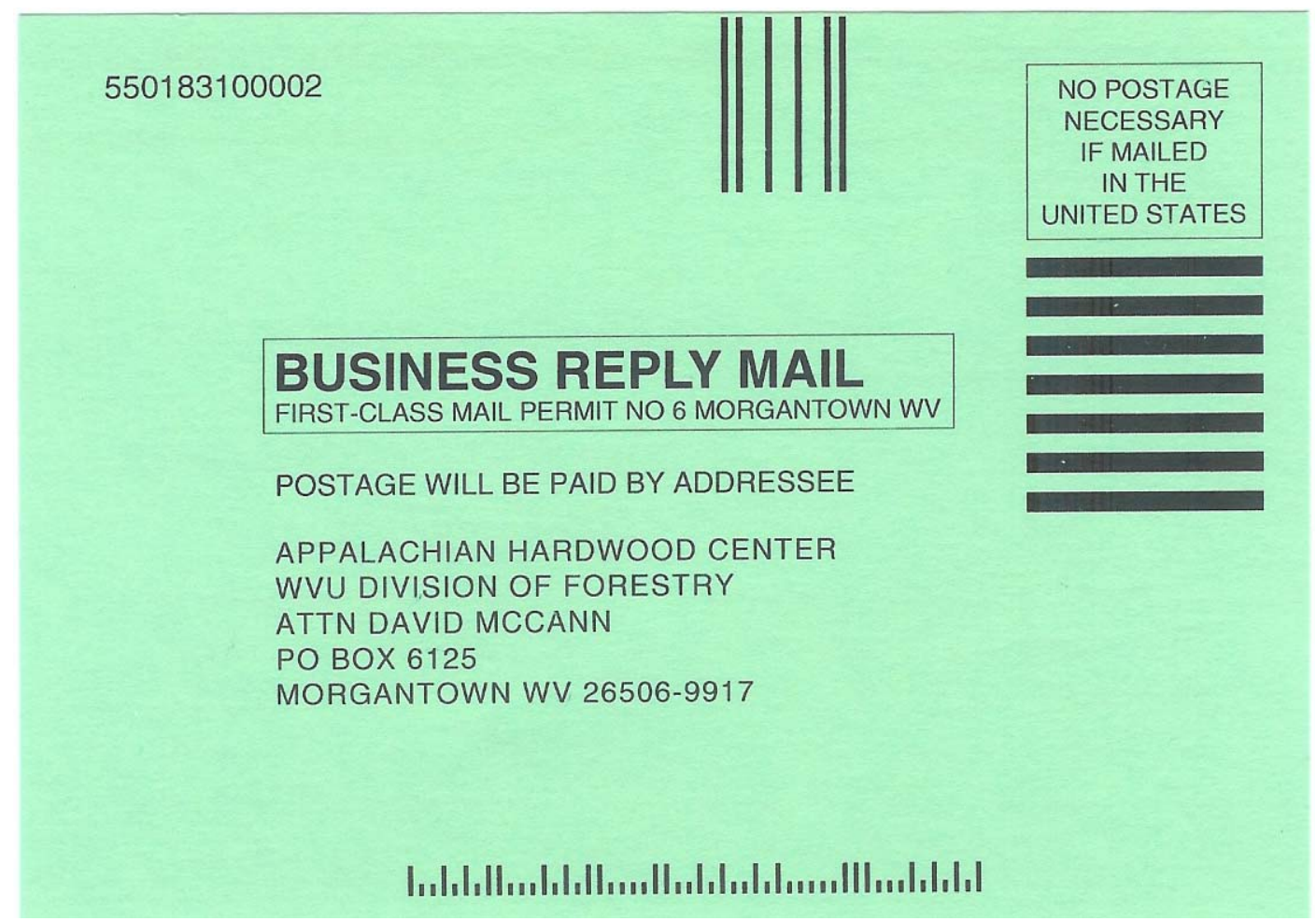

1. $\square$ I am currently knowledgeable about pests/diseases relevant to my property.

2. $\square$ I am currently engaged in pest/disease control measures on my property.

3. $\square \mathrm{I}$ am not interested in forest pests/diseases.

4. $\square$ I would prefer information on pests/diseases:

Pest/Disease

Gypsy moth

$\square$ Hemlock woolly adelgid

$\square$ Beech bark disease

$\square$ Sudden oak death

$\square$ Other

\section{Preferred Educational Format} (check one)

Information sheets

A visit to my property by a forest health professional

$\square$ A forest health workshop

$\square$ Other

Attn: 195 
September 26, 2005

Dear forest landowner,

Pests and diseases threaten the health of forests and the quality of forest products in West Virginia and around the country. The following are but a few of the organisms that are of concern in West Virginia forests:

Native pests/diseases

$\checkmark$ eastern tent caterpillar

$\checkmark$ red oak borer

$\checkmark$ oak wilt

\author{
Exotic pests/diseases $\quad$ New threats \\ $\checkmark$ gypsy moth emerald ash borer \\ $\checkmark$ hemlock woolly adelgid sudden oak death \\ $\checkmark$ beech bark disease
}

We are conducting a brief survey in order to determine the level of involvement in and awareness of forest health issues by forestland owners in our state. Enclosed is a map(s) that locates your property in a digital layer of risk rating. A point on your property is highlighted in blue. The higher the risk rating, the more organisms there are that may affect your property: for example, a risk rating of 11 means 11 organisms could influence your property.

Also enclosed with the risk rating map is a postage-paid postcard with four statements. Please take a few moments to review the postcard, check the appropriate boxes, and drop it in the mail.

This research is part of a master's degree thesis at the West Virginia University Division of Forestry. Your participation is completely voluntary and you do not have to respond to every statement in the post card. All information you provide will be kept completely confidential. Also, by answering questions about your preferred educational format, you will help us in determining the best way to extend forest health information to other landowners.

For information regarding your rights as a research subject, you may contact the Office of Research Compliance at 304-293-7073. If you have any questions or comments please call me at (304) 293-4411 ext. 2310, or e-mail me at dmccann1@mix.wvu.edu. Thank you for your help in this project.

Sincerely,

David McCann

Graduate Research Assistant

A WVU IRB approved copy of this letter is on file.

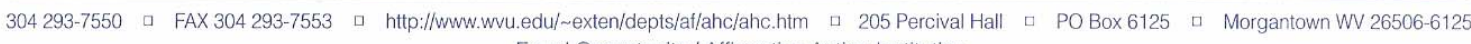
Equal Opportunity / Affirmative Action Institution 
September 26, 2005

Dear forest landowner,

Pests and diseases threaten the health of forests and the quality of forest products in West Virginia and around the country. The following are but a few of the organisms that are of concern in West Virginia forests:

\section{Native pests/diseases}

$\checkmark$ eastern tent caterpillar

$\rightarrow$ red oak borer

$\checkmark$ oak wilt

\section{Exotic pests/diseases \\ $\checkmark$ gypsy moth \\ - hemlock woolly adelgid \\ $\checkmark$ beech bark disease}

\section{New threats}

$\checkmark$ emerald ash borer

sudden oak death

We are conducting a brief survey in order to determine the level of involvement in and awareness of forest health issues by forestland owners in our state. Enclosed is a postage-paid postcard with four statements. Please take a few moments to review the postcard, check the appropriate boxes, and drop it in the mail.

This research is part of a master's degree thesis at the West Virginia University Division of Forestry. Your participation is completely voluntary and you do not have to respond to every statement in the post card. All information you provide will be kept completely confidential. Also, by answering questions about your preferred educational format, you will help us in determining the best way to extend forest health information to other landowners.

For information regarding your rights as a research subject, you may contact the Office of Research Compliance at 304-293-7073. If you have any questions or comments please call me at (304) 293-4411 ext.2310, or e-mail me at dmccann1@mix.wvu.edu. Thank you for your help in this project.

Sincerely,

David McCann

Graduate Research Assistant

A WVU IRB approved copy of this letter is on file.

304 293-7550 व FAX 304 293-7553 a http://www.wvu.edu/ exlen/depts/al/ahc/ahc.htm a 205 Percival Hall $\square$ PO Box6125 a Morgantown Wv 26506-6125 Equal Opportunity / Affirmative Action Institution 


\section{Appendix 4: Metadata for Shapefiles}

\section{Gypsy moth defoliation-1986}

Metadata also available as

\section{Frequently-anticipated questions:}

- What does this data set describe?

1. How should this data set be cited?

2. What geographic area does the data set cover?

3. What does it look like?

4. Does the data set describe conditions during a particular time period?

5. What is the general form of this data set?

6. How does the data set represent geographic features?

7. How does the data set describe geographic features?

- Who produced the data set?

1. Who are the originators of the data set?

2. Who also contributed to the data set?

3. To whom should users address questions about the data?

- Why was the data set created?

- How was the data set created?

1. From what previous works were the data drawn?

2. How were the data generated, processed, and modified?

3. What similar or related data should the user be aware of?

- How reliable are the data; what problems remain in the data set?

1. How well have the observations been checked?

2. How accurate are the geographic locations?

3. How accurate are the heights or depths?

4. Where are the gaps in the data? What is missing?

5. How consistent are the relationships among the data, including topology?

- How can someone get a copy of the data set?

1. Are there legal restrictions on access or use of the data?

2. Who distributes the data?

3. What's the catalog number I need to order this data set?

4. What legal disclaimers am I supposed to read?

5. How can I download or order the data?

- Who wrote the metadata?

\section{What does this data set describe?}

Title: wv_86

Abstract: REQUIRED: A brief narrative summary of the data set.

1. How should this data set be cited? 
REQUIRED: The name of an organization or individual that developed the data set., REQUIRED: The date when the data set is published or otherwise made available for release., wv_86.

Online Links:

o IIPERFOR339GRAD14\C\$\fspmapstufflann's stuff $\backslash w v \_86 . s h p$

2. What geographic area does the data set cover?

West_Bounding_Coordinate: -79.075552

East_Bounding_Coordinate: -77.931789

North_Bounding_Coordinate: 39.602101

South_Bounding_Coordinate: 39.027346

3. What does it look like?

4. Does the data set describe conditions during a particular time period?

Calendar_Date: REQUIRED: The year (and optionally month, or month and day) for which the data set corresponds to the ground.

Currentness_Reference:

REQUIRED: The basis on which the time period of content information is determined.

5. What is the general form of this data set?

Geospatial_Data_Presentation_Form: vector digital data

6. How does the data set represent geographic features?

a. How are geographic features stored in the data set?

This is a Vector data set. It contains the following vector data types (SDTS terminology):

- G-polygon (51)

b. What coordinate system is used to represent geographic features?

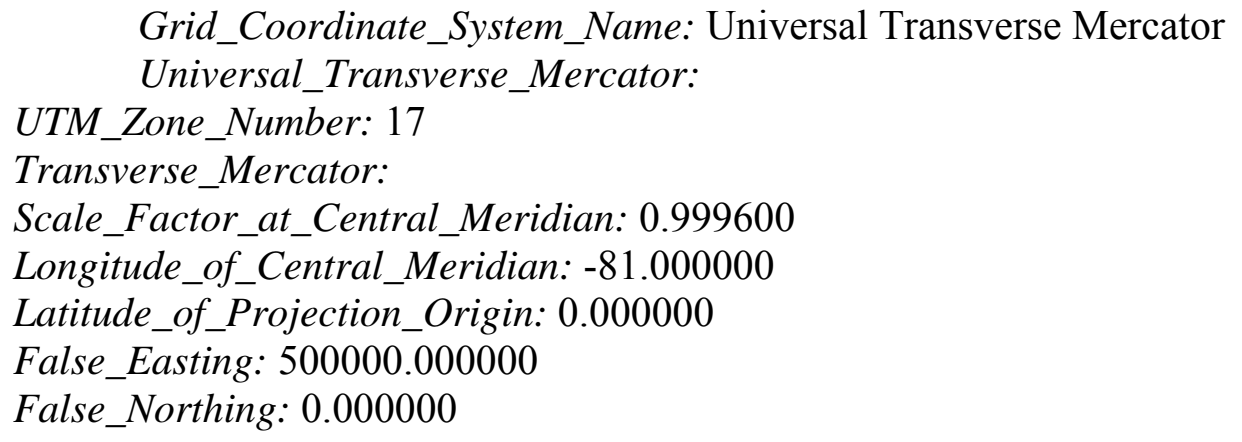

Planar coordinates are encoded using coordinate pair

Abscissae (x-coordinates) are specified to the nearest 0.000256 
Ordinates (y-coordinates) are specified to the nearest 0.000256

Planar coordinates are specified in meters

The horizontal datum used is North American Datum of 1983.

The ellipsoid used is Geodetic Reference System 80.

The semi-major axis of the ellipsoid used is 6378137.000000 .

The flattening of the ellipsoid used is $1 / 298.257222$.

7. How does the data set describe geographic features?

Wv_86

FID

Internal feature number. (Source: ESRI)

Sequential unique whole numbers that are automatically generated.

Shape

Feature geometry. (Source: ESRI)

Coordinates defining the features.
AREA
PERIMETER
WV 86
WV_86_ID
SURVEY_ID1
SURVEY_ID2
SURVEY ID3
DMG_TYPE1
DMG_TYPE2
DMG_TYPE3
SEVERITY1
SEVERITY2
SEVERITY3
PATTERN1
PATTERN2
PATTERN3
TPA1
TPA2
TPA3
NO_TREES1
NO_TREES2
NO_TREES3
DCA1
DCA2
DCA3
HOST1
HOST2
HOST3
FOR TYPE1
FOR_TYPE2
FOR_TYPE3
NOTES
value 


\section{Who produced the data set?}

1. Who are the originators of the data set? (may include formal authors, digital compilers, and editors)

o REQUIRED: The name of an organization or individual that developed the data set.

2. Who also contributed to the data set?

3. To whom should users address questions about the data?

Why was the data set created?

REQUIRED: A summary of the intentions with which the data set was developed.

\section{How was the data set created?}

1. From what previous works were the data drawn?

2. How were the data generated, processed, and modified?

3. What similar or related data should the user be aware of?

How reliable are the data; what problems remain in the data set?

\section{How can someone get a copy of the data set?}

Are there legal restrictions on access or use of the data?

Access_Constraints:

REQUIRED: Restrictions and legal prerequisites for accessing the data set.

Use_Constraints:

REQUIRED: Restrictions and legal prerequisites for using the data set after access is granted.

1. Who distributes the data set?[Distributor contact information not provided.]

2. What's the catalog number I need to order this data set?

Downloadable Data

3. What legal disclaimers am I supposed to read?

4. How can I download or order the data?

o Availability in digital form:

Data format: Size: 0.021 


\section{o Cost to order the data:}

\section{Who wrote the metadata?}

Dates:

Last modified: $18-\mathrm{Nov}-2005$

Metadata author:

REQUIRED: The organization responsible for the metadata information.

c/o REQUIRED: The person responsible for the metadata information.

REQUIRED: The city of the address., REQUIRED: The state or province of the address.

REQUIRED: The ZIP or other postal code of the address.

REQUIRED: The telephone number by which individuals can speak to the organization or individual. (voice)

Metadata standard:

FGDC Content Standards for Digital Geospatial Metadata (FGDC-STD-001-1998)

Metadata extensions used:

- $\quad \leq$ http://www.esri.com/metadata/esriprof80.html $>$

Generated by mp version 2.8.6 on Fri Nov 18 11:00:22 2005

\section{Gypsy moth defoliation -1987}

Metadata also available as

\section{Frequently-anticipated questions:}

- What does this data set describe?

1. How should this data set be cited?

2. What geographic area does the data set cover?

3. What does it look like?

4. Does the data set describe conditions during a particular time period?

5. What is the general form of this data set?

6. How does the data set represent geographic features?

7. How does the data set describe geographic features?

- Who produced the data set?

1. Who are the originators of the data set?

2. Who also contributed to the data set?

3. To whom should users address questions about the data?

- Why was the data set created? 
- How was the data set created?

1. From what previous works were the data drawn?

2. How were the data generated, processed, and modified?

3. What similar or related data should the user be aware of?

- How reliable are the data; what problems remain in the data set?

1. How well have the observations been checked?

2. How accurate are the geographic locations?

3. How accurate are the heights or depths?

4. Where are the gaps in the data? What is missing?

5. How consistent are the relationships among the data, including topology?

- How can someone get a copy of the data set?

1. Are there legal restrictions on access or use of the data?

2. Who distributes the data?

3. What's the catalog number I need to order this data set?

4. What legal disclaimers am I supposed to read?

5. How can I download or order the data?

- Who wrote the metadata?

\section{What does this data set describe?}

Title: wv_87

Abstract: REQUIRED: A brief narrative summary of the data set.

\section{How should this data set be cited?}

REQUIRED: The name of an organization or individual that developed the data set., REQUIRED: The date when the data set is published or otherwise made available for release., wv_87.

Online Links:

- \IPERFOR339GRAD14\C\$\fspmapstufflann's stufflwv_87.shp

2. What geographic area does the data set cover?

West_Bounding_Coordinate: -79.135174

East_Bounding_Coordinate: -77.705259

North_Bounding_Coordinate: 39.702648

South_Bounding_Coordinate: 38.988848

3. What does it look like?

4. Does the data set describe conditions during a particular time period?

Calendar_Date: REQUIRED: The year (and optionally month, or month and day) for which the data set corresponds to the ground.

Currentness_Reference:

REQUIRED: The basis on which the time period of content information is determined. 
5. What is the general form of this data set?

Geospatial_Data_Presentation_Form: vector digital data

6. How does the data set represent geographic features?

a. How are geographic features stored in the data set?

This is a Vector data set. It contains the following vector data types (SDTS terminology):

- G-polygon (170)

b. What coordinate system is used to represent geographic features?

Grid_Coordinate_System_Name: Universal Transverse Mercator

Universal_Transverse_Mercator:

UTM_Zone_Number: 17

Transverse_Mercator:

Scale_Factor_at_Central_Meridian: 0.999600

Longitude_of_Central_Meridian: -81.000000

Latitude_of_Projection_Origin: 0.000000

False_Easting: 500000.000000

False_Northing: 0.000000

Planar coordinates are encoded using coordinate pair

Abscissae (x-coordinates) are specified to the nearest 0.000256

Ordinates (y-coordinates) are specified to the nearest 0.000256

Planar coordinates are specified in meters

The horizontal datum used is North American Datum of 1983.

The ellipsoid used is Geodetic Reference System 80.

The semi-major axis of the ellipsoid used is 6378137.000000 .

The flattening of the ellipsoid used is $1 / 298.257222$.

7. How does the data set describe geographic features?

WV_87

FID

Internal feature number. (Source: ESRI)

Sequential unique whole numbers that are automatically generated.

Shape

Feature geometry. (Source: ESRI)

Coordinates defining the features.
AREA
PERIMETER
WV_87
WV_87_ID 


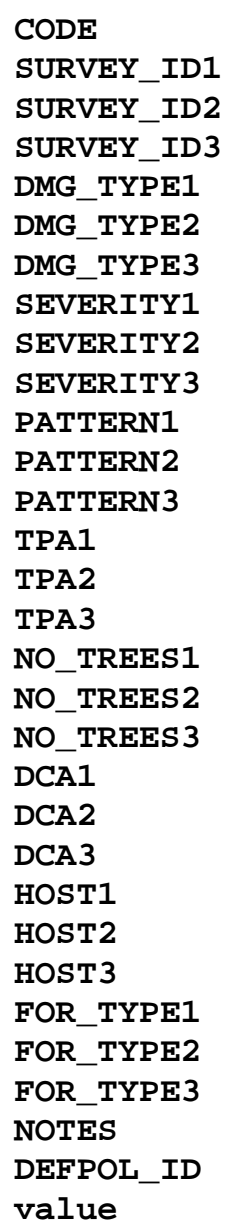

\section{Who produced the data set?}

1. Who are the originators of the data set? (may include formal authors, digital compilers, and editors)

o REQUIRED: The name of an organization or individual that developed the data set.

2. Who also contributed to the data set?

3. To whom should users address questions about the data?

\section{Why was the data set created?}

REQUIRED: A summary of the intentions with which the data set was developed.

\section{How was the data set created?}

1. From what previous works were the data drawn?

2. How were the data generated, processed, and modified?

3. What similar or related data should the user be aware of? 
How reliable are the data; what problems remain in the data set?

\section{How can someone get a copy of the data set?}

Are there legal restrictions on access or use of the data?

Access Constraints:

REQUIRED: Restrictions and legal prerequisites for accessing the data set.

Use_Constraints:

REQUIRED: Restrictions and legal prerequisites for using the data set after access is granted.

1. Who distributes the data set?[Distributor contact information not provided.]

2. What's the catalog number I need to order this data set?

Downloadable Data

3. What legal disclaimers am I supposed to read?

4. How can I download or order the data?

o Availability in digital form:

Data format: Size: 0.055

o Cost to order the data:

\section{Who wrote the metadata?}

Dates:

Last modified: 18-Nov-2005

Metadata author:

REQUIRED: The organization responsible for the metadata information.

c/o REQUIRED: The person responsible for the metadata information.

REQUIRED: The city of the address., REQUIRED: The state or province of the address.

REQUIRED: The ZIP or other postal code of the address.

REQUIRED: The telephone number by which individuals can speak to the organization or individual. (voice)

Metadata standard:

FGDC Content Standards for Digital Geospatial Metadata (FGDC-STD-001-1998)

Metadata extensions used:

- $\quad \leq$ http://www.esri.com/metadata/esriprof80.html $>$ 
Generated by mp version 2.8.6 on Fri Nov 18 11:00:05 2005

\section{Gypsy moth defoliation-1988}

Metadata also available as

\section{Frequently-anticipated questions:}

- What does this data set describe?

1. How should this data set be cited?

2. What geographic area does the data set cover?

3. What does it look like?

4. Does the data set describe conditions during a particular time period?

5. What is the general form of this data set?

6. How does the data set represent geographic features?

7. How does the data set describe geographic features?

- Who produced the data set?

1. Who are the originators of the data set?

2. Who also contributed to the data set?

3. To whom should users address questions about the data?

- Why was the data set created?

- How was the data set created?

1. From what previous works were the data drawn?

2. How were the data generated, processed, and modified?

3. What similar or related data should the user be aware of?

- How reliable are the data; what problems remain in the data set?

1. How well have the observations been checked?

2. How accurate are the geographic locations?

3. How accurate are the heights or depths?

4. Where are the gaps in the data? What is missing?

5. How consistent are the relationships among the data, including topology?

- How can someone get a copy of the data set?

1. Are there legal restrictions on access or use of the data?

2. Who distributes the data?

3. What's the catalog number I need to order this data set?

4. What legal disclaimers am I supposed to read?

5. How can I download or order the data?

- Who wrote the metadata?

\section{What does this data set describe?}

Title: wv_88 
Abstract: REQUIRED: A brief narrative summary of the data set.

1. How should this data set be cited?

REQUIRED: The name of an organization or individual that developed the data set., REQUIRED: The date when the data set is published or otherwise made available for release., Wv_88.

Online Links:

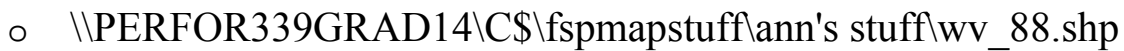

2. What geographic area does the data set cover?

West_Bounding_Coordinate: -78.825293

East_Bounding_Coordinate: -77.782135

North_Bounding_Coordinate: 39.690576

South_Bounding_Coordinate: 38.942810

3. What does it look like?

4. Does the data set describe conditions during a particular time period?

Calendar_Date: REQUIRED: The year (and optionally month, or month and day) for which the data set corresponds to the ground.

Currentness_Reference:

REQUIRED: The basis on which the time period of content information is determined.

5. What is the general form of this data set?

Geospatial_Data_Presentation_Form: vector digital data

6. How does the data set represent geographic features?

a. How are geographic features stored in the data set?

This is a Vector data set. It contains the following vector data types (SDTS terminology):

- G-polygon (351)

b. What coordinate system is used to represent geographic features?

Grid_Coordinate_System_Name: Universal Transverse Mercator

Universal_Transverse_Mercator:

UTM_Zone_Number: 17

Transverse_Mercator:

Scale_Factor_at_Central_Meridian: 0.999600

Longitude_of_Central_Meridian:-81.000000

Latitude_of_Projection_Origin: 0.000000

False_Easting: 500000.000000

False_Northing: 0.000000 
Planar coordinates are encoded using coordinate pair

Abscissae (x-coordinates) are specified to the nearest 0.000128

Ordinates (y-coordinates) are specified to the nearest 0.000128

Planar coordinates are specified in meters

The horizontal datum used is North American Datum of 1983.

The ellipsoid used is Geodetic Reference System 80.

The semi-major axis of the ellipsoid used is 6378137.000000 .

The flattening of the ellipsoid used is $1 / 298.257222$.

7. How does the data set describe geographic features?

WV_88

FID

Internal feature number. (Source: ESRI)

Sequential unique whole numbers that are automatically generated.

Shape

Feature geometry. (Source: ESRI)

Coordinates defining the features.
AREA
PERIMETER
WV_88
WV_88_ID
DEFOL_CODE
SURVEY_ID1
SURVEY_ID2
SURVEY_ID3
DMG_TYPE1
DMG_TYPE2
DMG_TYPE3
SEVERITY1
SEVERITY2
SEVERITY3
PATTERN1
PATTERN2
PATTERN3
TPA1
TPA2
TPA3
NO_TREES1
NO_TREES2
NO_TREES3
DCA1
DCA2
DCA3
HOST1
HOST2
HOST3
FOR_TYPE1
FOR TYPE2
FOR_TYPE3 
NOTES

CODE

ACRES

value

\section{Who produced the data set?}

1. Who are the originators of the data set? (may include formal authors, digital compilers, and editors)

o REQUIRED: The name of an organization or individual that developed the data set.

2. Who also contributed to the data set?

3. To whom should users address questions about the data?

Why was the data set created?

REQUIRED: A summary of the intentions with which the data set was developed.

How was the data set created?

1. From what previous works were the data drawn?

2. How were the data generated, processed, and modified?

3. What similar or related data should the user be aware of?

How reliable are the data; what problems remain in the data set?

\section{How can someone get a copy of the data set?}

Are there legal restrictions on access or use of the data?

Access_Constraints:

REQUIRED: Restrictions and legal prerequisites for accessing the data set.

Use_Constraints:

REQUIRED: Restrictions and legal prerequisites for using the data set after access is granted.

1. Who distributes the data set?[Distributor contact information not provided.]

2. What's the catalog number I need to order this data set?

Downloadable Data

3. What legal disclaimers am I supposed to read? 


\section{How can I download or order the data? \\ o Availability in digital form:}

Data format: Size: 0.189

o Cost to order the data:

\section{Who wrote the metadata?}

Dates:

Last modified: 18 -Nov-2005

Metadata author:

REQUIRED: The organization responsible for the metadata information.

c/o REQUIRED: The person responsible for the metadata information.

REQUIRED: The city of the address., REQUIRED: The state or province of the address.

REQUIRED: The ZIP or other postal code of the address.

REQUIRED: The telephone number by which individuals can speak to the organization or individual. (voice)

Metadata standard:

FGDC Content Standards for Digital Geospatial Metadata (FGDC-STD-001-1998)

Metadata extensions used:

- $\quad \leq$ http://www.esri.com/metadata/esriprof80.html>

Generated by mp version 2.8.6 on Fri Nov 18 10:59:49 2005

\section{Gypsy moth defoliation-1989}

Metadata also available as

\section{Frequently-anticipated questions:}

- What does this data set describe?

1. How should this data set be cited?

2. What geographic area does the data set cover?

3. What does it look like?

4. Does the data set describe conditions during a particular time period?

5. What is the general form of this data set?

6. How does the data set represent geographic features?

7. How does the data set describe geographic features? 
- Who produced the data set?

1. Who are the originators of the data set?

2. Who also contributed to the data set?

3. To whom should users address questions about the data?

- Why was the data set created?

- How was the data set created?

1. From what previous works were the data drawn?

2. How were the data generated, processed, and modified?

3. What similar or related data should the user be aware of?

- How reliable are the data; what problems remain in the data set?

1. How well have the observations been checked?

2. How accurate are the geographic locations?

3. How accurate are the heights or depths?

4. Where are the gaps in the data? What is missing?

5. How consistent are the relationships among the data, including topology?

- How can someone get a copy of the data set?

1. Are there legal restrictions on access or use of the data?

2. Who distributes the data?

3. What's the catalog number I need to order this data set?

4. What legal disclaimers am I supposed to read?

5. How can I download or order the data?

- Who wrote the metadata?

\section{What does this data set describe?}

Title: wv_89

Abstract: REQUIRED: A brief narrative summary of the data set.

1. How should this data set be cited?

REQUIRED: The name of an organization or individual that developed the data set., REQUIRED: The date when the data set is published or otherwise made available for release., wv_89.

Online Links:

o IVPERFOR339GRAD14\C\$\fspmapstufflann's stufflwv_89.shp

2. What geographic area does the data set cover?

West_Bounding_Coordinate: -79.750588

East_Bounding_Coordinate: -78.075920

North_Bounding_Coordinate: 39.721913

South_Bounding_Coordinate: 38.864898

3. What does it look like?

4. Does the data set describe conditions during a particular time period? 
Calendar_Date: REQUIRED: The year (and optionally month, or month and day) for which the data set corresponds to the ground.

Currentness_Reference:

REQUIRED: The basis on which the time period of content information is determined.

5. What is the general form of this data set?

Geospatial_Data_Presentation_Form: vector digital data

6. How does the data set represent geographic features?

a. How are geographic features stored in the data set?

This is a Vector data set. It contains the following vector data types (SDTS terminology):

- G-polygon (531)

b. What coordinate system is used to represent geographic features?

Grid_Coordinate_System_Name: Universal Transverse Mercator Universal_Transverse_Mercator:

UTM_Zone_Number: 17

Transverse_Mercator:

Scale_Factor_at_Central_Meridian: 0.999600

Longitude_of_Central_Meridian: -81.000000

Latitude_of_Projection_Origin: 0.000000

False_Easting: 500000.000000

False_Northing: 0.000000

Planar coordinates are encoded using coordinate pair

Abscissae (x-coordinates) are specified to the nearest 0.000256

Ordinates (y-coordinates) are specified to the nearest 0.000256

Planar coordinates are specified in meters

The horizontal datum used is North American Datum of 1983.

The ellipsoid used is Geodetic Reference System 80.

The semi-major axis of the ellipsoid used is 6378137.000000 .

The flattening of the ellipsoid used is $1 / 298.257222$.

7. How does the data set describe geographic features?

WV_89

FID

Internal feature number. (Source: ESRI)

Sequential unique whole numbers that are automatically generated.

Shape

Feature geometry. (Source: ESRI) 
Coordinates defining the features.
AREA
PERIMETER
ACRES
SURVEY_ID1
SURVEY_ID2
SURVEY_ID3
DMG_TYPE1
DMG_TYPE2
DMG_TYPE3
SEVERITY1
SEVERITY2
SEVERITY3
PATTERN1
PATTERN2
PATTERN3
TPA1
TPA2
TPA3
NO_TREES1
NO_TREES2
NO_TREES3
DCA1
DCA2
DCA3
HOST1
HOST2
HOST3
FOR TYPE1
FOR TYPE2
FOR_TYPE3
NOTES
value

\section{Who produced the data set?}

1. Who are the originators of the data set? (may include formal authors, digital compilers, and editors)

o REQUIRED: The name of an organization or individual that developed the data set.

2. Who also contributed to the data set?

3. To whom should users address questions about the data?

Why was the data set created?

REQUIRED: A summary of the intentions with which the data set was developed.

How was the data set created? 
1. From what previous works were the data drawn?

2. How were the data generated, processed, and modified?

3. What similar or related data should the user be aware of?

How reliable are the data; what problems remain in the data set?

How can someone get a copy of the data set?

Are there legal restrictions on access or use of the data?

Access_Constraints:

REQUIRED: Restrictions and legal prerequisites for accessing the data set.

Use_Constraints:

REQUIRED: Restrictions and legal prerequisites for using the data set after access is granted.

1. Who distributes the data set?[Distributor contact information not provided.]

2. What's the catalog number I need to order this data set?

Downloadable Data

3. What legal disclaimers am I supposed to read?

4. How can I download or order the data?

o Availability in digital form:

Data format: Size: 0.457

o Cost to order the data:

\section{Who wrote the metadata?}

Dates:

Last modified: 18-Nov-2005

Metadata author:

REQUIRED: The organization responsible for the metadata information.

c/o REQUIRED: The person responsible for the metadata information.

REQUIRED: The city of the address., REQUIRED: The state or province of the address.

REQUIRED: The ZIP or other postal code of the address.

REQUIRED: The telephone number by which individuals can speak to the organization or individual. (voice)

Metadata standard: 
FGDC Content Standards for Digital Geospatial Metadata (FGDC-STD-001-1998) Metadata extensions used:

- $\quad \leq$ http://www.esri.com/metadata/esriprof80.html>

Generated by mp version 2.8.6 on Fri Nov 18 10:59:30 2005 


\section{Gypsy moth defoliation-1990}

Metadata also available as

Frequently-anticipated questions:

- What does this data set describe?

1. How should this data set be cited?

2. What geographic area does the data set cover?

3. What does it look like?

4. Does the data set describe conditions during a particular time period?

5. What is the general form of this data set?

6. How does the data set represent geographic features?

7. How does the data set describe geographic features?

- Who produced the data set?

1. Who are the originators of the data set?

2. Who also contributed to the data set?

3. To whom should users address questions about the data?

- Why was the data set created?

- How was the data set created?

1. From what previous works were the data drawn?

2. How were the data generated, processed, and modified?

3. What similar or related data should the user be aware of?

- How reliable are the data; what problems remain in the data set?

1. How well have the observations been checked?

2. How accurate are the geographic locations?

3. How accurate are the heights or depths?

4. Where are the gaps in the data? What is missing?

5. How consistent are the relationships among the data, including topology?

- How can someone get a copy of the data set?

1. Are there legal restrictions on access or use of the data?

2. Who distributes the data?

3. What's the catalog number I need to order this data set?

4. What legal disclaimers am I supposed to read?

5. How can I download or order the data?

- Who wrote the metadata?

\section{What does this data set describe?}

Title: wv_90

Abstract: REQUIRED: A brief narrative summary of the data set.

\section{How should this data set be cited?}


REQUIRED: The name of an organization or individual that developed the data set., REQUIRED: The date when the data set is published or otherwise made available for release., wv_90.

Online Links:

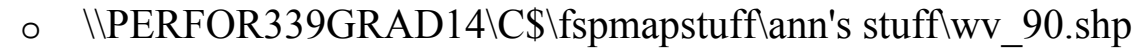

2. What geographic area does the data set cover?

West_Bounding_Coordinate: -79.876664

East_Bounding_Coordinate: -77.747403

North_Bounding_Coordinate: 39.719885

South_Bounding_Coordinate: 38.592932

3. What does it look like?

4. Does the data set describe conditions during a particular time period?

Calendar_Date: REQUIRED: The year (and optionally month, or month and day) for which the data set corresponds to the ground.

Currentness_Reference:

REQUIRED: The basis on which the time period of content information is determined.

5. What is the general form of this data set?

Geospatial_Data_Presentation_Form: vector digital data

6. How does the data set represent geographic features?

a. How are geographic features stored in the data set?

This is a Vector data set. It contains the following vector data types (SDTS terminology):

- G-polygon (1608)

b. What coordinate system is used to represent geographic features?

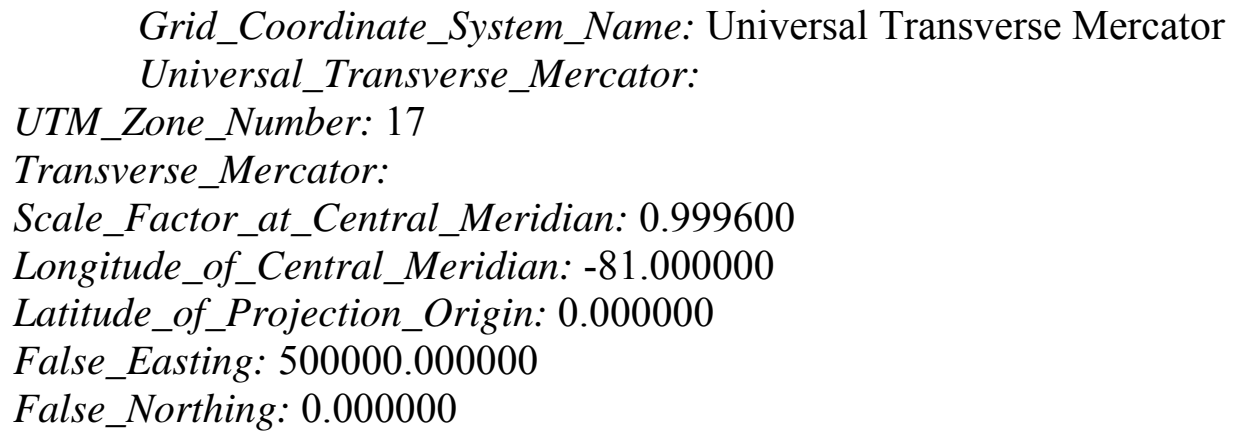

Planar coordinates are encoded using coordinate pair

Abscissae (x-coordinates) are specified to the nearest 0.000256 
Ordinates (y-coordinates) are specified to the nearest 0.000256

Planar coordinates are specified in meters

The horizontal datum used is North American Datum of 1983.

The ellipsoid used is Geodetic Reference System 80.

The semi-major axis of the ellipsoid used is 6378137.000000 .

The flattening of the ellipsoid used is $1 / 298.257222$.

7. How does the data set describe geographic features?

Wv_90

FID

Internal feature number. (Source: ESRI)

Sequential unique whole numbers that are automatically generated.

Shape

Feature geometry. (Source: ESRI)

Coordinates defining the features.
AREA
PERIMETER
INAIPM
SURVEY_ID1
SURVEY_ID2
SURVEY_ID3
DMG_TYPE1
DMG_TYPE2
DMG_TYPE3
SEVERITY1
SEVERITY2
SEVERITY3
PATTERN1
PATTERN2
PATTERN3
TPA1
TPA2
TPA3
NO_TREES1
NO_TREES2
NO_TREES3
DCA1
DCA2
DCA3
HOST1
HOST2
HOST3
FOR TYPE1
FOR TYPE2
FOR_TYPE3
NOTES
value 


\section{Who produced the data set?}

1. Who are the originators of the data set? (may include formal authors, digital compilers, and editors)

o REQUIRED: The name of an organization or individual that developed the data set.

2. Who also contributed to the data set?

3. To whom should users address questions about the data?

Why was the data set created?

REQUIRED: A summary of the intentions with which the data set was developed.

\section{How was the data set created?}

1. From what previous works were the data drawn?

2. How were the data generated, processed, and modified?

3. What similar or related data should the user be aware of?

How reliable are the data; what problems remain in the data set?

\section{How can someone get a copy of the data set?}

Are there legal restrictions on access or use of the data?

Access_Constraints:

REQUIRED: Restrictions and legal prerequisites for accessing the data set.

Use_Constraints:

REQUIRED: Restrictions and legal prerequisites for using the data set after access is granted.

1. Who distributes the data set?[Distributor contact information not provided.]

2. What's the catalog number I need to order this data set?

Downloadable Data

3. What legal disclaimers am I supposed to read?

4. How can I download or order the data?

o Availability in digital form:

Data format: Size: 2.043 


\section{o Cost to order the data:}

\section{Who wrote the metadata?}

Dates:

Last modified: $18-\mathrm{Nov}-2005$

Metadata author:

REQUIRED: The organization responsible for the metadata information.

c/o REQUIRED: The person responsible for the metadata information.

REQUIRED: The city of the address., REQUIRED: The state or province of the address.

REQUIRED: The ZIP or other postal code of the address.

REQUIRED: The telephone number by which individuals can speak to the organization or individual. (voice)

Metadata standard:

FGDC Content Standards for Digital Geospatial Metadata (FGDC-STD-001-1998)

Metadata extensions used:

- $\quad \leq$ http://www.esri.com/metadata/esriprof80.html $>$

Generated by $\underline{\mathrm{mp}}$ version 2.8.6 on Fri Nov 18 10:58:59 2005

\section{Gypsy moth defoliation-1991}

Metadata also available as

\section{Frequently-anticipated questions:}

- What does this data set describe?

1. How should this data set be cited?

2. What geographic area does the data set cover?

3. What does it look like?

4. Does the data set describe conditions during a particular time period?

5. What is the general form of this data set?

6. How does the data set represent geographic features?

7. How does the data set describe geographic features?

- Who produced the data set?

1. Who are the originators of the data set?

2. Who also contributed to the data set?

3. To whom should users address questions about the data?

- Why was the data set created? 
- How was the data set created?

1. From what previous works were the data drawn?

2. How were the data generated, processed, and modified?

3. What similar or related data should the user be aware of?

- How reliable are the data; what problems remain in the data set?

1. How well have the observations been checked?

2. How accurate are the geographic locations?

3. How accurate are the heights or depths?

4. Where are the gaps in the data? What is missing?

5. How consistent are the relationships among the data, including topology?

- How can someone get a copy of the data set?

1. Are there legal restrictions on access or use of the data?

2. Who distributes the data?

3. What's the catalog number I need to order this data set?

4. What legal disclaimers am I supposed to read?

5. How can I download or order the data?

- Who wrote the metadata?

\section{What does this data set describe?}

Title: wv 91

Abstract: REQUIRED: A brief narrative summary of the data set.

\section{How should this data set be cited?}

REQUIRED: The name of an organization or individual that developed the data set., REQUIRED: The date when the data set is published or otherwise made available for release., wv_91.

Online Links:

o IVPERFOR339GRAD14\C\$\fspmapstufflann's stufflwv_91.shp

2. What geographic area does the data set cover?

West_Bounding_Coordinate: -79.865272

East_Bounding_Coordinate: -77.791457

North_Bounding_Coordinate: 39.715275

South_Bounding_Coordinate: 38.476517

3. What does it look like?

4. Does the data set describe conditions during a particular time period?

Calendar_Date: REQUIRED: The year (and optionally month, or month and day) for which the data set corresponds to the ground.

Currentness_Reference:

REQUIRED: The basis on which the time period of content information is determined. 
5. What is the general form of this data set?

Geospatial_Data_Presentation_Form: vector digital data

6. How does the data set represent geographic features?

a. How are geographic features stored in the data set?

This is a Vector data set. It contains the following vector data types (SDTS terminology):

- G-polygon (798)

b. What coordinate system is used to represent geographic features?

Grid_Coordinate_System_Name: Universal Transverse Mercator

Universal_Transverse_Mercator:

UTM_Zone_Number: 17

Transverse_Mercator:

Scale_Factor_at_Central_Meridian: 0.999600

Longitude_of_Central_Meridian: -81.000000

Latitude_of_Projection_Origin: 0.000000

False_Easting: 500000.000000

False_Northing: 0.000000

Planar coordinates are encoded using coordinate pair

Abscissae (x-coordinates) are specified to the nearest 0.000256

Ordinates (y-coordinates) are specified to the nearest 0.000256

Planar coordinates are specified in meters

The horizontal datum used is North American Datum of 1983.

The ellipsoid used is Geodetic Reference System 80.

The semi-major axis of the ellipsoid used is 6378137.000000 .

The flattening of the ellipsoid used is $1 / 298.257222$.

7. How does the data set describe geographic features?

WV_91

FID

Internal feature number. (Source: ESRI)

Sequential unique whole numbers that are automatically generated.

Shape

Feature geometry. (Source: ESRI)

Coordinates defining the features.

\section{AREA}

PERIMETER

ACRES

SURVEY_ID1 


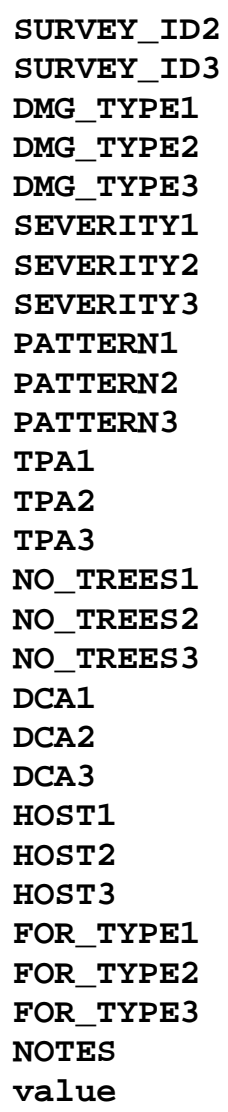

\section{Who produced the data set?}

1. Who are the originators of the data set? (may include formal authors, digital compilers, and editors)

o REQUIRED: The name of an organization or individual that developed the data set.

2. Who also contributed to the data set?

3. To whom should users address questions about the data?

Why was the data set created?

REQUIRED: A summary of the intentions with which the data set was developed.

\section{How was the data set created?}

1. From what previous works were the data drawn?

2. How were the data generated, processed, and modified?

3. What similar or related data should the user be aware of? 
How reliable are the data; what problems remain in the data set?

\section{How can someone get a copy of the data set?}

Are there legal restrictions on access or use of the data?

Access_Constraints:

REQUIRED: Restrictions and legal prerequisites for accessing the data set.

Use_Constraints:

REQUIRED: Restrictions and legal prerequisites for using the data set after access is granted.

1. Who distributes the data set?[Distributor contact information not provided.]

2. What's the catalog number I need to order this data set?

Downloadable Data

3. What legal disclaimers am I supposed to read?

4. How can I download or order the data?

o Availability in digital form:

Data format: Size: 0.811

o Cost to order the data:

\section{Who wrote the metadata?}

Dates:

Last modified: 18-Nov-2005

Metadata author:

REQUIRED: The organization responsible for the metadata information.

c/o REQUIRED: The person responsible for the metadata information.

REQUIRED: The city of the address., REQUIRED: The state or province of the address.

REQUIRED: The ZIP or other postal code of the address.

REQUIRED: The telephone number by which individuals can speak to the organization or individual. (voice)

Metadata standard:

FGDC Content Standards for Digital Geospatial Metadata (FGDC-STD-001-1998)

Metadata extensions used:

- $\quad \leq$ http://www.esri.com/metadata/esriprof80.html $>$ 
Generated by mp version 2.8.6 on Fri Nov 18 10:58:40 2005

\section{Gypsy moth defoliation-1992}

Metadata also available as

Frequently-anticipated questions:

- What does this data set describe?

1. How should this data set be cited?

2. What geographic area does the data set cover?

3. What does it look like?

4. Does the data set describe conditions during a particular time period?

5. What is the general form of this data set?

6. How does the data set represent geographic features?

7. How does the data set describe geographic features?

- Who produced the data set?

1. Who are the originators of the data set?

2. Who also contributed to the data set?

3. To whom should users address questions about the data?

- Why was the data set created?

- How was the data set created?

1. From what previous works were the data drawn?

2. How were the data generated, processed, and modified?

3. What similar or related data should the user be aware of?

- How reliable are the data; what problems remain in the data set?

1. How well have the observations been checked?

2. How accurate are the geographic locations?

3. How accurate are the heights or depths?

4. Where are the gaps in the data? What is missing?

5. How consistent are the relationships among the data, including topology?

- How can someone get a copy of the data set?

1. Are there legal restrictions on access or use of the data?

2. Who distributes the data?

3. What's the catalog number I need to order this data set?

4. What legal disclaimers am I supposed to read?

5. How can I download or order the data?

- Who wrote the metadata?

\section{What does this data set describe?}

Title: wv_92

Abstract: REQUIRED: A brief narrative summary of the data set. 
1. How should this data set be cited?

REQUIRED: The name of an organization or individual that developed the data set., REQUIRED: The date when the data set is published or otherwise made available for release., wv_92.

Online Links:

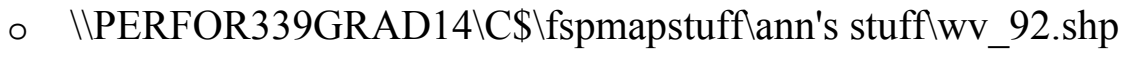

2. What geographic area does the data set cover?

West_Bounding_Coordinate: -79.867021

East_Bounding_Coordinate: -77.748297

North_Bounding_Coordinate: 39.703137

South_Bounding_Coordinate: 38.345082

3. What does it look like?

4. Does the data set describe conditions during a particular time period?

Calendar_Date: REQUIRED: The year (and optionally month, or month and day) for which the data set corresponds to the ground.

Currentness_Reference:

REQUIRED: The basis on which the time period of content information is determined.

5. What is the general form of this data set?

Geospatial_Data_Presentation_Form: vector digital data

6. How does the data set represent geographic features?

a. How are geographic features stored in the data set?

This is a Vector data set. It contains the following vector data types (SDTS terminology):

- G-polygon (301)

b. What coordinate system is used to represent geographic features?

Grid_Coordinate_System_Name: Universal Transverse Mercator

Universal_Transverse_Mercator:

UTM_Zone_Number: 17

Transverse_Mercator:

Scale_Factor_at_Central_Meridian: 0.999600

Longitude_of_Central_Meridian: -81.000000

Latitude_of_Projection_Origin: 0.000000

False_Easting: 500000.000000

False_Northing: 0.000000 
Planar coordinates are encoded using coordinate pair

Abscissae (x-coordinates) are specified to the nearest 0.000256

Ordinates (y-coordinates) are specified to the nearest 0.000256

Planar coordinates are specified in meters

The horizontal datum used is North American Datum of 1983.

The ellipsoid used is Geodetic Reference System 80.

The semi-major axis of the ellipsoid used is 6378137.000000 .

The flattening of the ellipsoid used is $1 / 298.257222$.

7. How does the data set describe geographic features?

WV_92

FID

Internal feature number. (Source: ESRI)

Sequential unique whole numbers that are automatically generated.

Shape

Feature geometry. (Source: ESRI)

Coordinates defining the features.

SURVEY_ID1

SURVEY_ID2

SURVEY_ID3

DMG_TYPE1

DMG_TYPE2

DMG_TYPE3

SEVERITY1

SEVERITY2

SEVERITY3

PATTERN1

PATTERN2

PATTERN3

TPA1

TPA2

TPA3

NO_TREES1

NO_TREES2

NO_TREES3

DCA1

DCA2

DCA3

HOST1

HOST2

HOST3

FOR TYPE1

FOR_TYPE2

FOR_TYPE3

NOTES

value 


\section{Who produced the data set?}

1. Who are the originators of the data set? (may include formal authors, digital compilers, and editors)

o REQUIRED: The name of an organization or individual that developed the data set.

2. Who also contributed to the data set?

3. To whom should users address questions about the data?

Why was the data set created?

REQUIRED: A summary of the intentions with which the data set was developed.

\section{How was the data set created?}

1. From what previous works were the data drawn?

2. How were the data generated, processed, and modified?

3. What similar or related data should the user be aware of?

How reliable are the data; what problems remain in the data set?

\section{How can someone get a copy of the data set?}

Are there legal restrictions on access or use of the data?

Access_Constraints:

REQUIRED: Restrictions and legal prerequisites for accessing the data set.

Use_Constraints:

REQUIRED: Restrictions and legal prerequisites for using the data set after access is granted.

1. Who distributes the data set?[Distributor contact information not provided.]

2. What's the catalog number I need to order this data set?

Downloadable Data

3. What legal disclaimers am I supposed to read?

4. How can I download or order the data?

o Availability in digital form:

Data format: Size: 0.387 


\section{o Cost to order the data:}

\section{Who wrote the metadata?}

Dates:

Last modified: $18-\mathrm{Nov}-2005$

Metadata author:

REQUIRED: The organization responsible for the metadata information.

c/o REQUIRED: The person responsible for the metadata information.

REQUIRED: The city of the address., REQUIRED: The state or province of the address.

REQUIRED: The ZIP or other postal code of the address.

REQUIRED: The telephone number by which individuals can speak to the organization or individual. (voice)

Metadata standard:

FGDC Content Standards for Digital Geospatial Metadata (FGDC-STD-001-1998)

Metadata extensions used:

- $\quad \leq$ http://www.esri.com/metadata/esriprof80.html $>$

Generated by mp version 2.8.6 on Fri Nov 18 10:58:22 2005

\section{Gypsy moth defoliation-1993}

Metadata also available as

\section{Frequently-anticipated questions:}

- What does this data set describe?

1. How should this data set be cited?

2. What geographic area does the data set cover?

3. What does it look like?

4. Does the data set describe conditions during a particular time period?

5. What is the general form of this data set?

6. How does the data set represent geographic features?

7. How does the data set describe geographic features?

- Who produced the data set?

1. Who are the originators of the data set?

2. Who also contributed to the data set?

3. To whom should users address questions about the data?

- Why was the data set created? 
- How was the data set created?

1. From what previous works were the data drawn?

2. How were the data generated, processed, and modified?

3. What similar or related data should the user be aware of?

- How reliable are the data; what problems remain in the data set?

1. How well have the observations been checked?

2. How accurate are the geographic locations?

3. How accurate are the heights or depths?

4. Where are the gaps in the data? What is missing?

5. How consistent are the relationships among the data, including topology?

- How can someone get a copy of the data set?

1. Are there legal restrictions on access or use of the data?

2. Who distributes the data?

3. What's the catalog number I need to order this data set?

4. What legal disclaimers am I supposed to read?

5. How can I download or order the data?

- Who wrote the metadata?

\section{What does this data set describe?}

Title: wv_93

Abstract: REQUIRED: A brief narrative summary of the data set.

\section{How should this data set be cited?}

REQUIRED: The name of an organization or individual that developed the data set., REQUIRED: The date when the data set is published or otherwise made available for release., wv_93.

Online Links:

o IVPERFOR339GRAD14\C\$\fspmapstufflann's stufflwv_93.shp

2. What geographic area does the data set cover?

West_Bounding_Coordinate: -79.999422

East_Bounding_Coordinate: -77.722528

North_Bounding_Coordinate: 39.712558

South_Bounding_Coordinate: 38.424812

3. What does it look like?

4. Does the data set describe conditions during a particular time period?

Calendar_Date: REQUIRED: The year (and optionally month, or month and day) for which the data set corresponds to the ground.

Currentness_Reference:

REQUIRED: The basis on which the time period of content information is determined. 
5. What is the general form of this data set?

Geospatial_Data_Presentation_Form: vector digital data

6. How does the data set represent geographic features?

a. How are geographic features stored in the data set?

This is a Vector data set. It contains the following vector data types (SDTS terminology):

- G-polygon (1248)

b. What coordinate system is used to represent geographic features?

Grid_Coordinate_System_Name: Universal Transverse Mercator Universal_Transverse_Mercator:

UTM_Zone_Number: 17

Transverse_Mercator:

Scale_Factor_at_Central_Meridian: 0.999600

Longitude_of_Central_Meridian: -81.000000

Latitude_of_Projection_Origin: 0.000000

False_Easting: 500000.000000

False_Northing: 0.000000

Planar coordinates are encoded using coordinate pair

Abscissae (x-coordinates) are specified to the nearest 0.000512

Ordinates (y-coordinates) are specified to the nearest 0.000512

Planar coordinates are specified in meters

The horizontal datum used is North American Datum of 1983.

The ellipsoid used is Geodetic Reference System 80.

The semi-major axis of the ellipsoid used is 6378137.000000 .

The flattening of the ellipsoid used is $1 / 298.257222$.

7. How does the data set describe geographic features?

Wv_93

FID

Internal feature number. (Source: ESRI)

Sequential unique whole numbers that are automatically generated.

Shape

Feature geometry. (Source: ESRI)

Coordinates defining the features.

\section{AREA}

PERIMETER

SURVEY_ID1

SURVEY_ID2 


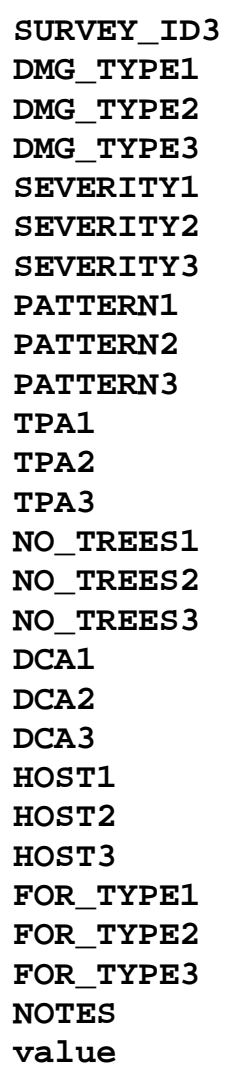

\section{Who produced the data set?}

1. Who are the originators of the data set? (may include formal authors, digital compilers, and editors)

o REQUIRED: The name of an organization or individual that developed the data set.

2. Who also contributed to the data set?

3. To whom should users address questions about the data?

Why was the data set created?

REQUIRED: A summary of the intentions with which the data set was developed.

\section{How was the data set created?}

1. From what previous works were the data drawn?

2. How were the data generated, processed, and modified?

3. What similar or related data should the user be aware of? 
How reliable are the data; what problems remain in the data set?

\section{How can someone get a copy of the data set?}

Are there legal restrictions on access or use of the data?

Access_Constraints:

REQUIRED: Restrictions and legal prerequisites for accessing the data set.

Use_Constraints:

REQUIRED: Restrictions and legal prerequisites for using the data set after access is granted.

1. Who distributes the data set?[Distributor contact information not provided.]

2. What's the catalog number I need to order this data set?

Downloadable Data

3. What legal disclaimers am I supposed to read?

4. How can I download or order the data?

o Availability in digital form:

Data format: Size: 1.464

o Cost to order the data:

\section{Who wrote the metadata?}

Dates:

Last modified: 18-Nov-2005

Metadata author:

REQUIRED: The organization responsible for the metadata information.

c/o REQUIRED: The person responsible for the metadata information.

REQUIRED: The city of the address., REQUIRED: The state or province of the address.

REQUIRED: The ZIP or other postal code of the address.

REQUIRED: The telephone number by which individuals can speak to the organization or individual. (voice)

Metadata standard:

FGDC Content Standards for Digital Geospatial Metadata (FGDC-STD-001-1998)

Metadata extensions used:

- $\quad \leq$ http://www.esri.com/metadata/esriprof80.html $>$ 
Generated by mp version 2.8.6 on Fri Nov 18 10:58:00 2005

\section{Gypsy moth defoliation-1994}

Metadata also available as

Frequently-anticipated questions:

- What does this data set describe?

1. How should this data set be cited?

2. What geographic area does the data set cover?

3. What does it look like?

4. Does the data set describe conditions during a particular time period?

5. What is the general form of this data set?

6. How does the data set represent geographic features?

7. How does the data set describe geographic features?

- Who produced the data set?

1. Who are the originators of the data set?

2. Who also contributed to the data set?

3. To whom should users address questions about the data?

- Why was the data set created?

- How was the data set created?

1. From what previous works were the data drawn?

2. How were the data generated, processed, and modified?

3. What similar or related data should the user be aware of?

- How reliable are the data; what problems remain in the data set?

1. How well have the observations been checked?

2. How accurate are the geographic locations?

3. How accurate are the heights or depths?

4. Where are the gaps in the data? What is missing?

5. How consistent are the relationships among the data, including topology?

- How can someone get a copy of the data set?

1. Are there legal restrictions on access or use of the data?

2. Who distributes the data?

3. What's the catalog number I need to order this data set?

4. What legal disclaimers am I supposed to read?

5. How can I download or order the data?

- Who wrote the metadata?

\section{What does this data set describe?}

Title: wv_94

Abstract: REQUIRED: A brief narrative summary of the data set. 
1. How should this data set be cited?

REQUIRED: The name of an organization or individual that developed the data set., REQUIRED: The date when the data set is published or otherwise made available for release., wv_94.

Online Links:

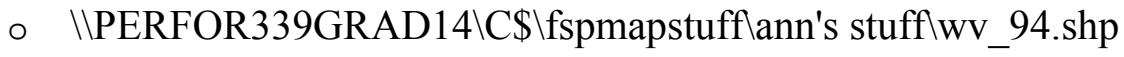

2. What geographic area does the data set cover?

West_Bounding_Coordinate: -79.925570

East_Bounding_Coordinate: -77.722707

North_Bounding_Coordinate: 39.648443

South_Bounding_Coordinate: 38.440748

3. What does it look like?

4. Does the data set describe conditions during a particular time period?

Calendar_Date: REQUIRED: The year (and optionally month, or month and day) for which the data set corresponds to the ground.

Currentness_Reference:

REQUIRED: The basis on which the time period of content information is determined.

5. What is the general form of this data set?

Geospatial_Data_Presentation_Form: vector digital data

6. How does the data set represent geographic features?

a. How are geographic features stored in the data set?

This is a Vector data set. It contains the following vector data types (SDTS terminology):

- G-polygon (399)

b. What coordinate system is used to represent geographic features?

Grid_Coordinate_System_Name: Universal Transverse Mercator

Universal_Transverse_Mercator:

UTM_Zone_Number: 17

Transverse_Mercator:

Scale_Factor_at_Central_Meridian: 0.999600

Longitude_of_Central_Meridian: -81.000000

Latitude_of_Projection_Origin: 0.000000

False_Easting: 500000.000000

False_Northing: 0.000000 
Planar coordinates are encoded using coordinate pair

Abscissae (x-coordinates) are specified to the nearest 0.000512 Ordinates (y-coordinates) are specified to the nearest 0.000512 Planar coordinates are specified in meters

The horizontal datum used is North American Datum of 1983. The ellipsoid used is Geodetic Reference System 80.

The semi-major axis of the ellipsoid used is 6378137.000000 .

The flattening of the ellipsoid used is $1 / 298.257222$.

7. How does the data set describe geographic features?

Wv_94

FID

Internal feature number. (Source: ESRI)

Sequential unique whole numbers that are automatically generated.

Shape

Feature geometry. (Source: ESRI)

Coordinates defining the features.
AREA
PERIMETER
ACRES
SURVEY_ID1
SURVEY_ID2
SURVEY_ID3
DMG_TYPE1
DMG_TYPE2
DMG_TYPE3
SEVERITY1
SEVERITY2
SEVERITY3
PATTERN1
PATTERN2
PATTERN3
TPA1
TPA2
TPA3
NO_TREES1
NO_TREES2
NO_TREES3
DCA1
DCA2
DCA3
HOST1
HOST2
HOST3
FOR_TYPE1
FOR_TYPE2
FOR_TYPE3
NOTES
value 


\section{Who produced the data set?}

1. Who are the originators of the data set? (may include formal authors, digital compilers, and editors)

o REQUIRED: The name of an organization or individual that developed the data set.

2. Who also contributed to the data set?

3. To whom should users address questions about the data?

Why was the data set created?

REQUIRED: A summary of the intentions with which the data set was developed.

\section{How was the data set created?}

1. From what previous works were the data drawn?

2. How were the data generated, processed, and modified?

3. What similar or related data should the user be aware of?

How reliable are the data; what problems remain in the data set?

\section{How can someone get a copy of the data set?}

Are there legal restrictions on access or use of the data?

Access_Constraints:

REQUIRED: Restrictions and legal prerequisites for accessing the data set.

Use_Constraints:

REQUIRED: Restrictions and legal prerequisites for using the data set after access is granted.

1. Who distributes the data set?[Distributor contact information not provided.]

2. What's the catalog number I need to order this data set?

Downloadable Data

3. What legal disclaimers am I supposed to read?

4. How can I download or order the data?

o Availability in digital form: 
Data format: Size: 0.471

o Cost to order the data:

\section{Who wrote the metadata?}

Dates:

Last modified: 18-Nov-2005

Metadata author:

REQUIRED: The organization responsible for the metadata information.

c/o REQUIRED: The person responsible for the metadata information.

REQUIRED: The city of the address., REQUIRED: The state or province of the address.

REQUIRED: The ZIP or other postal code of the address.

REQUIRED: The telephone number by which individuals can speak to the organization or individual. (voice)

Metadata standard:

FGDC Content Standards for Digital Geospatial Metadata (FGDC-STD-001-1998)

Metadata extensions used:

- $\quad \leq \mathrm{http}: / /$ www.esri.com/metadata/esriprof80.html $>$

Generated by mp version 2.8.6 on Fri Nov 18 10:57:36 2005

\section{Gypsy moth defoliation-1995}

Metadata also available as

\section{Frequently-anticipated questions:}

- What does this data set describe?

1. How should this data set be cited?

2. What geographic area does the data set cover?

3. What does it look like?

4. Does the data set describe conditions during a particular time period?

5. What is the general form of this data set?

6. How does the data set represent geographic features?

7. How does the data set describe geographic features?

- Who produced the data set?

1. Who are the originators of the data set?

2. Who also contributed to the data set? 
3. To whom should users address questions about the data?

- Why was the data set created?

- How was the data set created?

1. From what previous works were the data drawn?

2. How were the data generated, processed, and modified?

3. What similar or related data should the user be aware of?

- How reliable are the data; what problems remain in the data set?

1. How well have the observations been checked?

2. How accurate are the geographic locations?

3. How accurate are the heights or depths?

4. Where are the gaps in the data? What is missing?

5. How consistent are the relationships among the data, including topology?

- How can someone get a copy of the data set?

1. Are there legal restrictions on access or use of the data?

2. Who distributes the data?

3. What's the catalog number I need to order this data set?

4. What legal disclaimers am I supposed to read?

5. How can I download or order the data?

- Who wrote the metadata?

\section{What does this data set describe?}

Title: wv_95

Abstract: REQUIRED: A brief narrative summary of the data set.

\section{How should this data set be cited?}

REQUIRED: The name of an organization or individual that developed the data set., REQUIRED: The date when the data set is published or otherwise made available for release., Wv_95.

Online Links:

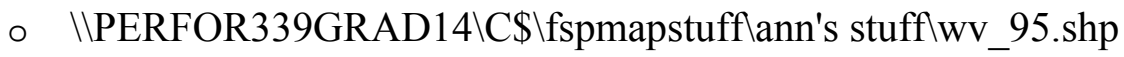

2. What geographic area does the data set cover?

West_Bounding_Coordinate: -80.587821

East_Bounding_Coordinate: -79.149035

North_Bounding_Coordinate: 39.719148

South_Bounding_Coordinate: 38.373993

3. What does it look like?

4. Does the data set describe conditions during a particular time period?

Calendar_Date: REQUIRED: The year (and optionally month, or month and day) for which the data set corresponds to the ground. 
Currentness_Reference:

REQUIRED: The basis on which the time period of content information is determined.

5. What is the general form of this data set?

Geospatial_Data_Presentation_Form: vector digital data

6. How does the data set represent geographic features?

a. How are geographic features stored in the data set?

This is a Vector data set. It contains the following vector data types (SDTS terminology):

- G-polygon (618)

b. What coordinate system is used to represent geographic features?

Grid_Coordinate_System_Name: Universal Transverse Mercator

Universal_Transverse_Mercator:

UTM_Zone_Number: 17

Transverse_Mercator:

Scale_Factor_at_Central_Meridian: 0.999600

Longitude_of_Central_Meridian: -81.000000

Latitude_of_Projection_Origin: 0.000000

False_Easting: 500000.000000

False_Northing: 0.000000

Planar coordinates are encoded using coordinate pair

Abscissae (x-coordinates) are specified to the nearest 0.000256

Ordinates (y-coordinates) are specified to the nearest 0.000256

Planar coordinates are specified in meters

The horizontal datum used is North American Datum of 1983.

The ellipsoid used is Geodetic Reference System 80.

The semi-major axis of the ellipsoid used is 6378137.000000.

The flattening of the ellipsoid used is $1 / 298.257222$.

7. How does the data set describe geographic features?

Wv_95

FID

Internal feature number. (Source: ESRI)

Sequential unique whole numbers that are automatically generated.

Shape

Feature geometry. (Source: ESRI)

Coordinates defining the features. 

AREA
PERIMETER
SURVEY_ID1
SURVEY_ID2
SURVEY_ID3
DMG TYPE1
DMG_TYPE2
DMG_TYPE3
SEVERITY1
SEVERITY2
SEVERITY3
PATTERN1
PATTERN2
PATTERN3
TPA1
TPA2
TPA3
NO_TREES1
NO_TREES2
NO_TREES3
DCA1
DCA2
DCA3
HOST1
HOST2
HOST3
FOR TYPE1
FOR_TYPE2
FOR_TYPE3
NOTES
value

\section{Who produced the data set?}

1. Who are the originators of the data set? (may include formal authors, digital compilers, and editors)

o REQUIRED: The name of an organization or individual that developed the data set.

2. Who also contributed to the data set?

3. To whom should users address questions about the data?

Why was the data set created?

REQUIRED: A summary of the intentions with which the data set was developed.

\section{How was the data set created?}

1. From what previous works were the data drawn?

2. How were the data generated, processed, and modified?

3. What similar or related data should the user be aware of? 
How reliable are the data; what problems remain in the data set?

\section{How can someone get a copy of the data set?}

Are there legal restrictions on access or use of the data?

Access Constraints:

REQUIRED: Restrictions and legal prerequisites for accessing the data set.

Use_Constraints:

REQUIRED: Restrictions and legal prerequisites for using the data set after access is granted.

1. Who distributes the data set?[Distributor contact information not provided.]

2. What's the catalog number I need to order this data set?

Downloadable Data

3. What legal disclaimers am I supposed to read?

4. How can I download or order the data?

o Availability in digital form:

Data format: Size: 0.695

o Cost to order the data:

\section{Who wrote the metadata?}

Dates:

Last modified: 18-Nov-2005

Metadata author:

REQUIRED: The organization responsible for the metadata information.

c/o REQUIRED: The person responsible for the metadata information.

REQUIRED: The city of the address., REQUIRED: The state or province of the address.

REQUIRED: The ZIP or other postal code of the address.

REQUIRED: The telephone number by which individuals can speak to the organization or individual. (voice)

Metadata standard:

FGDC Content Standards for Digital Geospatial Metadata (FGDC-STD-001-1998)

Metadata extensions used:

- $\quad \leq$ http://www.esri.com/metadata/esriprof80.html $>$ 
Generated by mp version 2.8.6 on Fri Nov 18 10:57:10 2005

\section{Gypsy moth defoliation-1996}

Metadata also available as

\section{Frequently-anticipated questions:}

- What does this data set describe?

1. How should this data set be cited?

2. What geographic area does the data set cover?

3. What does it look like?

4. Does the data set describe conditions during a particular time period?

5. What is the general form of this data set?

6. How does the data set represent geographic features?

7. How does the data set describe geographic features?

- Who produced the data set?

1. Who are the originators of the data set?

2. Who also contributed to the data set?

3. To whom should users address questions about the data?

- Why was the data set created?

- How was the data set created?

1. From what previous works were the data drawn?

2. How were the data generated, processed, and modified?

3. What similar or related data should the user be aware of?

- How reliable are the data; what problems remain in the data set?

1. How well have the observations been checked?

2. How accurate are the geographic locations?

3. How accurate are the heights or depths?

4. Where are the gaps in the data? What is missing?

5. How consistent are the relationships among the data, including topology?

- How can someone get a copy of the data set?

1. Are there legal restrictions on access or use of the data?

2. Who distributes the data?

3. What's the catalog number I need to order this data set?

4. What legal disclaimers am I supposed to read?

5. How can I download or order the data?

- Who wrote the metadata?

\section{What does this data set describe?}

Title: wv_96 
Abstract: REQUIRED: A brief narrative summary of the data set.

1. How should this data set be cited?

REQUIRED: The name of an organization or individual that developed the data set., REQUIRED: The date when the data set is published or otherwise made available for release., wv_96.

Online Links:

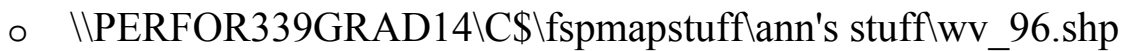

2. What geographic area does the data set cover?

West_Bounding_Coordinate: -80.683987

East_Bounding_Coordinate: -79.488521

North_Bounding_Coordinate: 40.007394

South_Bounding_Coordinate: 38.704871

3. What does it look like?

4. Does the data set describe conditions during a particular time period?

Calendar_Date: REQUIRED: The year (and optionally month, or month and day) for which the data set corresponds to the ground.

Currentness_Reference:

REQUIRED: The basis on which the time period of content information is determined.

5. What is the general form of this data set?

Geospatial_Data_Presentation_Form: vector digital data

6. How does the data set represent geographic features?

a. How are geographic features stored in the data set?

This is a Vector data set. It contains the following vector data types (SDTS terminology):

- G-polygon (343)

b. What coordinate system is used to represent geographic features?

Grid_Coordinate_System_Name: Universal Transverse Mercator

Universal_Transverse_Mercator:

UTM_Zone_Number: 17

Transverse_Mercator:

Scale_Factor_at_Central_Meridian: 0.999600

Longitude_of_Central_Meridian: -81.000000

Latitude_of_Projection_Origin: 0.000000

False_Easting: 500000.000000

False_Northing: 0.000000 
Planar coordinates are encoded using coordinate pair

Abscissae (x-coordinates) are specified to the nearest 0.000256

Ordinates (y-coordinates) are specified to the nearest 0.000256

Planar coordinates are specified in meters

The horizontal datum used is North American Datum of 1983.

The ellipsoid used is Geodetic Reference System 80.

The semi-major axis of the ellipsoid used is 6378137.000000 .

The flattening of the ellipsoid used is $1 / 298.257222$.

7. How does the data set describe geographic features?

WV_96

FID

Internal feature number. (Source: ESRI)

Sequential unique whole numbers that are automatically generated.

Shape

Feature geometry. (Source: ESRI)

Coordinates defining the features.
AREA
PERIMETER
WV_96
WV_96_ID
AIDDS96_ID
RPT_RGN
SURVEY_YR
SURVEY_TYP
DMG_TYPE
SEVERITY
PATTERN
TPA
NO_TREES
DCA
HOST
FOR_TYPE
ACRES
NOTES
GRP
OBJECTID
OBJECTID_1
DAMAGE_ARE
DAMAGE_LEN
value

\section{Who produced the data set?}

1. Who are the originators of the data set? (may include formal authors, digital compilers, and editors) 
o REQUIRED: The name of an organization or individual that developed the data set.

2. Who also contributed to the data set?

3. To whom should users address questions about the data?

Why was the data set created?

REQUIRED: A summary of the intentions with which the data set was developed.

How was the data set created?

1. From what previous works were the data drawn?

2. How were the data generated, processed, and modified?

3. What similar or related data should the user be aware of?

How reliable are the data; what problems remain in the data set?

How can someone get a copy of the data set?

Are there legal restrictions on access or use of the data?

Access_Constraints:

REQUIRED: Restrictions and legal prerequisites for accessing the data set.

Use_Constraints:

REQUIRED: Restrictions and legal prerequisites for using the data set after access is granted.

1. Who distributes the data set?[Distributor contact information not provided.]

2. What's the catalog number I need to order this data set?

Downloadable Data

3. What legal disclaimers am I supposed to read?

4. How can I download or order the data?

o Availability in digital form:

Data format: Size: 0.245

o Cost to order the data: 


\section{Who wrote the metadata?}

Dates:

Last modified: $18-\mathrm{Nov}-2005$

Metadata author:

REQUIRED: The organization responsible for the metadata information.

c/o REQUIRED: The person responsible for the metadata information.

REQUIRED: The city of the address., REQUIRED: The state or province of the address.

REQUIRED: The ZIP or other postal code of the address.

REQUIRED: The telephone number by which individuals can speak to the organization or individual. (voice)

Metadata standard:

FGDC Content Standards for Digital Geospatial Metadata (FGDC-STD-001-1998)

Metadata extensions used:

- $\quad \leq$ http://www.esri.com/metadata/esriprof80.html>

Generated by mp version 2.8.6 on Fri Nov 18 10:56:41 2005

\section{Gypsy moth defoliation-1997}

Metadata also available as

Frequently-anticipated questions:

- What does this data set describe?

1. How should this data set be cited?

2. What geographic area does the data set cover?

3. What does it look like?

4. Does the data set describe conditions during a particular time period?

5. What is the general form of this data set?

6. How does the data set represent geographic features?

7. How does the data set describe geographic features?

- Who produced the data set?

1. Who are the originators of the data set?

2. Who also contributed to the data set?

3. To whom should users address questions about the data?

- Why was the data set created?

- How was the data set created?

1. From what previous works were the data drawn?

2. How were the data generated, processed, and modified?

3. What similar or related data should the user be aware of? 
- How reliable are the data; what problems remain in the data set?

1. How well have the observations been checked?

2. How accurate are the geographic locations?

3. How accurate are the heights or depths?

4. Where are the gaps in the data? What is missing?

5. How consistent are the relationships among the data, including topology?

- How can someone get a copy of the data set?

1. Are there legal restrictions on access or use of the data?

2. Who distributes the data?

3. What's the catalog number I need to order this data set?

4. What legal disclaimers am I supposed to read?

5. How can I download or order the data?

- Who wrote the metadata?

\section{What does this data set describe?}

Title: wv_97

Abstract: REQUIRED: A brief narrative summary of the data set.

\section{How should this data set be cited?}

REQUIRED: The name of an organization or individual that developed the data set., REQUIRED: The date when the data set is published or otherwise made available for release., wv_97.

Online Links:

o IVPERFOR339GRAD14\C\$\fspmapstufflann's stufflwv_97.shp

2. What geographic area does the data set cover?

West_Bounding_Coordinate: -80.680722

East_Bounding_Coordinate: -79.577552

North_Bounding_Coordinate: 39.995649

South_Bounding_Coordinate: 39.477758

3. What does it look like?

4. Does the data set describe conditions during a particular time period?

Calendar_Date: REQUIRED: The year (and optionally month, or month and day) for which the data set corresponds to the ground.

Currentness_Reference:

REQUIRED: The basis on which the time period of content information is determined.

5. What is the general form of this data set?

Geospatial_Data_Presentation_Form: vector digital data 
6. How does the data set represent geographic features?

a. How are geographic features stored in the data set?

This is a Vector data set. It contains the following vector data types (SDTS terminology):

- G-polygon (22)

b. What coordinate system is used to represent geographic features?

Grid_Coordinate_System_Name: Universal Transverse Mercator Universal_Transverse_Mercator:

UTM_Zone_Number: 17

Transverse_Mercator:

Scale_Factor_at_Central_Meridian: 0.999600

Longitude_of_Central_Meridian: -81.000000

Latitude_of_Projection_Origin: 0.000000

False_Easting: 500000.000000

False_Northing: 0.000000

Planar coordinates are encoded using coordinate pair

Abscissae (x-coordinates) are specified to the nearest 0.000256

Ordinates (y-coordinates) are specified to the nearest 0.000256

Planar coordinates are specified in meters

The horizontal datum used is North American Datum of 1983.

The ellipsoid used is Geodetic Reference System 80.

The semi-major axis of the ellipsoid used is 6378137.000000 .

The flattening of the ellipsoid used is $1 / 298.257222$.

7. How does the data set describe geographic features?

Wv_97

FID

Internal feature number. (Source: ESRI)

Sequential unique whole numbers that are automatically generated.

Shape

Feature geometry. (Source: ESRI)

Coordinates defining the features.

AREA

PERIMETER

ACRES

SURVEY_ID1

SURVEY_ID2

SURVEY_ID3

DMG_TYPE1

DMG_TYPE2

DMG_TYPE3 
SEVERITY1

SEVERITY2

SEVERITY3

PATTERN1

PATTERN2

PATTERN3

TPA1

TPA2

TPA3

NO_TREES1

NO_TREES2

NO_TREES3

DCA1

DCA2

DCA3

HOST1

HOST2

HOST3

FOR_TYPE1

FOR_TYPE2

FOR_TYPE3

NOTES

value

Who produced the data set?

1. Who are the originators of the data set? (may include formal authors, digital compilers, and editors)

- REQUIRED: The name of an organization or individual that developed the data set.

2. Who also contributed to the data set?

3. To whom should users address questions about the data?

Why was the data set created?

REQUIRED: A summary of the intentions with which the data set was developed.

How was the data set created?

1. From what previous works were the data drawn?

2. How were the data generated, processed, and modified?

3. What similar or related data should the user be aware of?

How reliable are the data; what problems remain in the data set? 


\section{How can someone get a copy of the data set?}

Are there legal restrictions on access or use of the data?

Access_Constraints:

REQUIRED: Restrictions and legal prerequisites for accessing the data set.

Use_Constraints:

REQUIRED: Restrictions and legal prerequisites for using the data set after access is granted.

1. Who distributes the data set?[Distributor contact information not provided.]

2. What's the catalog number I need to order this data set?

Downloadable Data

3. What legal disclaimers am I supposed to read?

4. How can I download or order the data?

o Availability in digital form:

Data format: Size: 0.016

o Cost to order the data:

\section{Who wrote the metadata?}

Dates:

Last modified: 18-Nov-2005

Metadata author:

REQUIRED: The organization responsible for the metadata information.

c/o REQUIRED: The person responsible for the metadata information.

REQUIRED: The city of the address., REQUIRED: The state or province of the address.

REQUIRED: The ZIP or other postal code of the address.

REQUIRED: The telephone number by which individuals can speak to the organization or individual. (voice)

Metadata standard:

FGDC Content Standards for Digital Geospatial Metadata (FGDC-STD-001-1998)

Metadata extensions used:

- $\quad \leq$ http://www.esri.com/metadata/esriprof80.html>

Generated by mp version 2.8.6 on Fri Nov 18 10:55:59 2005 
This page is intended to be blank. 


\section{Gypsy moth defoliation-1998}

Metadata also available as

Frequently-anticipated questions:

- What does this data set describe?

1. How should this data set be cited?

2. What geographic area does the data set cover?

3. What does it look like?

4. Does the data set describe conditions during a particular time period?

5. What is the general form of this data set?

6. How does the data set represent geographic features?

7. How does the data set describe geographic features?

- Who produced the data set?

1. Who are the originators of the data set?

2. Who also contributed to the data set?

3. To whom should users address questions about the data?

- Why was the data set created?

- How was the data set created?

1. From what previous works were the data drawn?

2. How were the data generated, processed, and modified?

3. What similar or related data should the user be aware of?

- How reliable are the data; what problems remain in the data set?

1. How well have the observations been checked?

2. How accurate are the geographic locations?

3. How accurate are the heights or depths?

4. Where are the gaps in the data? What is missing?

5. How consistent are the relationships among the data, including topology?

- How can someone get a copy of the data set?

1. Are there legal restrictions on access or use of the data?

2. Who distributes the data?

3. What's the catalog number I need to order this data set?

4. What legal disclaimers am I supposed to read?

5. How can I download or order the data?

- Who wrote the metadata?

\section{What does this data set describe?}

Title: wv_98

Abstract: REQUIRED: A brief narrative summary of the data set.

\section{How should this data set be cited?}


REQUIRED: The name of an organization or individual that developed the data set., REQUIRED: The date when the data set is published or otherwise made available for release., wv_98.

Online Links:

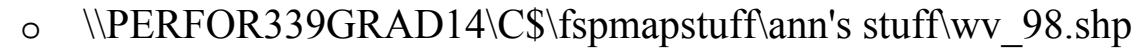

2. What geographic area does the data set cover?

West_Bounding_Coordinate: -80.739557

East_Bounding_Coordinate: -80.525103

North_Bounding_Coordinate: 39.938066

South_Bounding_Coordinate: 39.735288

3. What does it look like?

4. Does the data set describe conditions during a particular time period?

Calendar_Date: REQUIRED: The year (and optionally month, or month and day) for which the data set corresponds to the ground.

Currentness_Reference:

REQUIRED: The basis on which the time period of content information is determined.

5. What is the general form of this data set?

Geospatial_Data_Presentation_Form: vector digital data

6. How does the data set represent geographic features?

a. How are geographic features stored in the data set?

This is a Vector data set. It contains the following vector data types (SDTS terminology):

- G-polygon (43)

b. What coordinate system is used to represent geographic features?

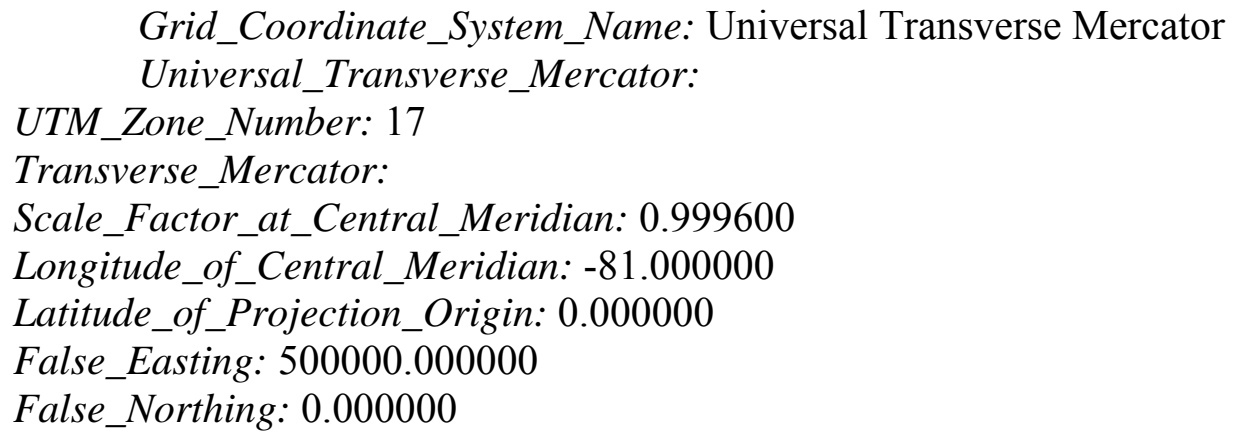

Planar coordinates are encoded using coordinate pair

Abscissae (x-coordinates) are specified to the nearest 0.000032 
Ordinates (y-coordinates) are specified to the nearest 0.000032

Planar coordinates are specified in meters

The horizontal datum used is North American Datum of 1983.

The ellipsoid used is Geodetic Reference System 80.

The semi-major axis of the ellipsoid used is 6378137.000000 .

The flattening of the ellipsoid used is $1 / 298.257222$.

7. How does the data set describe geographic features?

Wv_98

FID

Internal feature number. (Source: ESRI)

Sequential unique whole numbers that are automatically generated.

Shape

Feature geometry. (Source: ESRI)

Coordinates defining the features.
AREA
PERIMETER
WV 98
WV_98_ID
CALCACRAGE
YEAR
SURVEY_TYP
DMG_TYPE1
DMG_TYPE2
DMG_TYPE3
SEVERITY1
SEVERITY2
SEVERITY3
PATTERN1
PATTERN2
PATTERN3
TPA1
TPA2
TPA3
NO_TREES1
NO_TREES2
NO_TREES3
DCA1
DCA2
DCA3
HOST1
HOST2
HOST3
FIPS
COMMENT
ACRES
value 


\section{Who produced the data set?}

1. Who are the originators of the data set? (may include formal authors, digital compilers, and editors)

o REQUIRED: The name of an organization or individual that developed the data set.

2. Who also contributed to the data set?

3. To whom should users address questions about the data?

Why was the data set created?

REQUIRED: A summary of the intentions with which the data set was developed.

\section{How was the data set created?}

1. From what previous works were the data drawn?

2. How were the data generated, processed, and modified?

3. What similar or related data should the user be aware of?

How reliable are the data; what problems remain in the data set?

\section{How can someone get a copy of the data set?}

Are there legal restrictions on access or use of the data?

Access_Constraints:

REQUIRED: Restrictions and legal prerequisites for accessing the data set.

Use_Constraints:

REQUIRED: Restrictions and legal prerequisites for using the data set after access is granted.

1. Who distributes the data set?[Distributor contact information not provided.]

2. What's the catalog number I need to order this data set?

Downloadable Data

3. What legal disclaimers am I supposed to read?

4. How can I download or order the data?

o Availability in digital form:

Data format: Size: 0.034 


\section{o Cost to order the data:}

\section{Who wrote the metadata?}

Dates:

Last modified: $18-\mathrm{Nov}-2005$

Metadata author:

REQUIRED: The organization responsible for the metadata information.

c/o REQUIRED: The person responsible for the metadata information.

REQUIRED: The city of the address., REQUIRED: The state or province of the address.

REQUIRED: The ZIP or other postal code of the address.

REQUIRED: The telephone number by which individuals can speak to the organization or individual. (voice)

Metadata standard:

FGDC Content Standards for Digital Geospatial Metadata (FGDC-STD-001-1998)

Metadata extensions used:

- $\quad \leq \mathrm{http}: / /$ www.esri.com/metadata/esriprof80.html $>$

Generated by mp version 2.8.6 on Fri Nov 18 10:55:37 2005

\section{Annual Aerial Survey Spatial Database - 2000}

Metadata also available as

\section{Frequently-anticipated questions:}

- What does this data set describe?

1. How should this data set be cited?

2. What geographic area does the data set cover?

3. What does it look like?

4. Does the data set describe conditions during a particular time period?

5. What is the general form of this data set?

6. How does the data set represent geographic features?

7. How does the data set describe geographic features?

- Who produced the data set?

1. Who are the originators of the data set?

2. Who also contributed to the data set?

3. To whom should users address questions about the data?

- Why was the data set created?

- How was the data set created?

1. From what previous works were the data drawn? 
2. How were the data generated, processed, and modified?

3. What similar or related data should the user be aware of?

- How reliable are the data; what problems remain in the data set?

1. How well have the observations been checked?

2. How accurate are the geographic locations?

3. How accurate are the heights or depths?

4. Where are the gaps in the data? What is missing?

5. How consistent are the relationships among the data, including topology?

- How can someone get a copy of the data set?

1. Are there legal restrictions on access or use of the data?

2. Who distributes the data?

3. What's the catalog number I need to order this data set?

4. What legal disclaimers am I supposed to read?

5. How can I download or order the data?

- Who wrote the metadata?

\section{What does this data set describe?}

Title: Annual Aerial Survey Spatial Database - 2000

Abstract:

This dataset is a compilation of year 2000 annual insect and disease aerial detection surveys for the Regions that comprise the 48 contiguous states. The aerial surveys are comprised mainly of sketch-mapped data that has been converted to digital form. Aerial sketchmaps are an efficient and economical method of detecting and monitoring forest health over large areas.

1. How should this data set be cited?

Forest Health Technology Enterprise Team - USDA Forest Service, 20010803, Annual Aerial Survey Spatial Database - 2000.

Online Links:

o IIPERFOR339GRAD14\C\$ \ads\ads_wv00.shp

2. What geographic area does the data set cover?

West_Bounding_Coordinate: -126.940432

East_Bounding_Coordinate: -65.704351

North_Bounding_Coordinate: 51.396525

South_Bounding_Coordinate: 26.570382

3. What does it look like?

4. Does the data set describe conditions during a particular time period?

Calendar_Date: 2000

Currentness_Reference: 2000 
5. What is the general form of this data set?

Geospatial_Data_Presentation_Form: vector digital data

6. How does the data set represent geographic features?

a. How are geographic features stored in the data set?

This is a Vector data set. It contains the following vector data types (SDTS terminology):

- G-polygon (1147)

b. What coordinate system is used to represent geographic features?

The map projection used is Albers Conical Equal Area.

Projection parameters:

Standard_Parallel: 29.500000

Standard_Parallel: 45.500000

Longitude_of_Central_Meridian:-96.000000

Latitude_of_Projection_Origin: 23.000000

False_Easting: 0.000000

False_Northing: 0.000000

Planar coordinates are encoded using coordinate pair

Abscissae (x-coordinates) are specified to the nearest 0.002210

Ordinates (y-coordinates) are specified to the nearest 0.002210

Planar coordinates are specified in meters

The horizontal datum used is D_Clarke_1866.

The ellipsoid used is Clarke 1866 .

The semi-major axis of the ellipsoid used is 6378206.400000 .

The flattening of the ellipsoid used is $1 / 294.978698$.

Vertical_Coordinate_System_Definition:

Altitude_System_Definition:

Altitude_Resolution: 1.000000

Altitude_Encoding_Method:

Explicit elevation coordinate included with horizontal coordinates

7. How does the data set describe geographic features?

ads_Wv00

OBJECTID

ArcSDE layer definition

\begin{tabular}{|c|c|}
\hline Value & Definition \\
\hline polygon & \\
\hline
\end{tabular}

DMG_ID

Feature geometry. (Source: ESRI) 
Coordinates defining the features.

RPT_RGN

USFS Region that reported the polygon (Source: Aerial Survey Geographic Information System Handbook, USDA Forest Service, January 2001)

\begin{tabular}{|l|l|}
\hline Value & \multicolumn{1}{|c|}{ Definition } \\
\hline 1 & Region 1 \\
\hline 2 & Region 2 \\
\hline 3 & Region 3 \\
\hline 4 & Region 4 \\
\hline 5 & Region 5 \\
\hline 6 & Region 6 \\
\hline 8 & Region 8 \\
\hline 9 & Northeastern Area \\
\hline \multicolumn{2}{|l|}{ SURVEY_YR } \\
\hline
\end{tabular}

Year in which survey was conducted (Source: Aerial Survey Geographic Information System Handbook, USDA Forest Service, January 2001)

\begin{tabular}{|l|l|}
\hline Value & Definition \\
\hline 2000 & \\
\hline
\end{tabular}

SURVEY_ID

ID number assigned for unique polygons within each RPT_RGN (Source: Aerial Survey Geographic Information System Handbook, USDA Forest Service, January 2001) DMG_TYPE

Damage type identification code (Source: Aerial Survey Geographic Information System Handbook, USDA Forest Service, January 2001)

\begin{tabular}{|l|l|}
\hline Value & \multicolumn{1}{|c|}{ Definition } \\
\hline-1 & No Data \\
\hline 1 & Defoliation \\
\hline 2 & Mortality \\
\hline 3 & Discoloration \\
\hline 4 & Dieback \\
\hline 5 & Topkill \\
\hline 6 & Branch Breakage \\
\hline 7 & Main Stem Broken/Uprooted \\
\hline 8 & Brach Flagging \\
\hline 9 & No Damage \\
\hline
\end{tabular}


\begin{tabular}{|l|l|}
\hline 10 & Other damage \\
\hline
\end{tabular}

SEVERITY

Defoliation severity code (Source: Aerial Survey Geographic Information System

Handbook, USDA Forest Service, January 2001)

\begin{tabular}{|l|l|}
\hline Value & \multicolumn{1}{|c|}{ Definition } \\
\hline-1 & No Data \\
\hline 1 & Low (Wqual to or Less than $50 \%$ defoliaton) \\
\hline 2 & High (More than 50\% defoliation) \\
\hline
\end{tabular}

\section{PATTERN}

Defoliation pattern code (Source: Aerial Survey Geographic Information System Handbook, USDA Forest Service, January 2001)

\begin{tabular}{|l|l|}
\hline Value & \multicolumn{1}{c|}{ Definition } \\
\hline-1 & No Data \\
\hline 1 & $\begin{array}{l}\text { Host type or species is }>50 \% \text { and the damage is contiguous (relatively } \\
\text { continuous) }\end{array}$ \\
\hline 2 & $\begin{array}{l}\text { Host type or species is }>50 \% \text { and damage is patchy (concentrated in discrete } \\
\text { pockets or individual trees) }\end{array}$ \\
\hline 3 & Host type or species $<50 \%$ and damge in continuous \\
\hline 4 & Host type or species $<50 \%$ and damage is scattered \\
\hline TPA &
\end{tabular}

Dead trees per acre - a measure of mortality (Source: Aerial Survey Geographic

Information System Handbook, USDA Forest Service, January 2001)

\begin{tabular}{|l|l|}
\hline \multicolumn{2}{|c|}{ Range of values } \\
\hline Minimum: & 0 \\
\hline Maximum: & 9999.99 \\
\hline NO_TREES \\
\hline
\end{tabular}

Number of dead trees detected - measure of mortality (Source: Aerial Survey Geographic Information System Handbook, USDA Forest Service, January 2001)

\begin{tabular}{|l|l|}
\hline \multicolumn{2}{|c|}{ Range of values } \\
\hline Minimum: & 0 \\
\hline Maximum: & 9999999 \\
\hline DCA
\end{tabular}

Damage-causing agent code (Source: FSVeg Field Sampled Vegetation Data Dictionary Version 1.3(March 1999) and Aerial Survey Geographic Information System Handbook, USDA Forest Service, January 2001)

\begin{tabular}{|l|l|}
\hline \multicolumn{1}{|c|}{ Value } & \multicolumn{1}{c|}{ Definition } \\
\hline 99999 & No Data \\
\hline 0 to 999999 & User-defined \\
\hline
\end{tabular}


HOST

Host tree species code (Source: USDA Forest Service, Environmental Monitoring and Assessment Program (EMAP) FHM Manual (Eastern and Western), Appendix A and Aerial Survey Geographic Information System Handbook, USDA Forest Service, January 2001)

\begin{tabular}{|l|l|}
\hline \multicolumn{1}{|c|}{ Value } & Definition \\
\hline-1 & No Data \\
\hline 0 to 9999 & User defined \\
\hline FOR_TYPE
\end{tabular}

Forest Type Code (Source: USDA Forest Service, Environmental Monitoring and Assessment Program (EMAP) FHM Manual (Eastern and Western), Appendix C and Aerial Survey Geographic Information System Handbook, USDA Forest Service, January 2001)

\begin{tabular}{|l|l|}
\hline \multicolumn{1}{|c|}{ Value } & \multicolumn{1}{c|}{ Definition } \\
\hline-1 & No Data \\
\hline 0 to 9999 & User defined \\
\hline ACRES & \\
\hline
\end{tabular}

Area in acres of the polygon (Source: Aerial Survey Geographic Information System Handbook, USDA Forest Service, January 2001)

\begin{tabular}{|l|l|}
\hline \multicolumn{1}{|c|}{ Value } & \multicolumn{1}{c|}{ Definition } \\
\hline-1 & No Data \\
\hline 0 to 999999.99 & User defined (can be calculated from AREA attribute) \\
\hline GRP
\end{tabular}

Used to identify which attribute group the original record came from (can be used to prevent double-counting)

\begin{tabular}{|l|l|}
\hline Value & \multicolumn{1}{|c|}{ Definition } \\
\hline 1 & Attibute group 1 - first record for this polygon \\
\hline 2 & Attribute group 2 - second record for this polygon \\
\hline 3 & Attribute group 3 - third record for this polygon \\
\hline FID &
\end{tabular}

Internal feature number. (Source: ESRI)

Sequential unique whole numbers that are automatically generated.

NOTES

Notes or comments (Source: Aerial Survey Geographic Information System Handbook, USDA Forest Service, January 2001)

Shape

Feature geometry. (Source: ESRI)

Coordinates defining the features. 
SHAPE

Feature geometry. (Source: ESRI)

Coordinates defining the features.

CAT_RGN_ID

(Source: ESRI)

SHAPE_AREA

Area of feature in internal units squared. (Source: ESRI)

Positive real numbers that are automatically generated.

SHAPE LEN

COMMON NAM

SCIENTIFIC

\section{Who produced the data set?}

1. Who are the originators of the data set? (may include formal authors, digital compilers, and editors)

o Forest Health Technology Enterprise Team - USDA Forest Service

2. Who also contributed to the data set?

3. To whom should users address questions about the data?

Ross Pywell

USDA Forest Service, Forest Health Protection, Forest Health Technology Enterprise

Team

Program Manager, GIS and Spatial Analysis

2150 Centre Ave

Fort Collins, CO 80526

USA

\section{Why was the data set created?}

To provide a single source for all aerially detected insect, disease, and abiotic forest damage data to facilitate national and multi-regional level reporting of damage for both Forest Health Monitoring and Foest Health Protection.

\section{How was the data set created?}

1. From what previous works were the data drawn?

(source 1 of 11)

Lawrence Stipe, Entomologist, Region 1 Aerial Insect and Disease Detection Survey for insect and disease activity: 2000 . 
Other_Citation_Details:

Forest Service - USDA Missoula, MT

Type_of_Source_Media: ArcInfo export files

Source_Scale_Denominator: unknown

(source 2 of 11)

Erik Johnson, Aerial Survey Program Manager, Region 2 Aerial Insect and Disease

Detection Survey for insect and disease activity: 2000.

Other_Citation_Details:

Forest Service - USDA Denver, CO

Type_of_Source_Media: ArcInfo export files

Source_Scale_Denominator: 100,000

(source 3 of 11)

Steve Dudley, Biological Technician, Region 3, Arizona - Aerial Insect and Disease

Detection Survey for insect and disease activity: 2000.

Other_Citation_Details:

Forest Service - USDA Flagstaff, AZ

Type_of_Source_Media: ArcInfo export files

Source_Scale_Denominator: unknown

(source 4 of 11)

Terry Rogers, Entomologist, Region 3, New Mexico - Aerial Insect and Disease

Detection Survey for insect and disease activity: 2000.

Other_Citation_Details:

Forest Service - USDA

Albuquerque, NM

Type_of_Source_Media: ArcInfo export files

Source_Scale_Denominator: 100,000

(source 5 of 11)

Dick Halsey, GIS Specialist, Region 4 Aerial Insect and Disease Detection Survey for insect and disease activity: 2000.

Other_Citation_Details:

Forest Service - USDA Boise, ID

Type_of_Source_Media: ArcInfo export files

Source_Scale_Denominator: 100,000

(source 6 of 11)

Lisa Levien, Remote Sensing Specialist, Region 5 Aerial Insect and Disease Detection

Survey for insect and disease activity: 2000.

Other_Citation_Details:

Forest Service - USDA Sacramento, CA

Type_of_Source_Media: ArcInfo export files

Source_Scale_Denominator: unknown

(source 7 of 11)

Julie Johnson, GIS Specialist, Region 6 Aerial Insect and Disease Detection Survey for insect and disease activity: 2000.

Other_Citation_Details:

Forest Service - USDA Portland, OR

Type_of_Source_Media: ArcInfo export files

Source_Scale_Denominator: unknown 
(source 8 of 11)

Edwin Yockey, Biological Scientist, Region 8 Aerial Insect and Disease Detection

Survey for insect and disease activity: 2000.

Other_Citation_Details:

Forest Service - USDA Asheville, NC

Type_of_Source_Media: ArcInfo export files

Source_Scale_Denominator: 100,000 and 126,720 and others unknown

(source 9 of 11)

Tom Luther, Forester, Northeastern Area, Durham Field Office, Aerial Insect and

Disease Detection Survey for insect and disease activity: 2000.

Other_Citation_Details:

Forest Service - USDA Durham, NH

Type_of_Source_Media: ArcInfo export files

Source_Scale_Denominator: unknown

(source 10 of 11)

Steketee, Ann, Northeastern Area, Morgantown Field Office, Aerial Insect and Disease

Detection Survey for insect and disease activity: 2000.

Other_Citation_Details:

Forest Service - USDA Mogantown, WV

Type_of_Source_Media: ArcView shapefiles

Source_Scale_Denominator: unknown

(source 11 of 11)

Quinn Chavez, Computer Systems Analyst, Northeastern Area, St. Paul Field Office,

Aerial Insect and Disease Detection Survey for insect and disease activity: 2000.

Other_Citation_Details:

Forest Service - USDA St. Paul, MN

Type_of_Source_Media: ArcInfo export files

Source_Scale_Denominator: unknown

\section{How were the data generated, processed, and modified?}

(process 1 of 5)

When digital data is recieved, it is first checked for proper projection, polygon label errors and dangling nodes. If needed, data is reprojected into Albers and label errors and dangling nodes are fixed. In some cases, a Region will submit several coverages. These are appended together to create a single coverage for each region.

Person who carried out this activity:

Jeanine Pascke

INTECS International Inc, for USDA Forest Service, FHP, FHTET

GIS/Image Processing Specialist

2150 Centre Ave

Fort Collins, CO 80526

USA

(process 2 of 5)

Attributes are checked for adherence to the national standards and corrected if needed.

Within each Regional coverage, the coverage ID is recalculated to be a unique number 
for each record. It is calculated by taking the internal ArcInfo "\#" number and subtracting one. Three additional attributes are added to all coverages to create a combination of attributes that ensure uniqueness once the data is normalized and loaded into SDE. They are ""RPT_RGN","SURVEY_YR" and "GRP". Once all Regional coverages are complete, they are saved as shapefiles. All shapefiles are then "merged" into a single shapefile using the ArcView 3.2a geoprocessing wizard. From that large shapefile, 3 separate shapefiles are created, one for each "GRP" attribute.

Person who carried out this activity:

Jeanine Paschke

INTECS International Inc., for USDA Forest Service, FHP, FHTET

GIS/Image Processing Specialist

(process 3 of 5)

The 3 shapefiles created in the previous step are normalized and loaded into SDE. In the Arcinfo source coverage, there is one record for each polygon or shape. That record can hold information for more that one pest occurring on that same site by using the appropriately numbered attribute (dca1, dca2, dca3, etc). When the data is loaded into SDE, that one record with repeated attributes is converted into several records with nonrepeating attributes. This is a much more efficient way to store the data in a relational database environment and it is also easier to query.

Person who carried out this activity:

Jeanine Paschke

INTECS International Inc., for USDA Forest Service, FHP, FHTET

GIS/Image Processing Specialist

(process 4 of 5)

Dataset copied.

Data sources used in this process:

o Server=sv7.wo.fs.fed.us; Service=esri_sde; Database=idb.cell3.wo; User=jpaschke; Version=SDE.DEFAULT

(process 5 of 5)

Dataset copied.

Data sources used in this process:

o Server $=$ sv3.ftcol.wo.fs.fed.us; Service $=$ esri_sde; Database $=i d b$; User $=$ fssde; Version=FSSDE.FSSDE

3. What similar or related data should the user be aware of?

\section{How reliable are the data; what problems remain in the data set?}


1. How well have the observations been checked?

2. How accurate are the geographic locations?

3. How accurate are the heights or depths?

4. Where are the gaps in the data? What is missing?

5. How consistent are the relationships among the observations, including topology?

\section{How can someone get a copy of the data set?}

Are there legal restrictions on access or use of the data?

Access_Constraints:

Users need to exercise caution regarding the spatial accuracy of these data due to the subjective nature of aerial sketchmapping and the varying scales of source materials.

Use_Constraints:

Data may be viewed and used upon request. Data should not be changed by anyone other than the originators or FHTET. The USDA Forest Service does not guarantee accuracy of these data.

1. Who distributes the data set?[Distributor contact information not provided.]

2. What's the catalog number I need to order this data set?

Downloadable Data

3. What legal disclaimers am I supposed to read?

4. How can I download or order the data?

0 Availability in digital form:

Data format: Size: 0.801

o Cost to order the data:

\section{Who wrote the metadata?}

Dates:

Last modified: 18 -Nov-2005

Metadata author:

USDA Forest Service, Forest Health Technology Enterprise Team

c/o REQUIRED: The person responsible for the metadata information.

2150 Centre Ave

Fort Collins, CO 80526

REQUIRED: The telephone number by which individuals can speak to the organization or individual. (voice)

Metadata standard: 
FGDC Content Standards for Digital Geospatial Metadata (FGDC-STD-001-1998) Metadata extensions used:

- $\quad<\mathrm{http}: / / \mathrm{www}$.esri.com/metadata/esriprof80.html $>$

- $\leq \mathrm{http} / /$ www.esri.com/metadata/esriprof80.html $>$

- $\quad<$ http://www.esri.com/metadata/esriprof80.html $>$

Generated by mp version 2.8.6 on Fri Nov 18 10:52:34 2005

\section{Gypsy moth defoliation-2001}

Metadata also available as

\section{Frequently-anticipated questions:}

- What does this data set describe?

1. How should this data set be cited?

2. What geographic area does the data set cover?

3. What does it look like?

4. Does the data set describe conditions during a particular time period?

5. What is the general form of this data set?

6. How does the data set represent geographic features?

7. How does the data set describe geographic features?

- Who produced the data set?

1. Who are the originators of the data set?

2. Who also contributed to the data set?

3. To whom should users address questions about the data?

- Why was the data set created?

- How was the data set created?

1. From what previous works were the data drawn?

2. How were the data generated, processed, and modified?

3. What similar or related data should the user be aware of?

- How reliable are the data; what problems remain in the data set?

1. How well have the observations been checked?

2. How accurate are the geographic locations?

3. How accurate are the heights or depths?

4. Where are the gaps in the data? What is missing?

5. How consistent are the relationships among the data, including topology?

- How can someone get a copy of the data set?

1. Are there legal restrictions on access or use of the data?

2. Who distributes the data?

3. What's the catalog number I need to order this data set?

4. What legal disclaimers am I supposed to read?

5. How can I download or order the data?

- Who wrote the metadata? 


\section{What does this data set describe?}

Title: ads_wv01

Abstract:

This dataset is a compilation of year 2001 annual insect and disease aerial detection surveys for the Regions that comprise the 48 contiguous states. The aerial surveys are comprised mainly of sketch-mapped data that has been converted to digital form. Aerial sketchmaps are an efficient and economical method of detecting and monitoring forest health over large areas.

1. How should this data set be cited?

Forest Health Technology Enterprise Team - USDA Forest Service, 20010803, ads_wv01.

Online Links:

o IVPERFOR339GRAD14\C\$\ads\ads_wv01.shp

2. What geographic area does the data set cover?

West_Bounding_Coordinate: -127.001641

East_Bounding_Coordinate: -65.706014

North_Bounding_Coordinate: 51.392880

South_Bounding_Coordinate: 26.744200

3. What does it look like?

4. Does the data set describe conditions during a particular time period?

Calendar_Date: 2001

Currentness_Reference: 2001

5. What is the general form of this data set?

Geospatial_Data_Presentation_Form: vector digital data

6. How does the data set represent geographic features?

a. How are geographic features stored in the data set?

This is a Vector data set. It contains the following vector data types (SDTS terminology):

- G-polygon (782)

b. What coordinate system is used to represent geographic features?

The map projection used is Albers Conical Equal Area. 
Projection parameters:

Standard_Parallel: 29.500000

Standard_Parallel: 45.500000

Longitude_of_Central_Meridian:-96.000000

Latitude_of_Projection_Origin: 23.000000

False_Easting: 0.000000

False_Northing: 0.000000

Planar coordinates are encoded using coordinate pair

Abscissae (x-coordinates) are specified to the nearest 0.002210

Ordinates (y-coordinates) are specified to the nearest 0.002210

Planar coordinates are specified in meters

The horizontal datum used is D_Clarke 1866.

The ellipsoid used is Clarke $18 \overline{6} 6$.

The semi-major axis of the ellipsoid used is 6378206.400000 .

The flattening of the ellipsoid used is 1/294.978698.

Vertical_Coordinate_System_Definition:

Altitude_System_Definition:

Altitude_Resolution: 1.000000

Altitude_Encoding_Method:

Explicit elevation coordinate included with horizontal coordinates

7. How does the data set describe geographic features?

ads_Wv01

OBJECTID

ArcSDE layer definition

\begin{tabular}{|l|l|}
\hline Value & Definition \\
\hline polygon & \\
\hline DMG_ID &
\end{tabular}

Feature geometry. (Source: ESRI)

Coordinates defining the features.

RPT_RGN

USFS Region that reported the polygon (Source: Aerial Survey Geographic Information System Handbook, USDA Forest Service, January 2001)

\begin{tabular}{|l|l|}
\hline Value & \multicolumn{1}{|c|}{ Definition } \\
\hline 1 & Region 1 \\
\hline 2 & Region 2 \\
\hline 3 & Region 3 \\
\hline 4 & Region 4 \\
\hline 5 & Region 5 \\
\hline
\end{tabular}




\begin{tabular}{|l|l|}
\hline 6 & Region 6 \\
\hline 8 & Region 8 \\
\hline 9 & Northeastern Area \\
\hline
\end{tabular}

SURVEY_YR

Year in which survey was conducted (Source: Aerial Survey Geographic Information System Handbook, USDA Forest Service, January 2001)

\begin{tabular}{|l|l|}
\hline Value & Definition \\
\hline 2001 & \\
\hline
\end{tabular}

SURVEY_ID

ID number assigned for unique polygons within each RPT_RGN (Source: Aerial Survey Geographic Information System Handbook, USDA Forest Service, January 2001) DMG_TYPE

Damage type identification code (Source: Aerial Survey Geographic Information System Handbook, USDA Forest Service, January 2001)

\begin{tabular}{|l|l|}
\hline Value & \multicolumn{1}{|c|}{ Definition } \\
\hline-1 & No Data \\
\hline 1 & Defoliation \\
\hline 2 & Mortality \\
\hline 3 & Discoloration \\
\hline 4 & Dieback \\
\hline 5 & Topkill \\
\hline 6 & Branch Breakage \\
\hline 7 & Main Stem Broken/Uprooted \\
\hline 8 & Brach Flagging \\
\hline 9 & No Damage \\
\hline 10 & Other damage \\
\hline SEVERITY \\
\hline
\end{tabular}

Defoliation severity code (Source: Aerial Survey Geographic Information System Handbook, USDA Forest Service, January 2001)

\begin{tabular}{|l|l|}
\hline Value & \multicolumn{1}{|c|}{ Definition } \\
\hline-1 & No Data \\
\hline 1 & Low (Wqual to or Less than $50 \%$ defoliaton) \\
\hline 2 & High (More than $50 \%$ defoliation) \\
\hline \multicolumn{2}{|l}{ PATTERN }
\end{tabular}

Defoliation pattern code (Source: Aerial Survey Geographic Information System Handbook, USDA Forest Service, January 2001)

Value Definition




\begin{tabular}{|l|l|}
\hline-1 & No Data \\
\hline 1 & $\begin{array}{l}\text { Host type or species is }>50 \% \text { and the damage is contiguous (relatively } \\
\text { continuous) }\end{array}$ \\
\hline 2 & $\begin{array}{l}\text { Host type or species is }>50 \% \text { and damage is patchy (concentrated in discrete } \\
\text { pockets or individual trees) }\end{array}$ \\
\hline 3 & Host type or species $<50 \%$ and damge in continuous \\
\hline 4 & Host type or species $<50 \%$ and damage is scattered \\
\hline
\end{tabular}

TPA

Dead trees per acre - a measure of mortality (Source: Aerial Survey Geographic

Information System Handbook, USDA Forest Service, January 2001)

\begin{tabular}{|l|l|}
\hline \multicolumn{2}{|c|}{ Range of values } \\
\hline Minimum: & 0 \\
\hline Maximum: & 9999.99 \\
\hline NO_tREES \\
\hline
\end{tabular}

Number of dead trees detected - measure of mortality (Source: Aerial Survey Geographic Information System Handbook, USDA Forest Service, January 2001)

\begin{tabular}{|l|l|}
\hline \multicolumn{2}{|c|}{ Range of values } \\
\hline Minimum: & 0 \\
\hline Maximum: & 9999999 \\
\hline DCA
\end{tabular}

Damage-causing agent code (Source: FSVeg Field Sampled Vegetation Data Dictionary Version 1.3(March 1999) and Aerial Survey Geographic Information System Handbook, USDA Forest Service, January 2001)

\begin{tabular}{|l|l|}
\hline \multicolumn{1}{|c|}{ Value } & \multicolumn{1}{c|}{ Definition } \\
\hline 99999 & No Data \\
\hline 0 to 999999 & User-defined \\
\hline HOST &
\end{tabular}

Host tree species code (Source: USDA Forest Service, Environmental Monitoring and Assessment Program (EMAP) FHM Manual (Eastern and Western), Appendix A and Aerial Survey Geographic Information System Handbook, USDA Forest Service, January 2001)

\begin{tabular}{|l|l|}
\hline \multicolumn{1}{|c|}{ Value } & Definition \\
\hline-1 & No Data \\
\hline 0 to 9999 & User defined \\
\hline FOR_TYPE &
\end{tabular}

Forest Type Code (Source: USDA Forest Service, Environmental Monitoring and Assessment Program (EMAP) FHM Manual (Eastern and Western), Appendix C and Aerial Survey Geographic Information System Handbook, USDA Forest Service, January 2001) 


\begin{tabular}{|l|l|}
\hline \multicolumn{1}{|c|}{ Value } & \multicolumn{1}{|c|}{ Definition } \\
\hline-1 & No Data \\
\hline 0 to 9999 & User defined \\
\hline
\end{tabular}

Area in acres of the polygon (Source: Aerial Survey Geographic Information System Handbook, USDA Forest Service, January 2001)

\begin{tabular}{|l|l|}
\hline \multicolumn{1}{|c|}{ Value } & \multicolumn{1}{c|}{ Definition } \\
\hline-1 & No Data \\
\hline 0 to 999999.99 & User defined (can be calculated from AREA attribute) \\
\hline GRP
\end{tabular}

Used to identify which attribute group the original record came from (can be used to prevent double-counting)

\begin{tabular}{|l|l|}
\hline Value & \multicolumn{1}{|c|}{ Definition } \\
\hline 1 & Attibute group 1 - first record for this polygon \\
\hline 2 & Attribute group 2 - second record for this polygon \\
\hline 3 & Attribute group 3 - third record for this polygon \\
\hline FID
\end{tabular}

Internal feature number. (Source: ESRI)

Sequential unique whole numbers that are automatically generated.

NOTES

Notes or comments (Source: Aerial Survey Geographic Information System Handbook, USDA Forest Service, January 2001)

Shape

Feature geometry. (Source: ESRI)

Coordinates defining the features.

SHAPE

Feature geometry. (Source: ESRI)

Coordinates defining the features.

CAT_RGN_ID

(Source: ESRI)

SHAPE_AREA

Area of feature in internal units squared. (Source: ESRI)

Positive real numbers that are automatically generated.

SHAPE_LEN

COMMON_NAM

SCIENTIFIC 


\section{Who produced the data set?}

1. Who are the originators of the data set? (may include formal authors, digital compilers, and editors)

o Forest Health Technology Enterprise Team - USDA Forest Service

2. Who also contributed to the data set?

3. To whom should users address questions about the data?

Ross Pywell

USDA Forest Service, Forest Health Protection, Forest Health Technology Enterprise

Team

Program Manager, GIS and Spatial Analysis

2150 Centre Ave

Fort Collins, CO 80526

USA

\section{Why was the data set created?}

To provide a single source for all aerially detected insect, disease, and abiotic forest damage data to facilitate national and multi-regional level reporting of damage for both Forest Health Monitoring and Foest Health Protection.

\section{How was the data set created?}

1. From what previous works were the data drawn?

(source 1 of 11)

Lawrence Stipe, Entomologist, Region 1 Aerial Insect and Disease Detection Survey for insect and disease activity: 2001.

Other_Citation_Details:

Forest Service - USDA Missoula, MT

Type_of_Source_Media: ArcInfo export files

Source_Scale_Denominator: unknown

(source 2 of 11)

Erik Johnson, Aerial Survey Program Manager, Region 2 Aerial Insect and Disease

Detection Survey for insect and disease activity: 2001.

Other_Citation_Details:

Forest Service - USDA Denver, CO

Type_of_Source_Media: ArcInfo export files

Source_Scale_Denominator: 100,000

(source 3 of 11)

Steve Dudley, Biological Technician, Region 3, Arizona - Aerial Insect and Disease

Detection Survey for insect and disease activity: 2001.

Other_Citation_Details:

Forest Service - USDA Flagstaff, AZ 
Type_of_Source_Media: ArcInfo export files

Source_Scale_Denominator: unknown

(source 4 of 11)

Terry Rogers, Entomologist, Region 3, New Mexico - Aerial Insect and Disease

Detection Survey for insect and disease activity: 2001.

Other_Citation_Details:

Forest Service - USDA

Albuquerque, NM

Type_of_Source_Media: ArcInfo export files

Source_Scale_Denominator: 100,000

(source 5 of 11)

Dick Halsey, GIS Specialist, Region 4 Aerial Insect and Disease Detection Survey for insect and disease activity: 2001.

Other_Citation_Details:

Forest Service - USDA Boise, ID

Type_of_Source_Media: ArcInfo export files

Source_Scale_Denominator: 100,000

(source 6 of $1 \overline{1}$ )

Jeff Mai, Remote Sensing Specialist, Region 5 Aerial Insect and Disease Detection

Survey for insect and disease activity: 2001.

Other_Citation_Details:

Forest Service - USDA Sacramento, CA

Type_of_Source_Media: ArcInfo export files

Source_Scale_Denominator: unknown

(source 7 of 11)

Julie Johnson, GIS Specialist, Region 6 Aerial Insect and Disease Detection Survey for insect and disease activity: 2001.

Other_Citation_Details:

Forest Service - USDA Portland, OR

Type_of_Source_Media: ArcInfo export files

Source_Scale_Denominator: unknown

(source 8 of 11)

Edwin Yockey, Biological Scientist, Region 8 Aerial Insect and Disease Detection

Survey for insect and disease activity: 2001.

Other_Citation_Details:

Forest Service - USDA Asheville, NC

Type_of_Source_Media: ArcInfo export files

Source_Scale_Denominator: 100,000 and 126,720 and others unknown

(source 9 of 11)

Tom Luther, Forester, Northeastern Area, Durham Field Office, Aerial Insect and

Disease Detection Survey for insect and disease activity: 2001.

Other_Citation_Details:

Forest Service - USDA Durham, NH

Type_of_Source_Media: ArcInfo export files

Source_Scale_Denominator: unknown

(source 10 of 11) 
Steketee, Ann, Northeastern Area, Morgantown Field Office, Aerial Insect and Disease Detection Survey for insect and disease activity: 2001.

Other_Citation_Details:

Forest Service - USDA Mogantown, WV

Type_of_Source_Media: ArcView shapefiles

Source_Scale_Denominator: unknown

(source 11 of 11)

Quinn Chavez, Computer Systems Analyst, Northeastern Area, St. Paul Field Office,

Aerial Insect and Disease Detection Survey for insect and disease activity: 2001.

Other_Citation_Details:

Forest Service - USDA St. Paul, MN

Type_of_Source_Media: ArcInfo export files

Source_Scale_Denominator: unknown

\section{How were the data generated, processed, and modified?}

(process 1 of 5)

When digital data is recieved, it is first checked for proper projection, polygon label errors and dangling nodes. If needed, data is reprojected into Albers and label errors and dangling nodes are fixed. In some cases, a Region will submit several coverages. These are appended together to create a single coverage for each region.

Person who carried out this activity:

Jeanine Pascke

INTECS International Inc, for USDA Forest Service, FHP, FHTET

GIS/Image Processing Specialist

2150 Centre Ave

Fort Collins, CO 80526

USA

(process 2 of 5 )

Attributes are checked for adherence to the national standards and corrected if needed. Within each Regional coverage, the coverage ID is recalculated to be a unique number for each record. It is calculated by taking the internal ArcInfo "\#" number and subtracting one. Three additional attributes are added to all coverages to create a combination of attributes that ensure uniqueness once the data is normalized and loaded into SDE. They are ""RPT_RGN","SURVEY_YR" and "GRP". Once all Regional coverages are complete, they are saved as shapefiles. All shapefiles are then "merged" into a single shapefile using the ArcView 3.2a geoprocessing wizard. From that large shapefile, 3 separate shapefiles are created, one for each "GRP" attribute.

Person who carried out this activity:

Jeanine Paschke

INTECS International Inc., for USDA Forest Service, FHP, FHTET

GIS/Image Processing Specialist

(process 3 of 5) 
The 3 shapefiles created in the previous step are normalized and loaded into SDE. In the ArcInfo source coverage, there is one record for each polygon or shape. That record can hold information for more that one pest occurring on that same site by using the appropriately numbered attribute (dca1, dca2, dca3, etc). When the data is loaded into $\mathrm{SDE}$, that one record with repeated attributes is converted into several records with nonrepeating attributes. This is a much more efficient way to store the data in a relational database environment and it is also easier to query.

Person who carried out this activity:

Jeanine Paschke

INTECS International Inc., for USDA Forest Service, FHP, FHTET

GIS/Image Processing Specialist

(process 4 of 5)

Dataset copied.

Data sources used in this process:

o Server=sv7.wo.fs.fed.us; Service=esri_sde; Database=idb.cell3.wo; User=jpaschke; Version=SDE.DEFAULT

(process 5 of 5 )

Dataset copied.

Data sources used in this process:

o Server $=$ sv3.ftcol.wo.fs.fed.us; Service $=$ esri $s d e ;$ Database $=$ idb; User $=$ fssde; Version=FSSDE.FSSDE

3. What similar or related data should the user be aware of?

How reliable are the data; what problems remain in the data set?

1. How well have the observations been checked?

2. How accurate are the geographic locations?

3. How accurate are the heights or depths?

4. Where are the gaps in the data? What is missing?

5. How consistent are the relationships among the observations, including topology?

\section{How can someone get a copy of the data set?}

\section{Are there legal restrictions on access or use of the data?}

Access_Constraints:

Users need to exercise caution regarding the spatial accuracy of these data due to the subjective nature of aerial sketchmapping and the varying scales of source materials. 
Use_Constraints:

Data may be viewed and used upon request. Data should not be changed by anyone other than the originators or FHTET. The USDA Forest Service does not guarantee accuracy of these data.

1. Who distributes the data set?[Distributor contact information not provided.]

2. What's the catalog number I need to order this data set?

Downloadable Data

3. What legal disclaimers am I supposed to read?

4. How can I download or order the data?

o Availability in digital form:

Data format: Size: 0.561

o Cost to order the data:

\section{Who wrote the metadata?}

Dates:

Last modified: $18-\mathrm{Nov}-2005$

Metadata author:

USDA Forest Service, Forest Health Technology Enterprise Team

c/o REQUIRED: The person responsible for the metadata information.

2150 Centre Ave

Fort Collins, CO 80526

REQUIRED: The telephone number by which individuals can speak to the organization or individual. (voice)

Metadata standard:

FGDC Content Standards for Digital Geospatial Metadata (FGDC-STD-001-1998)

Metadata extensions used:

- $\quad \leq$ http://www.esri.com/metadata/esriprof80.html $>$

- $\quad \leq$ http://www.esri.com/metadata/esriprof80.html $>$

- $\quad \leq \mathrm{http}: / /$ www.esri.com/metadata/esriprof80.html $>$

Generated by mp version 2.8.6 on Fri Nov 18 10:54:28 2005

Gypsy moth defoliation -2002 
Metadata also available as

\section{Frequently-anticipated questions:}

- What does this data set describe?

1. How should this data set be cited?

2. What geographic area does the data set cover?

3. What does it look like?

4. Does the data set describe conditions during a particular time period?

5. What is the general form of this data set?

6. How does the data set represent geographic features?

7. How does the data set describe geographic features?

- Who produced the data set?

1. Who are the originators of the data set?

2. Who also contributed to the data set?

3. To whom should users address questions about the data?

- Why was the data set created?

- How was the data set created?

1. From what previous works were the data drawn?

2. How were the data generated, processed, and modified?

3. What similar or related data should the user be aware of?

- How reliable are the data; what problems remain in the data set?

1. How well have the observations been checked?

2. How accurate are the geographic locations?

3. How accurate are the heights or depths?

4. Where are the gaps in the data? What is missing?

5. How consistent are the relationships among the data, including topology?

- How can someone get a copy of the data set?

1. Are there legal restrictions on access or use of the data?

2. Who distributes the data?

3. What's the catalog number I need to order this data set?

4. What legal disclaimers am I supposed to read?

5. How can I download or order the data?

- Who wrote the metadata?

\section{What does this data set describe?}

Title: wv_02

Abstract: REQUIRED: A brief narrative summary of the data set.

\section{How should this data set be cited?}

REQUIRED: The name of an organization or individual that developed the data set., REQUIRED: The date when the data set is published or otherwise made available for release., Wv_02. 
Online Links:

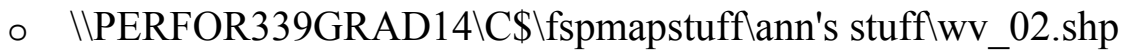

2. What geographic area does the data set cover?

West_Bounding_Coordinate: -81.246109

East_Bounding_Coordinate: -77.719833

North_Bounding_Coordinate: 39.722485

South_Bounding_Coordinate: 37.911587

3. What does it look like?

4. Does the data set describe conditions during a particular time period?

Calendar_Date: REQUIRED: The year (and optionally month, or month and day) for which the data set corresponds to the ground.

Currentness_Reference:

REQUIRED: The basis on which the time period of content information is determined.

5. What is the general form of this data set?

Geospatial_Data_Presentation_Form: vector digital data

6. How does the data set represent geographic features?

a. How are geographic features stored in the data set?

This is a Vector data set. It contains the following vector data types (SDTS terminology):

- G-polygon (550)

b. What coordinate system is used to represent geographic features?

Grid_Coordinate_System_Name: Universal Transverse Mercator

Universal_Transverse_Mercator:

UTM_Zone_Number: 17

Transverse_Mercator:

Scale_Factor_at_Central_Meridian: 0.999600

Longitude_of_Central_Meridian: -81.000000

Latitude_of_Projection_Origin: 0.000000

False_Easting: 500000.000000

False_Northing: 0.000000

Planar coordinates are encoded using coordinate pair

Abscissae (x-coordinates) are specified to the nearest 0.000512

Ordinates (y-coordinates) are specified to the nearest 0.000512

Planar coordinates are specified in meters

The horizontal datum used is North American Datum of 1983.

The ellipsoid used is Geodetic Reference System 80. 
The semi-major axis of the ellipsoid used is 6378137.000000 .

The flattening of the ellipsoid used is $1 / 298.257222$.

7. How does the data set describe geographic features?

Wv_02

FID

Internal feature number. (Source: ESRI)

Sequential unique whole numbers that are automatically generated.

Shape

Feature geometry. (Source: ESRI)

Coordinates defining the features.
AREA
PERIMETER
WV_02
WV_02_ID
ACRES
SURVEY_ID1
SURVEY ID2
SURVEY_ID3
DMG_TYPE1
DMG_TYPE2
DMG_TYPE3
SEVERITY1
SEVERITY2
SEVERITY3
PATTERN1
PATTERN2
PATTERN3
TPA1
TPA2
TPA3
NO_TREES1
NO_TREES2
NO_TREES3
DCA1
DCA2
DCA3
HOST1
HOST2
HOST3
FOR_TYPE1
FOR_TYPE2
FOR_TYPE3
NOTES
CNTY
value

Who produced the data set? 
1. Who are the originators of the data set? (may include formal authors, digital compilers, and editors)

o REQUIRED: The name of an organization or individual that developed the data set.

2. Who also contributed to the data set?

3. To whom should users address questions about the data?

Why was the data set created?

REQUIRED: A summary of the intentions with which the data set was developed.

\section{How was the data set created?}

1. From what previous works were the data drawn?

2. How were the data generated, processed, and modified?

3. What similar or related data should the user be aware of?

How reliable are the data; what problems remain in the data set?

How can someone get a copy of the data set?

Are there legal restrictions on access or use of the data?

Access_Constraints:

REQUIRED: Restrictions and legal prerequisites for accessing the data set.

Use_Constraints:

REQUIRED: Restrictions and legal prerequisites for using the data set after access is granted.

1. Who distributes the data set?[Distributor contact information not provided.]

2. What's the catalog number I need to order this data set?

Downloadable Data

3. What legal disclaimers am I supposed to read?

4. How can I download or order the data?

o Availability in digital form:

Data format: Size: 0.215

o Cost to order the data: 


\section{Who wrote the metadata?}

Dates:

Last modified: 18 -Nov-2005

Metadata author:

REQUIRED: The organization responsible for the metadata information.

c/o REQUIRED: The person responsible for the metadata information.

REQUIRED: The city of the address., REQUIRED: The state or province of the address.

REQUIRED: The ZIP or other postal code of the address.

REQUIRED: The telephone number by which individuals can speak to the organization or individual. (voice)

Metadata standard:

FGDC Content Standards for Digital Geospatial Metadata (FGDC-STD-001-1998)

Metadata extensions used:

- $\quad \leq$ http://www.esri.com/metadata/esriprof80.html $>$

Generated by mp version 2.8.6 on Fri Nov 18 11:02:17 2005

\section{Gypsy moth defoliation-2003}

Metadata also available as

\section{Frequently-anticipated questions:}

- What does this data set describe?

1. How should this data set be cited?

2. What geographic area does the data set cover?

3. What does it look like?

4. Does the data set describe conditions during a particular time period?

5. What is the general form of this data set?

6. How does the data set represent geographic features?

7. How does the data set describe geographic features?

- Who produced the data set?

1. Who are the originators of the data set?

2. Who also contributed to the data set?

3. To whom should users address questions about the data?

- Why was the data set created?

- How was the data set created?

1. From what previous works were the data drawn? 
2. How were the data generated, processed, and modified?

3. What similar or related data should the user be aware of?

- How reliable are the data; what problems remain in the data set?

1. How well have the observations been checked?

2. How accurate are the geographic locations?

3. How accurate are the heights or depths?

4. Where are the gaps in the data? What is missing?

5. How consistent are the relationships among the data, including topology?

- How can someone get a copy of the data set?

1. Are there legal restrictions on access or use of the data?

2. Who distributes the data?

3. What's the catalog number I need to order this data set?

4. What legal disclaimers am I supposed to read?

5. How can I download or order the data?

- Who wrote the metadata?

\section{What does this data set describe?}

Title: wv_03

Abstract: REQUIRED: A brief narrative summary of the data set.

\section{How should this data set be cited?}

REQUIRED: The name of an organization or individual that developed the data set., REQUIRED: The date when the data set is published or otherwise made available for release., wv_03.

Online Links:

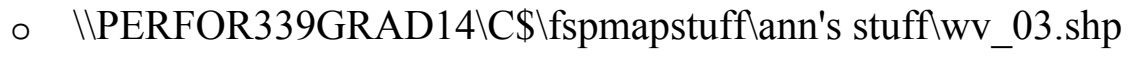

2. What geographic area does the data set cover?

West_Bounding_Coordinate:

REQUIRED: Western-most coordinate of the limit of coverage expressed in longitude. East_Bounding_Coordinate:

REQUIRED: Eastern-most coordinate of the limit of coverage expressed in longitude. North_Bounding_Coordinate:

REQUIRED: Northern-most coordinate of the limit of coverage expressed in latitude. South_Bounding_Coordinate:

REQUIRED: Southern-most coordinate of the limit of coverage expressed in latitude.

3. What does it look like?

4. Does the data set describe conditions during a particular time period?

Calendar_Date: REQUIRED: The year (and optionally month, or month and day) for which the data set corresponds to the ground. 
Currentness_Reference:

REQUIRED: The basis on which the time period of content information is determined.

5. What is the general form of this data set?

Geospatial_Data_Presentation_Form: vector digital data

6. How does the data set represent geographic features?

a. How are geographic features stored in the data set?

This is a Vector data set. It contains the following vector data types (SDTS terminology):

- G-polygon (1285)

b. What coordinate system is used to represent geographic features?

7. How does the data set describe geographic features?

WV_03

FID

Internal feature number. (Source: ESRI)

Sequential unique whole numbers that are automatically generated.

Shape

Feature geometry. (Source: ESRI)

Coordinates defining the features.

OBJECTID

DMG_ID

RPT_RGN

SURVEY YR

SURVEY ID

DMG_TYPE

SEVERITY

PATTERN

TPA

NO_TREES

DCA

HOST

FOR_TYPE

ACRES

NOTES

GRP

CAT_RGN_ID

NOTES2

SHAPE_AREA

Area of feature in internal units squared. (Source: ESRI)

Positive real numbers that are automatically generated.

SHAPE LEN

COMMON_NAM 


\section{Who produced the data set?}

1. Who are the originators of the data set? (may include formal authors, digital compilers, and editors)

o REQUIRED: The name of an organization or individual that developed the data set.

2. Who also contributed to the data set?

3. To whom should users address questions about the data?

\section{Why was the data set created?}

REQUIRED: A summary of the intentions with which the data set was developed.

\section{How was the data set created?}

1. From what previous works were the data drawn?

2. How were the data generated, processed, and modified?

3. What similar or related data should the user be aware of?

How reliable are the data; what problems remain in the data set?

\section{How can someone get a copy of the data set?}

Are there legal restrictions on access or use of the data?

Access_Constraints:

REQUIRED: Restrictions and legal prerequisites for accessing the data set.

Use_Constraints:

REQUIRED: Restrictions and legal prerequisites for using the data set after access is granted.

1. Who distributes the data set?[Distributor contact information not provided.]

2. What's the catalog number I need to order this data set?

Downloadable Data

3. What legal disclaimers am I supposed to read?

4. How can I download or order the data? 
o Availability in digital form:

Data format: Size: 0.601

o Cost to order the data:

\section{Who wrote the metadata?}

Dates:

Last modified: $18-\mathrm{Nov}-2005$

Metadata author:

REQUIRED: The organization responsible for the metadata information.

c/o REQUIRED: The person responsible for the metadata information.

REQUIRED: The city of the address., REQUIRED: The state or province of the address.

REQUIRED: The ZIP or other postal code of the address.

REQUIRED: The telephone number by which individuals can speak to the organization or individual. (voice)

Metadata standard:

FGDC Content Standards for Digital Geospatial Metadata (FGDC-STD-001-1998)

Metadata extensions used:

- $\quad \leq \mathrm{http}: / / \mathrm{www}$. esri.com/metadata/esriprof80.html $>$

Generated by mp version 2.8.6 on Fri Nov 18 11:01:55 2005

\section{Gypsy moth defoliation-2004}

Metadata also available as

\section{Frequently-anticipated questions:}

- What does this data set describe?

1. How should this data set be cited?

2. What geographic area does the data set cover?

3. What does it look like?

4. Does the data set describe conditions during a particular time period?

5. What is the general form of this data set?

6. How does the data set represent geographic features?

7. How does the data set describe geographic features?

- Who produced the data set? 
1. Who are the originators of the data set?

2. Who also contributed to the data set?

3. To whom should users address questions about the data?

- Why was the data set created?

- How was the data set created?

1. From what previous works were the data drawn?

2. How were the data generated, processed, and modified?

3. What similar or related data should the user be aware of?

- How reliable are the data; what problems remain in the data set?

1. How well have the observations been checked?

2. How accurate are the geographic locations?

3. How accurate are the heights or depths?

4. Where are the gaps in the data? What is missing?

5. How consistent are the relationships among the data, including topology?

- How can someone get a copy of the data set?

1. Are there legal restrictions on access or use of the data?

2. Who distributes the data?

3. What's the catalog number I need to order this data set?

4. What legal disclaimers am I supposed to read?

5. How can I download or order the data?

- Who wrote the metadata?

\section{What does this data set describe?}

Title: wv_04

Abstract: REQUIRED: A brief narrative summary of the data set.

\section{How should this data set be cited?}

REQUIRED: The name of an organization or individual that developed the data set., REQUIRED: The date when the data set is published or otherwise made available for release., wv_04.

Online Links:

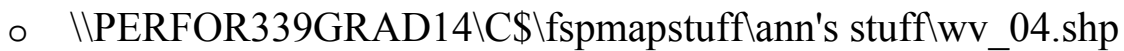

\section{What geographic area does the data set cover?}

West_Bounding_Coordinate:

REQUIRED: Western-most coordinate of the limit of coverage expressed in longitude. East_Bounding_Coordinate:

REQUIRED: Eastern-most coordinate of the limit of coverage expressed in longitude. North_Bounding_Coordinate:

REQUIRED: Northern-most coordinate of the limit of coverage expressed in latitude. South_Bounding_Coordinate:

REQUIRED: Southern-most coordinate of the limit of coverage expressed in latitude. 
3. What does it look like?

4. Does the data set describe conditions during a particular time period?

Calendar_Date: REQUIRED: The year (and optionally month, or month and day) for which the data set corresponds to the ground.

Currentness_Reference:

REQUIRED: The basis on which the time period of content information is determined.

5. What is the general form of this data set?

Geospatial_Data_Presentation_Form: vector digital data

6. How does the data set represent geographic features?

a. How are geographic features stored in the data set?

This is a Vector data set. It contains the following vector data types (SDTS terminology):

- G-polygon (286)

b. What coordinate system is used to represent geographic features?

7. How does the data set describe geographic features?

Wv_04

FID

Internal feature number. (Source: ESRI)

Sequential unique whole numbers that are automatically generated.

Shape

Feature geometry. (Source: ESRI)

Coordinates defining the features.

AREA

PERIMETER

ID

SURVEY_ID1

SURVEY_ID2

SURVEY_ID3

DMG_TYPE1

DMG_TYPE2

DMG_TYPE3

SEVERITY1

SEVERITY2

SEVERITY3

PATTERN1

PATTERN2

PATTERN3

TPA1

TPA2

TPA3

NO_TREES1

NO_TREES2 
NO_TREES3

DCA1

DCA2

DCA3

HOST1

HOST2

HOST3

FOR_TYPE1

FOR_TYPE2

FOR_TYPE3

NOTES

ACRES

value

\section{Who produced the data set?}

1. Who are the originators of the data set? (may include formal authors, digital compilers, and editors)

o REQUIRED: The name of an organization or individual that developed the data set.

2. Who also contributed to the data set?

3. To whom should users address questions about the data?

\section{Why was the data set created?}

REQUIRED: A summary of the intentions with which the data set was developed.

\section{How was the data set created?}

1. From what previous works were the data drawn?

2. How were the data generated, processed, and modified?

3. What similar or related data should the user be aware of?

How reliable are the data; what problems remain in the data set?

\section{How can someone get a copy of the data set?}

Are there legal restrictions on access or use of the data?

Access_Constraints:

REQUIRED: Restrictions and legal prerequisites for accessing the data set.

Use_Constraints: 
REQUIRED: Restrictions and legal prerequisites for using the data set after access is granted.

1. Who distributes the data set?[Distributor contact information not provided.]

2. What's the catalog number I need to order this data set?

Downloadable Data

3. What legal disclaimers am I supposed to read?

4. How can I download or order the data?

0 Availability in digital form:

Data format: Size: 0.453

o Cost to order the data:

\section{Who wrote the metadata?}

Dates:

Last modified: $18-$ Nov-2005

Metadata author:

REQUIRED: The organization responsible for the metadata information.

c/o REQUIRED: The person responsible for the metadata information.

REQUIRED: The city of the address., REQUIRED: The state or province of the address.

REQUIRED: The ZIP or other postal code of the address.

REQUIRED: The telephone number by which individuals can speak to the organization or individual. (voice)

Metadata standard:

FGDC Content Standards for Digital Geospatial Metadata (FGDC-STD-001-1998) Metadata extensions used:

- $\quad \leq$ http://www.esri.com/metadata/esriprof80.html $>$

Generated by mp version 2.8.6 on Fri Nov 18 11:00:55 2005 


\section{Beech bark disease-current spread}

Metadata also available as

Frequently-anticipated questions:

- What does this data set describe?

1. How should this data set be cited?

2. What geographic area does the data set cover?

3. What does it look like?

4. Does the data set describe conditions during a particular time period?

5. What is the general form of this data set?

6. How does the data set represent geographic features?

7. How does the data set describe geographic features?

- Who produced the data set?

1. Who are the originators of the data set?

2. Who also contributed to the data set?

3. To whom should users address questions about the data?

- Why was the data set created?

- How was the data set created?

1. From what previous works were the data drawn?

2. How were the data generated, processed, and modified?

3. What similar or related data should the user be aware of?

- How reliable are the data; what problems remain in the data set?

1. How well have the observations been checked?

2. How accurate are the geographic locations?

3. How accurate are the heights or depths?

4. Where are the gaps in the data? What is missing?

5. How consistent are the relationships among the data, including topology?

- How can someone get a copy of the data set?

1. Are there legal restrictions on access or use of the data?

2. Who distributes the data?

3. What's the catalog number I need to order this data set?

4. What legal disclaimers am I supposed to read?

5. How can I download or order the data?

- Who wrote the metadata?

\section{What does this data set describe?}

Title: wv_bbd2

Abstract: REQUIRED: A brief narrative summary of the data set.

\section{How should this data set be cited?}


REQUIRED: The name of an organization or individual that developed the data set., REQUIRED: The date when the data set is published or otherwise made available for release., wv_bbd2.

Online Links:

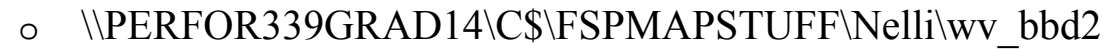

2. What geographic area does the data set cover?

West_Bounding_Coordinate: -84.181909

East_Bounding_Coordinate: -76.675924

North_Bounding_Coordinate: 41.723748

South_Bounding_Coordinate: 36.051891

3. What does it look like?

4. Does the data set describe conditions during a particular time period?

Calendar_Date: REQUIRED: The year (and optionally month, or month and day) for which the data set corresponds to the ground.

Currentness_Reference:

REQUIRED: The basis on which the time period of content information is determined.

5. What is the general form of this data set?

Geospatial_Data_Presentation_Form: raster digital data

6. How does the data set represent geographic features?

a. How are geographic features stored in the data set?

This is a Raster data set. It contains the following raster data types:

- Dimensions 622 x 625 × 1, type Grid Cell

b. What coordinate system is used to represent geographic features?

Grid_Coordinate_System_Name: Universal Transverse Mercator

Universal_Transverse_Mercator:

UTM_Zone_Number: 17

Transverse_Mercator:

Scale_Factor_at_Central_Meridian: 0.999600

Longitude_of_Central_Meridian: -81.000000

Latitude_of_Projection_Origin: 0.000000

False_Easting: 500000.000000

False_Northing: 0.000000

Planar coordinates are encoded using row and column

Abscissae (x-coordinates) are specified to the nearest 1000.000000

Ordinates (y-coordinates) are specified to the nearest 1000.000000

Planar coordinates are specified in meters 
The horizontal datum used is North American Datum of 1983.

The ellipsoid used is Geodetic Reference System 80.

The semi-major axis of the ellipsoid used is 6378137.000000 .

The flattening of the ellipsoid used is $1 / 298.257222$.

7. How does the data set describe geographic features?

wv_bbd2

ObjectID

Internal feature number. (Source: ESRI)

Sequential unique whole numbers that are automatically generated.

Value

Count

\section{Who produced the data set?}

1. Who are the originators of the data set? (may include formal authors, digital compilers, and editors)

o REQUIRED: The name of an organization or individual that developed the data set.

2. Who also contributed to the data set?

3. To whom should users address questions about the data?

\section{Why was the data set created?}

REQUIRED: A summary of the intentions with which the data set was developed.

\section{How was the data set created?}

1. From what previous works were the data drawn?

2. How were the data generated, processed, and modified?

3. What similar or related data should the user be aware of?

How reliable are the data; what problems remain in the data set?

How can someone get a copy of the data set?

Are there legal restrictions on access or use of the data? 
Access_Constraints:

REQUIRED: Restrictions and legal prerequisites for accessing the data set.

Use_Constraints:

REQUIRED: Restrictions and legal prerequisites for using the data set after access is granted.

1. Who distributes the data set?[Distributor contact information not provided.]

2. What's the catalog number I need to order this data set?

Downloadable Data

3. What legal disclaimers am I supposed to read?

4. How can I download or order the data?

o Availability in digital form:

Data format: Size: 0.030

o Cost to order the data:

\section{Who wrote the metadata?}

Dates:

Last modified: 18-Nov-2005

Metadata author:

REQUIRED: The organization responsible for the metadata information.

c/o REQUIRED: The person responsible for the metadata information.

REQUIRED: The city of the address., REQUIRED: The state or province of the address.

REQUIRED: The ZIP or other postal code of the address.

REQUIRED: The telephone number by which individuals can speak to the organization or individual. (voice)

Metadata standard:

FGDC Content Standards for Digital Geospatial Metadata (FGDC-STD-001-1998)

Metadata extensions used:

- $\quad \leq \mathrm{http}: / / \mathrm{www}$. esri.com/metadata/esriprof80.html $>$

Generated by mp version 2.8.6 on Fri Nov 18 11:18:03 2005 


\section{Beech bark disease predicted spread}

Metadata also available as

Frequently-anticipated questions:

- What does this data set describe?

1. How should this data set be cited?

2. What geographic area does the data set cover?

3. What does it look like?

4. Does the data set describe conditions during a particular time period?

5. What is the general form of this data set?

6. How does the data set represent geographic features?

7. How does the data set describe geographic features?

- Who produced the data set?

1. Who are the originators of the data set?

2. Who also contributed to the data set?

3. To whom should users address questions about the data?

- Why was the data set created?

- How was the data set created?

1. From what previous works were the data drawn?

2. How were the data generated, processed, and modified?

3. What similar or related data should the user be aware of?

- How reliable are the data; what problems remain in the data set?

1. How well have the observations been checked?

2. How accurate are the geographic locations?

3. How accurate are the heights or depths?

4. Where are the gaps in the data? What is missing?

5. How consistent are the relationships among the data, including topology?

- How can someone get a copy of the data set?

1. Are there legal restrictions on access or use of the data?

2. Who distributes the data?

3. What's the catalog number I need to order this data set?

4. What legal disclaimers am I supposed to read?

5. How can I download or order the data?

- Who wrote the metadata?

\section{What does this data set describe?}

Title: wv_bbd_sprd2

Abstract: REQUIRED: A brief narrative summary of the data set.

\section{How should this data set be cited?}


REQUIRED: The name of an organization or individual that developed the data set., REQUIRED: The date when the data set is published or otherwise made available for release., wv_bbd_sprd2.

Online Links:

o IIPERFOR339GRAD14\CS\FSPMAPSTUFF\Nelli \wv_bbd_sprd2

2. What geographic area does the data set cover?

West_Bounding_Coordinate: -84.181909

East_Bounding_Coordinate: -76.675924

North_Bounding_Coordinate: 41.723748

South_Bounding_Coordinate: 36.051891

3. What does it look like?

4. Does the data set describe conditions during a particular time period?

Calendar_Date: REQUIRED: The year (and optionally month, or month and day) for which the data set corresponds to the ground.

Currentness_Reference:

REQUIRED: The basis on which the time period of content information is determined.

5. What is the general form of this data set?

Geospatial_Data_Presentation_Form: raster digital data

6. How does the data set represent geographic features?

a. How are geographic features stored in the data set?

This is a Raster data set. It contains the following raster data types:

- Dimensions 622 x 625 × 1, type Grid Cell

b. What coordinate system is used to represent geographic features?

Grid_Coordinate_System_Name: Universal Transverse Mercator

Universal_Transverse_Mercator:

UTM_Zone_Number: 17

Transverse_Mercator:

Scale_Factor_at_Central_Meridian: 0.999600

Longitude_of_Central_Meridian: -81.000000

Latitude_of_Projection_Origin: 0.000000

False_Easting: 500000.000000

False_Northing: 0.000000

Planar coordinates are encoded using row and column

Abscissae (x-coordinates) are specified to the nearest 1000.000000

Ordinates (y-coordinates) are specified to the nearest 1000.000000

Planar coordinates are specified in meters 
The horizontal datum used is North American Datum of 1983.

The ellipsoid used is Geodetic Reference System 80.

The semi-major axis of the ellipsoid used is 6378137.000000 .

The flattening of the ellipsoid used is $1 / 298.257222$.

7. How does the data set describe geographic features?

Wv_bbd_sprd2

ObjectID

Internal feature number. (Source: ESRI)

Sequential unique whole numbers that are automatically generated.

Value

Count

\section{Who produced the data set?}

1. Who are the originators of the data set? (may include formal authors, digital compilers, and editors)

o REQUIRED: The name of an organization or individual that developed the data set.

2. Who also contributed to the data set?

3. To whom should users address questions about the data?

\section{Why was the data set created?}

REQUIRED: A summary of the intentions with which the data set was developed.

\section{How was the data set created?}

1. From what previous works were the data drawn?

2. How were the data generated, processed, and modified?

3. What similar or related data should the user be aware of?

How reliable are the data; what problems remain in the data set?

How can someone get a copy of the data set?

Are there legal restrictions on access or use of the data? 
Access_Constraints:

REQUIRED: Restrictions and legal prerequisites for accessing the data set.

Use_Constraints:

REQUIRED: Restrictions and legal prerequisites for using the data set after access is granted.

1. Who distributes the data set?[Distributor contact information not provided.]

2. What's the catalog number I need to order this data set?

Downloadable Data

3. What legal disclaimers am I supposed to read?

4. How can I download or order the data?

o Availability in digital form:

Data format: Size: 0.044

o Cost to order the data:

\section{Who wrote the metadata?}

Dates:

Last modified: 18-Nov-2005

Metadata author:

REQUIRED: The organization responsible for the metadata information.

c/o REQUIRED: The person responsible for the metadata information.

REQUIRED: The city of the address., REQUIRED: The state or province of the address.

REQUIRED: The ZIP or other postal code of the address.

REQUIRED: The telephone number by which individuals can speak to the organization or individual. (voice)

Metadata standard:

FGDC Content Standards for Digital Geospatial Metadata (FGDC-STD-001-1998)

Metadata extensions used:

- $\quad \leq \mathrm{http}: / / \mathrm{www}$. esri.com/metadata/esriprof80.html $>$

Generated by mp version 2.8.6 on Fri Nov 18 11:18:29 2005 


\section{Beech habitat}

Metadata also available as

Frequently-anticipated questions:

- What does this data set describe?

1. How should this data set be cited?

2. What geographic area does the data set cover?

3. What does it look like?

4. Does the data set describe conditions during a particular time period?

5. What is the general form of this data set?

6. How does the data set represent geographic features?

7. How does the data set describe geographic features?

- Who produced the data set?

1. Who are the originators of the data set?

2. Who also contributed to the data set?

3. To whom should users address questions about the data?

- Why was the data set created?

- How was the data set created?

1. From what previous works were the data drawn?

2. How were the data generated, processed, and modified?

3. What similar or related data should the user be aware of?

- How reliable are the data; what problems remain in the data set?

1. How well have the observations been checked?

2. How accurate are the geographic locations?

3. How accurate are the heights or depths?

4. Where are the gaps in the data? What is missing?

5. How consistent are the relationships among the data, including topology?

- How can someone get a copy of the data set?

1. Are there legal restrictions on access or use of the data?

2. Who distributes the data?

3. What's the catalog number I need to order this data set?

4. What legal disclaimers am I supposed to read?

5. How can I download or order the data?

- Who wrote the metadata?

\section{What does this data set describe?}

Title: rcbbd-gap

Abstract: REQUIRED: A brief narrative summary of the data set.

\section{How should this data set be cited?}


REQUIRED: The name of an organization or individual that developed the data set., REQUIRED: The date when the data set is published or otherwise made available for release., rcbbd-gap.

Online Links:

o IIPERFOR339GRAD14\C\$\FSPMAPTUFF \risk-calc \rcbbd-gap

2. What geographic area does the data set cover?

West_Bounding_Coordinate: -82.706617

East_Bounding_Coordinate: -77.665758

North_Bounding_Coordinate: 40.638400

South_Bounding_Coordinate: 37.163477

3. What does it look like?

4. Does the data set describe conditions during a particular time period?

Calendar_Date: REQUIRED: The year (and optionally month, or month and day) for which the data set corresponds to the ground.

Currentness_Reference:

REQUIRED: The basis on which the time period of content information is determined.

5. What is the general form of this data set?

Geospatial_Data_Presentation_Form: raster digital data

6. How does the data set represent geographic features?

a. How are geographic features stored in the data set?

This is a Raster data set. It contains the following raster data types:

- Dimensions 4232 x 4739 x 1, type Grid Cell

b. What coordinate system is used to represent geographic features?

Grid_Coordinate_System_Name: Universal Transverse Mercator

Universal_Transverse_Mercator:

UTM_Zone_Number: 17

Transverse_Mercator:

Scale_Factor_at_Central_Meridian: 0.999600

Longitude_of_Central_Meridian: -81.000000

Latitude_of_Projection_Origin: 0.000000

False_Easting: 500000.000000

False_Northing: 0.000000

Planar coordinates are encoded using row and column

Abscissae (x-coordinates) are specified to the nearest 90.000000

Ordinates (y-coordinates) are specified to the nearest 90.000000

Planar coordinates are specified in meters 
The horizontal datum used is North American Datum of 1983.

The ellipsoid used is Geodetic Reference System 80.

The semi-major axis of the ellipsoid used is 6378137.000000 .

The flattening of the ellipsoid used is $1 / 298.257222$.

7. How does the data set describe geographic features?

RCbbd-gap

objectID

Internal feature number. (Source: ESRI)

Sequential unique whole numbers that are automatically generated.

Value

Count

\section{Who produced the data set?}

1. Who are the originators of the data set? (may include formal authors, digital compilers, and editors)

o REQUIRED: The name of an organization or individual that developed the data set.

2. Who also contributed to the data set?

3. To whom should users address questions about the data?

\section{Why was the data set created?}

REQUIRED: A summary of the intentions with which the data set was developed.

\section{How was the data set created?}

1. From what previous works were the data drawn?

2. How were the data generated, processed, and modified?

3. What similar or related data should the user be aware of?

How reliable are the data; what problems remain in the data set?

How can someone get a copy of the data set?

Are there legal restrictions on access or use of the data? 
Access_Constraints:

REQUIRED: Restrictions and legal prerequisites for accessing the data set.

Use_Constraints:

REQUIRED: Restrictions and legal prerequisites for using the data set after access is granted.

1. Who distributes the data set?[Distributor contact information not provided.]

2. What's the catalog number I need to order this data set?

Downloadable Data

3. What legal disclaimers am I supposed to read?

4. How can I download or order the data?

o Availability in digital form:

Data format: Size: 3.170

o Cost to order the data:

\section{Who wrote the metadata?}

Dates:

Last modified: 18 -Nov-2005

Metadata author:

REQUIRED: The organization responsible for the metadata information.

c/o REQUIRED: The person responsible for the metadata information.

REQUIRED: The city of the address., REQUIRED: The state or province of the address.

REQUIRED: The ZIP or other postal code of the address.

REQUIRED: The telephone number by which individuals can speak to the organization or individual. (voice)

Metadata standard:

FGDC Content Standards for Digital Geospatial Metadata (FGDC-STD-001-1998)

Metadata extensions used:

- $\quad \leq \mathrm{http}: / / \mathrm{www}$. esri.com/metadata/esriprof80.html $>$

Generated by mp version 2.8.6 on Fri Nov 18 11:20:27 2005 


\section{Hemlock woolly adelgid current spread}

Metadata also available as

\section{Frequently-anticipated questions:}

- What does this data set describe?

1. How should this data set be cited?

2. What geographic area does the data set cover?

3. What does it look like?

4. Does the data set describe conditions during a particular time period?

5. What is the general form of this data set?

6. How does the data set represent geographic features?

7. How does the data set describe geographic features?

- Who produced the data set?

1. Who are the originators of the data set?

2. Who also contributed to the data set?

3. To whom should users address questions about the data?

- Why was the data set created?

- How was the data set created?

1. From what previous works were the data drawn?

2. How were the data generated, processed, and modified?

3 . What similar or related data should the user be aware of?

- How reliable are the data; what problems remain in the data set?

1. How well have the observations been checked?

2. How accurate are the geographic locations?

3. How accurate are the heights or depths?

4. Where are the gaps in the data? What is missing?

5. How consistent are the relationships among the data, including topology?

- How can someone get a copy of the data set?

1. Are there legal restrictions on access or use of the data?

2. Who distributes the data?

3. What's the catalog number I need to order this data set?

4. What legal disclaimers am I supposed to read?

5. How can I download or order the data?

- Who wrote the metadata?

\section{What does this data set describe?}

Title: wv_hwa2

Abstract: REQUIRED: A brief narrative summary of the data set.

\section{How should this data set be cited?}


REQUIRED: The name of an organization or individual that developed the data set., REQUIRED: The date when the data set is published or otherwise made available for release., wv_hwa2.

Online Links:

o IIPERFOR339GRAD14\C\$\FSPMAPSTUFF \Nelli \wv_hwa2

2. What geographic area does the data set cover?

West_Bounding_Coordinate: -103.168749

East_Bounding_Coordinate: -64.985093

North_Bounding_Coordinate: 51.283464

South_Bounding_Coordinate: 22.466911

3. What does it look like?

4. Does the data set describe conditions during a particular time period?

Calendar_Date: REQUIRED: The year (and optionally month, or month and day) for which the data set corresponds to the ground.

Currentness_Reference:

REQUIRED: The basis on which the time period of content information is determined.

5. What is the general form of this data set?

Geospatial_Data_Presentation_Form: raster digital data

6. How does the data set represent geographic features?

a. How are geographic features stored in the data set?

This is a Raster data set. It contains the following raster data types:

- Dimensions $3112 \times 2752$ × 1, type Grid Cell

b. What coordinate system is used to represent geographic features?

The map projection used is Transverse Mercator.

Projection parameters:

Scale_Factor_at_Central_Meridian: 0.999600

Longitude_of_Central_Meridian: -81.000000

Latitude_of_Projection_Origin: 0.000000

False_Easting: 500000.000000

False_Northing: 0.000000

Planar coordinates are encoded using row and column

Abscissae (x-coordinates) are specified to the nearest 1000.000000

Ordinates (y-coordinates) are specified to the nearest 1000.000000

Planar coordinates are specified in meters 
The horizontal datum used is D_GRS_1980.

The ellipsoid used is Geodetic Reference System 80.

The semi-major axis of the ellipsoid used is 6378137.000000 .

The flattening of the ellipsoid used is $1 / 298.257222$.

7. How does the data set describe geographic features?

wv_hwa2

objectid

Internal feature number. (Source: ESRI)

Sequential unique whole numbers that are automatically generated.

Value

Count

Who produced the data set?

1. Who are the originators of the data set? (may include formal authors, digital compilers, and editors)

o REQUIRED: The name of an organization or individual that developed the data set.

2. Who also contributed to the data set?

3. To whom should users address questions about the data?

Why was the data set created?

REQUIRED: A summary of the intentions with which the data set was developed.

How was the data set created?

1. From what previous works were the data drawn?

2. How were the data generated, processed, and modified?

3. What similar or related data should the user be aware of?

How reliable are the data; what problems remain in the data set?

How can someone get a copy of the data set?

Are there legal restrictions on access or use of the data? 
Access_Constraints:

REQUIRED: Restrictions and legal prerequisites for accessing the data set.

Use_Constraints:

REQUIRED: Restrictions and legal prerequisites for using the data set after access is granted.

1. Who distributes the data set?[Distributor contact information not provided.]

2. What's the catalog number I need to order this data set?

Downloadable Data

3. What legal disclaimers am I supposed to read?

4. How can I download or order the data?

o Availability in digital form:

Data format: Size: 0.181

o Cost to order the data:

\section{Who wrote the metadata?}

Dates:

Last modified: 18 -Nov-2005

Metadata author:

REQUIRED: The organization responsible for the metadata information.

c/o REQUIRED: The person responsible for the metadata information.

REQUIRED: The city of the address., REQUIRED: The state or province of the address.

REQUIRED: The ZIP or other postal code of the address.

REQUIRED: The telephone number by which individuals can speak to the organization or individual. (voice)

Metadata standard:

FGDC Content Standards for Digital Geospatial Metadata (FGDC-STD-001-1998)

Metadata extensions used:

- $\quad \leq \mathrm{http}: / / \mathrm{www}$. esri.com/metadata/esriprof80.html $>$

Generated by mp version 2.8.6 on Fri Nov 18 11:17:09 2005 


\section{Hemlock woolly adelgid predicted spread}

Metadata also available as

Frequently-anticipated questions:

- What does this data set describe?

1. How should this data set be cited?

2. What geographic area does the data set cover?

3. What does it look like?

4. Does the data set describe conditions during a particular time period?

5. What is the general form of this data set?

6. How does the data set represent geographic features?

7. How does the data set describe geographic features?

- Who produced the data set?

1. Who are the originators of the data set?

2. Who also contributed to the data set?

3. To whom should users address questions about the data?

- Why was the data set created?

- How was the data set created?

1. From what previous works were the data drawn?

2. How were the data generated, processed, and modified?

3. What similar or related data should the user be aware of?

- How reliable are the data; what problems remain in the data set?

1. How well have the observations been checked?

2. How accurate are the geographic locations?

3. How accurate are the heights or depths?

4. Where are the gaps in the data? What is missing?

5. How consistent are the relationships among the data, including topology?

- How can someone get a copy of the data set?

1. Are there legal restrictions on access or use of the data?

2. Who distributes the data?

3. What's the catalog number I need to order this data set?

4. What legal disclaimers am I supposed to read?

5. How can I download or order the data?

- Who wrote the metadata?

\section{What does this data set describe?}

Title: wv_hwa_sprd2

Abstract: REQUIRED: A brief narrative summary of the data set.

\section{How should this data set be cited?}


REQUIRED: The name of an organization or individual that developed the data set., REQUIRED: The date when the data set is published or otherwise made available for release.,wv_hwa_sprd2.

Online Links:

o IIPERFOR339GRAD14\CS\FSPMAPSTUFF\Nelli \wv_hwa_sprd2

2. What geographic area does the data set cover?

West_Bounding_Coordinate: -103.168749

East_Bounding_Coordinate: -64.985093

North_Bounding_Coordinate: 51.283464

South_Bounding_Coordinate: 22.466911

3. What does it look like?

4. Does the data set describe conditions during a particular time period?

Calendar_Date: REQUIRED: The year (and optionally month, or month and day) for which the data set corresponds to the ground.

Currentness_Reference:

REQUIRED: The basis on which the time period of content information is determined.

5. What is the general form of this data set?

Geospatial_Data_Presentation_Form: raster digital data

6. How does the data set represent geographic features?

a. How are geographic features stored in the data set?

This is a Raster data set. It contains the following raster data types:

- Dimensions $3112 \times 2752$ × 1, type Grid Cell

b. What coordinate system is used to represent geographic features?

The map projection used is Transverse Mercator.

Projection parameters:

Scale_Factor_at_Central_Meridian: 0.999600

Longitude_of_Central_Meridian: -81.000000

Latitude_of_Projection_Origin: 0.000000

False_Easting: 500000.000000

False_Northing: 0.000000

Planar coordinates are encoded using row and column

Abscissae (x-coordinates) are specified to the nearest 1000.000000

Ordinates (y-coordinates) are specified to the nearest 1000.000000

Planar coordinates are specified in meters 
The horizontal datum used is D_GRS_1980.

The ellipsoid used is Geodetic Reference System 80.

The semi-major axis of the ellipsoid used is 6378137.000000 .

The flattening of the ellipsoid used is $1 / 298.257222$.

7. How does the data set describe geographic features?

Wv_hwa_sprd2

objectID

Internal feature number. (Source: ESRI)

Sequential unique whole numbers that are automatically generated.

Value

Count

\section{Who produced the data set?}

1. Who are the originators of the data set? (may include formal authors, digital compilers, and editors)

- REQUIRED: The name of an organization or individual that developed the data set.

2. Who also contributed to the data set?

3. To whom should users address questions about the data?

Why was the data set created?

REQUIRED: A summary of the intentions with which the data set was developed.

How was the data set created?

1. From what previous works were the data drawn?

2. How were the data generated, processed, and modified?

3. What similar or related data should the user be aware of?

How reliable are the data; what problems remain in the data set?

How can someone get a copy of the data set?

Are there legal restrictions on access or use of the data? 
Access_Constraints:

REQUIRED: Restrictions and legal prerequisites for accessing the data set.

Use_Constraints:

REQUIRED: Restrictions and legal prerequisites for using the data set after access is granted.

1. Who distributes the data set?[Distributor contact information not provided.]

2. What's the catalog number I need to order this data set?

Downloadable Data

3. What legal disclaimers am I supposed to read?

4. How can I download or order the data?

o Availability in digital form:

Data format: Size: 0.209

o Cost to order the data:

\section{Who wrote the metadata?}

Dates:

Last modified: 18 -Nov-2005

Metadata author:

REQUIRED: The organization responsible for the metadata information.

c/o REQUIRED: The person responsible for the metadata information.

REQUIRED: The city of the address., REQUIRED: The state or province of the address.

REQUIRED: The ZIP or other postal code of the address.

REQUIRED: The telephone number by which individuals can speak to the organization or individual. (voice)

Metadata standard:

FGDC Content Standards for Digital Geospatial Metadata (FGDC-STD-001-1998)

Metadata extensions used:

- $\quad \leq$ http://www.esri.com/metadata/esriprof80.html $>$

Generated by mp version 2.8.6 on Fri Nov 18 11:17:39 2005 


\section{Hemlock habitat}

Metadata also available as

\section{Frequently-anticipated questions:}

- What does this data set describe?

1. How should this data set be cited?

2. What geographic area does the data set cover?

3. What does it look like?

4. Does the data set describe conditions during a particular time period?

5. What is the general form of this data set?

6. How does the data set represent geographic features?

7. How does the data set describe geographic features?

- Who produced the data set?

1. Who are the originators of the data set?

2. Who also contributed to the data set?

3. To whom should users address questions about the data?

- Why was the data set created?

- How was the data set created?

1. From what previous works were the data drawn?

2. How were the data generated, processed, and modified?

3. What similar or related data should the user be aware of?

- How reliable are the data; what problems remain in the data set?

1. How well have the observations been checked?

2. How accurate are the geographic locations?

3. How accurate are the heights or depths?

4. Where are the gaps in the data? What is missing?

5. How consistent are the relationships among the data, including topology?

- How can someone get a copy of the data set?

1. Are there legal restrictions on access or use of the data?

2. Who distributes the data?

3. What's the catalog number I need to order this data set?

4. What legal disclaimers am I supposed to read?

5. How can I download or order the data?

- Who wrote the metadata?

\section{What does this data set describe?}

Title: rchwa-gap

Abstract: REQUIRED: A brief narrative summary of the data set.

\section{How should this data set be cited?}


REQUIRED: The name of an organization or individual that developed the data set., REQUIRED: The date when the data set is published or otherwise made available for release., rchwa-gap.

Online Links:

o IIPERFOR339GRAD14\C\$\FSPMAPSTUFF\risk-calc \rchwa-gap

2. What geographic area does the data set cover?

West_Bounding_Coordinate: -82.706617

East_Bounding_Coordinate: -77.665758

North_Bounding_Coordinate: 40.638400

South_Bounding_Coordinate: 37.163477

3. What does it look like?

4. Does the data set describe conditions during a particular time period?

Calendar_Date: REQUIRED: The year (and optionally month, or month and day) for which the data set corresponds to the ground.

Currentness_Reference:

REQUIRED: The basis on which the time period of content information is determined.

5. What is the general form of this data set?

Geospatial_Data_Presentation_Form: raster digital data

6. How does the data set represent geographic features?

a. How are geographic features stored in the data set?

This is a Raster data set. It contains the following raster data types:

- Dimensions 4232 x 4739 x 1, type Grid Cell

b. What coordinate system is used to represent geographic features?

The map projection used is Transverse Mercator.

Projection parameters:

Scale_Factor_at_Central_Meridian: 0.999600

Longitude_of_Central_Meridian: -81.000000

Latitude_of_Projection_Origin: 0.000000

False_Easting: 500000.000000

False_Northing: 0.000000

Planar coordinates are encoded using row and column

Abscissae (x-coordinates) are specified to the nearest 90.000000

Ordinates (y-coordinates) are specified to the nearest 90.000000

Planar coordinates are specified in meters 
The horizontal datum used is D_GRS_1980.

The ellipsoid used is Geodetic Reference System 80.

The semi-major axis of the ellipsoid used is 6378137.000000 .

The flattening of the ellipsoid used is $1 / 298.257222$.

7. How does the data set describe geographic features?

RChwa-gap

ObjectID

Internal feature number. (Source: ESRI)

Sequential unique whole numbers that are automatically generated.

Value

Count

Who produced the data set?

1. Who are the originators of the data set? (may include formal authors, digital compilers, and editors)

o REQUIRED: The name of an organization or individual that developed the data set.

2. Who also contributed to the data set?

3. To whom should users address questions about the data?

Why was the data set created?

REQUIRED: A summary of the intentions with which the data set was developed.

How was the data set created?

1. From what previous works were the data drawn?

2. How were the data generated, processed, and modified?

3. What similar or related data should the user be aware of?

How reliable are the data; what problems remain in the data set?

How can someone get a copy of the data set?

Are there legal restrictions on access or use of the data? 
Access_Constraints:

REQUIRED: Restrictions and legal prerequisites for accessing the data set.

Use_Constraints:

REQUIRED: Restrictions and legal prerequisites for using the data set after access is granted.

1. Who distributes the data set?[Distributor contact information not provided.]

2. What's the catalog number I need to order this data set?

Downloadable Data

3. What legal disclaimers am I supposed to read?

4. How can I download or order the data?

o Availability in digital form:

Data format: Size: 3.083

o Cost to order the data:

\section{Who wrote the metadata?}

Dates:

Last modified: 18 -Nov-2005

Metadata author:

REQUIRED: The organization responsible for the metadata information.

c/o REQUIRED: The person responsible for the metadata information.

REQUIRED: The city of the address., REQUIRED: The state or province of the address.

REQUIRED: The ZIP or other postal code of the address.

REQUIRED: The telephone number by which individuals can speak to the organization or individual. (voice)

Metadata standard:

FGDC Content Standards for Digital Geospatial Metadata (FGDC-STD-001-1998)

Metadata extensions used:

- $\quad \leq$ http://www.esri.com/metadata/esriprof80.html $>$

Generated by mp version 2.8.6 on Fri Nov 18 11:19:55 2005 